\title{
Blockages in LMFBR Fuel Assemblies- A Review of Experimental and Theoretical Studies
}

\section{MASTER J.T.Han}

\section{OAK RIDGE NATIONAL LABORATORY}




\section{DISCLAIMER}

This report was prepared as an account of work sponsored by an agency of the United States Government. Neither the United States Government nor any agency Thereof, nor any of their employees, makes any warranty, express or implied, or assumes any legal liability or responsibility for the accuracy, completeness, or usefulness of any information, apparatus, product, or process disclosed, or represents that its use would not infringe privately owned rights. Reference herein to any specific commercial product, process, or service by trade name, trademark, manufacturer, or otherwise does not necessarily constitute or imply its endorsement, recommendation, or favoring by the United States Government or any agency thereof. The views and opinions of authors expressed herein do not necessarily state or reflect those of the United States Government or any agency thereof. 


\section{DISCLAIMER}

Portions of this document may be illegible in electronic image products. Images are produced from the best available original document. 
Printed in the United States of America. Available from the Energy Research and Development Administration, Technical Informatiun Center

P $\cap$ Box 62, Dak Ridgo, Tonnossco 37830

Price: Printed Copy $\$ 6.75 ;$ Microfiche $\$ 3.00$

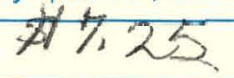

I his report was prepared as an account of work sponsored by the United States Government. Neither the United States nor the Energy Research and Development Administration/United States Nuclear Regulatory Commission, nor any of their employees, nor any of their contractors, subcontractors, or their employees, makes any warranty, express or implied, or assumes any legal liability or responsibility for the accuracy, completeness or usefulness of any information, apparatus, product or process disclosed, or represents that its use would not infringe privately owned rights. 
ORNL/TM-5839

Dist. Category UC-79, $-79 e,-79 p$

Contract No. W-7405-eng-26

Engineering Technology Division

BLOCKAGES IN LMFBR FUEL ASSEMBLIES - A REVIEW OF EXPERIMENTAL AND THEORETICAL STUDIES

J. T. Han

Manuscript Completed - August 8, 1977

Date Published - September 1977

This repOTICE

This report was prepared as an account of work the United States nor the Unovernment. Neither Research and Development Administration, Energy their employees, nor any of their, nor any of subcontractors, or their employees, makes warranty, express or implied, or assumes any logal tiability or responsibility for the accuracy, completeness or usefilness of any information, apparatus, product or infringe privately or represents that its use would not

NOTICE: This document contains information of a preliminary nature. It is subject to revision or correction and therefore does not represent a final report.

\author{
Prepared by the \\ OAK RIDGE NATIONAL LABORATORY \\ Oak Ridge, Tennessee 37830 \\ operated by \\ UNION CARBIDE CORPORATION \\ for the \\ ENERGY RESEARCH AND DEVELOPMENT ADMINISTRATION
}


THIS PAGE

\section{WAS INTENTIONALLY LEFT BLANK}


CONTENTS

$\underline{\text { Page }}$

ABSTRACT $\ldots \ldots \ldots \ldots \ldots \ldots \ldots \ldots \ldots \ldots \ldots \ldots \ldots \ldots \ldots \ldots \ldots \ldots \ldots \ldots \ldots$

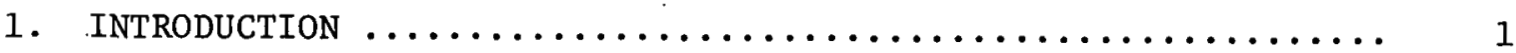

2. EXPERIMENTAL RESULTS ON BLOCKAGES .................. 3

2.1 ORNL Thermal-Hydraulic Out-of-Reactor Safety

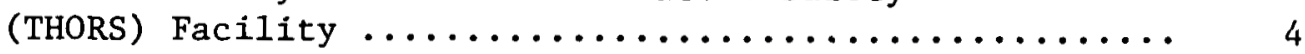

2.1.1 Inlet blockages of 13 and 24 channels in a

19 -pin sodium-cooled bundle .............. 4

2.1.2 Central blockage of 6 channels in a 19-pin sodium-cooled bundle .................... 20

2.1.3 Edge blockages of 14 channels in 19-pin sodium-cooled bundles .................. 34

2.2 THORS Water Mockup of a Three-Scale 19-Pin Bundle ...... 48

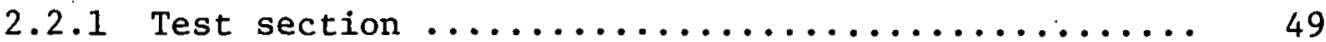

2.2.2 Results and discussion ................. 51

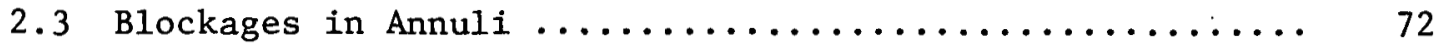

2.3.1 Thermal-hydraulic studies ................ 72

2.3.2 Heat transfer in the wake $\ldots \ldots \ldots \ldots \ldots \ldots \ldots \ldots . . \ldots$

2.4 Blockages in Simulated SNR Fuel Assemblies .......... 84

2.4.1 Phenomenological flow distributions in the wake .. 84

2.4 .2 Thermal-hydraulic studies ................ 86

2.5 Miscellaneous Results ..................... 104

2.5.1 Six-channel blockage in a 7-pin sodium-cooled

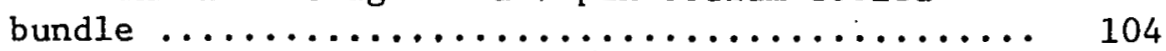

2.5.2 Four-channel blockage in a 19-pin water-cooled bundle ........................... 111

2.5.3 Velocity profiles in a 39-pin air bundle with 1 - and 4-channel blockages ............... 112

2.5.4 Studies of wakes behind blockages without pins ... 117

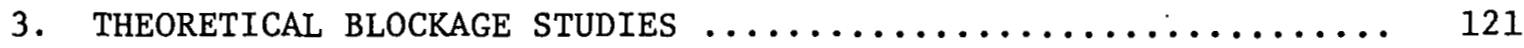

3.1 Results and Discussions $\ldots \ldots \ldots \ldots \ldots \ldots \ldots \ldots \ldots \ldots \ldots \ldots$

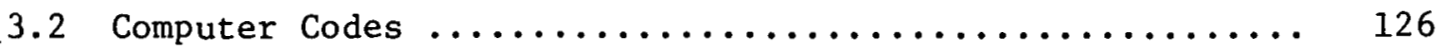

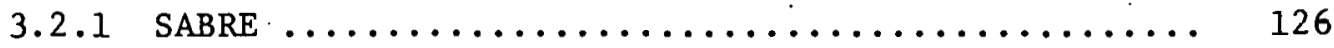

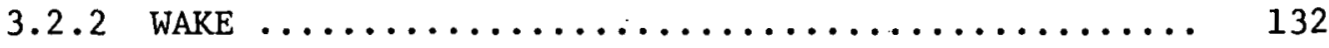

4. BLOCKAGE DETECTION $\ldots \ldots \ldots \ldots \ldots \ldots \ldots \ldots \ldots \ldots \ldots \ldots \ldots \ldots \ldots \ldots \ldots$

5. CONCLUSTONS ................................ 139

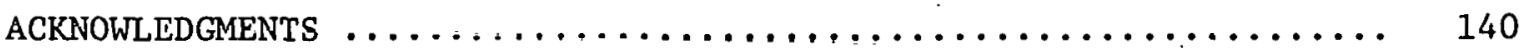

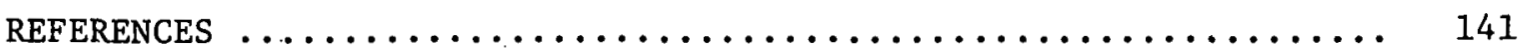




\title{
BLOCKAGES IN LMFBR FUEL ASSEMBLIES - A REVIEW OF EXPERIMENTAL AND THEORETICAL STUDIES
}

J. T. Han

\section{ABSTRACT}

\begin{abstract}
This is a state-of-the-art report on the thermal-hydraulic effects of flow-channel blockages in liquid-metal fast breeder reactor (LMFBR) pin bundles. Most of the experimental and theoretical studies for simulating blockages in various prototype LMFBR fuel assemblies done in the United States and abroad through 1976 are presented and summarized. A brief summary on blockage detection is included.
\end{abstract}

Keywords: blockage, LMFBR, fuel assemblies, pin, channel, wake, sodium, temperature.

\section{INTRODUCTION}

The core region of a liquid-metal fast breeder reactor (LMFBR), such as the Fast Flux Test Facility (FFTF) being built at Richland, Washington, and the Clinch River Brceder Reactor (CRBR) to be built at Oak Ridge, Tennessee, consists of stainless-steel-clad $\mathrm{UO}_{2}$ fuel pins. The pins are 5.84 $\mathrm{mm}$ (0.230 in.) in outside diameter and are spaced by $1.42-\mathrm{mm}$-diam (0.056in.) wires wrapped on a 305-mm (12-in.) helical pitch. They are clad with $0.381-\mathrm{mm}$-thick (0.015-in.) stainless steel, and the distance between the adjacent pin centers is $7.26 \mathrm{~mm}$ (0.286 in.). The FFTF and the CRBR fuel assemblies have 217 pins enclosed in a hexagonal duct with a wall thickness of $3.05 \mathrm{~mm}(0.120 \mathrm{in.})$. The FFTF and the CRBR have 76 and 196 fuel assemblies, respectively. Sodium, which is used as the coolant, flows vertically upward through the space between the pins in the core to remove the generated hear.

Hypothetical mechanisms that may cause channel blockages in the fuel assemblies have been identified: (1) lodging of foreign materials carried into the core by the sodium, (2) bending and swelling of the fuel pins, and (3) lodging of debris from failed fuel pins and broken wire-wrap spacers.

The effects of blockages upon reactor safety depend on several factors, e.g., the size, material, and location of the blockage; the mean fluid velocity in the pin bunde; and the power-generation rates of the fuel pins. 
Hydrodynamically, the presence of the blockage in the flow channels will increase the pressure drop and decrease the flow. The amount of the flow reduction in the blocked channels is primarily dependent on the blockage size as well as on the mean fluid velocity. More importantly, the fluid and the cladding temperatures in the wake (recirculation zone) downstream of the blockage will become higher than those under normal conditions without a blockage.

The primary objectives of this report are to summarize and assess the experimental and analytical studies on blockages available in the literature and to present a state-of-the-art report on the subject, both quantitatively and qualitatively. 


\section{EXPERIMENTAL RESULTS ON BLOCKAGES}

Experimental studies ${ }^{1-13}$ have been carried out to investigate the thermal-hydraulic effects of various sizes of blockages in simulated fuel assemblies. Sodium, water, and air are the coolants commonly used.

The most extensive experiments on blockage are probably those performed by Fontana et al. ${ }^{1,2}$ at the Oak Ridge National Laboratory (ORNL) Thermal-Hydraulic Out-of-Reactor Safety (THORS) facility. * Temperature measurements for flows with various blockages have been obtained in a sodium-cooled 19-pin electrically heated bundle which simulates the fuel assemblies of the FFTF and the CRBR. Heat transfer coefficients, wake lengths and patterns, and mass exchange rates were obtained for various blockages in the THORS water mockup, which is a three-scale water-cooled 19-pin bundle.

Extensive experimental blockage studies ${ }^{5-8}$ have also been performed at the Karlsruhe Nuclear Research Center in West Germany. Kirsch and Schleisiek ${ }^{5}$ measured the temperature distribution, wake length, and mass exchange rate in a blocked annulus using both sodium and water as coolants. Schleisiek ${ }^{6}$ also investigated the heat transfer rate and the temperature rise in the wake of a blocked annulus with sodium and water as fluids. Basmer et al: ${ }^{7}$ observed flow patterns in the wake by injecting air bubbles into water in one-half of a 169-pin bundle which.simulates the fuel assemblies of the German sodium-cooled fast breeder reactor (SNR). Kirsch ${ }^{8}$ obtained pressure and temperature profiles and mass exchange rates behind blockages in a 169-pin water-cooled bundle.

Daigo et al. 9 measured the temperature rise behind a blockage in a 7pin sodium-cooled electrically heated bundle. Van Erp and Chawla ${ }^{10}$ obtained heat transfer measurements in a 19-pin water-cooled electrically heated bundle. Vegter et al. ${ }^{11}$ investigated velocity distribution and wake length in a 39 -pin air bundle, and Carmody ${ }^{12}$ obtained velocity and pressure measurements for the wake behind a circular disk in an air stream. Castro ${ }^{13}$ investigated the wake characteristics behind a two-dimensional perforated plate normal to an air stream.

\footnotetext{
*Previously called the Fuel Failure Mockup (FFM).
} 


\subsection{ORNL Thermal-Hydraulic Out-of-Reactor Safety (THORS) Facility}

A flow diagram of the THORS ${ }^{1}{ }^{2}$ facility is shown in Fig. 1 . The centrifugal pump has a flow capacity of $38 \mathrm{l} / \mathrm{s}$ (600 gpm), which is adequate for testing full-scale simulated 217-pin assemblies of the FFTF and the CRBR. The electrically heated stainless-steel-clad pins are $5.84 \mathrm{~mm}(0.230$ in.) in outside diameter and are spaced by 1.42-mm-diam (0.056-in.) wires wrapped on a 305-mm (12-in.) helical pitch. The distance between the adjacent pin centers is $7.26 \mathrm{~mm}$ (0.286 in.). Figure 2 shows the internal structure of a typical pin. The cladding thickness and the heated length vary for different bundles. The cladding thickness $t$ is $0.457,0.432$, and $0.381 \mathrm{~mm}(0.018,0.017$, and $0.015 \mathrm{in.})$ for bundles $2 \mathrm{~B}, 3 \mathrm{~A}$, and 5 , respect1vely.

\subsubsection{Inlet blockages of 13 and 24 channels. in a 19-pin sodium-cooled bundle}

Test section. THORS bundle $2 \mathrm{~B}^{1}$ was used to investigate the thermalhydraulic effects of $13-$ and 24-channel inlet blockages. In the test section (Fig. 3), sodium enters the bundle at the lower end and flows upward. Tlie pius liave a heared length of $533 \mathrm{~mm}$ (2i in.) preceded by an unheated length of $76.2 \mathrm{~mm}$ ( 3 in.). The stainless stepl blockage platc, located at the bottom of the pins, is $1.59 \mathrm{~mm}(0.0625 \mathrm{in.})$ thick.

There are four types of temperature instrumentation in this bundle:

1. Thirteen wire-wrap spacers each contaln two ungrounded ChromelAlumel thermocouples spaced $50.8 \mathrm{~mm}$ (2 in.) or $305 \mathrm{~mm}$ (12 in.) apart axia.1.1y ,

2. Six wire-wrap spacers each contain two grounded Chrome1-Alumel thermocouples diametrically opposed in the wrap; bundle $2 B$ has three pairs at both the 50.8- and 76.2-mm (2- and 3-in.) Icve1.a.

3. Alternate chromel-Alumel bare wires (10 mils in diameter) are installed in the heater in the 0.99-mm (0.039-in.) clearance between the heating element and the sheath (see Fig. 2). These wires are separately joined to the heater sheath to form an intrinsic thermocouple junction on the inner surface.

4. Chromel-Alumel thermocouples are installed at intervals along the bundle length to measure the wall temperatures of the hexagonal duct. 
ORNL-DWG 73-8794

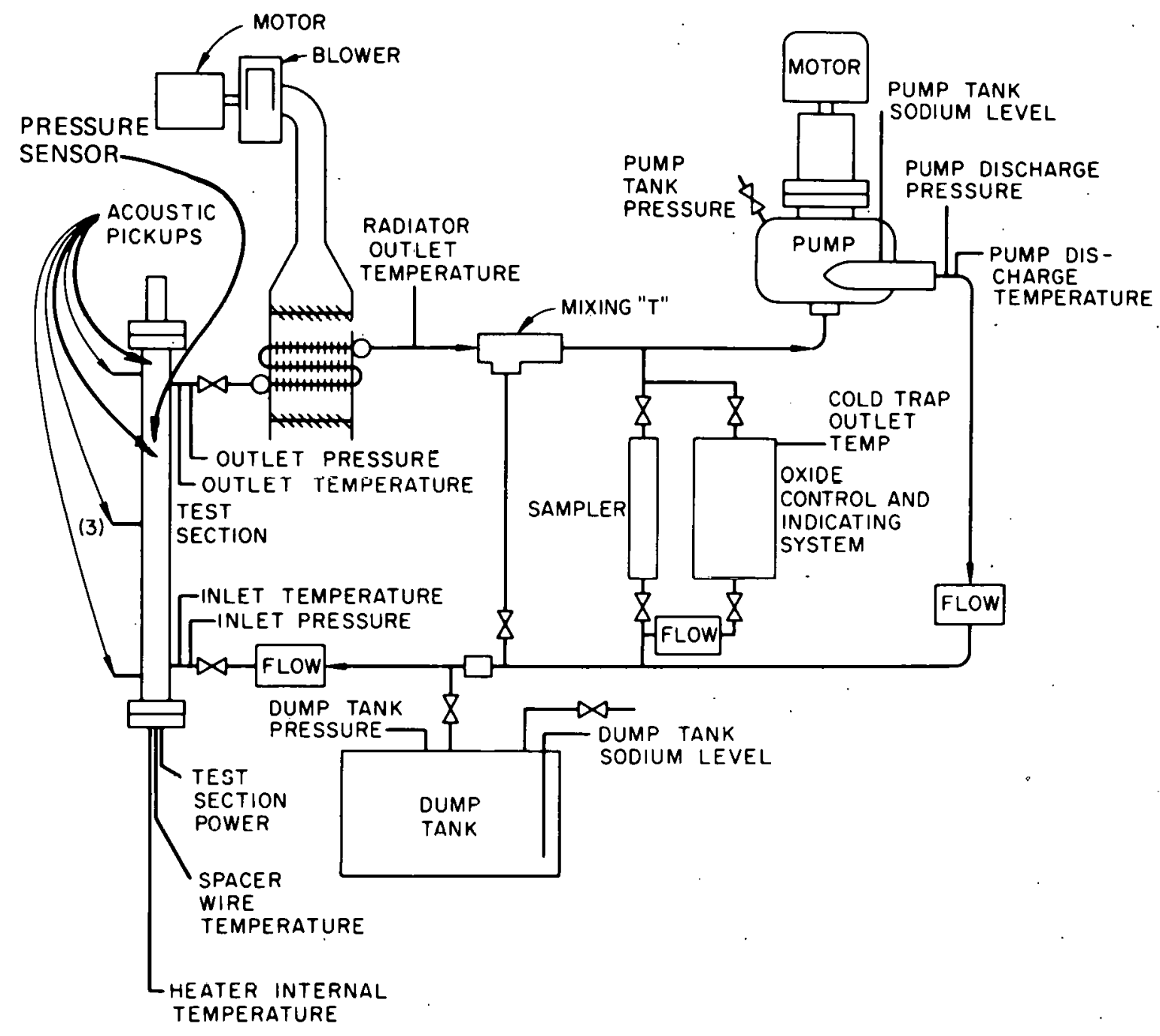

Fig. 1. Flow diagram of the Thermal-Hydraulic Out-of-Reactor Safety (THORS) facility (Fontana et al. ${ }^{1}$ ).

The locations of the thermocoules inside the heaters, the grounded wire-wrap thermocouples, and the 76.2-mm level duct-wall thermocouples for THORS bundle 2B are shown in Fig. 4, along with the pin and channel numbering convention. Figure 5 illustrates the locations of ungrounded wire-wrap thermocouples. The large circles in the flgures represent the heaters that simulate the fuel pins; these are identified by the central number. The small tangent circles represent thermocouple junctions at the indicated azimuthal position of the wire-wrap spacers. The junctions are located at 


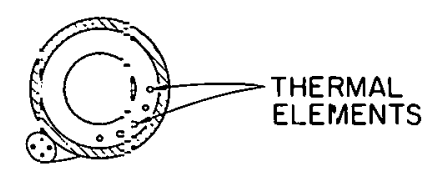

SECTION A-A

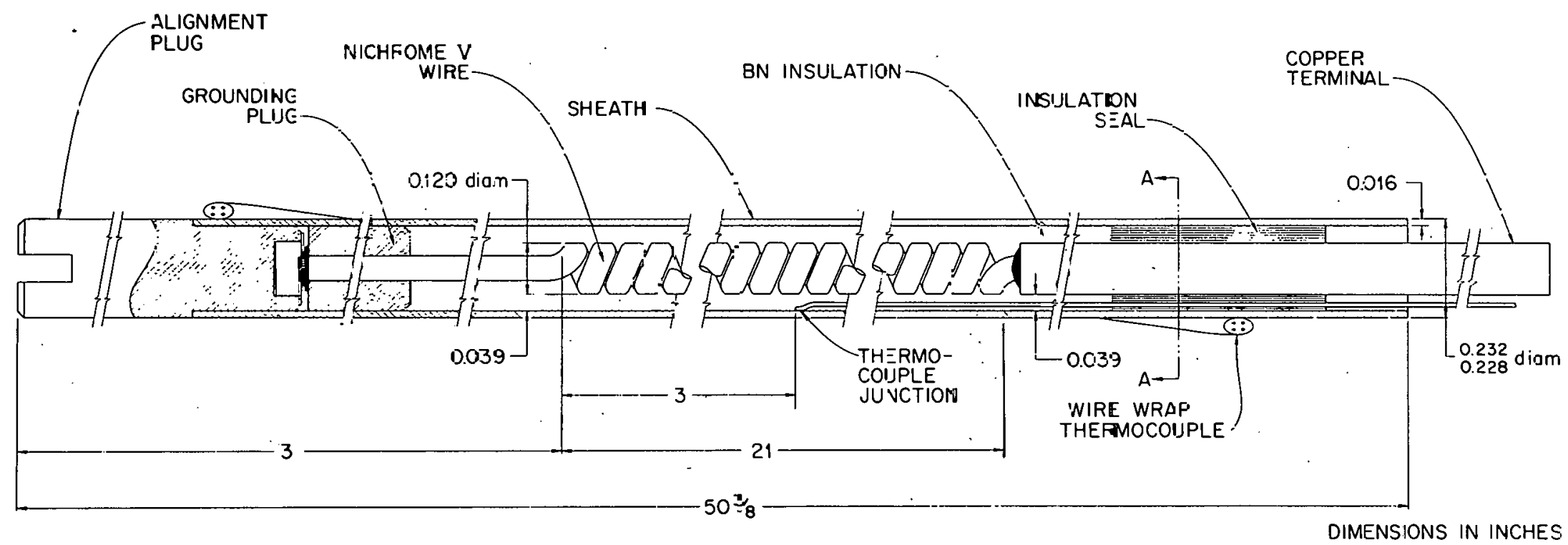

Fig. 2. THORS heacer pin (Fontara et al. ${ }^{1}$ ). 
ORNL-DWG $73-9008$

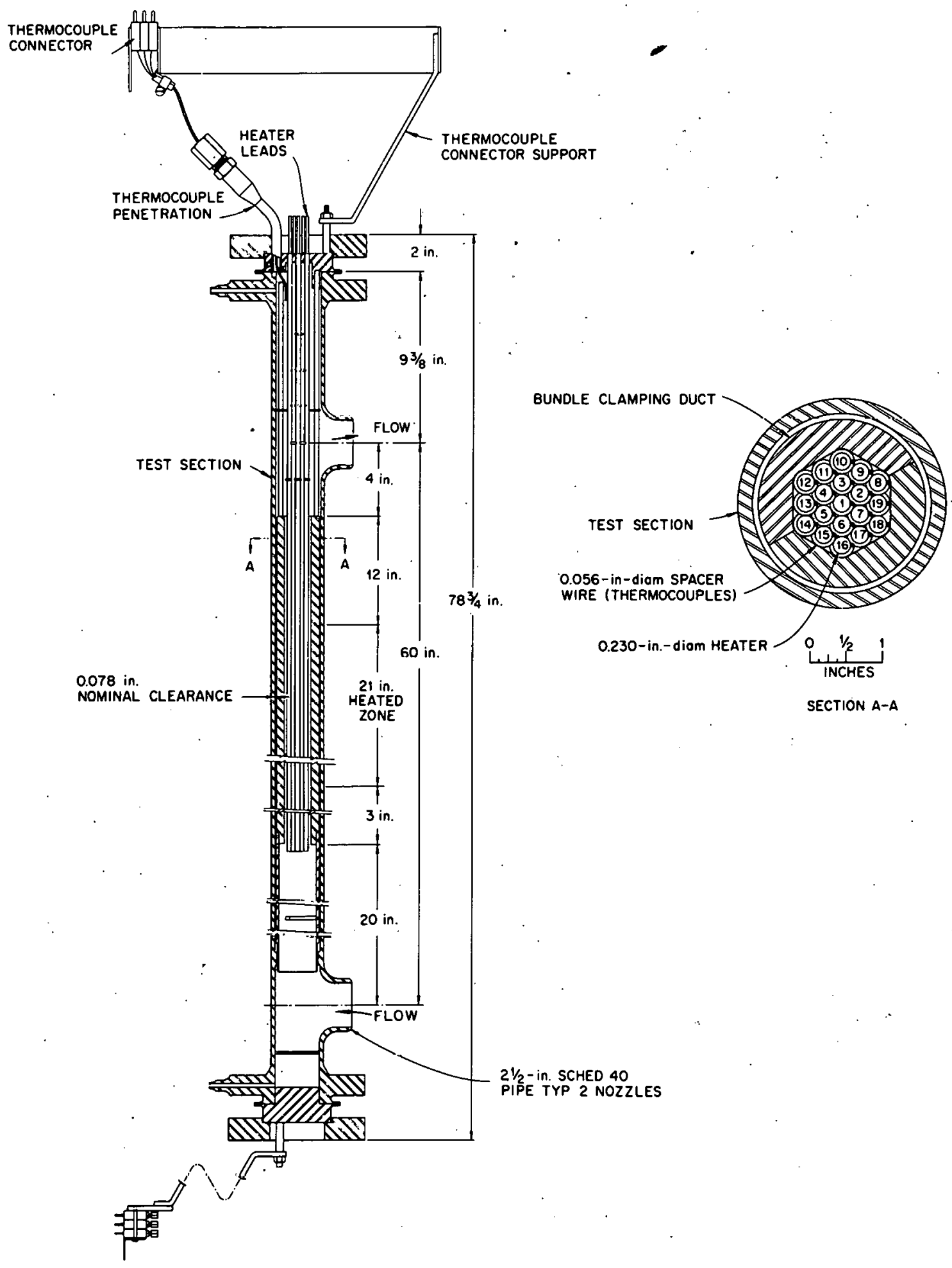

Fig. 3. Test section for THORS bundle 2B (Fontana e1 al. ${ }^{1}$ ). 


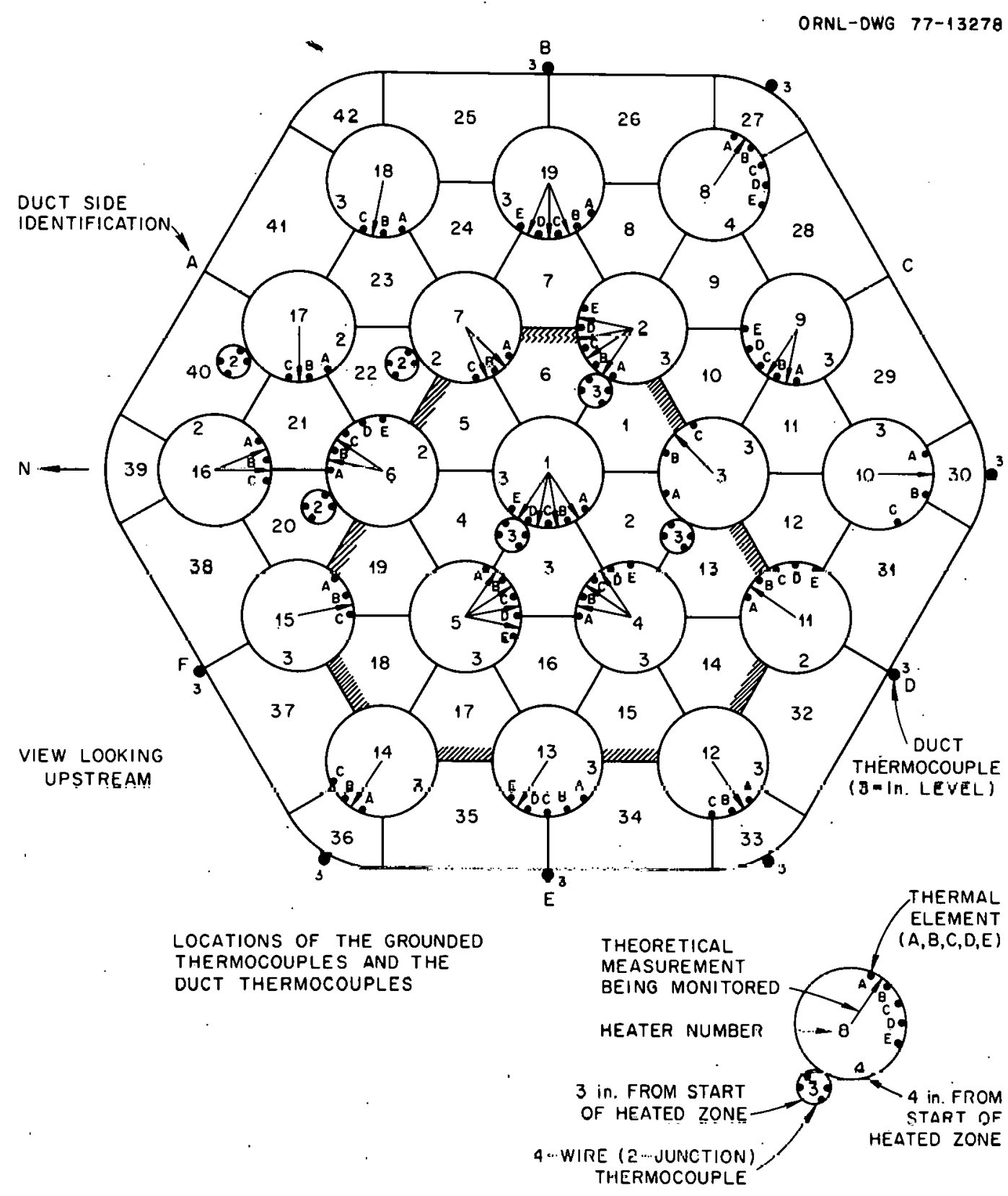

Fig. 4. Locations of heater thermocouples, grounded wire-wrap thermocouples, and duct-wall thermocouples in THORS bundle 2B. Thirteen blocked channels are shown in shaded area (Fontana et al. ${ }^{1}$ ). 


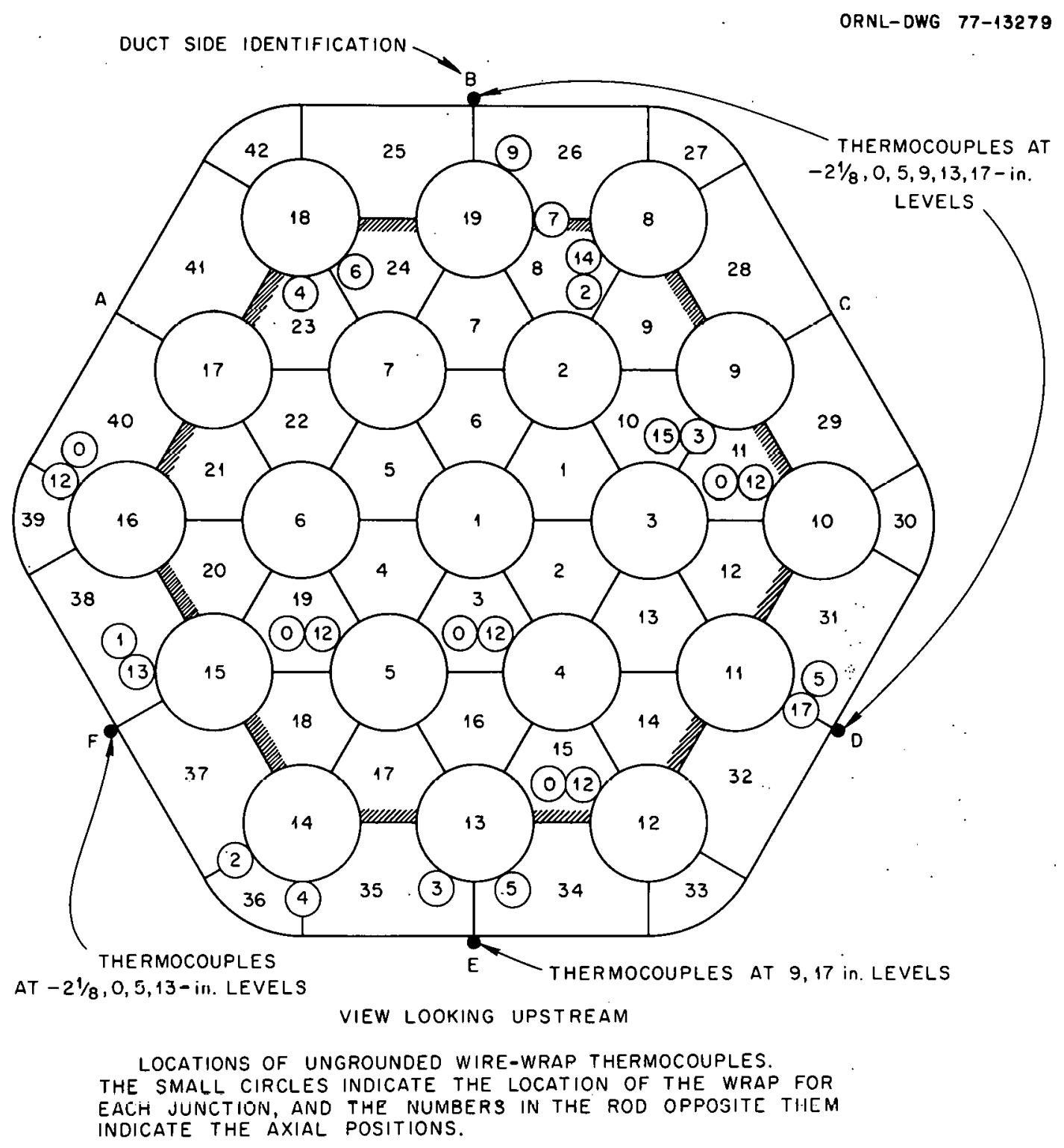

Fig. 5. Locations of ungrounded wire-wrap thermocouples for THORS bundle 2B. Twenty-four blocked channels are shown in shaded area (Fontana et $\left.\mathrm{al} .^{1}\right)$.

axial levels indicated by the numbers in the small circles; these levels have units of inches from the start of the heated zone. The small circles containing pairs of dots indicate the locations of grounded-junction thermocouples. The pair of dots next to the heater surface indicates that a thermocouple junction in the wire wrap is adjacent to the heater, whereas the pair of dots on the opposite side indicates that the other junction at 
the same axial level measures temperatures near the center of the flow channel. The flow channels, defined by the lines connecting the centers of the heaters, are identified by the numbers in the triangles. The fuel-pin simulators have thermal elements attached to the inner surface of the cladding, as indicated by the dots in the large circles labeled A, B, C, etc.

As shown in Fig. 4, testing was conducted with no inlet blockage and with 13 channels blocked (channels 1 to 6 and 13 to 19); as shown in Fig. 5 , testing was conducted with channels 1 to 24 blocked (all but the peripheral channels). The 13- and the 24-channel inlet blockage plates are shown in Figs. 6 and 7, respectively. When the 24-channel inlet blockage plate was installed, a duct-wall extension piece was added to give a more realistic inlet-flow distribution (Fig. 7). The 24-channel inlet blockage plate blocks approximately half of the flow area. Radial heat loss from the test section was reduced by the use of insulation and guard heaters controlled to give zero temperature gradient in the insulation as measured by two thermocouples.

Results and discussion. During this series of tests the flow was varied from $0.63 \mathrm{l} / \mathrm{s}$ (10 gpm), which is approximately $20 \%$ of full flow; to $3.5 \mathrm{l} / \mathrm{s}$ (55 gpm), which is approximately $100 \%$ of full flow; all 19 pins were heated at a uniform rate of 6.6 to $26 \mathrm{~kW} / \mathrm{m}(2$ to $8 \mathrm{~kW} / \mathrm{ft}$ ) per pin. 'lhe increase in total pressure drops through the bundle due to the inlet blockages of up to $50 \%$ of the total flow area over this range appears to be small (see Fig. 8).

Table 1 gives the dimensionless temperature rises, ( $\mathrm{T}-\mathrm{I}_{\text {in }}$ )/( $\mathrm{I}_{\text {out }}$ $\mathrm{T}_{\text {in }}$ ), at the 76.2-mm (3-in.) level above the start of the heated zone for no blockage, for a 13-channel inlet blockage, and for a 24-channel inlet blockage at several radial locations under various sodium flows and pinpower lcvelo. ( $\mathrm{T}_{\text {in }}$ ic the codium temperature at the bundle inlet and $\mathrm{T}_{\text {out }}$ is the bulk sodium temperature at the bundle outlet.)

Figure 9 shows the normalized dimensionless temperature rises (averaged for cases 700 to 702 as specifled in Table 1) vs axial positions for all channel thermocouples. These measurements were made in an unblocked bundle with a total sodium flow of about $3.4 \mathrm{l} / \mathrm{s}$ (54 gpm) and powers of 13, 16 , and $20 \mathrm{~kW} / \mathrm{m}(4,5$, and $6 \mathrm{~kW} / \mathrm{ft})$ per pin. 


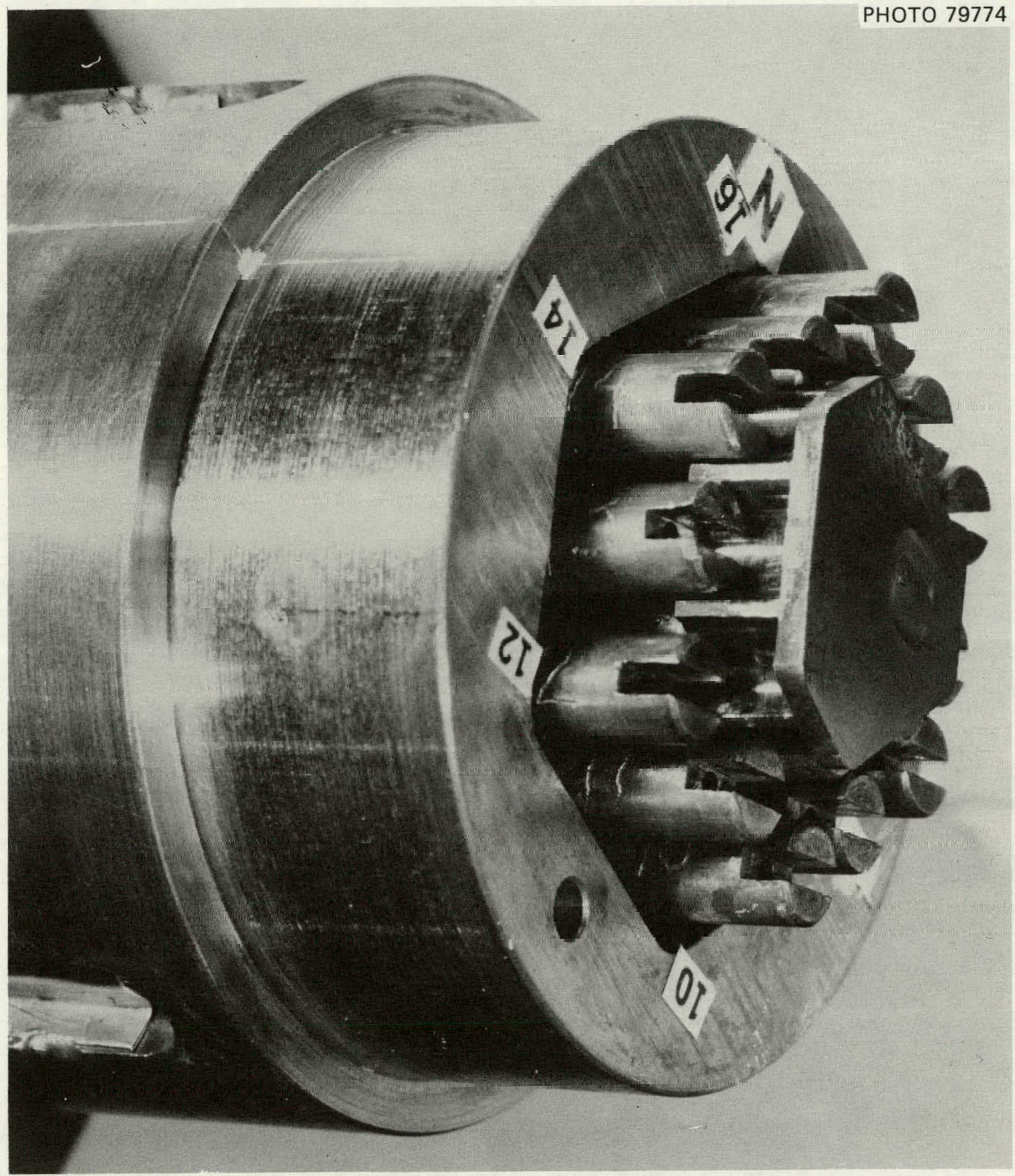

Fig. 6. Inlet end of THORS bundle $2 \mathrm{~B}$ with the 13-channel inlet blockage plate (Fontana et al. ${ }^{1}$ ). 


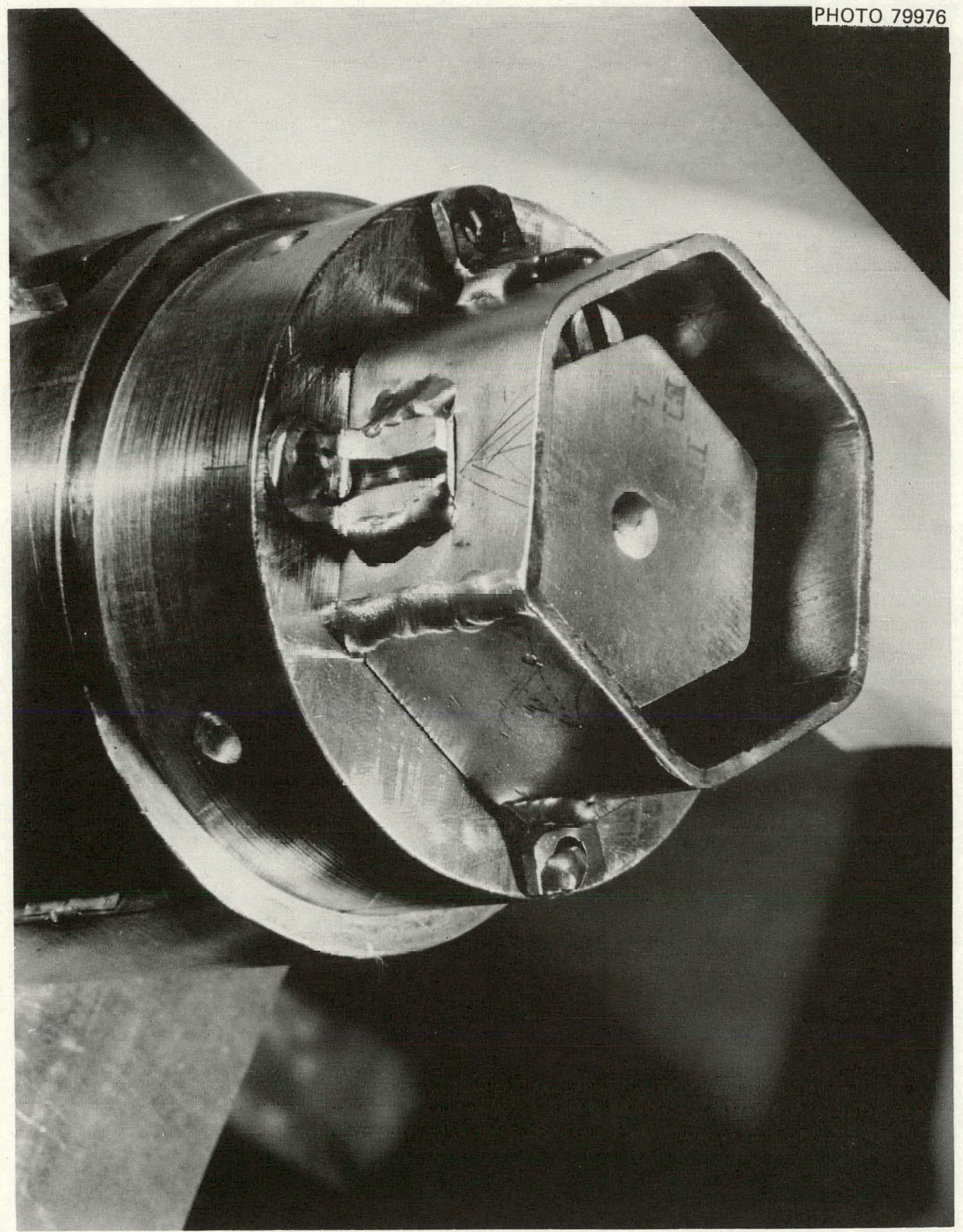

Fig. 7. Inlet end of THORS bundle $2 \mathrm{~B}$ with the 24-channel inlet blockage plate and the inlet shroud (Fontana et al. ${ }^{1}$ ). 


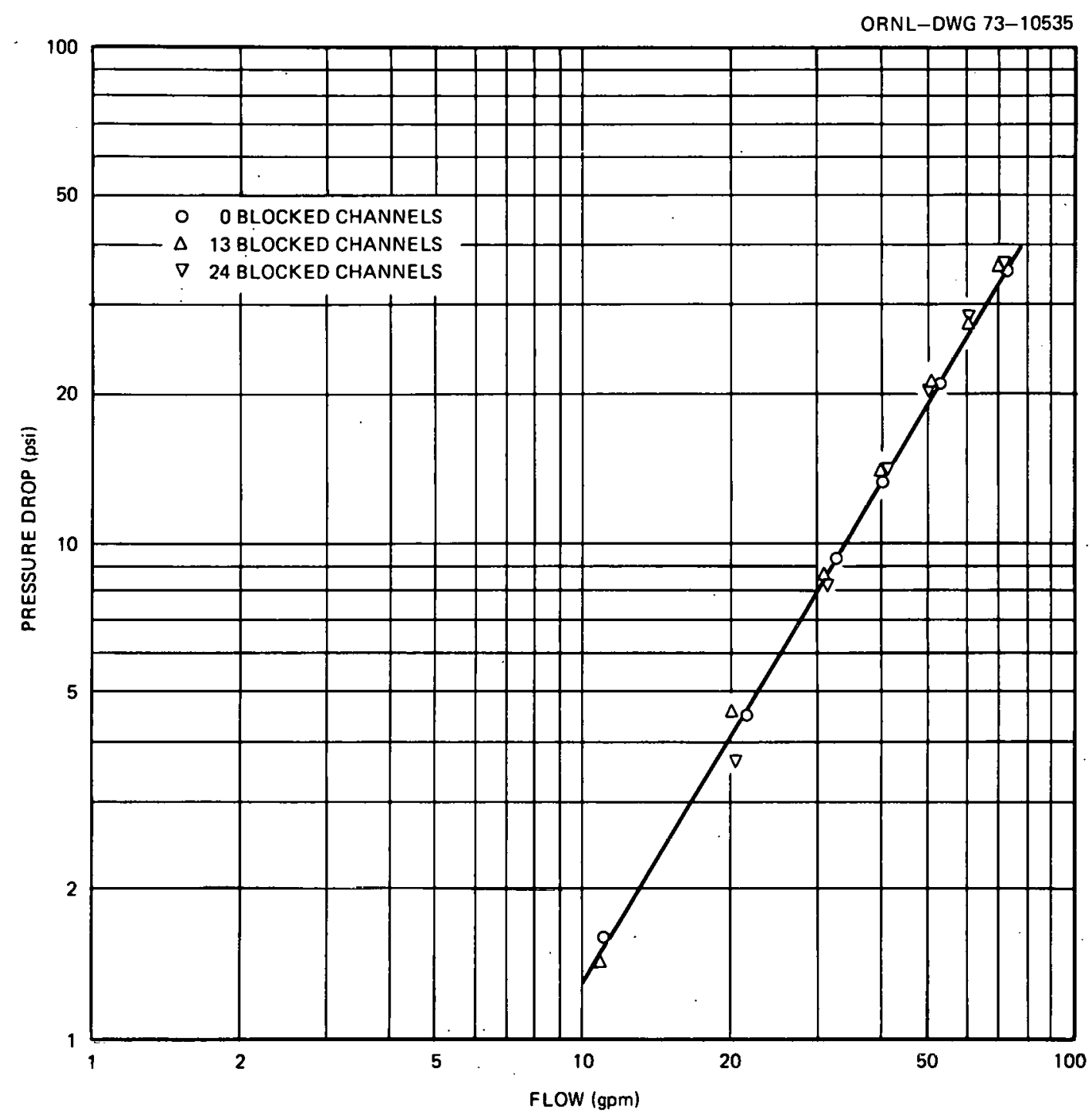

Fig. 8. Pressure drop for THORS bundle 2B with no blockage, 13channel inlet blockage, and 24-channel inlet blockage (Fontana et a1. ${ }^{1}$ ).

The ratios of $\left[\left(\mathrm{T}-\mathrm{T}_{\text {in }}\right) /\left(\mathrm{T}_{\text {out }}-\mathrm{T}_{\text {in }}\right)\right]_{\mathrm{blocked}}$ to $\left[\left(\mathrm{T}-\mathrm{T}_{\text {in }}\right) /\left(\mathrm{T}_{\text {out }}-\right.\right.$

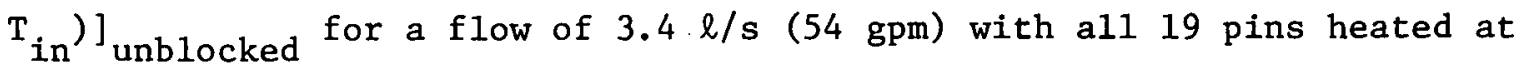
$16 \mathrm{~kW} / \mathrm{m}$ ( $5 \mathrm{~kW} / \mathrm{ft})$ per pin are given in Figs. 10 and 11 for the 13- and 24channel inlet blockages, respectively. It may be seen from these figures that this ratio is generally greater than 1.0 for channels downstream from the inlet blockage and, due to the increased bypass flow, is less than 1.0 for the unblocked channels (channels 7 to 12 and 20 to 42 for the 13-channel inlet blockage and channels 25 to 42 for the 24-channel inlet blockage). 


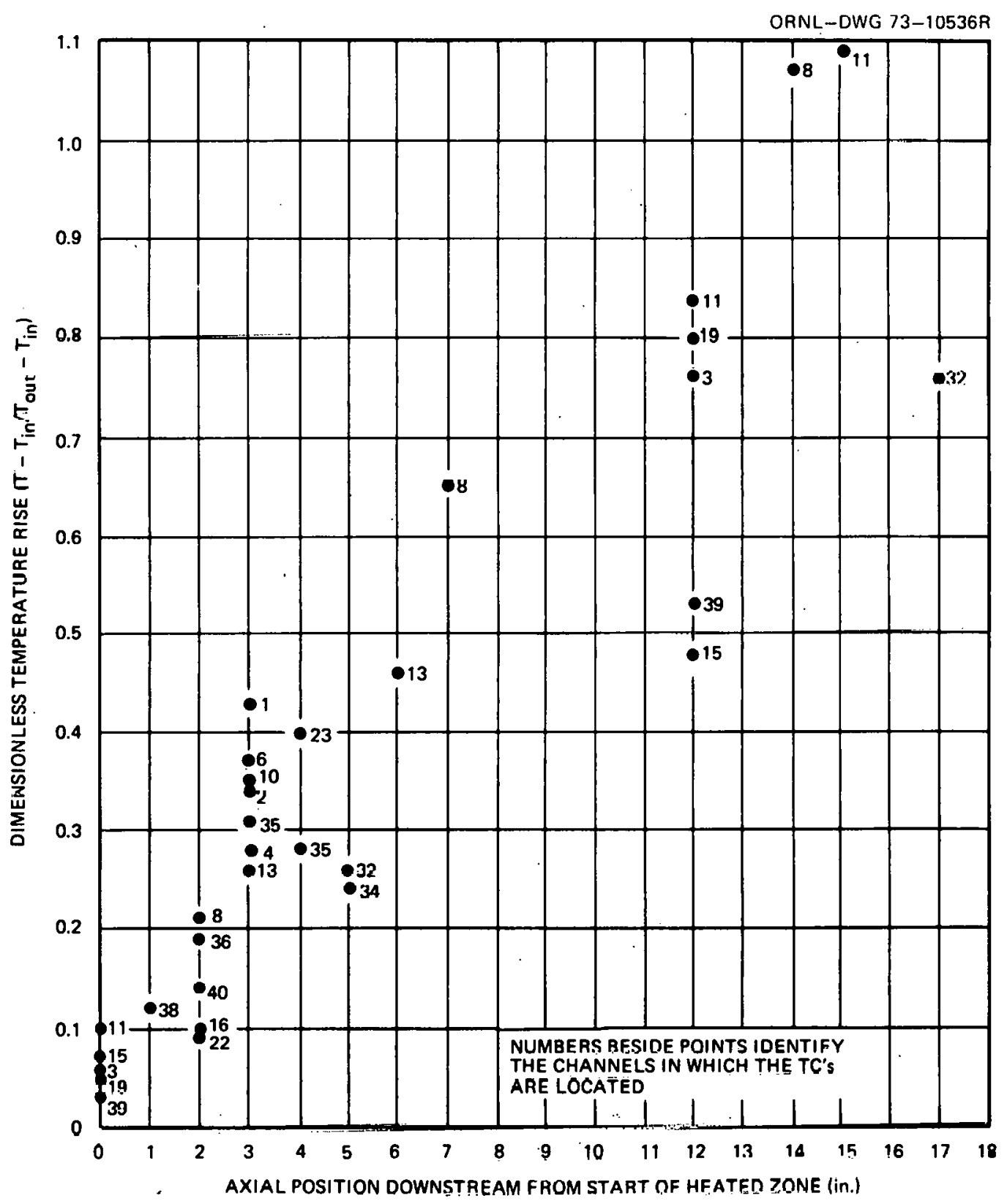

Fig. 9. Dimensionless temperature rise $\left[\left(T-T_{1 n}\right) /\left(T_{\text {out }}-T_{1 n}\right)\right]$ vs axial distance for unblocked tests in THORS bundle 2B. All pins are heated at 13,16 , and $20 \mathrm{~kW} / \mathrm{m}(4,5$, and $6 \mathrm{~kW} / \mathrm{ft})$ per pin with a flow of $3.4 \mathrm{l} / \mathrm{s}$ ( $54 \mathrm{gpm}$ ) (Fontana et $\mathrm{al} .^{1}$ ). 
Table 1. Comparison of dimensionless temperature rises $\left[\left(T-T_{i n}\right) /\left(T_{\text {out }}-T_{\text {in }}\right)\right]$ in THORS bundle $2 \mathrm{~B}$ with all 19 pins heated, $76 \mathrm{~mm}$ ( 3 in.) downstream from Ene start of the heated section (152 mm from the inlet blockage)

\begin{tabular}{|c|c|c|c|c|c|c|c|c|c|c|}
\hline \multirow{2}{*}{$\begin{array}{l}\text { Case } \\
\text { No. }\end{array}$} & \multirow{2}{*}{$\begin{array}{l}\text { Flow } \\
{[\ell / s} \\
(g p m)]\end{array}$} & \multirow{2}{*}{$\begin{array}{l}\text { Power } \\
{[\mathrm{kW} / \mathrm{m}} \\
(\mathrm{kW} / \mathrm{ft})]\end{array}$} & \multirow{2}{*}{$\begin{array}{l}\mathrm{T}_{\text {out }}-\mathrm{T}_{\text {in }} \\
{\left[{ }^{\circ} \mathrm{C}\left({ }^{\circ} \mathrm{F}\right)\right]}\end{array}$} & \multirow{2}{*}{$\begin{array}{l}\text { Number } \\
\text { of } \\
\text { blocked } \\
\text { channels }\end{array}$} & \multicolumn{6}{|c|}{$\left(\mathrm{T}-\mathrm{T}_{\text {in }}\right) /\left(\mathrm{T}_{\text {out }}-\mathrm{T}_{\text {in }}\right)$} \\
\hline & & & & & $1(2)^{a}$ & $2(3)$ & $4(1)$ & $6(2)$ & $10(9)$ & $35(13)$ \\
\hline 700 & $3.4(54)$ & $13(4)$ & 34 (61) & 0 & 0.43 & 0.34 & 0.27 & 0.36 & 0.34 & 0.30 \\
\hline 701 & $3.4(54)$ & $16(5)$ & $42(76)$ & 0 & 0.43 & 0,34 & 0.28 & 0.37 & 0.35 & 0.31 \\
\hline 702 & $3.4(54)$ & $20(6)$ & 51 (91) & 0 & 0.43 & 0,34 & 0.28 & 0.37 & 0.35 & 0.31 \\
\hline 717 & $3.4(54)$ & $6.6 \quad(2)$ & 17. (30) & 13 & 0.36 & 0.32 & 0.35 & 0.20 & 0.34 & 0.36 \\
\hline 718 & $3.4(54)$ & 13 (4) & $34(61)$ & 13 & 0.38 & 0.33 & 0.36 & 0.22 & 0.35 & 0.35 \\
\hline 719 & $3.4(54)$ & $16(5)$ & $42(76)$ & 13 & 0.38 & 0.33 & 0.35 & 0.22 & 0.35 & 0.36 \\
\hline 720 & $3.4(54)$ & $16(5)$ & $42(76)$ & 13 & 0.38 & 0.33 & 0.35 & 0.22 & 0.35 & 0.36 \\
\hline 731 & $3.4(54)$ & $16(5)$ & $42(76)$ & 13 & 0.38 & 0.33 & 0.35 & 0.22 & 0.35 & 0.36 \\
\hline 721 & $3.4(54)$ & $20(6)$ & 51 (91) & 13 & 0.39 & 0.34 & 0.35 & 0.23 & 0.35 & 0.35 \\
\hline 738 & $3.4(54)$ & $6.6(2)$ & $17(30)$ & 24 & 0.57 & 0.46 & 0.43 & 0.45 & 0.40 & 0.32 \\
\hline 739 & $3.4(54)$ & $13(4)$ & $34(61)$ & 24 & 0.56 & 0.50 & 0.46 & 0.43 & 0.39 & 0.34 \\
\hline 740 & $3.4(54)$ & $16(5)$ & $42(76)$ & 24 & 0.56 & 0.51 & 0.44 & 0.42 & 0.37 & 0.32 \\
\hline 741 & $3.4(54)$ & $16(5)$ & $42(76)$ & .24 & 0.56 & 0.51 & 0.45 & 0.42 & 0.37 & 0.32 \\
\hline 742 & $3.4(54)$ & $18(5.5)$ & $47(84)$ & 24 & 0.57 & 0.51 & 0.45 & 0.42 & 0.37 & 0.33 \\
\hline 747 & $3.4(54)$ & $26(8)$ & $68(122)$ & 24 & 0.56 & 0.51 & 0.44 & 0.42 & 0.37 & 0.32 \\
\hline 732 & $2.7(43)$ & $16(5)$ & $53(95)$ & 13 & 0.35 & 0.32 & 0.34 & 0.22 & 0.33 & 0.34 \\
\hline 751 & $2.7 \quad(43)$ & $16(5)$ & $53(95)$ & 24 & 0.51 & 0.47 & 0.42 & 0.38 & 0.33 & 0.31 \\
\hline 733 & 2.7 (33) & $16(5)$ & 71 (127) & 13 & 0.31 & 0.30 & 0.30 & 0.20 & 0.29 & 0.30 \\
\hline 754 & 2.7 (33) & $16(5)$ & 71 (127) & 24 & 0.45 & 0.44 & 0.39 & 0.34 & 0.29 & 0.28 \\
\hline 734 & $1.4(22)$ & $16(5)$ & 106 (190) & 13 & 0.27 & 0.28 & 0.28 & 0.19 & 0.25 & 0.27 \\
\hline 753 & $1.4(22)$ & $16(5)$ & $106(190)$ & 24 & 0.37 & 0.38 & 0.34 & 0.30 & 0.25 & 0.26 \\
\hline 736 & 0.88 (14) & $16(5)$ & 166 (299) & 13 & 0.24 & 0.26 & 0.25 & 0.18 & 0.23 & 0.26 \\
\hline 735 & 0.69 (11) & $1.6(5)$ & $211(380)$ & 13 & 0.23 & 0.26 & 0.24 & 0.18 & 0.18 & 0.26 \\
\hline 752 & 0.69 (11) & 16 (5) & $211(380)$ & 24 & 0.31 & 0.34 & 0.30 & 0.27 & 0.20 & 0.24 \\
\hline
\end{tabular}

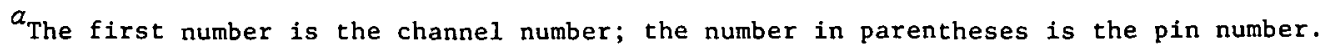

The effect of blockage, as indicated by substantial departures of the ratio from unity, is limited to about $76 \mathrm{~mm}$ ( $3 \mathrm{in.}$ ) downstream from the start of the heated section, which is $152 \mathrm{~mm}$ ( 6 in.) from the inlet blockage plate or about five to six equivalent blockage diameters downstream. No excessively high temperatures were observed. The highest temperatures (see Fi.g. 11) occurred for a 24-channel blockage with a flow of $3.4 \mathrm{l} / \mathrm{s}$ (54 gpm) in channel 22 (see Fig. 4) at an axial position $51 \mathrm{~mm}$ (2 in.) downstream from the start of the heated section $[127 \mathrm{~mm}$ (5 in.) from the inlet blockage]. The ratio at that location was approximately 1.8 , thus indicating 


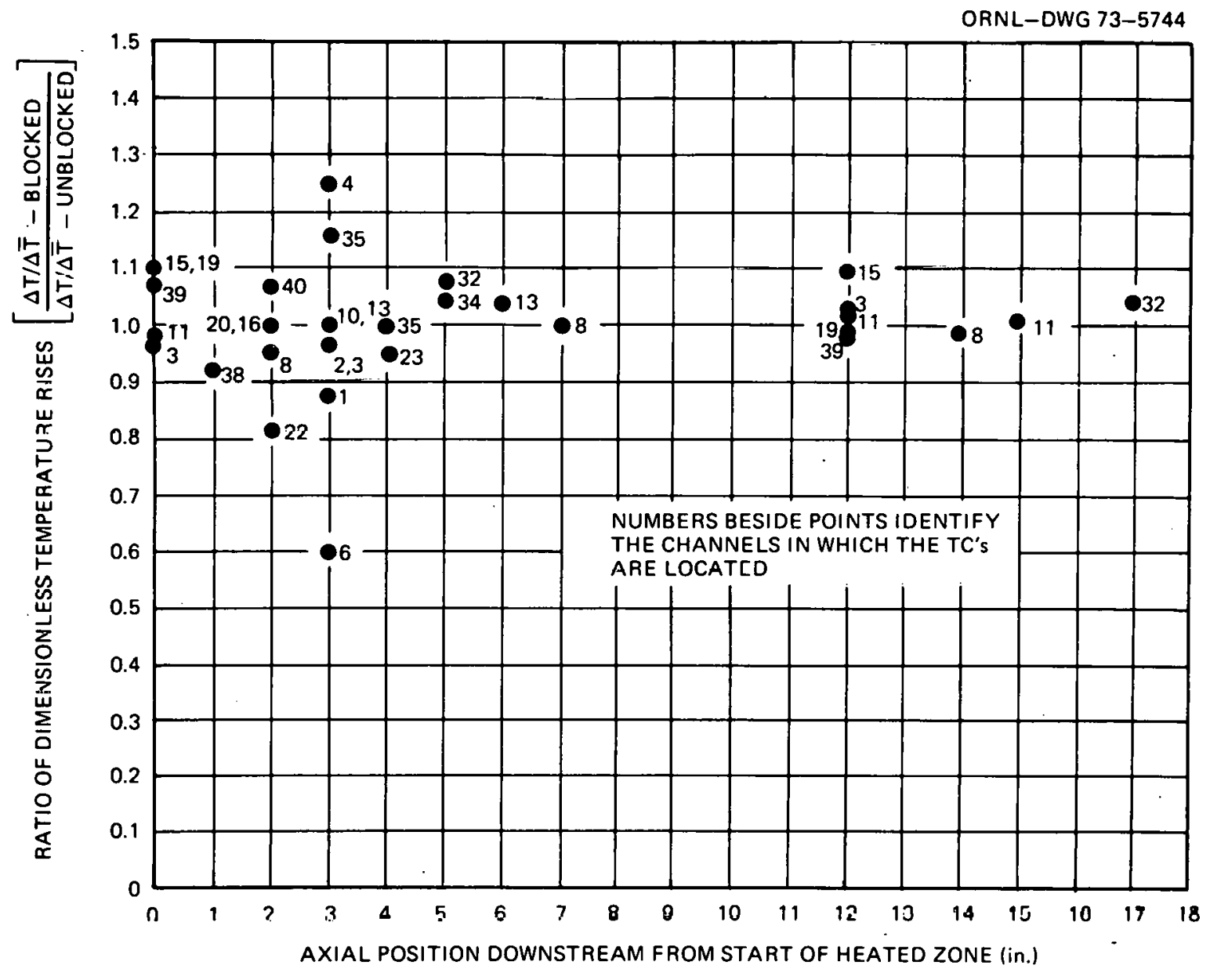

Fig. 10. Ratio of dimensionless temperature increases above the inlet temperature in THORS bundle $2 \mathrm{~B}$ with 1.3-channe1. inlet blockage $\mathrm{LT}_{\text {in }}=\sim 316^{\circ} \mathrm{C}\left(600^{\circ} \mathrm{F}\right)$ with a flow of $\left.3.4 \mathrm{l} / \mathrm{s}(54 \mathrm{gpm})\right]$ (Fontana et al. ${ }^{1}$ ).

an $80 \%$ increase in the temperature rise over that of the unblocked bundle. Although the temperature rise for the unblosked bundle at that position was approximately $3.9^{\circ} \mathrm{C}\left(7^{\circ} \mathrm{F}\right)$, the temperature rise in the blocked bundle was approximately $7.2^{\circ} \mathrm{C}\left(13^{\circ} \mathrm{F}\right)$ - an increase of only $3.3^{\circ} \mathrm{C}\left(6^{\circ} \mathrm{F}\right)$. Temperature differences resulting from the wire-wrap perturbations (shifting during a test) in normal bundles are often greater than this.

Figure 12 shows the ratio of the dimensionless temperature rise at $0.69 \mathrm{l} / \mathrm{s}(11 \mathrm{gpm})$ to that at $3.4 \mathrm{l} / \mathrm{s}$ (54 gpm) for the 13-channel inlet blockage with all 19 pins heated. 


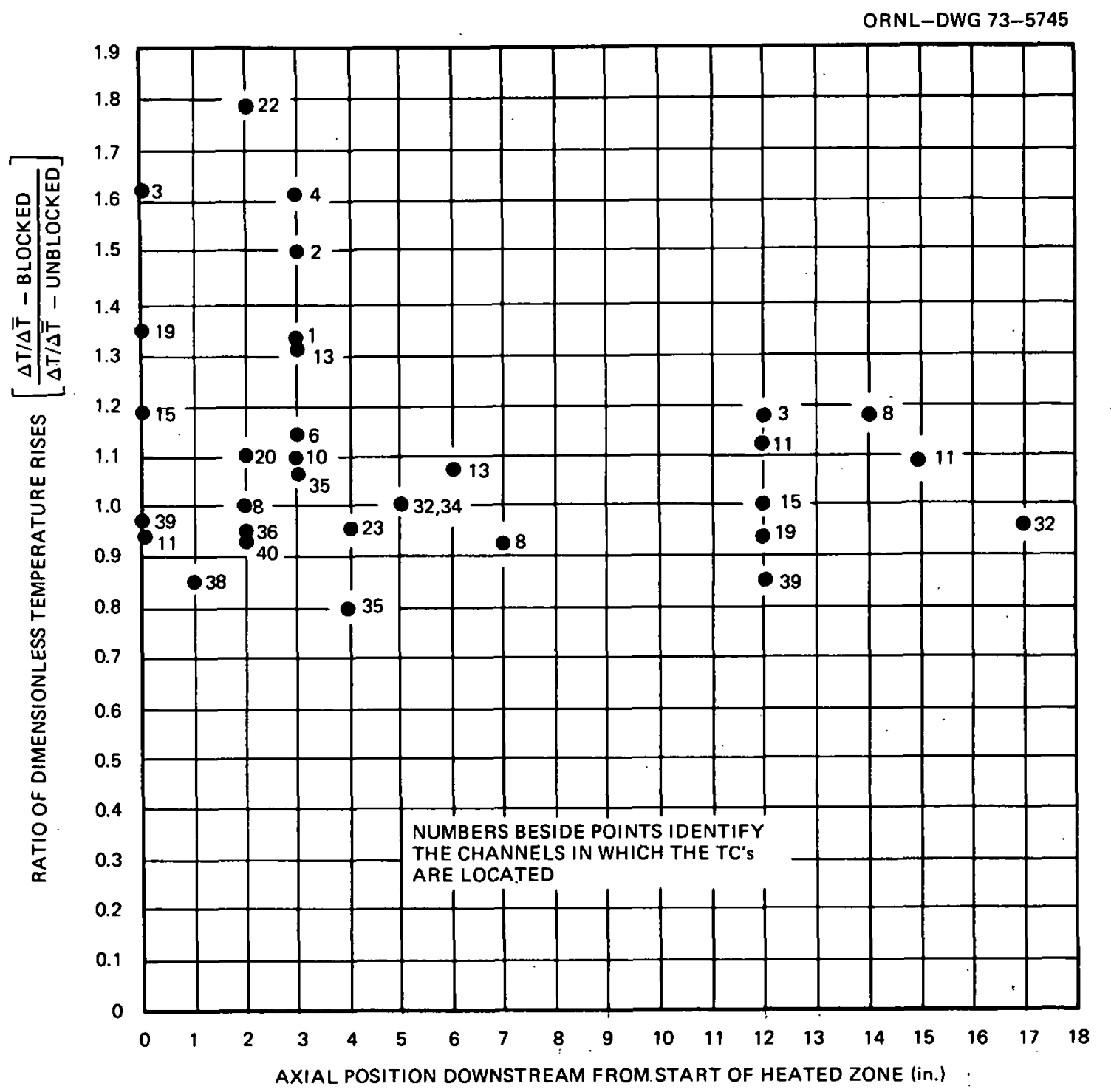

Fig. 11. Ratio of dimensionless temperature increases above the inlet temperature in THORS bundle $2 \mathrm{~B}$ with 24-channel inlet blockage $\left[\mathrm{T}_{\text {in }}=\sim 316^{\circ} \mathrm{C}\left(600^{\circ} \mathrm{F}\right)\right.$ with a flow of $\left.3.4 \mathrm{l} / \mathrm{s}(54 \mathrm{gpm})\right]$ (Fontana et $\left.\mathrm{al} .^{1}\right)$.

Figure 13 shows the temperature rises caused by the blockages for a sodium flow of $3.5 \mathrm{l} / \mathrm{s}(55 \mathrm{gpm})$ at a power level of $16 \mathrm{~kW} / \mathrm{m}(5 \mathrm{~kW} / \mathrm{ft})$ per pin. Also shown for comparison are the temperatures measured at the same points for the no-blockage case. Note that the maximum temperature increase of $7.2^{\circ} \mathrm{C}\left(13^{\circ} \mathrm{F}\right)$ found due to inlet blockages was for the 24 -channel blockage. Effects at luwer flows were similar. 
ORNL-DWG 73-5747R

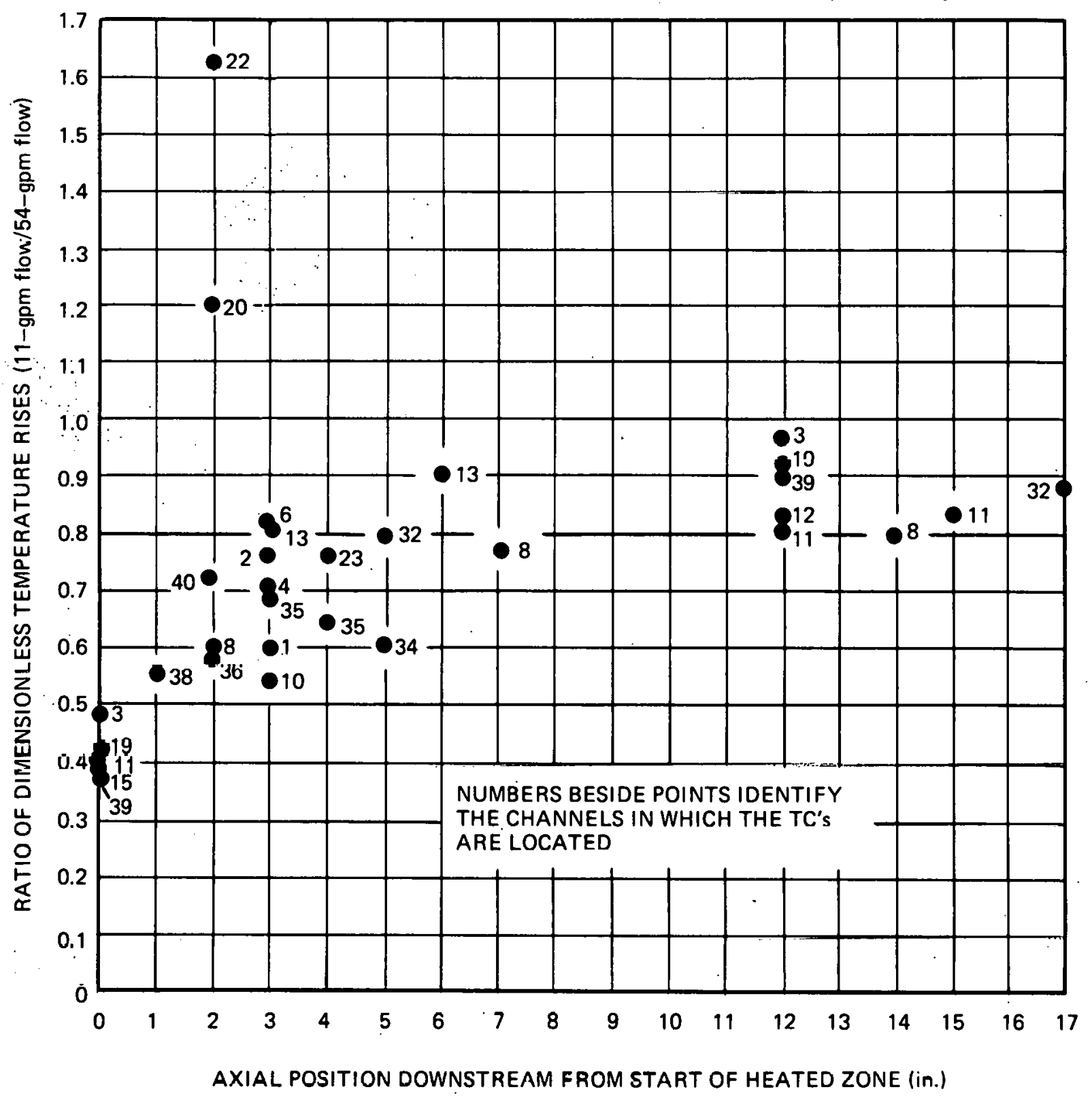

Fig. 12. Ratio of dimensionless temperature rise $\left[\left(T-T_{\text {in }}\right) /\right.$ $\left(\mathrm{T}_{\text {out }}-\mathrm{T}_{\text {in }}\right)$ ] at $0.69 \mathrm{l} / \mathrm{s}(11 \mathrm{gpm})$ to dimensionless temperature rise at $3.4 \mathrm{l} / \mathrm{s}(54 \mathrm{gpm})$ for a 13-channel blockage (Fontana et a1. ${ }^{\mathrm{l}}$ ). 


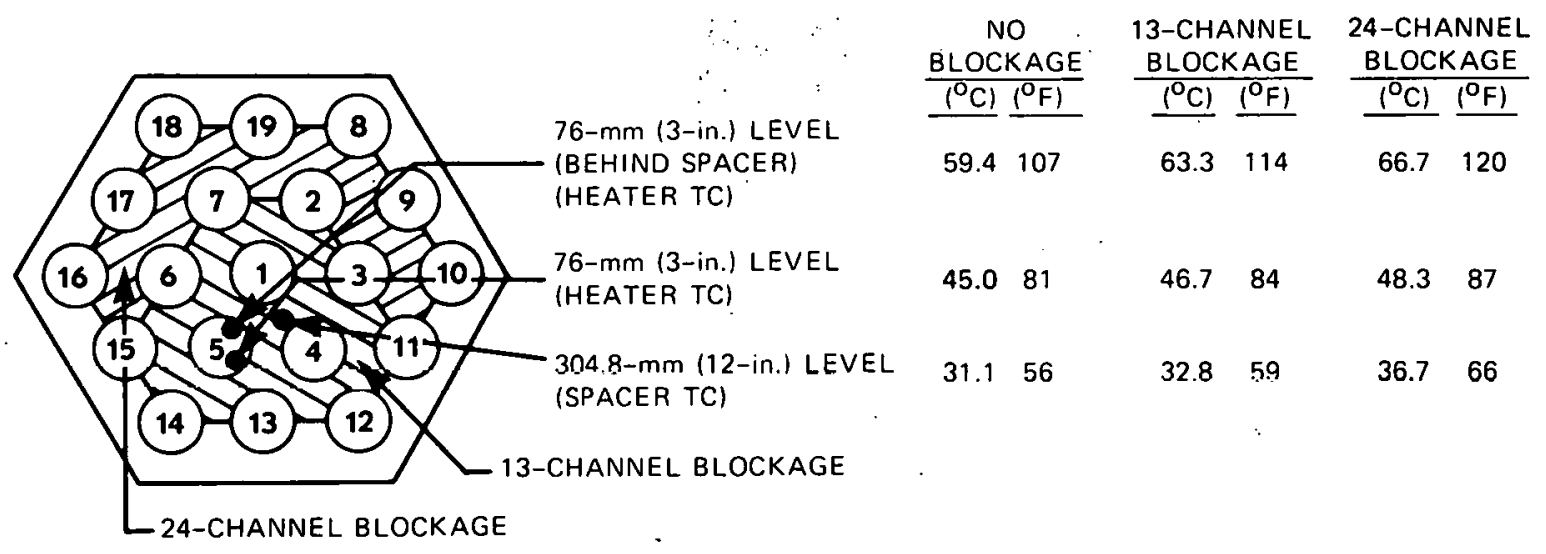

ORNL-DWG $77-13280$

Fig. 13. Maximum temperature differences $\left(T-T_{\text {in }}\right)$ with no blockage and 13- and 24-channel blockages at the inlet of THORS bundle 2B, $76 \mathrm{~mm}$ upstream from start of heated zone. Flow $=3.5 \mathrm{l} / \mathrm{s}(55 \mathrm{gpm})$, power per $\mathrm{pin}=16 \mathrm{~kW} / \mathrm{m}(5 \mathrm{~kW} / \mathrm{ft})$, and $\mathrm{T}_{\text {out }}-\mathrm{T}_{\text {in }}=42^{\circ} \mathrm{C}\left(76^{\circ} \mathrm{F}\right)$ (Fontana et $\left.\mathrm{al} .^{1}\right)$.

Results from the duct-wall thermocouples are not considered in this discussion, since they yielded little information with respect to blockages except that wall temperatures are slightly reduced as flow is diverted to the outer channels by centrally located blockages. It is concluded that centrally located inlet blockages of up to one-half of the flow area of a 19-pin bundle with a 76-mm (3-in.) unheated entrance length do not result in excessively high temperatures. The temperature increases attributed to the inlet blockages are of the same magnitude as the temperature variations normally observed in unblocked bundles.

Since the unheated entrance length between a possible inlet blockage and the start of the heat-generating section of the fuel pins in an FFTF 217-pin assembly is $152 \mathrm{~mm}$ (6 in.) (twice that of these tests), the flow maldistribution caused by the inlet blockage should be significantly reduced in the additional $76 \mathrm{~mm}$, and one would expect correspondingly lower temperature increases in the FFTF assembly. However, there are two other differences between the 19-pin experiment and the FFTF assembly which produce effects that are difficult to extrapolate to the FFTF configuration. In these tests the fractions of the frontal area covered by the inlet blockage plates were quite large, amounting to approximately one-half of the 
flow area (in the 19-pin bundle) for the 24-channel inlet blockage. The fluid velocities around the blockage plate were correspondingly higher than nominal and may have aided in correcting the flow maldistributions caused by the blockages. In addition, the proximity of the duct wall in the 19-pin bundle may have had some influence in diverting the flow inward behind the blockages in comparison to the relative remoteness of the wall in an FFTF assembly. These two effects (which probably interact) would cause these tests to underpredict local temperature rises caused by similarly sized inlet blockages in larger bundles.

However, it is not thought that these effects, extrapolated to a fullsize FFTF bundle, would be sufficient to offset the mitigating effect of Lhe longer unheaced entrance length and the relatively small temperature increases observed. Fontana et al. ${ }^{1,2}$ conclude that inlet blockages of as many as 24 channels will not result in excessively high temperatures in the FFTF 217-pin assembly.

\subsubsection{Central blockage of 6 channels in a 19-pin sodium-cooled bundle}

Test section: THORS bundle $3 \mathrm{~A}$ also simulates the FFTF and the CRBR configurations. Nineteen electrically heated pins are contained inside a round duct which has unheated dummy pins along the duct wall. The central six channels are blocked by a non-heat-generating 6.35-mm-thick (0.25-in.) stainless steel plate (see Fig. 14 for test section). The pins have a heated length of $533 \mathrm{~mm}$ ( $21 \mathrm{in.}$ ), and the blockage plate is located $381 \mathrm{~mm}$ (15 in.) above the start of the heated zone.

In this series of experiments the bundle was inserted from the bottom of the test section with the free ends of the heaters facing upward. This allowed the use of a thermocouple rake, entering from the opposite end of the test section, for monitoring exit temperatures for selected flow channels.

The bundle instrumentation layout is shown in Fig. 15. The convention for identifying thermocouples, heaters, and channels is similar to that of bundle $2 B$, except that the positions of the exit rake thermocouples are indicated by circles containing crosses. 


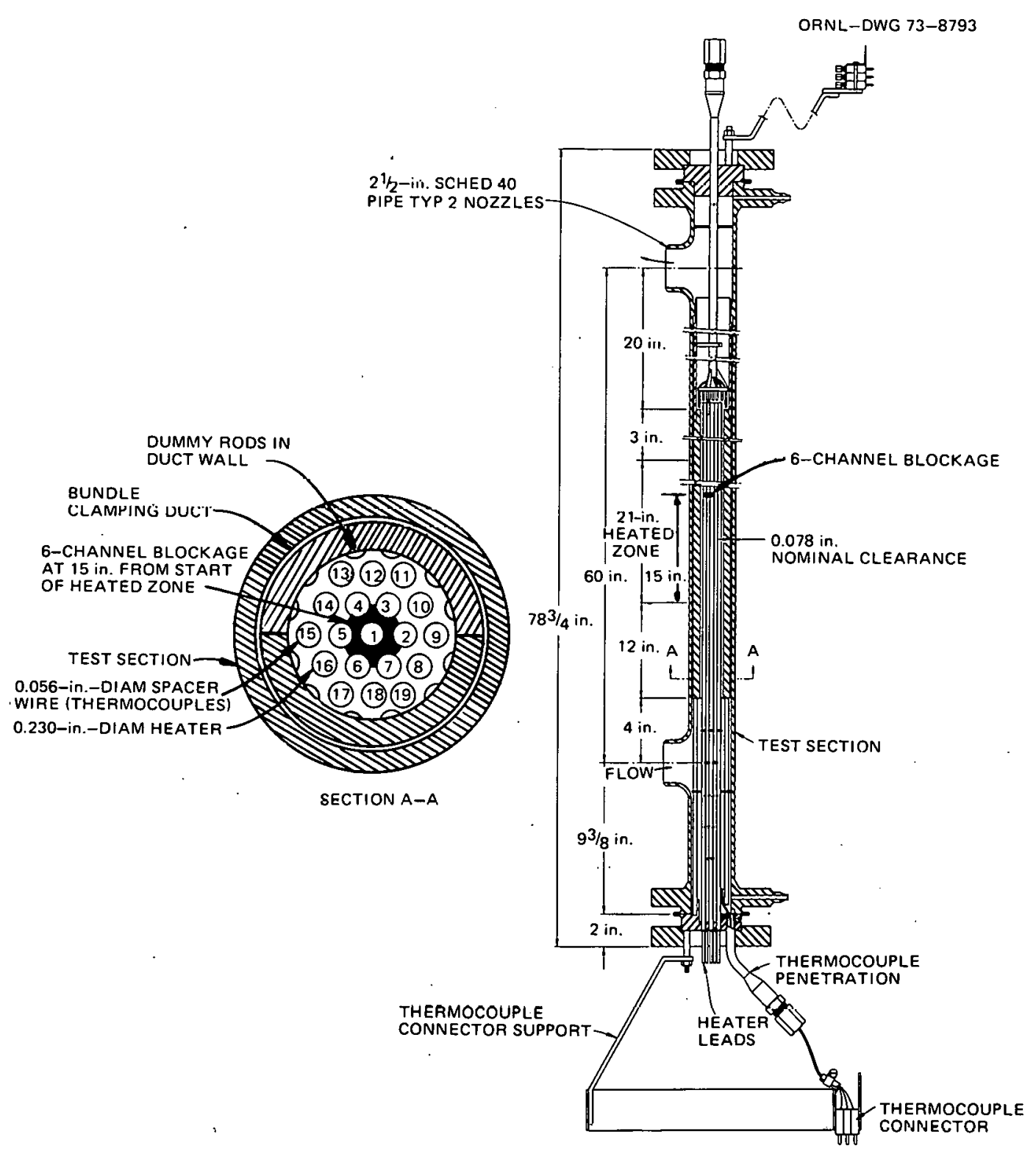

Fig. 14. Test section for THORS bundle 3A (Fontana et al. ${ }^{1}$ ).

In THORS bundle $3 \mathrm{~A}$, the ends of these thermal elements internal to the heaters were grounded to the inner surface of the cladding at $15^{\circ}$ azimuthal intervals and at $6.35-\mathrm{mm}(0.25-\mathrm{in}$ ) axial intervals; thus the junction formed by two thermal elements and the intervening stainless steel cladding measured an average of the temperatures at the two junctions. This measurement can be taken as the approximate average temperature dlong the spiral 


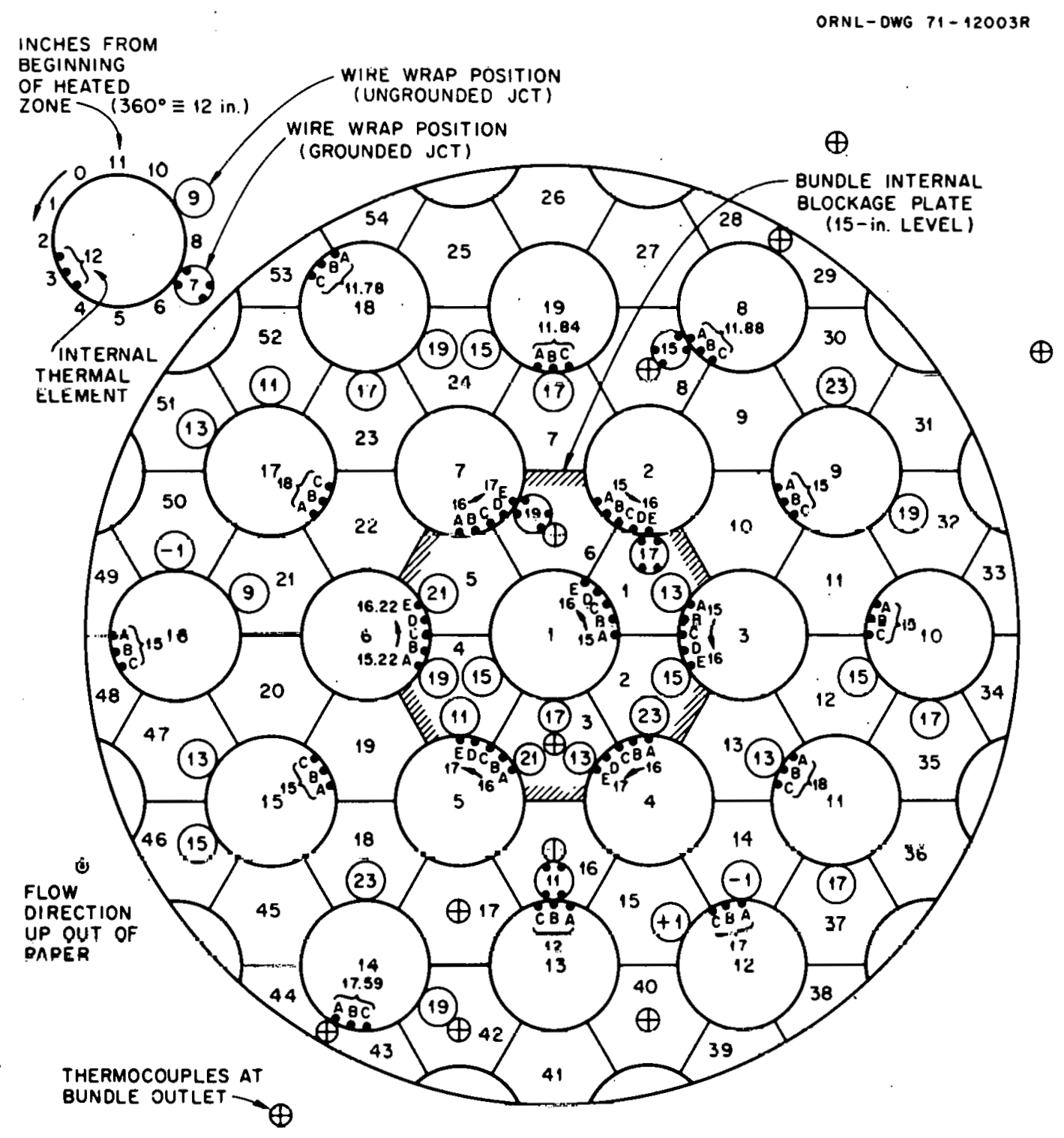

Fig. 15. Thermocouple locations for THORS bundle 3A (Fontana et al. ${ }^{1}$ ).

path on the inner surface of cladding between the two junctions. Notice that the thermal elements in heaters 1,2 , and 3 measure temperatures from 381 to $406 \mathrm{~mm}$ (15 to $16 \mathrm{in.}$ ) from the start of the heated zone in $6.35-\mathrm{mm}$ (0.25-in.) increments; those in heater 6 measure from 387 to $412 \mathrm{~mm}$ (15.22 to $16.22 \mathrm{in.)}$; and those in heaters 4,5 , and 7 measure from 406 to $432 \mathrm{~mm}$ (16 to 17 in.). 
Radial heat loss from the test section was reduced by the use of insulation and guard heaters, which were controlled to give zero temperature gradient in the insulation next to the test section wall as measured by two thermocouples in the insulation between the wall and the external guard heaters.

Results and discussion. Temperature measurements were obtained for all 19 pins heated at powers of $16.4,24.6$, and $32.8 \mathrm{~kW} / \mathrm{m}(5,7.5$, and 10 $\mathrm{kW} / \mathrm{ft}$ ) with sodium flows of $3.41,2.73$, and $2.04 \mathrm{l} / \mathrm{s}(54,43.2$, and 32.4 gpm), which is equivalent to 100,80 , and $60 \%$ of specific FFTF full flow for 19 pins. These experiments cover the base case of full flow at FFTF average power of $24 \mathrm{~kW} / \mathrm{m}(7.3 \mathrm{~kW} / \mathrm{ft})$ and CRBR average power of $22 \mathrm{~kW} / \mathrm{m}(6.6$ $\mathrm{kW} / \mathrm{ft}$ ). Table 2 summarizes these test conditions.

Figure 16 shows the central channel temperatures (above inlet temperature) vs distance from the start of the heated zone for run $101(33 \mathrm{~kW} / \mathrm{m}$, $100 \%$ flow). This run is of particular interest because it represents $100 \%$ of FFTF specific flow ( $3.41 \mathrm{l} / \mathrm{s}$ for 19 pins) and a power of $33 \mathrm{~kW} / \mathrm{m}$, which is significantly above the average FFTF linear power density. In these experiments, temperatures were measured by thermocouples inside the seven

Table 2. Experiments performed with THORS bundle $3 \mathrm{~A}$ with all 19 pins heated

\begin{tabular}{lll}
\hline Kun & \multicolumn{1}{c}{$\begin{array}{c}\text { Flow } \\
{[\ell / \mathrm{s}(\mathrm{gpm})]}\end{array}$} & $\begin{array}{c}\text { Power } \\
{[\mathrm{kW} / \mathrm{m} \cdot(\mathrm{kW} / \mathrm{ft})]}\end{array}$ \\
\hline 101 & $3.41(54)$ & $33(10)$ \\
102 & $3.41(54)$ & $25(7.5)$ \\
103 & $3.41(54)$ & $16(5)$ \\
104 & $2.73(43.2)$ & $33(10)$ \\
105 & $2.73(43.2)$ & $25(7.5)$ \\
106 & $2.73(43.2)$ & $16(5)$ \\
107 & $2.04(32.4)$ & $33(10)$ \\
108 & $2.04(32.4)$ & $25(7.5)$ \\
109 & $2.04(32.4)$ & $16(5)$ \\
\hline
\end{tabular}




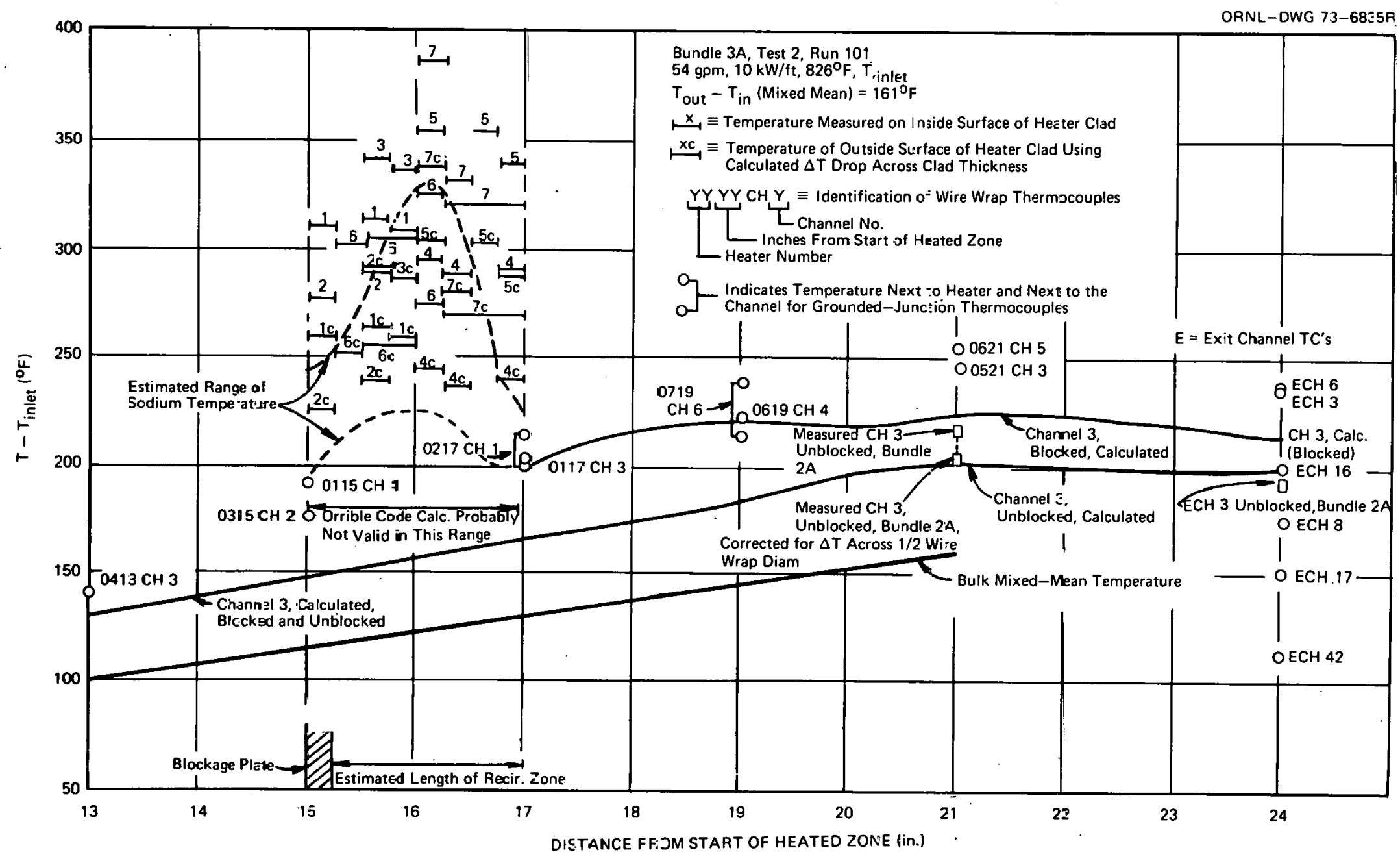

Fig. 16. Temperatures along the central six channels for THORS bundle $3 \mathrm{~A}$ at $3.4 \mathrm{l} / \mathrm{s}(54 \mathrm{gPm})$ and $33 \mathrm{~kW} / \mathrm{m}\left(10 \mathrm{~kW} / \mathrm{ft}\right.$ ) per pin (Fontana et al. ${ }^{1}$ ). 
central heaters and by wire-wrap thermocouples in the six central channels. The temperatures measured by the thermocouples inside the heaters are shown in Fig. 16 as horizontal lines extending the axial distance between the two thermal elements that make up the particular thermocouple being plotted. This distance is usually $6.35 \mathrm{~mm}$ ( $0.25 \mathrm{in.})$, and the indicated temperature can be considered as an average along that length. The number near each line indicates the pin within which that particular thermocouple resides. The outer cladding surface temperature was computed by subtracting the temperature drop across the cladding calculated for the given heat flux and assuming radial heat flow (which should be valid everywhere except directly underneath the blockage pl.ate). These computed outer cladding surface temperatures are indicated in the figures by the letter c.

Temperatures measured by thermocouples in the wire-wrap spacers are plotted and labeled so that the first two digits indicate the heater to which the spacer is attached; the second two digits indicate the axial distance downstream from the start of the heated zone; and the last digit indicates the channel in which the spacer resides at that particular axial elevation. For example, $0413 \mathrm{CH} 3$ refers to heater $4,13 \mathrm{in}$. from the start of the heated zone, channel 3. Grounded-junction thermocouples in the wirewrap spacers indicate two temperatures at the same elevation, one near the heater surface and the other near the center of the flow channel, both of which are plotted.

The abscissa in Fig. 16 begins at $330 \mathrm{~mm}$ (13 in.) from the start of the heated zone because all information of interest is downstream of this point. The blockage plate is at the 381-mm (15-in.) leve1. The estimated length of the recirculation zone is shown as $51 \mathrm{~mm}$ (2 in.), which is about 7 times the radius of the blockage plate, or 12 times the step height of the blockage plate above the surface of the central pin.

Figure 16 also shows bulk mean temperature rises calculated by heat balances. At the plane of the blockage, the highest measured temperature (pin 7 at 16 to 16.25 in.), adjusted to give the external cladding temperature, is approximately $122^{\circ} \mathrm{C}\left(220^{\circ} \mathrm{F}\right)$ higher than the bulk mean temperature at that point. For comparison, there should be more realistic temperature distributions in the same, but unblocked bundle. Since no experimental 
data were available, the ORRIBLE $\operatorname{code}^{3}$ was used to calculate the axial temperature distribution of channel 3 (as if it were unblocked); the result is shown on the second line from the top in Fig. 16. The cladding outer surface temperatures appear to be about $44^{\circ} \mathrm{C}\left(80^{\circ} \mathrm{F}\right)$ to $100^{\circ} \mathrm{C}\left(180^{\circ} \mathrm{F}\right)$ above the average temperature of the unblocked channel at the 381- to 432$\mathrm{mm}$ (15- to 17-in.) level. The hottest temperature measured on the inner surface of the cladding was about $211^{\circ} \mathrm{C}\left(380^{\circ} \mathrm{F}\right)$. above the $441^{\circ} \mathrm{C}\left(826^{\circ} \mathrm{F}\right)$ inlet temperature and about $150^{\circ} \mathrm{C}\left(270^{\circ} \mathrm{F}\right)$ higher than the predicted bulk mean sodium temperature at the elevation of the thermocouple $[406 \mathrm{~mm}$ (16 in.)] for the unblocked case.

Figure 16 also shows the temperatures measured by the ungrounded thermocouples in the wire-wrap spacers in the central six channels: $0413 \mathrm{CH} 3$, $0115 \mathrm{CH} 4,0315 \mathrm{CH} 2,0619 \mathrm{CH} 4,0621 \mathrm{CH} 5$, and 0521CH3. Also plotted are the grounded-junction thermocouple readings, which show the radial temperature difference across the wire-wrap spacers: $0217 \mathrm{CH} 1$ and $0719 \mathrm{CH} 6$. These indicate that the temperature differentials across the wire wraps are about $8.3^{\circ} \mathrm{C}\left(15^{\circ} \mathrm{F}\right)$ at $0217 \mathrm{CH} 1$ to $14^{\circ} \mathrm{C}\left(25^{\circ} \mathrm{F}\right)$ at $0719 \mathrm{CH} 6$. Since the ungroundedjunction thermocouples are in approximately the center of the wire-wrap spacers, a rough estimate can be made of the sodium channel temperatures by subtracting one-half the $\Delta T$ obtained from the grounded-junction thermocouples ( 7 to $12^{\circ} \mathrm{F}$ ) from the readings obtained with the ungrounded-junction thermocouples. Adjusted readings (plotted in Fig. 16) are compared with ORRIBLE predictions for temperatures in channel 3 in the blocked configuration, which serves as an indicator of the behavior of all six central channels. The prediction of temperatures downstream from the blockage is satisfactory for the purpose intended.

Since ORRIBLE $^{3}$ has no provisions for calculating recirculating flow (the wake), predictions obtained with it should not be valid in the recirculating zone. If it is assumed that a 5.5 to $11^{\circ} \mathrm{C}\left(10\right.$ to $\left.20^{\circ} \mathrm{F}\right)$ "film. drop $\Delta T^{\prime \prime}$ exists between the cladding outer surface and the average channel sodium temperature, the temperatures of the sodium in the recirculating zone could be estimated as being in the range enclosed by the two dashed lines in Fig. 16, which indicates that a blockage of the size tested is tolerable at full flow and power. 
Figure 17 shows the central channel temperatures for run $104[33 \mathrm{~kW} / \mathrm{m}$ $(10 \mathrm{~kW} / \mathrm{ft}), 80 \% \mathrm{flow}$. The descriptive comments concerning Fig. 16 also apply here except that the temperatures measured were higher because of the lower flow. The blockage tested can be tolerated at this flow.

Figure 18 shows the central channel temperatures for run $107[33 \mathrm{~kW} / \mathrm{m}$ $(10 \mathrm{~kW} / \mathrm{ft}), 60 \% \mathrm{flow}$, which is of particular interest because it represents the most severe condition imposed on the test bundle so far. The cladding outer surface temperatures in the vicinity of the blockage ranged 44 to $122^{\circ} \mathrm{C}$ ( 80 to $220^{\circ} \mathrm{F}$ ) higher than expected for the sodium temperature in the central channels (represented by channel 3) of the unblocked bundle. The hottest cladding internal surface temperature was $719^{\circ} \mathrm{C}\left(1327^{\circ} \mathrm{F}\right)$, which is about $300^{\circ} \mathrm{C}\left(540^{\circ} \mathrm{F}\right)$ higher than the inlet temperature of $418^{\circ} \mathrm{C}\left(785^{\circ} \mathrm{F}\right)$. These results indicate that a non-heat-generating blockage of the size tested is still acceptable even at $60 \%$ nominal flow.

Figure 19 shows the results for run $102[25 \mathrm{~kW} / \mathrm{m}(7.5 \mathrm{~kW} / \mathrm{ft}), 100 \%$ flow], which represents the full flow and average power conditions for the FFTF. Note that cladding temperatures are only $156^{\circ} \mathrm{C}\left(280^{\circ} \mathrm{F}\right)$ higher than the inlet temperature and $83^{\circ} \mathrm{C}\left(150^{\circ} \mathrm{F}\right)$ higher than the anticipated sodium temperature in channel 3 if it were unblocked.

The temperatures at the exits of selected channels (see Fig. 15) were measured using the exit rake thermocouples. [Note that the mixing occurred in the 76-mm (3-in.) unheated length between the end of the heated zone and the channel exit.] These measurements indicate the magnitude of the influence of an in-core blockage on the exit temperature profile and should help indicate the feasibility of detecting the blockage by thermal devices 1ocated in the exit region.

Figure 20 shows the exit temperature distribution expressed as $\mathrm{T}-\mathrm{T}$ in for the experimental case of $33 \mathrm{~kW} / \mathrm{m}(10 \mathrm{~kW} / \mathrm{ft})$ and $100 \%$ flow $(54 \mathrm{gpm})$ and for the pertinent calculated blocked and unblocked cases. The experimental results for bundle $3 \mathrm{~A}$. (Fig. 20). show a temperature increase of approximately $17^{\circ} \mathrm{C}\left(30^{\circ} \mathrm{F}\right)$ in the blocked region sver the temperature (calculated) in the unblocked bundle. The ORRIBLE predictions for the blocked bundle show better agreement at channel 6 (approximately $6^{\circ} \mathrm{F}$ ) than at channel 3 (approximately $16^{\circ} \mathrm{F}$ ) and poorer agreement in the exterior channels. The poorer 
ORNL-DWG 77-13281

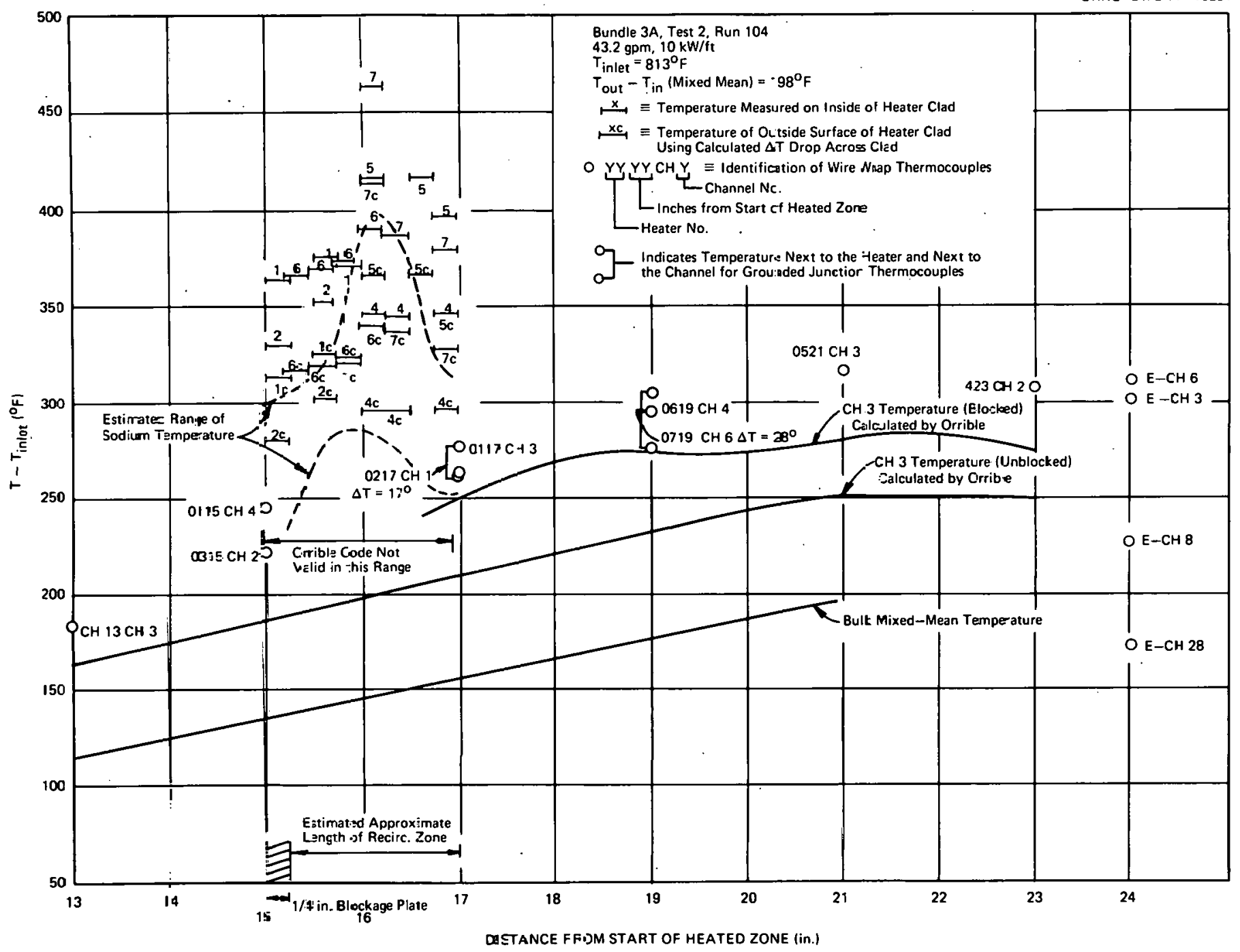

Fig. 17. Temperatures along the central six channels for THORS bundle $3 \mathrm{~A}$ at $2.7 \mathrm{l} / \mathrm{s}(43 \mathrm{gpm})$ ard $3 \cong \mathrm{kW} / \mathrm{m}(10 \mathrm{~kW} / \mathrm{f}=)$ per pin (Fontana et al. ${ }^{1}$ ). 
ORNL-DWG 73-6837

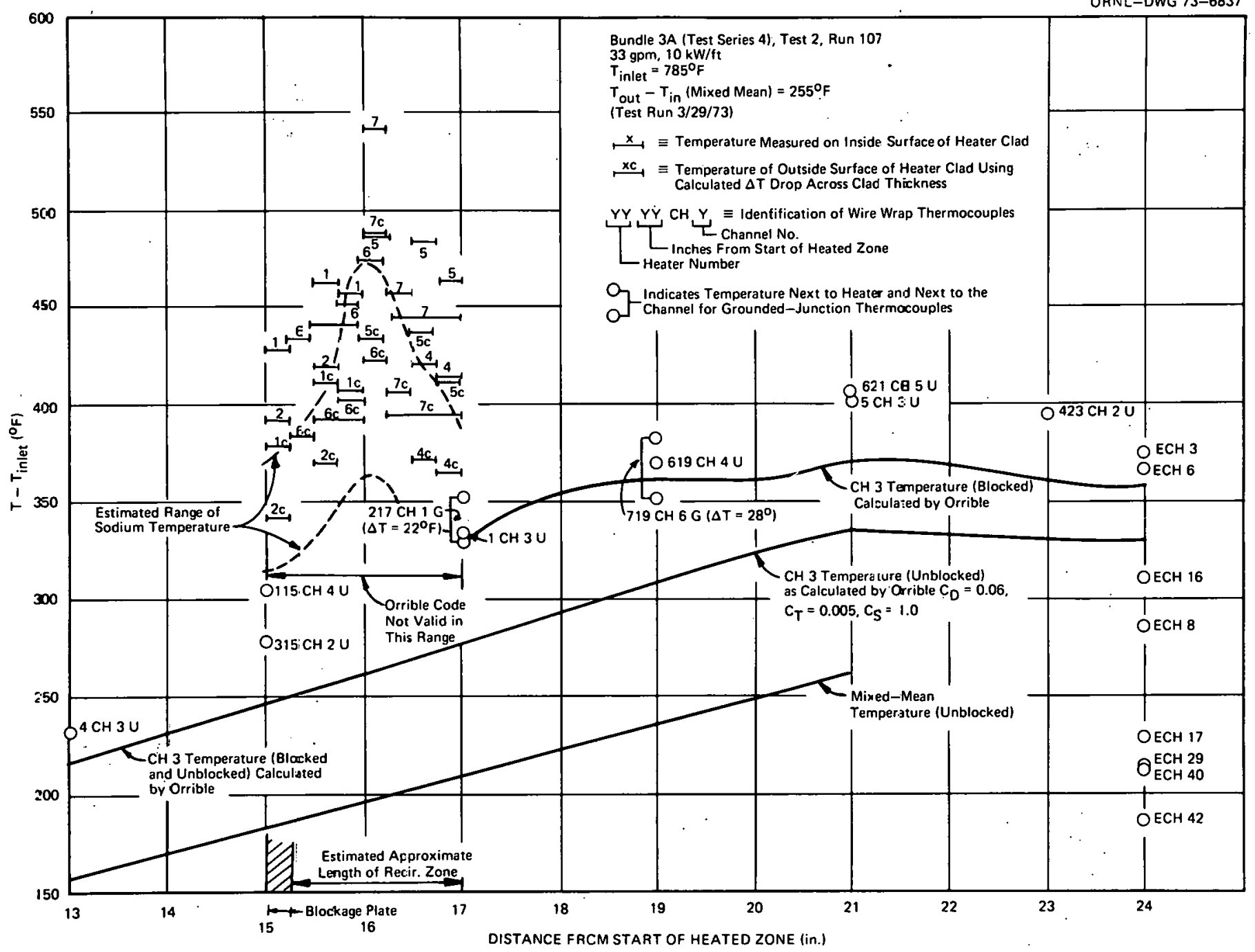

Fig. 18. Temperatures along the central six channels for THORS bundle $3 \mathrm{~A}$ at $2.1 \mathrm{~L} / \mathrm{s}(33 \mathrm{gpm})$ and $33 \mathrm{~kW} / \mathrm{m}\left(10 \mathrm{~kW} / \mathrm{ft}\right.$ ) per pin (Fontana et al. ${ }^{1}$ ). 
ORNL-DWG 77-13282

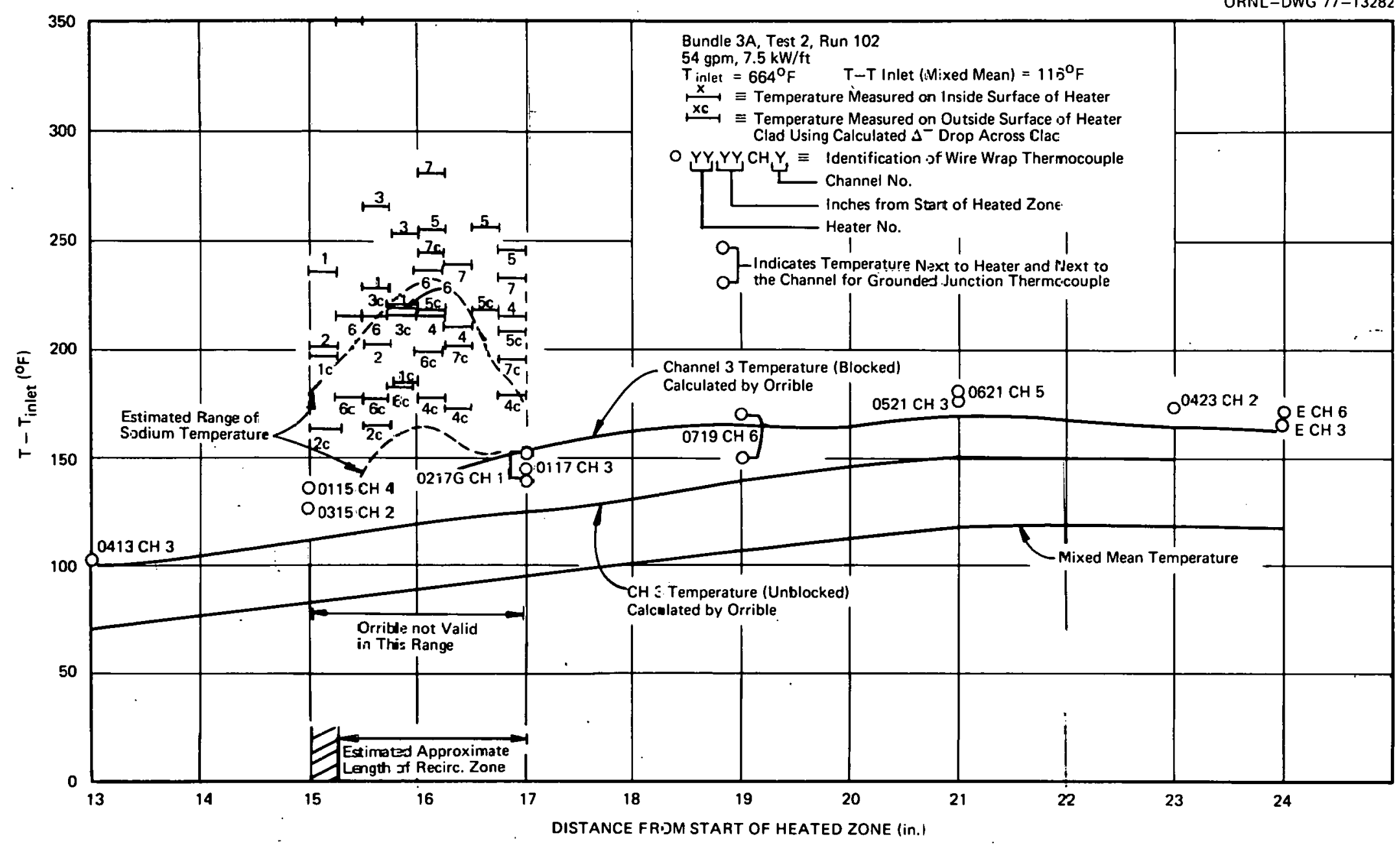

Fig. 19. Temperatures along the central six channels for THORS bundle $3 \mathrm{~A}$ at $3.4 \mathrm{l} / \mathrm{s}(54 \mathrm{gpm})$ and $25 \mathrm{~kW} / \mathrm{m}(7.5 \mathrm{~kW} / \mathrm{ft})$ per pin (Fontana et al. ${ }^{13}$. 


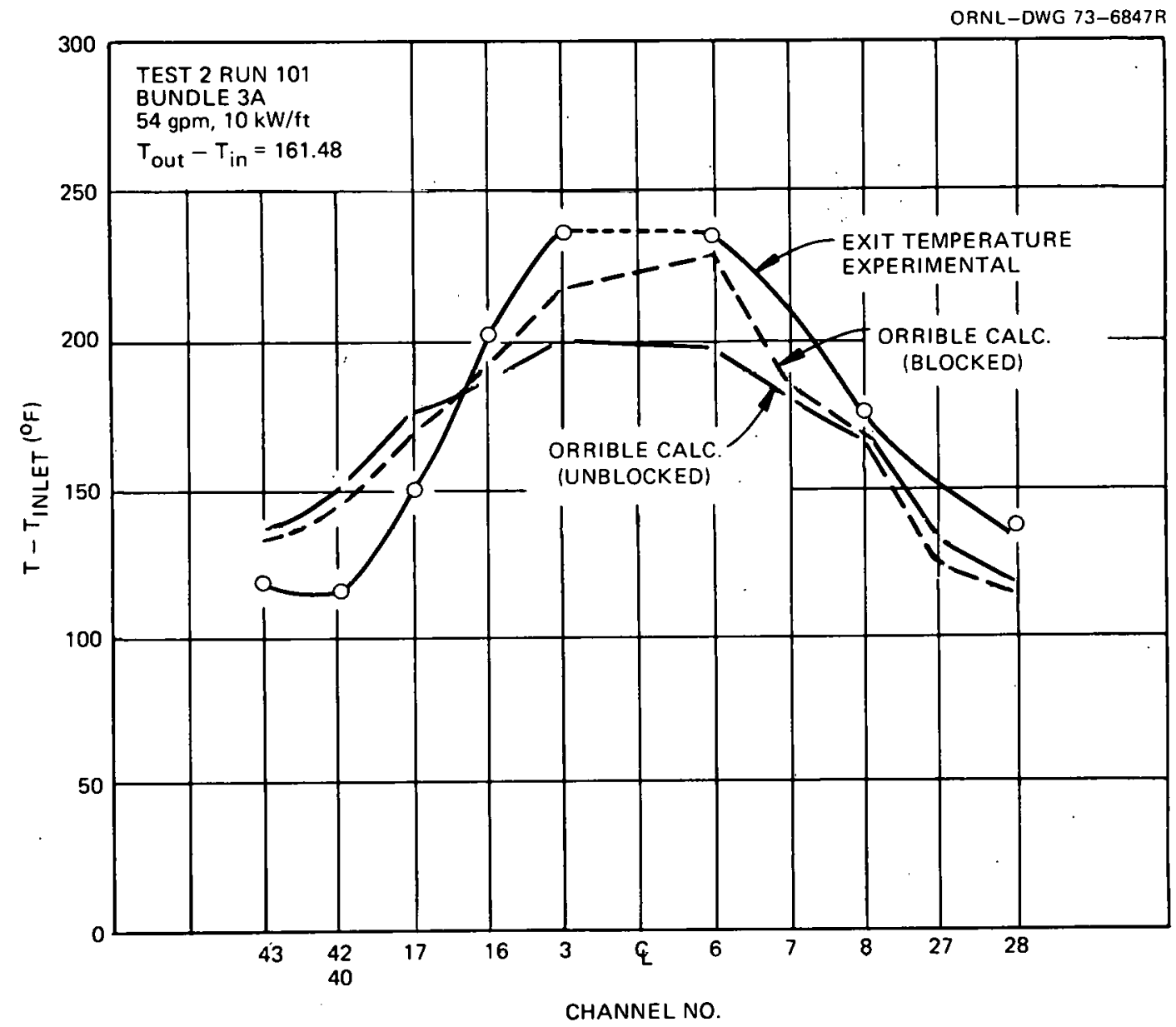

Fig. 20. Measured and calculated exit temperatures for THORS bundle $3 \mathrm{~A}$ at $3.4 \mathrm{l} / \mathrm{s}(54 \mathrm{gpm})$ and $33 \mathrm{~kW} / \mathrm{m}(10 \mathrm{~kW} / \mathrm{ft})$ per pin (Fontana et al. ${ }^{1}$ ).

agreement in the exterior channels may be due to steeper temperature gradients in that region, since ORRIBLE code calculates average channel temperatures, whereas the thermocouples might be in a channel temperature gradient.

Figure 21 shows measured and calculated results for the most severe case of $33 \mathrm{~kW} / \mathrm{m}(10 \mathrm{~kW} / \mathrm{ft}), 60 \%$ flow $(33 \mathrm{gpm})$. Both sets of measurements imply 17 to $22^{\circ} \mathrm{C}\left(30\right.$ to $40^{\circ} \mathrm{F}$ ) differences between blocked and unblocked cases.

The FFTF fuel has fission gas plena that are $1070 \mathrm{~mm}$ (42 in.) long. If THORS bundle $3 \mathrm{~A}$ had an exit unheated length of $1070 \mathrm{~mm}$, the temperature distribution as calculated by ORRIBLE would be as shown in Fig. 22 . 


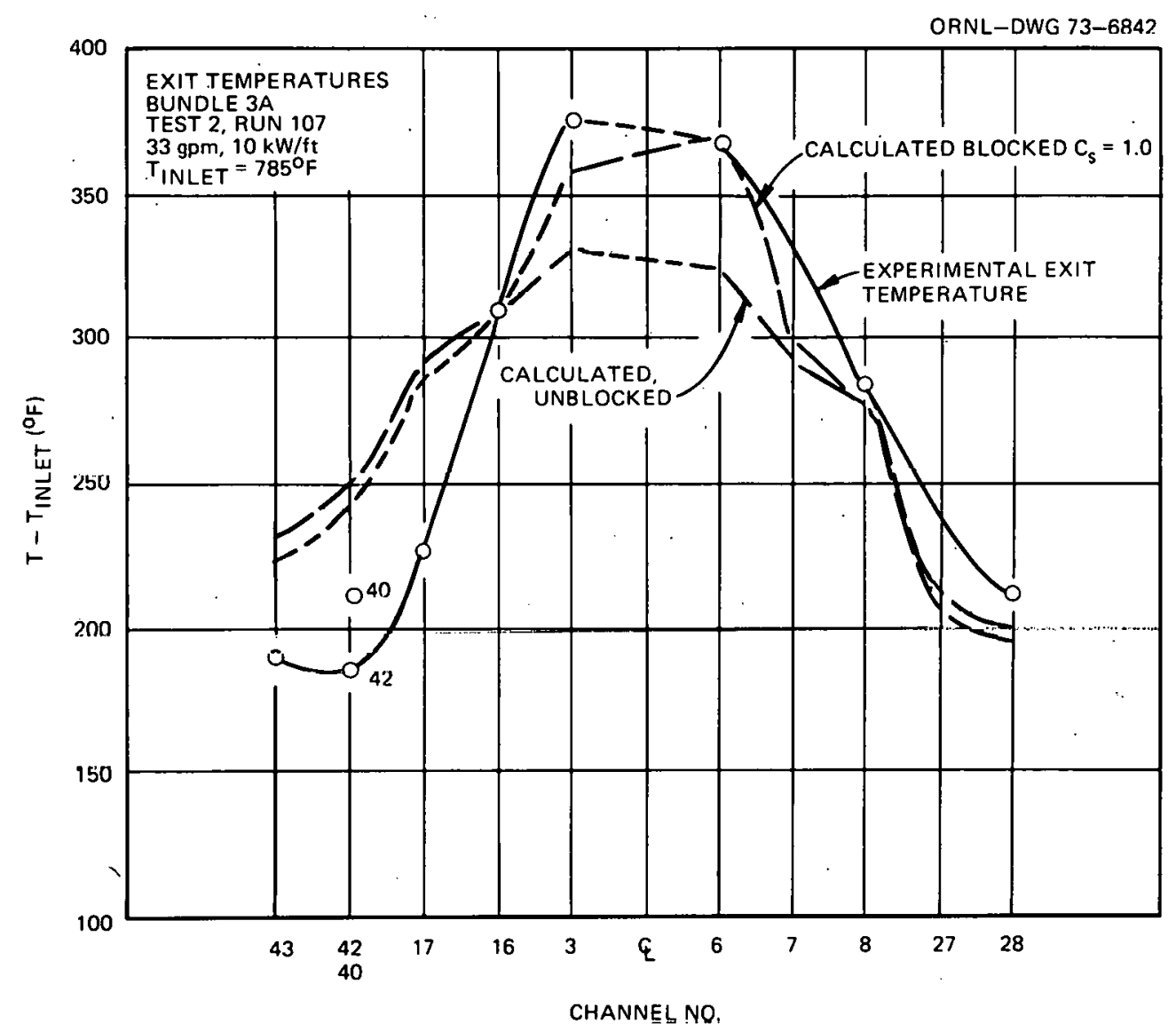

Fig. 21. Measured and calculated exit temperatures for THORS bundle $3 \mathrm{~A}$ at $2.1 \mathrm{l} / \mathrm{s}(33 \mathrm{gpm})$ and $33 \mathrm{~kW} / \mathrm{m}(10 \mathrm{~kW} / \mathrm{ft})$ per. pin (Fontana et a1. ${ }^{1}$ ).

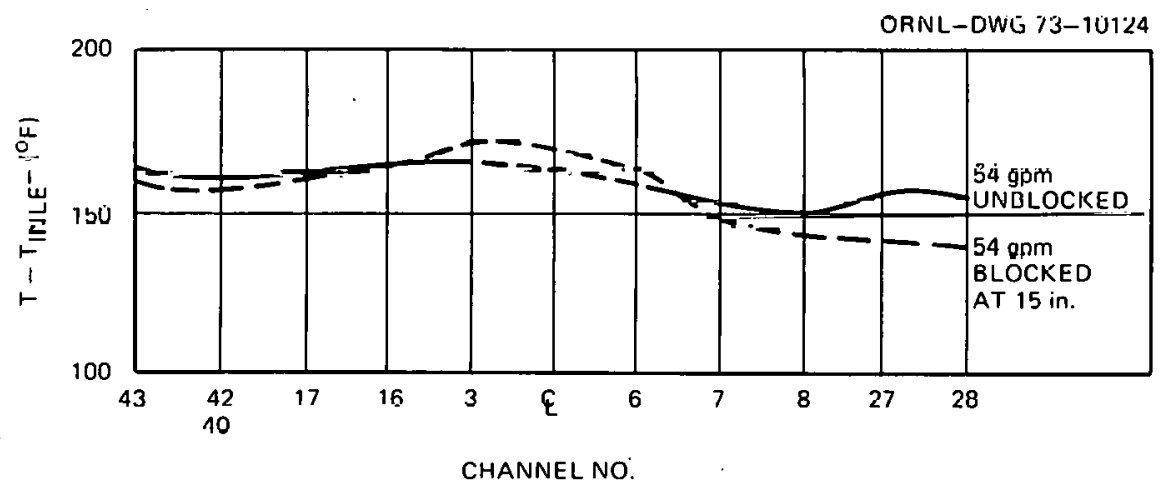

Fig. 22. Calculated exit temperature distribution for THORS bundle 3A type with 1070-mm (42-in.) exit plenum (Fontana et al. .). 


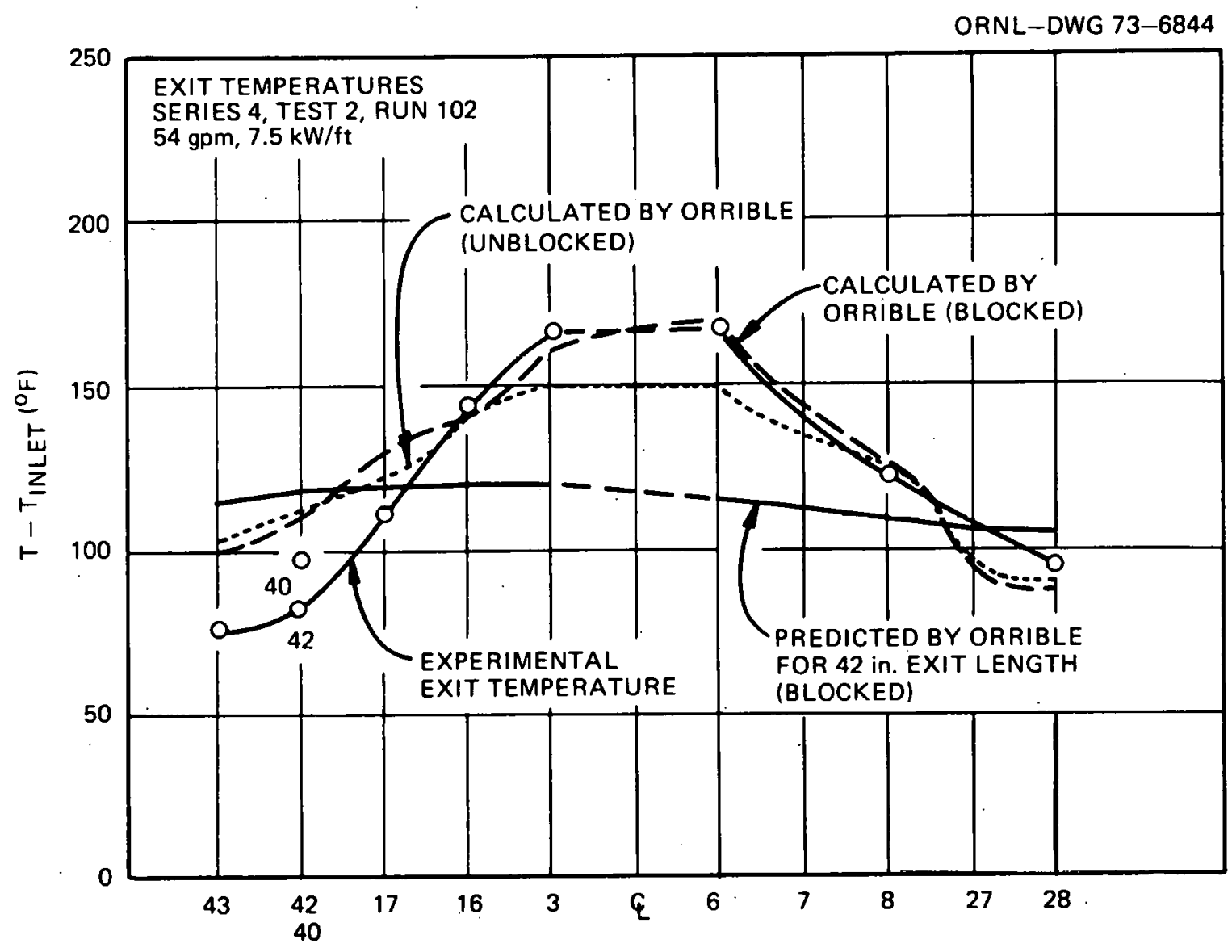

CHANNEL NO.

Fig. 23. Exit temperature distribution for THORS bundle $3 \mathrm{~A}$ type with 76-mm (3-in.) and 1070-mm (42-in.) exit plena (Fontana et al. ${ }^{1}$ ).

Figure 23.shows the exit temperature distribution for the 76- and 1070-mm (3- and 42-in.) unheated zones for the average operating case of $25 \mathrm{~kW} / \mathrm{m}(7.5 \mathrm{~kW} / \mathrm{ft})$ and $100 \%$ flow.

It was concluded ${ }^{1}$ that excessive temperatures are not generated in the heater pins as a consequence of a 6.35-mm-1ong (0.25-in.) non-heatgenerating blockage over an area of six channels in the 19-pin THORS bundle $3 \mathrm{~A}$ even at $33 \mathrm{~kW} / \mathrm{m}$ and $60 \%$ flow. Since the blockage covers a flow area of only about $12 \%$ of the total area, one would expect the wall effects on the flow in the vicinity of the blockage to be small. A similar nonheat-generating blockage would be expected to behave essentially the same way in a ful1-size 217-pin FFTF and CRBR fuel assembly and therefore would not cause excessive temperatures to be generated. 


\subsubsection{Edge blockages of 14 channels in 19-pin sodium-cooled bundles}

Test section. THORS bundle 5 has the same fuel configuration as bundle $2 \mathrm{~B}$, except that $0.711-\mathrm{mm}-\mathrm{diam}(0.028-i n$.$) wire-wrap spacers are used to sep-$ arate the peripheral pins from the duct wall. The half-size spacers are used to reduce the flow in the peripheral flow channels and to cause a flatter radial temperature profile across the bundle. The pins have a heated length of $457 \mathrm{~mm}$ (18 in.). A 3.175-mm-thick (0.125-in.) stainless steel blockage plate is located $102 \mathrm{~mm}$ ( $4 \mathrm{in}$.) above the start of the heated zone to block 14 edge and internal channels along the duct wall. The test section layout is shown in Fig. 24.

THORS bundle 5 was designed fur luur flow conflgurations. Bundle 5A had the edge blockage plate held flush against the duct wall. Due to early failure of thermal elements inside the heaters and failure of an important heater pin (pin 16 as shown in Fig. 25), the test program was curtailed and the bundle was rebuilt. In the rebuilt bundle (5B), there was a slight leak between the duct wall and the blockage. In bundle 5B-d, the blockage plate was intentionally displaced $0.356 \mathrm{~mm}$ (0.014 in.) away from flat A of the duct wall. The blockage plate was then completely removed from the test section and the bundle designated as bundle $5 \mathrm{C}$.

Four types of lemperdlure Instrumentation were used in the bundle: (1) thermocouples in the helical wire wraps, (2) thermocouples in the flats of the hexagonal duct to measure duct-wall temperatures, (3) thermal elements within the heater sheaths (bundles $5 \mathrm{~B}$ and $5 \mathrm{C}$ only), and (4) an exit thermocouple rake to measure the temperature of the sodium leaving selected flow shannolo.

In the instrumentation layout shown in Fig. 25, the large circles represent the heaters that simulate the fuel pins; these are identified by the central number. The small tangent circles indicate thermocouple junctions at the indicated azimuthal position of the wire-wrap spacers. The junctions are located at axial levels indicated by the numbers in the small circles, which have units of inches from the start of the heated zone. The 1.42-mm-diam (0.056-in.) wire wraps on the seven central pins contained 


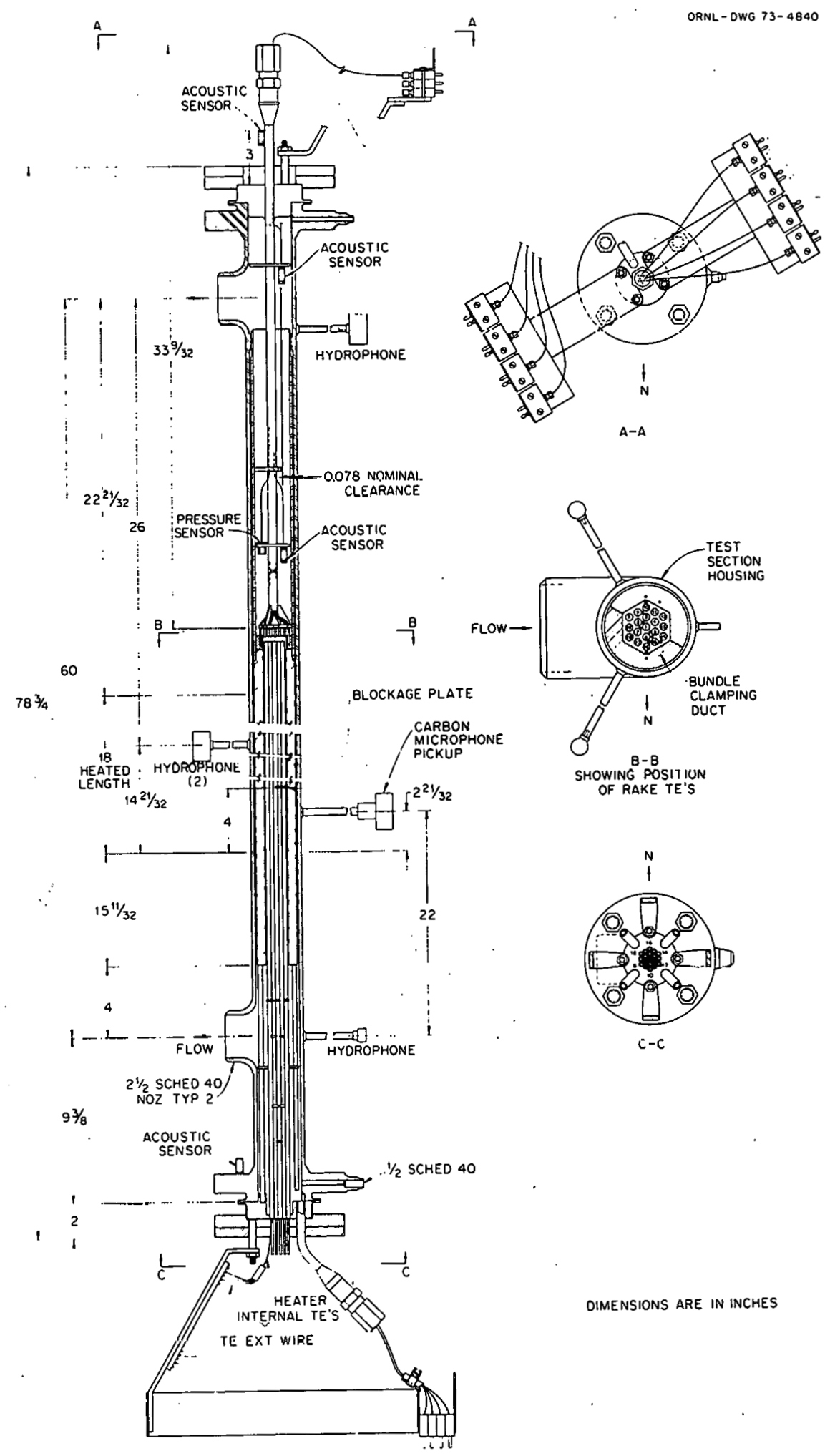

Fig. 24. Test section for THORS bundles 5A, 5B, 5B-d, and 5C (Fontana et $a 1 .^{2}$ ). 


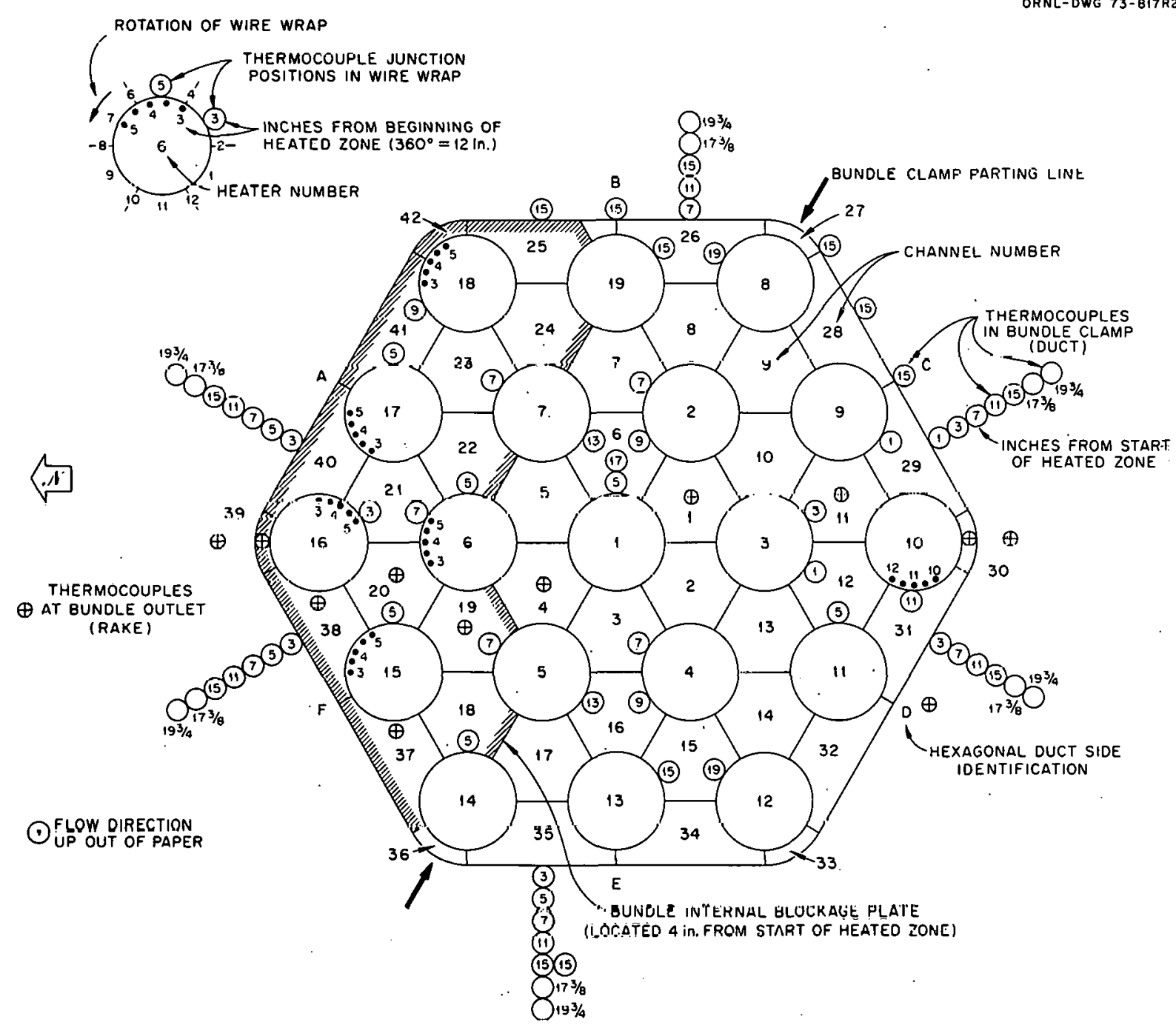

ORNL-DWG 73-817R2

Fig. 25. Cross section of THORS bundles 5A, 5B, 5B-d, and 5C showing the outline of the blockage plate in the bundles except $5 \mathrm{C}$ and all test section temperature instrumentation. (The heater-internal thermocouples in pins 6,10 , and 15-18 were not operable in bundle 5A) (Fontana et $a 1 .{ }^{2}$ ).

four thermal-element wires that were formed into ungrounded temperaturemeasuring junctions at two axial locations. The wire wraps on the 12 peripheral pins were $0.711 \mathrm{~mm}(0.028 \mathrm{in.})$ in diameter, and each contained a single grounded thermocouple junction. Where 1.42-mm (0.056-in.) spacing was required (between adjacent pins), the wire wraps were sleeved with sections of stainless steel tubing $[1.40 \mathrm{~mm}(0.055 \mathrm{in.})$ in outside diameter 
and $0.229 \mathrm{~mm}(0.009 \mathrm{in.})$ in wall thickness]. These sleeves were mechanically attached to the $0.711-\mathrm{mm}(0.028-i n$.$) wire wraps by reducing the in-$ side diameter at the section ends by a rolling process. The locations of the duct wall thermocouples are similarly indicated in Fig. 25. The flow channels, defined by the lines connecting the centers of the heaters, are identified by the numbers in the triangles. The small circles with interior crosses indicate channels that are monitored by exit thermocouples. Bundles 5B, 5B-d, and $5 \mathrm{C}$ had thermocouples inside pins $6,10,15,16,17$, and 18. The axial locations of Chromel-Alumel junctions are given by the small numbers at the wire locations (in inches downstream from the start of the heated section).

The bundle was installed from the bottom of the test section housing. Sodium entered the test section at the bottom, flowed upward, and exited at the top of the test section housing as shown in Fig. 24.

Results and discussion. Results for bundles $5 \mathrm{~A}, 5 \mathrm{~B}, 5 \mathrm{~B}-\mathrm{d}$, and $5 \mathrm{C}$ were obtained for base tests at a flow of $2.6 \mathrm{l} / \mathrm{s}$ (4I gpm); a sodium inlet temperature of $316^{\circ} \mathrm{C}\left(600^{\circ} \mathrm{F}\right)$; and a power rate of $16 \mathrm{~kW} / \mathrm{m}(5 \mathrm{~kW} / \mathrm{ft})$ per pin for all 19 pins. The corresponding bulk sodium temperature rise, $\mathrm{T}_{\text {out }}$ $\mathrm{T}_{\text {in }}$, for these conditions was $47^{\circ} \mathrm{C}\left(85^{\circ} \mathrm{F}\right)$.

Figure 26 compares the results from all wire-wrap thermocouples. The numbers by the points indicate the numbers of the channels (see Fig. 25) in which the thermocouples are located. The blockage plate is in channels 18 to 25 and 37 to 42 . The largest temperature measured was at channel 41 at $25 \mathrm{~mm}$ ( 1 in.) downstream from the blockage plate; the dimensionless temperature had a value of 1.39 at this point. Since the dimensionless temperature in unblocked bundle $5 \mathrm{C}$ was 0.42 , the excess due to the blockage was $1.42-0.45=0.97$; that is, about the same magnitude as the bulk tempcrature rise in the bundle. However, these experiments were performed with a bundle having a 457-mm (18-in.) heated length, which, for a given power and flow, would have an inlet-to-outlet temperature increase of about one-half that of a reactor having a $914-\mathrm{mm}$ (36-in.) heated zone. Since the local temperature increase due to the blockage is a function of local power and flow conditions, it would have the same magnitude in the experiment as it would for a blockage in the reactor. Since $T_{\text {out }}-T_{\text {in }}$ in 


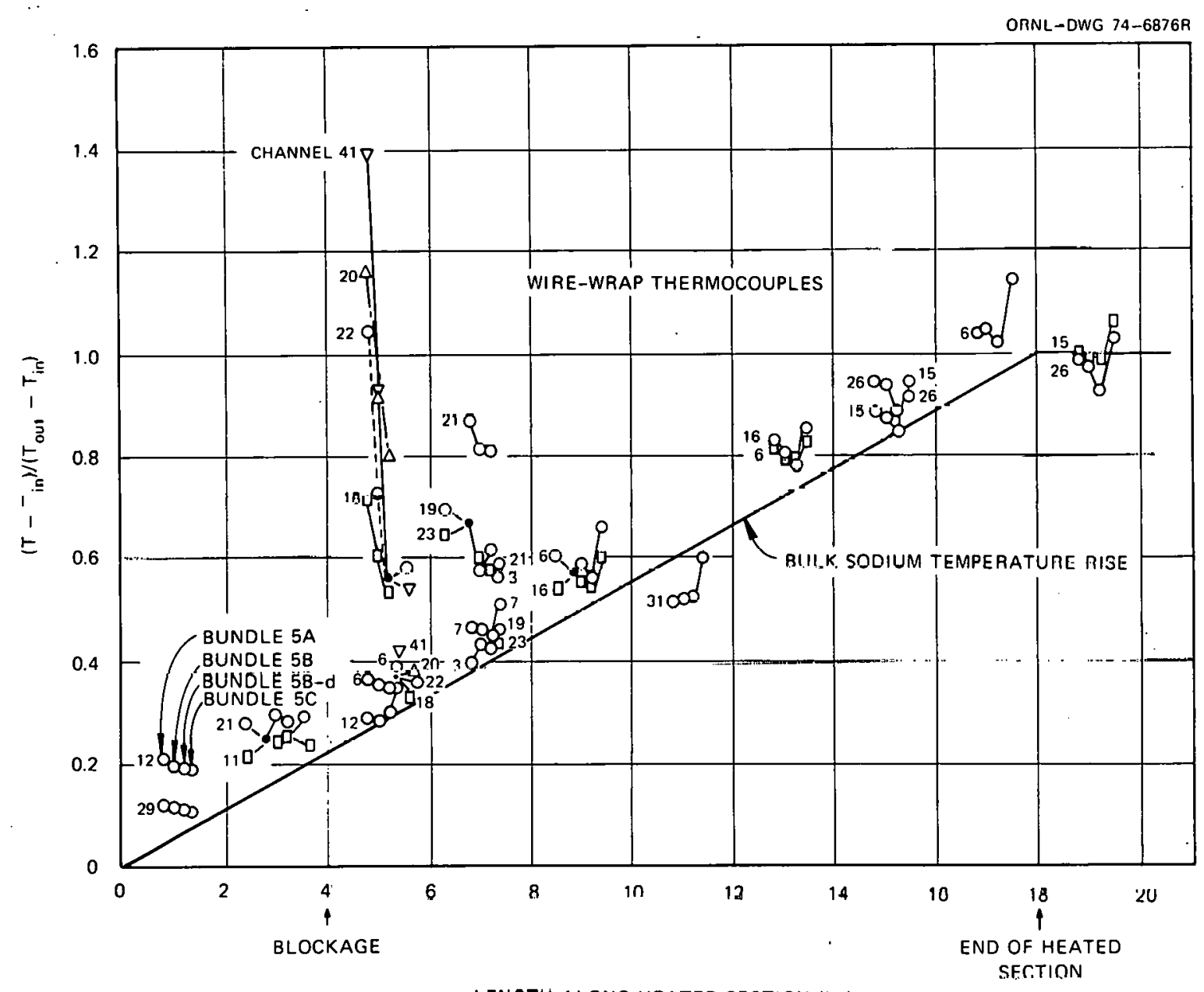

I. F.NFTH ALQNG HEATED EECTION (in.)

Fig. 26. Normalized temperature rises, $\left(T-T_{i n}\right) /\left(T_{\text {out }}-T_{\text {in }}\right)$, from the wire-wrap thermocouples in THORS bundles $5 \mathrm{~A}, 5 \mathrm{~B}, 5 \mathrm{~B}-\mathrm{d}$ (with blockage plate displaced by 0.014 in.) and $5 \mathrm{C}$ (with the blockage plate completely removed). Flow $=2.6 \mathrm{l} / \mathrm{s}(41 \mathrm{gpm})$; uniform power per pin $=16 \mathrm{~kW} / \mathrm{m}$ ( 5 $\mathrm{kW} / \mathrm{ft}) ; \mathrm{T}_{\text {in }}=316^{\circ} \mathrm{C}\left(600^{\circ} \mathrm{F}\right) ;$ and $\mathrm{T}_{\text {out }}-\mathrm{T}_{\text {in }}=47^{\circ} \mathrm{C}\left(85^{\circ} \mathrm{F}\right)$ (Fontana et a $\left.1 .^{2}\right)$.

the reactor is twice that of these experiments, the local temperature excesses norililized by the $\mathrm{T}_{\text {out }}-\mathrm{I}_{\text {in }}$ of the reactor would have nne-half the value shown in the figures presented here. Therefore, the local temperature excess due to the blockage, if it occurred in a reactor having a $\mathrm{T}_{\text {out }}-\mathrm{T}_{\text {in }}$ of $167^{\circ} \mathrm{C}\left(300^{\circ} \mathrm{F}\right)$, would be $0.95 / 2 \times(167)=79^{\circ} \mathrm{C}\left(143^{\circ} \mathrm{F}\right)$. This increase is not of major significance with respect to reactor safety.

The effects of the duct-wall thermocouples on the hexagonal flats (A and F) adjacent to the blockage plate, compared in Fig. 27, are similar 


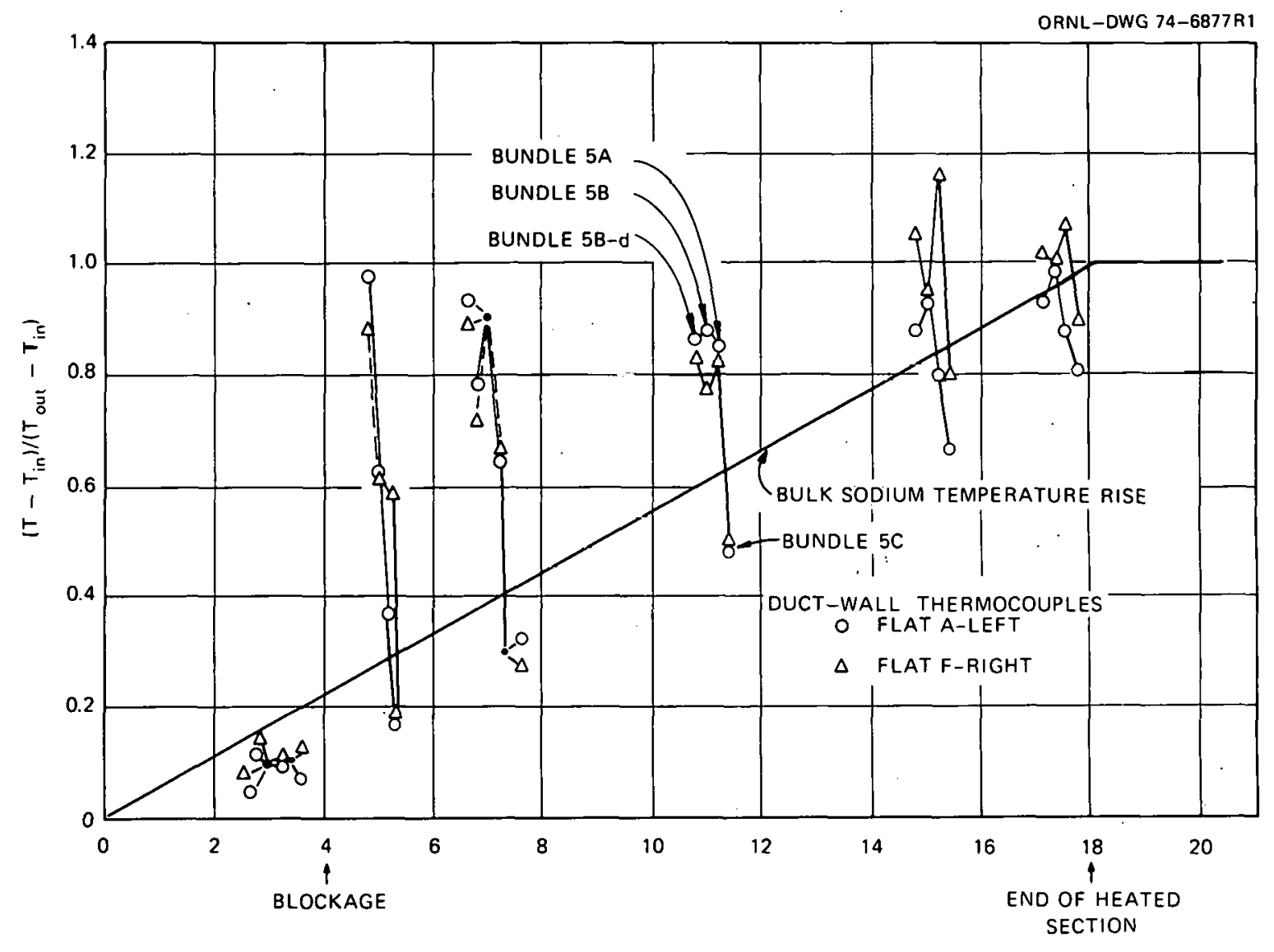

LENGTH ALONG HEATED SECTION (in.)

Fig. 27. Normalized temperature rises, $\left(T-T_{\text {in }}\right) /\left(T_{\text {out }}-T_{\text {in }}\right)$, from the duct-wall thermocouples on hexagonal flats $A$ and $F$, which are adjacent to the blockage plate. Flow $=2.6 \mathrm{l} / \mathrm{s}(41 \mathrm{gpm})$; uniform power per pin = $16 \mathrm{~kW} / \mathrm{m}(5 \mathrm{~kW} / \mathrm{ft}) ; \mathrm{T}_{\text {in }}=316^{\circ} \mathrm{C}\left(600^{\circ} \mathrm{F}\right)$; and $\mathrm{T}_{\text {out }}-\mathrm{T}_{\text {in }}=47^{\circ} \mathrm{C}\left(85^{\circ} \mathrm{F}\right)$ (Fontana et $\left.a 1 .^{2}\right)$.

to those of the wire-wrap thermocouples. For bundles 5A, 5B, and 5B-d, these temperature rises are consistently higher than the local bulk sodium temperature downstream of the blockage plate, and, with the exception of the region immediately downstream of the plate, there appears to be little variation between the three sets of data. The results from bundle 5C show that the duct-wall temperatures are consistently lower than the bulk sodium temperature in an unblocked bundle.

The results of the duct-wall thermocouples one flat away from the blockage plate ( $B$ and $E$ ) are compared in Fig. 28. The relatively large temperature rise on flat $E$ (bundles $5 \mathrm{~A}, 5 \mathrm{~B}$, and $5 \mathrm{~B}-\mathrm{d}$ ) at the $127 \mathrm{~mm}$ (5-in.) 


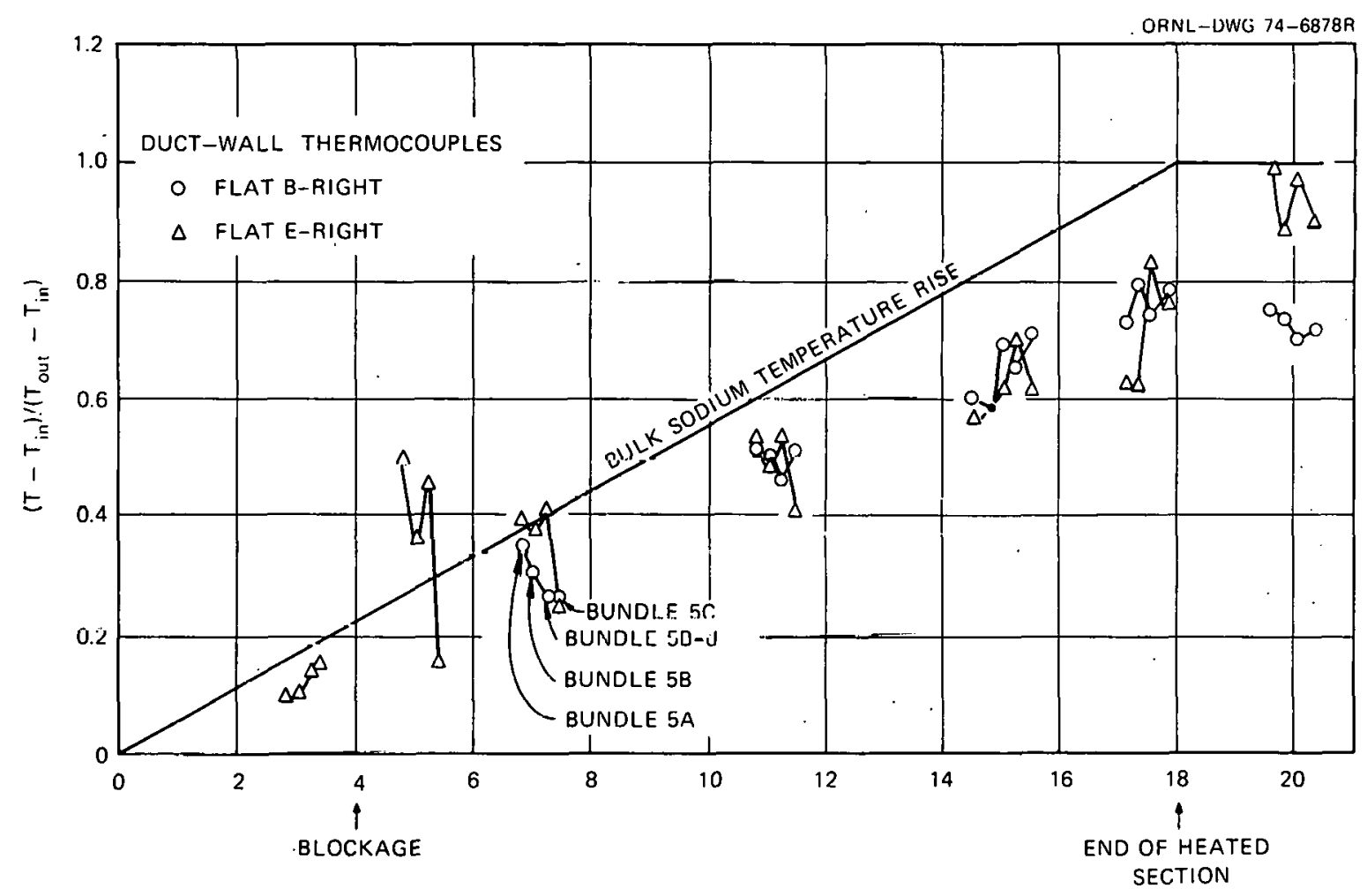

LENGTH ALONG HEATED SECTION (in.)

Fig. 28. Normalized temperature rises from the durt-wa1.1 thermocoupies on hexagonal filats $B$ and $E$, which are near (but not blocked by) the blockage plate. Flow $=2.6 \mathrm{l} / \mathrm{s}(41 \mathrm{gpm})$; uniform power per pin = $16 \mathrm{~kW} / \mathrm{m}(5 \mathrm{~kW} / \mathrm{ft}) ; \mathrm{T}_{1 \mathrm{n}}=316^{\circ} \mathrm{S}\left(\mathrm{h} \cap 0^{\circ} \mathrm{F}\right) ; \mathrm{T}_{\text {out }}-\mathrm{T}_{\text {in }}=47^{\circ} \mathrm{C}\left(05^{\circ} \mathrm{F}\right)$ (Funtana et $\left.a 1 .^{2}\right)$.

level is thought to be due to counterclockwise peripheral edge swirl carrying hot fluid from behind the blockage plate to this flat. There is little varialiun among the three sets of data for tests with the blockage plate. The resules from bundle $5 \mathrm{C}$ show that the blockage platc has little influence on these temperatures beyond approximately $254 \mathrm{~mm}$ (10 in.) downstream from the start of the heated section.

The effects of the duct-wall thermocouples on the flats opposite the blockage plate (flats C and D) are compared in Fig. 29. The temperature rises are consistently lower than that of the bulk sodium, and there is little variation among the sets of data. 


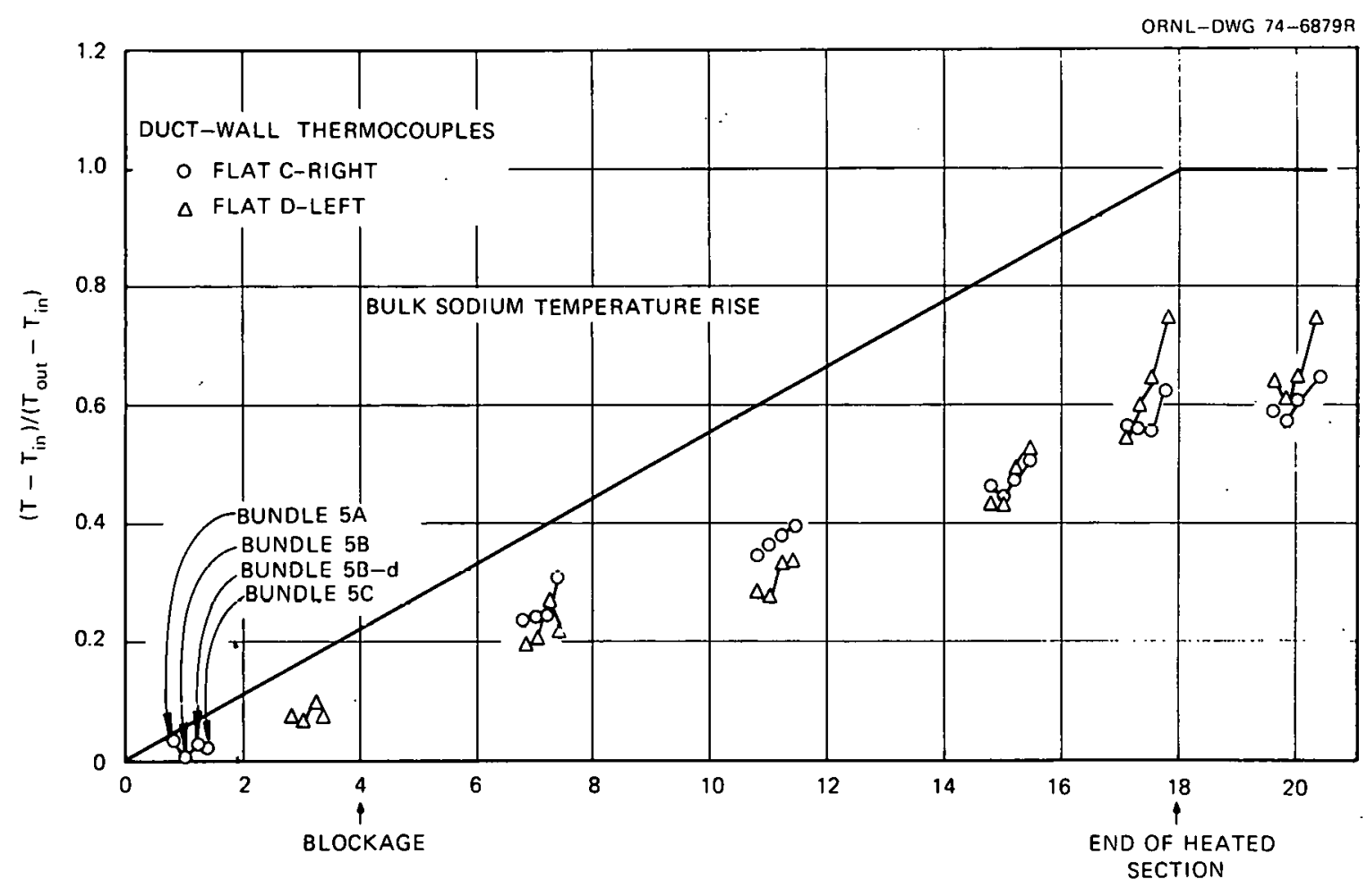

LENGTH ALONG HEATED SECTION (in:)

Fig. 29. Normalized temperature rises from the duct-wall thermocouples on hexagonal flats $\mathrm{C}$ and $\mathrm{D}$, which are far away from the blockage plate. Flow $=2.6 \mathrm{l} / \mathrm{s}(41 \mathrm{gpm})$; uniform power per pin $=16 \mathrm{~kW} / \mathrm{m}(5 \mathrm{~kW} / \mathrm{ft})$; $\mathrm{T}_{\text {in }}=316^{\circ} \mathrm{C}\left(600^{\circ} \mathrm{F}\right)$; and $\mathrm{T}_{\text {out }}-\mathrm{T}_{\text {in }}=47^{\circ} \mathrm{C}\left(85^{\circ} \mathrm{F}\right)$. (Fontana et al. ${ }^{2}$ ).

The results of all duct-wall thermocouples at the $381-\mathrm{mm}$ (15-in.) level are compared in $\mathrm{Fig}$. 30 , and the results of the exit rake thermu= couples are compared in Fig. 31. Both show a higher temperature rise downstream of the blockage plate with little effect of displacement of the plate. The slightly higher temperatures seen in the unblocked bundle (5C) at the previously blocked positions, may be due to normal bundle distortion resulting from uneven spacing from the walls by the helical spacer wires.

The results of the heater-internal thermocouples for THORS bundles 5B, $5 \mathrm{~B}-\mathrm{d}$, and $5 \mathrm{C}$ are given in Table 3. A comparison of the test results from bundles $5 \mathrm{~B}$ and $5 \mathrm{~B}-\mathrm{d}$ reveals that the temperature rises are slightly, but not significantly, lower when the blockage plate is intentionally displaced 0.36 $\mathrm{mm}(0.014$ in.). 


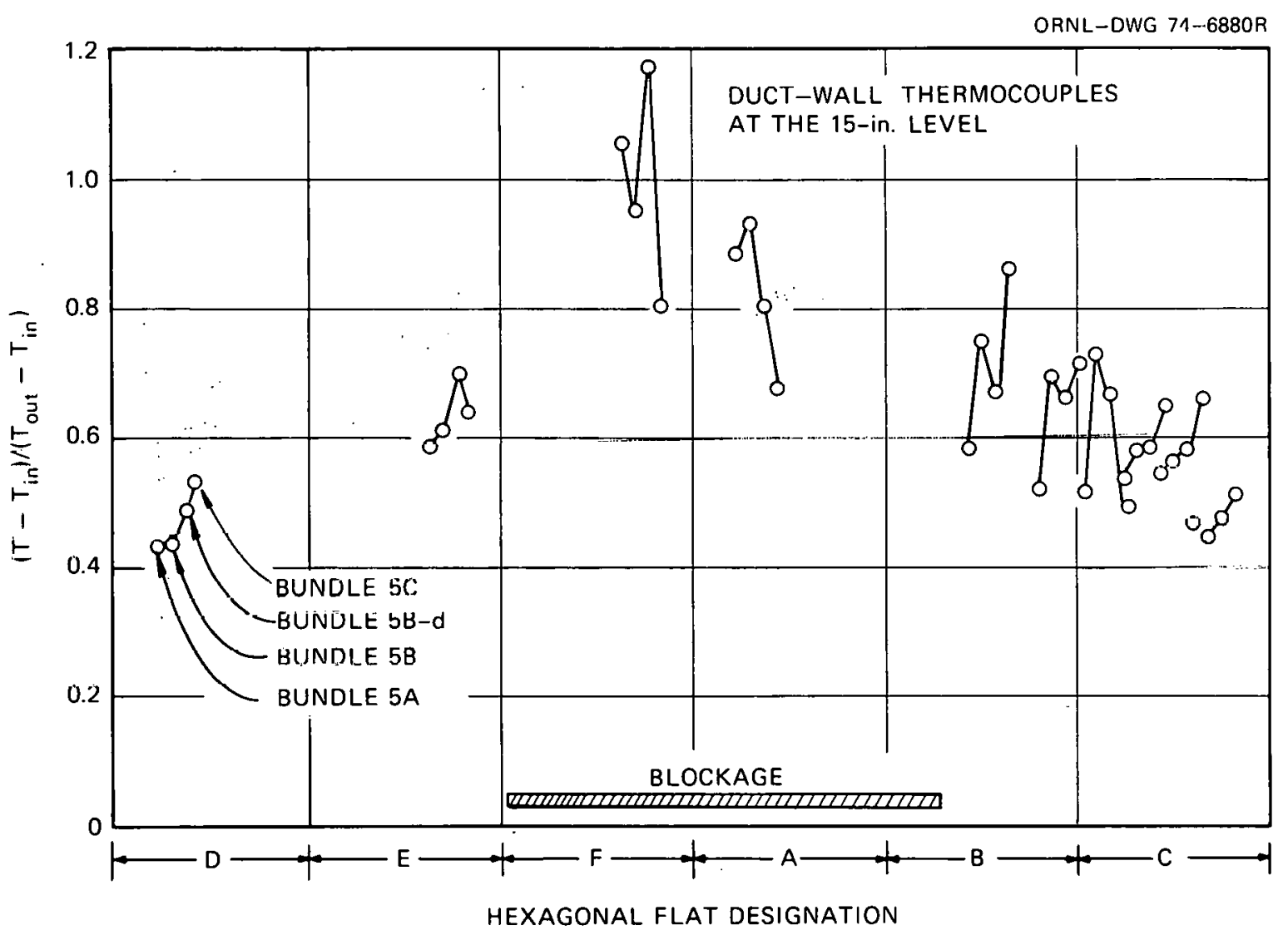

Fig. 30. Normalized temperature rises from all duct-wall thermocouples at the 381-mm (15-in.) level in THORS bundles 5A, 5B, 5B-d, (with the blockage plate displaced by 0.014 in.), and 5C (wi.th the blockage plate completely removed). Flow $=2.6 \ell(41 \mathrm{gpm})$; uniform power per pin $=16 \mathrm{~kW} / \mathrm{m}(5 \mathrm{~kW} / \mathrm{ft}) ; \mathrm{T}_{\text {in }}=316^{\circ} \mathrm{C}\left(600^{\circ} \mathrm{F}\right) ;$ and $\mathrm{T}_{\text {out }}-\mathrm{T}_{\text {In }}=47^{\circ} \mathrm{C}\left(85^{\circ} \mathrm{F}\right)$ (Fontana et al. ${ }^{2}$ ).

Temperature rise vs flow for three selected wire-wrap thermocouples is shown in Figs. 32 to 34. These results are for uniform pin power, with most data taken at $16.4 \mathrm{~kW} / \mathrm{m}(5 \mathrm{~kW} / \mathrm{ft})$ per pin. The data at $0.505 \mathrm{l} / \mathrm{s}$ (8 gpm) and $0.252 \mathrm{l} / \mathrm{s}(4 \mathrm{gpm})$ were taken at $12 \mathrm{~kW} / \mathrm{m}(3.6 \mathrm{~kW} / \mathrm{ft})$ per pin; the data at $0.126 \mathrm{l} / \mathrm{s}$ (2 giii) were Laken at $5.9 \mathrm{~kW} / \mathrm{m}$ ( $(1.8 \mathrm{~kW} / \mathrm{ft})$ per pin. Figure 32 compares the results of the wire-wrap thermocouples at the 127-mm (5-in.) level (25.4 mm downstream from the blockage plate) on pin 17 . Since this thermocouple was in channel 41 (see Fig. 25), its temperature immediately downstream from the blockage plate would be strongly influenced by any leakage around the edge of the plate. For this thermocouple, the difference between the limited results from bundle $5 \mathrm{~A}$ and the results from bundle 


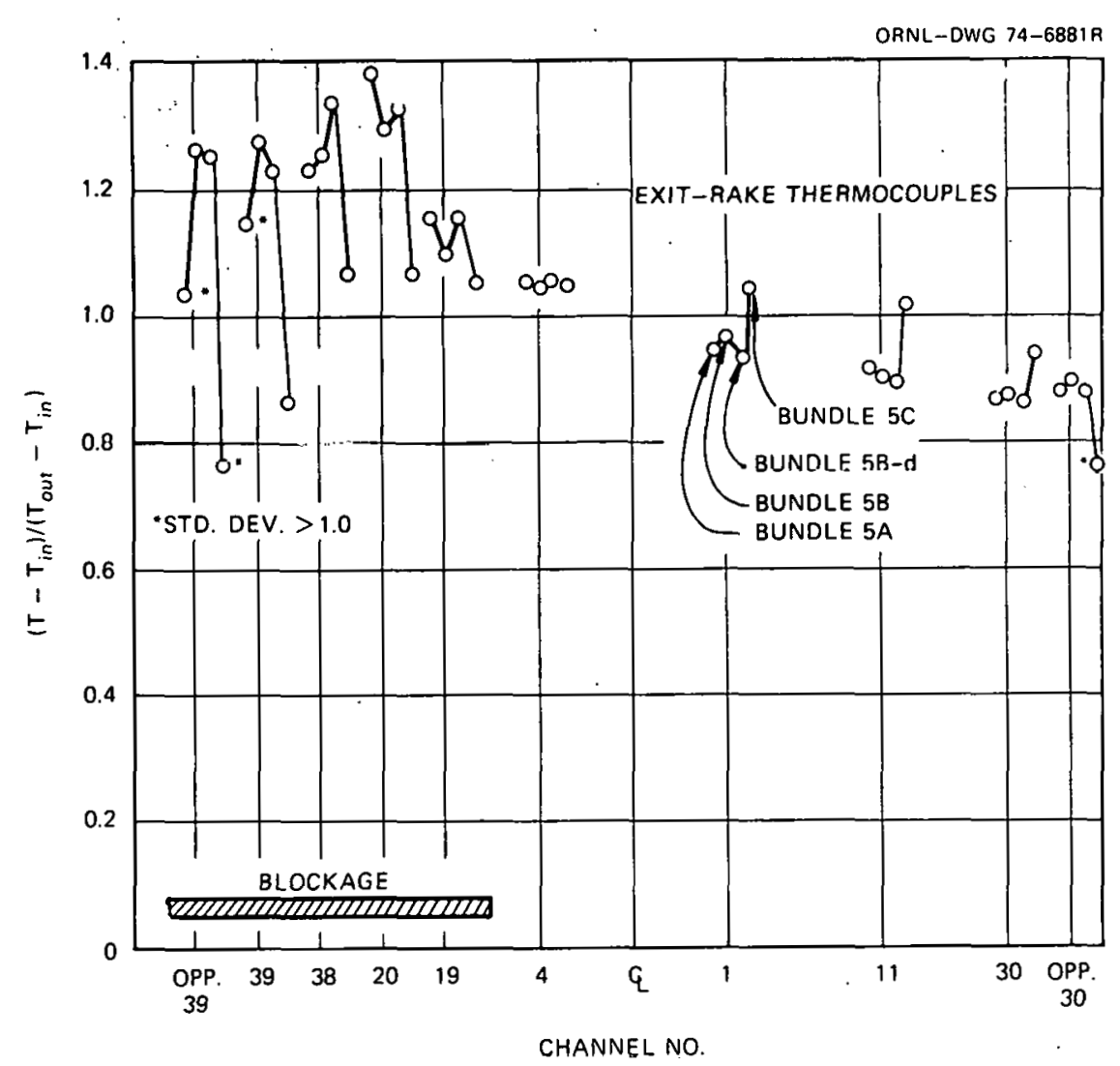

Fig. 31. Normalized temperature rises from the exit-rake thermocouples in THORS bundles $5 \mathrm{~A}, 5 \mathrm{~B}, 5 \mathrm{~B}-\mathrm{d}$, and $5 \mathrm{C}$. Flow $=2.6 \mathrm{l} / \mathrm{s}$ (41 gpm); uniform power per pin $=16 \mathrm{~kW} / \mathrm{m}(5 \mathrm{~kW} / \mathrm{ft}) ; \mathrm{T}_{\text {in }}=316^{\circ} \mathrm{C}\left(600^{\circ} \mathrm{F}\right)$; and $\mathrm{T}_{\text {out }}-\mathrm{T}_{\text {in }}=47^{\circ} \mathrm{C}\left(85^{\circ} \mathrm{F}\right)$ (Fontana et $\mathrm{a} 1 .^{2}$ ).

$5 B$, which had the same nominal configurations, is about the same as the difference between the results of bundle $5 B$ and bundle $5 B-d$. The results from the two blocked bundles ( $5 \mathrm{~B}$ and $5 \mathrm{~B}-\mathrm{d}$ ) for which low-flow data exist show a slight temperature maximum at about one-third the nominal flow of $2.6 \mathrm{l} / \mathrm{s}(41 \mathrm{gpm})$. The unblocked bundle $(5 \mathrm{C})$ shows a flat profile that tapers off at very low flows, where extraneous effects (heat losses, axial conduction) become significant.

Figure 33 compares analogous results for the wire-wrap thermocouple al the same axial level on pin 15. This thermocouple was in channel 20, which is an internal channel in the approximate center of the region downstream from the blockage plate. These results are similar to those shown in Fig. 32 , except that the temperature rises in bundle $5 \mathrm{~B}-\mathrm{d}$ are slightly lower 
Table 3. Dimensionless temperature rises, $\left(\mathrm{T}-\mathrm{T}_{\text {in }}\right) /$

$\left(\mathrm{T}_{\text {out }}-\mathrm{T}_{\text {in }}\right)$, from heater-internal thermcouples in 'IHOKS bundles $5 \mathrm{~B}, 5 \mathrm{~B}-\mathrm{d}$, and $5 \mathrm{C}$

Flow $=2.6 \mathrm{l} / \mathrm{s}(41 \mathrm{gpm})$, uniform power per pin $=$ $16 \mathrm{~kW} / \mathrm{m}(5 \mathrm{~kW} / \mathrm{ft}), \mathrm{T}_{\text {in }}=316^{\circ} \mathrm{C}\left(600^{\circ} \mathrm{F}\right), \mathrm{T}_{\text {out }}-\mathrm{T}_{\text {in }}=$

\begin{tabular}{|c|c|c|c|c|}
\hline \multirow{2}{*}{$\begin{array}{l}\text { Axial location } \\
\text { (inches from start } \\
\text { of heated section) }\end{array}$} & \multirow{2}{*}{$\begin{array}{l}\text { Pin } \\
\text { No. }\end{array}$} & \multicolumn{3}{|c|}{$\left(T-T_{\text {in }}\right) /\left(T_{\text {out }}-T_{\text {in }}\right)$} \\
\hline & & Bundle 5B & Bundle $5 \mathrm{~B}-\mathrm{d}$ & Bundle $5 \mathrm{C}$ \\
\hline $3.0-3.5$ & $\begin{array}{r}6 \\
16 \\
18\end{array}$ & $\begin{array}{l}0.75 \\
0.75 \\
0.79\end{array}$ & $\begin{array}{l}0.72 \\
0.74 \\
0.77\end{array}$ & $\begin{array}{l}0.73 \\
0.72 \\
0.72\end{array}$ \\
\hline $\begin{array}{l}3.5-4.0 \\
\because \\
\end{array}$ & $\begin{array}{r}6 \\
15 \\
16 \\
18\end{array}$ & $\begin{array}{l}0.98 \\
0.92 \\
0.95 \\
0.95\end{array}$ & $\begin{array}{l}0.98 \\
0.99 \\
0.90 \\
0.96\end{array}$ & $\begin{array}{l}0.74 \\
0.71 \\
0.77 \\
0.74\end{array}$ \\
\hline 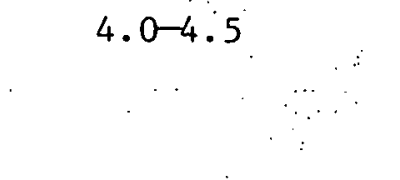 & $\begin{array}{r}6 \\
15 \\
16 \\
18\end{array}$ & $\begin{array}{l}1.58 \\
1.45^{a} \\
1.55^{a} \\
1.12\end{array}$ & $\begin{array}{l}1.66 \\
1.58^{a} \\
0.99\end{array}$ & $\begin{array}{l}0.76 \\
0.80 \\
0.76\end{array}$ \\
\hline $4.5-5.0$ & $\begin{array}{r}6 \\
15 \\
16 \\
17 \\
18\end{array}$ & $\begin{array}{l}1.52 \\
1.10^{\alpha} \\
1.55 \\
1.59 \\
1.11\end{array}$ & $\begin{array}{l}1.49 \\
1.47 \\
1.04 \\
0.91\end{array}$ & $\begin{array}{l}0.78 \\
0.81 \\
0.84 \\
0.76\end{array}$ \\
\hline $10.0-10.5$ & 10 & 0.93 & 0.96 & 0.99 \\
\hline $10.5-11.0$ & 10 & 0.97 & 0.98 & 1.02 \\
\hline $11.0-11.5$ & 10 & 1.04 & 1.05 & 1.07 \\
\hline $11.5-12.0$ & 10 & 1.06 & $\because$ & \\
\hline
\end{tabular}

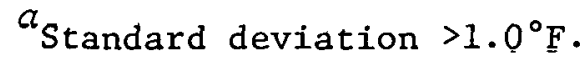

than those obtained with bundle 5B. This indicates that the slight leakage in bundle $5 \mathrm{~B}$ was as effective in reducing this temperature rise as was the intentional leakage in bundle $5 \mathrm{~B}-\mathrm{d}$.

Figurc 34 compares the results ubtalned from the wire-wrap thermocouple at the 178-mm (7-in.) level on pin 6. This thermocouple was in channel 21, an internal channel adjacent to channel 20. The results from bundles $5 \mathrm{~B}$ and $5 \mathrm{~B}-\mathrm{d}$ are essentially identical and not significantly lower than the 
ORNL-DWG 75-3465

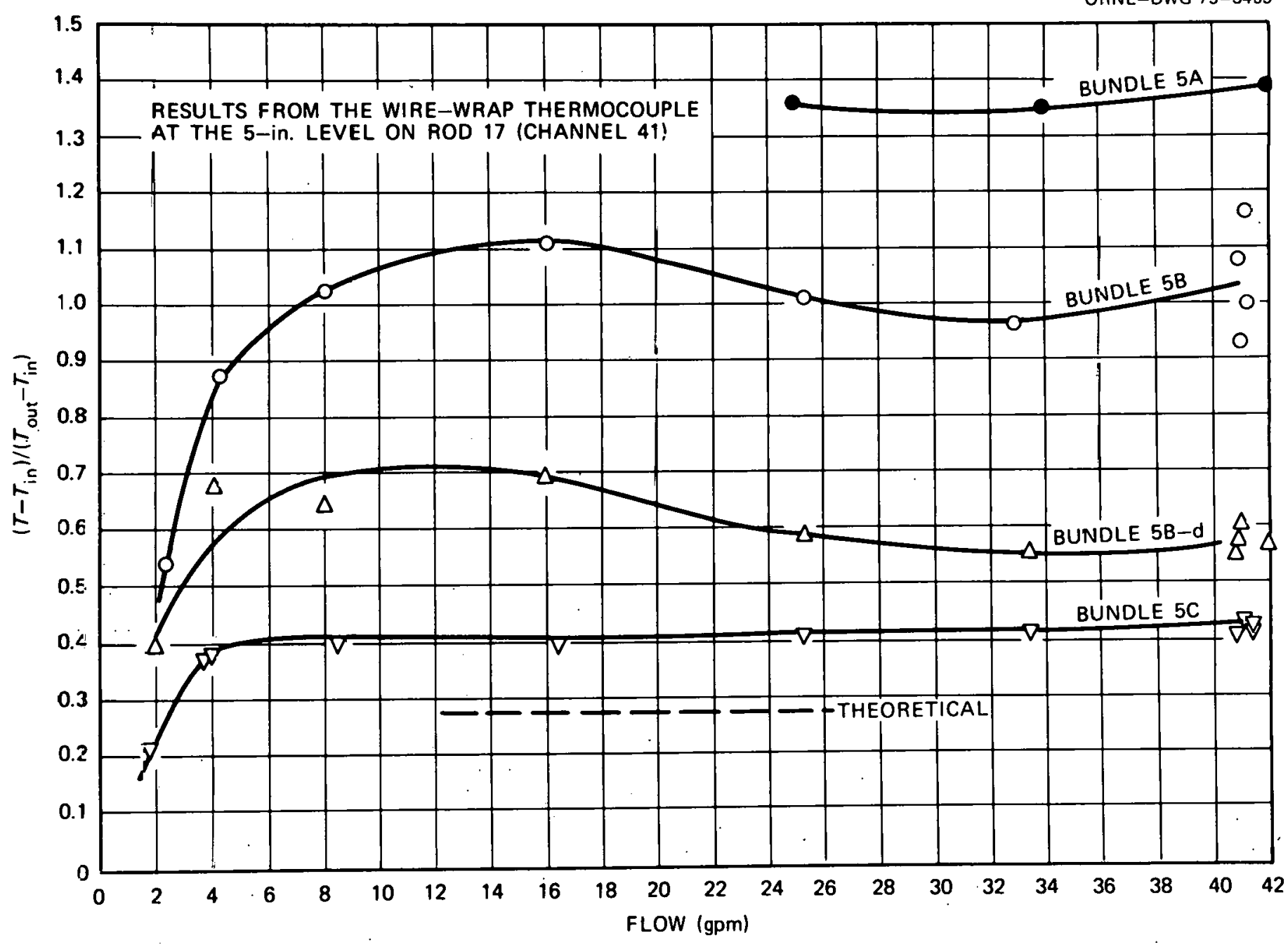

Fig. 32. Normalized temperature rises vs flow with uniform heater power from the wire-wrap thermocouple at the 127-mm (5-in.) level on pin 17 (channe1 41) for THORS bundles 5A, 5B, 5B-d, and 5C (Fontana et al. ${ }^{2}$ ). 
ORNL-DWG 75-3464

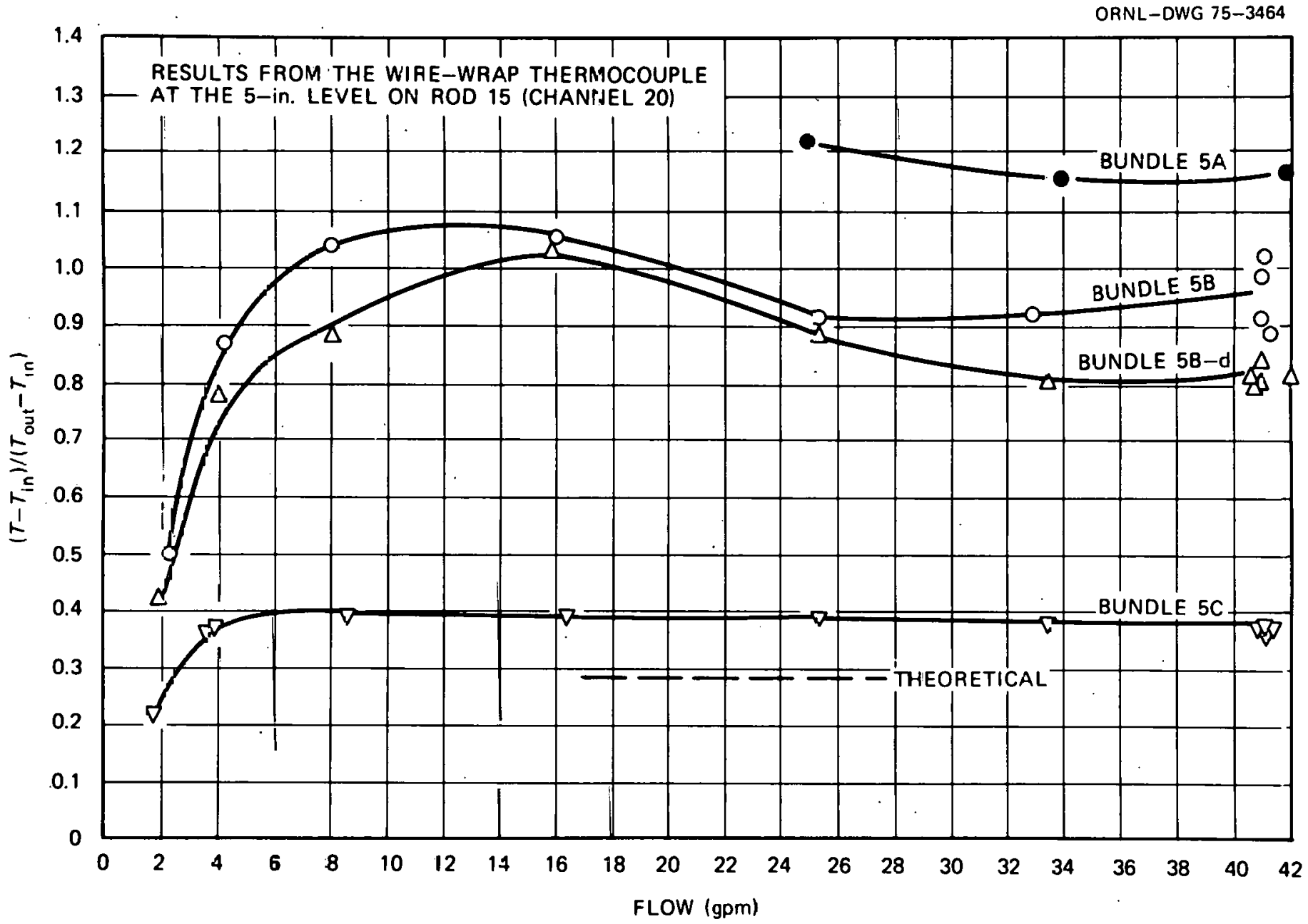

Fig. 33. Normalized temperature rises vs flow with uniform heater powar from the wire-wrap thermocouple at the 127-mm i5-in.) level on pin 15 (channe1 20 ) for THORS bundles 5A, 5B, 5B-d, and $5 \mathrm{C}$ (Fontana et $a 1^{2}$ ). 


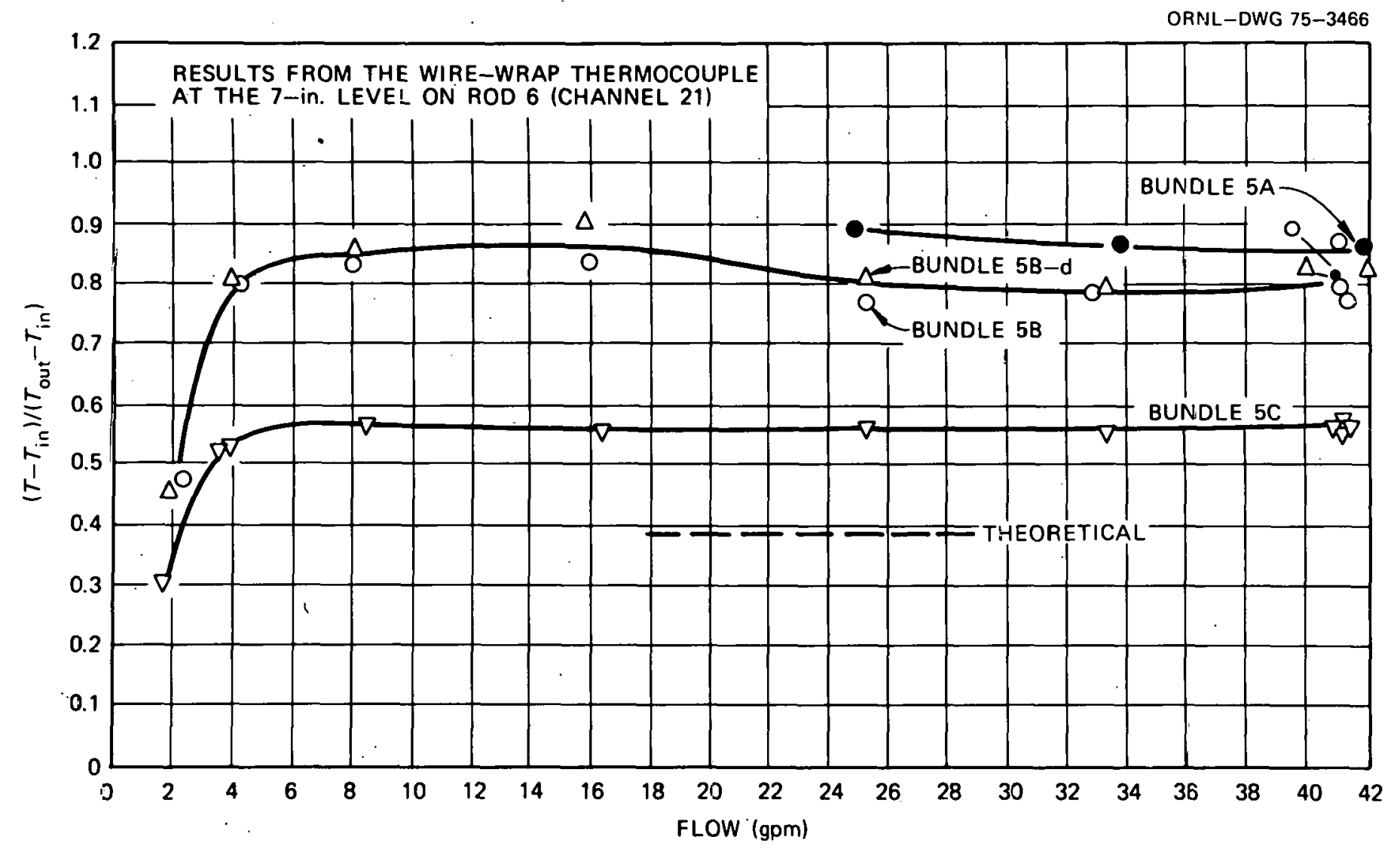

Fig. 34. Vormalized temperature rises vs flow with uniform heater power from the wire-wrap thermocouple at the 178-mm (7-in.) level on pin 6 (channel 21) for THOFS bundles 5A, 5B, 5B-d, and 5C (Fontana et al. ${ }^{2}$ ). 
limited results obtained from bundle 5A. The maximum temperature rise at approximately one-third nominal flow observed at the 127-mm (5-in.) level is barely discernible at the 178-mm level.

It is possible that the $127-\mathrm{mm}$ level is in the wake (recirculation zone) region, while the 178-mm level is in the far wake region (downstream of the recirculation zone behind the blockage). Leakage past the blockage plate would affect the temperatures in the wake region much more strongly than in the far-wake region.

The maximum temperature excess caused by the blockage measured in all experiments was on the order of the $\mathrm{T}_{\text {out }}-\mathrm{T}_{\text {in }}$ in the pin bundle. Since the local effect of the blockage would be of the same magnitude in the reactor under the same 1ncal. conditions of power and flow and the heated zone of the reactor is twice as long as that used in these experiments (36 vs 18 in.), the $T_{\text {uut }}-T_{i n}$ in the reactor $i$ twice that of the experiments. Therefore, the normalized temperature excesses reported here must be divided by 2 if normalization to reactor conditions is to be realized.

Fontana et al. ${ }^{2}$ concluded that the 14-channel edge blockage against the duct wall, which blocked one-third of the flow area, did not cause excessive temperature increases from the standpoint of reactor safety. However, it should be emphasized that these experiments were performed with full-size pins and spacers and were intended to represent local flow conditions (as much as possible within the constraints of a 19-pin assembly). Therefore, these results cannot be used to infer that a blockage covering one-third of the flow area of a fuel assembly would hehave similarly. It wuuld be more relevant to compare the experimental bloskage condition to an in-core blockage that extends from the duct to the centerline of the serond row of pins and then laterally over a distance of three pins measured from the corner defined by the intersection of two duct flats.

\subsection{THORS Water Mockup of a Three-Scale 19-Pin Bundle}

The THORS water mockup is a three-scale water-cooled model of the THIORS facility. ${ }^{2}$ Blockage tests have been performed by Thomas $^{2}$ to determine the effect of various blockage geometries on (1) heat transfer coefficient distributions along the pin surface; (2) flow patterns in the vicinity of a 
blockage (i.e., the extent of regions of recirculation); (3) mass exchange rate between the wake zone behind the blockage and the free stream; and (4) pressure drop in the pin bundle. The advantages of using water for such tests are that the shroud can be fabricated from clear plastic, thus permitting flow visualization studies; mass exchange rate may be determined using salt solution as tracer; and water is much easier to work with than liquid sodium. However, care must be taken in interpreting the results in terms of possible consequences of a flow blockage in a sodium-cooled system.

\section{2 .1 Test section}

To measure distributions of the local heat transfer coefficient upstream and downstream of the blockage, a 19-pin bundle was enclosed in a Plexiglas shroud of a hexagonal cross section. One pin was an A-nickel tube that was resistance heated to achieve heat fluxes of approximately

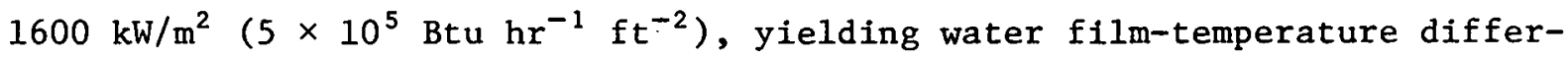
ences of approximately $78^{\circ} \mathrm{C}\left(140^{\circ} \mathrm{F}\right)$; the remaining 18 pins were constructed of Plexiglas. The heated pin could be positioned at either the central or a corner position in the bundle. Blockage plates used in this study are illustrated in Fig. 35. Six thermocouples at each of three axial stations were utilized to measure the bulk water temperature in channels near the central heated pin. A traversing thermocouple assembly was used to measure the inner wall temperature of the A-nickel pin at any destred axial or circumferential position. Local heat transfer coefficients were calculated from the derived film-temperature differences and heat flux.

Demineralized water was circulated through the test section by a centrifugal pump at the rate of $31.5 \mathrm{l} / \mathrm{s}(500 \mathrm{gpm})$, with the flow measured by a shedding-vortex flowneter. Flow blockages in the test section were simulated by inserting Plexiglas blockage plates in the bundle.

The Plexiglas shroud assembly containing the 19-pin bundle was $1370 \mathrm{~mm}$ (54 in.) long with an external cross section of $152 \mathrm{~mm}$ (6 in.) $\times 165 \mathrm{~mm}$ (6.5 in.). Attached to the lower (upstream) end of the shroud was a 762-mmlong (30-in.), 127-mm-diam (5-in.) stainless stee1 tee that contained a flow redistribution sieve plate and a 76-mm-long (3-in.) Plexiglas transition piece to change the flow cross section from circular to hexagonal. The upper (downstream) end of the shroud had a similar tee which was $305 \mathrm{~mm}$ 
EDGE B_OCKAGE PLATES

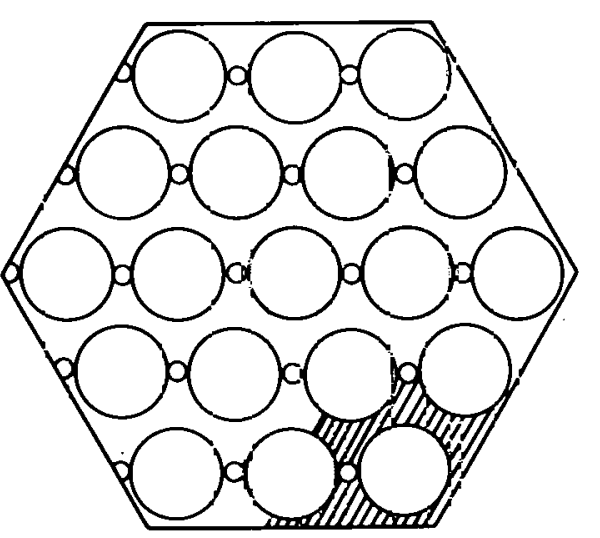

(a) 5 CHANNELS

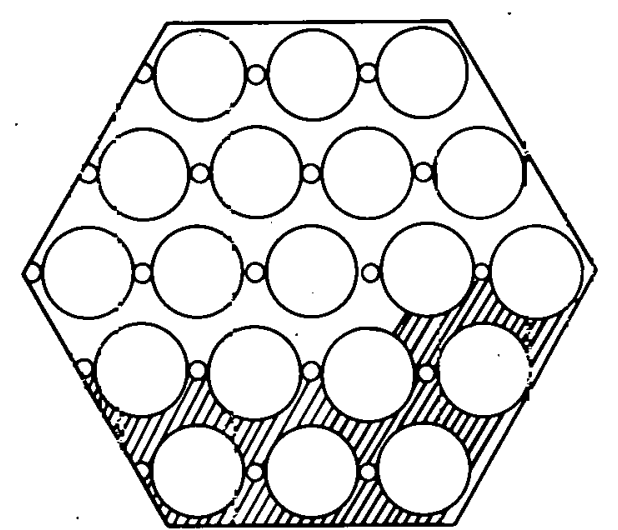

(b) 14 CHANNELS

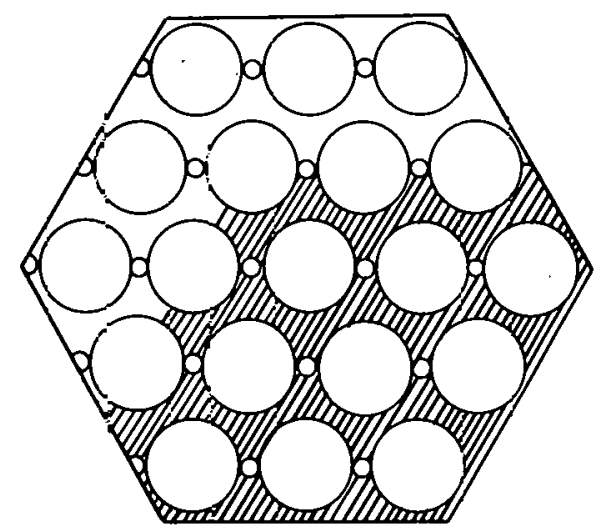

ic) 24 CHANNELS

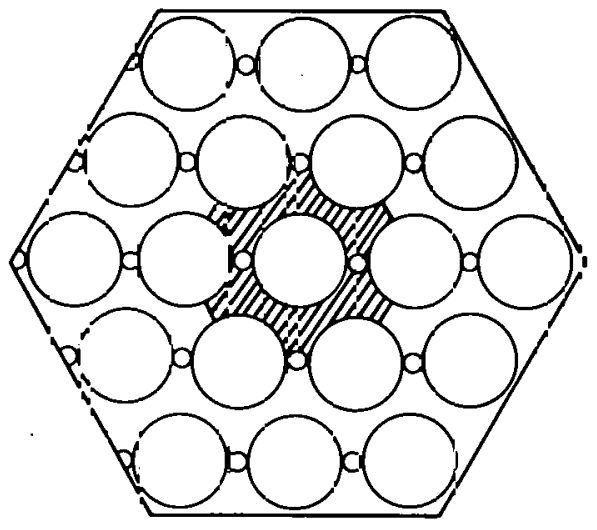

(d) 6 CHANNELS

\section{ZENTRAL \\ BLOCKAGE \\ PLATES}

Fig. 35. Blockage plates in THORS water mockup (Fontana et al. ${ }^{2}$ ).

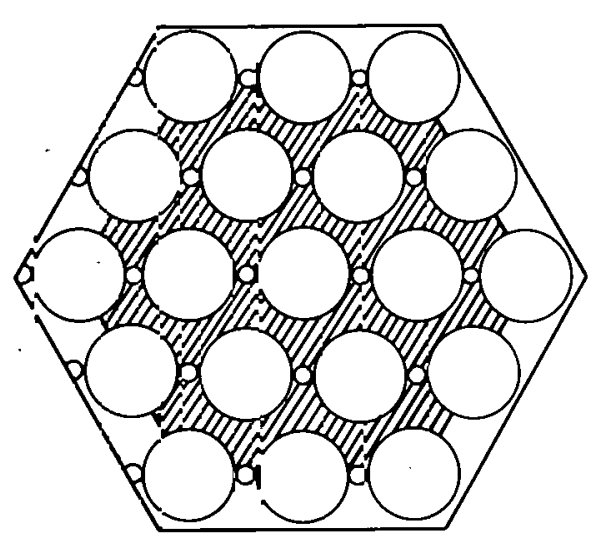

(e) 24 CHANNELS 
(12 in.) long. The blockage plate was generally located in the middle of the pin length.

\section{2 .2 Results and discussion}

Conditions for the heat transfer studies with edge channel blockages are summarized in Table 4. Figure 36 shows the local heat transfer coefficient and flow pattern around a 14-channel edge blockage at a Reynolds number of $2.5 \times 10^{4}\left(\mathrm{~T}_{\mathrm{BM}}\right.$ is the bulk mean temperature at the blockage). Flow visualization studies with injected air indicated a strong wake downstream of the blockage plate. Figure 37 shows axial variations of heat transfer coefficient and flow patterns around the 14-channel edge blockage plate at the highest flow achieved in the edge blockage tests (mean water velocity = 28.1 fps and Reynolds number $=9.40 \times 10^{4}$ ). The downstream end of the wake

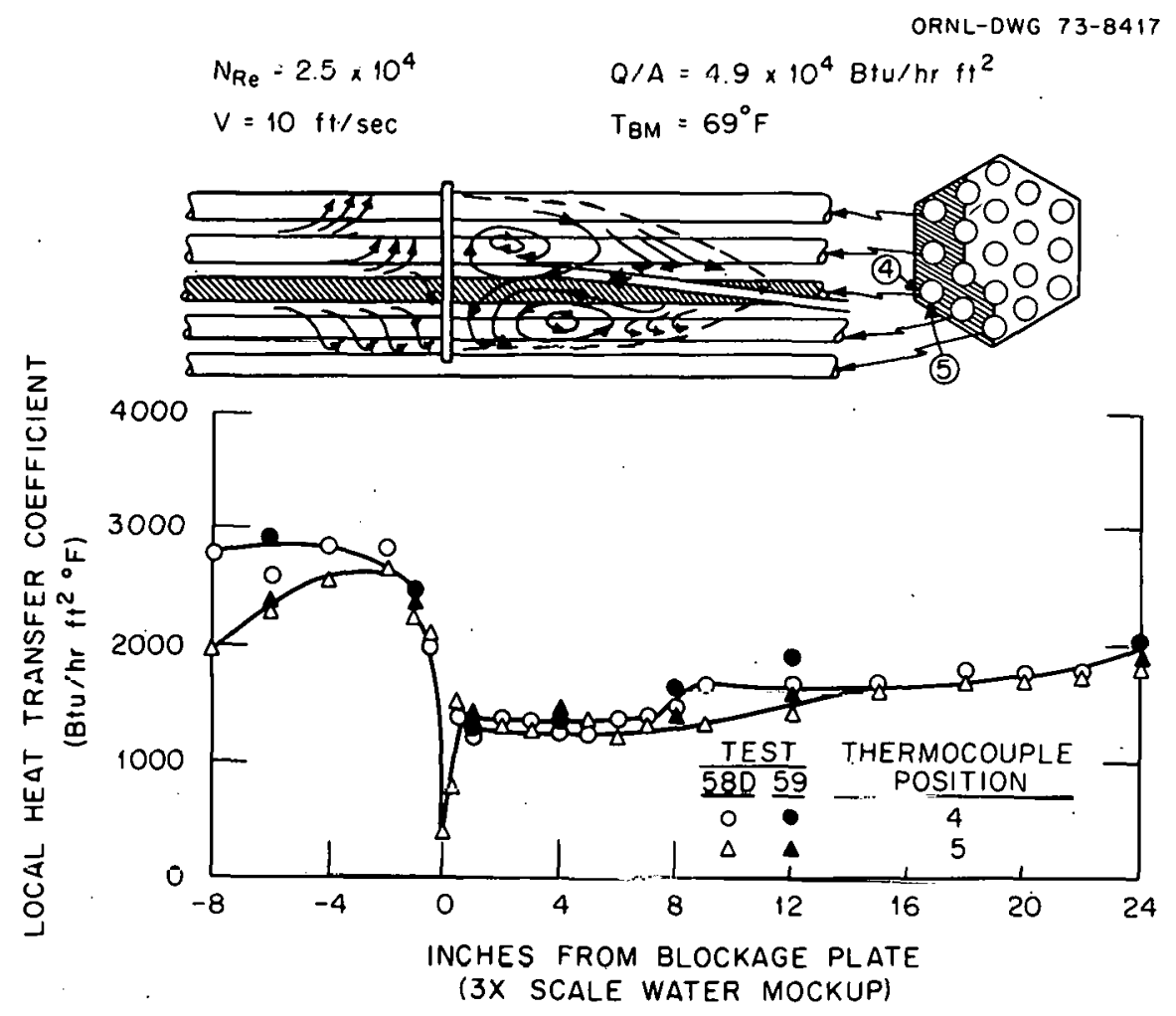

Fig. 36. Local heat transfer coefficient and flow pattern with a 1.4-channel edge blockage in THORS water mockup at a Reynolds number of $2.5 \times 10^{4}$ (Fontana et $a .^{2}$ ). 
Table 4.' Test performed in THORS water mocku? with an edge blockage

\begin{tabular}{|c|c|c|c|c|c|c|}
\hline $\begin{array}{l}\text { Test } \\
\text { No. }\end{array}$ & $\begin{array}{l}\text { Number of } \\
\text { channels } \\
\text { blocked }\end{array}$ & $\begin{array}{c}\text { Average } \\
\text { velocity } \\
{[\mathrm{m} / \mathrm{s} \text { (fps)] }}\end{array}$ & $\begin{array}{l}\text { Reynolds } \\
\text { No. }\end{array}$ & $\left.\left[{ }^{\circ} \mathrm{C}{ }^{\mathrm{T}_{3 \mathrm{M}}}{ }^{\circ} \mathrm{F}\right)\right]$ & {$\left[\mathrm{w} \mathrm{m}^{-2}\right.$} & $\begin{array}{l}\text { Heat flux } \\
\left.\left(\text { Btu } h r^{-1} \mathrm{ft}^{-2}\right)\right]\end{array}$ \\
\hline & . & & $\times 10^{4}$ & & & $\times 10^{4}$ \\
\hline 59 & 14 & $3.05(10.0)$ & 2.6 & $38.3 \div 69.0)$ & & $15.5(4.9)$ \\
\hline 60 & 14 & $8.56(28.1)$ & 9.4 & $53.2 \quad(95.7)$ & & $21.4 \quad(6.8)$ \\
\hline $62^{a}$ & 14 & $3.14(10.3)$ & $2.6^{\circ}$ & $34.4 \quad(62.0)$ & & $23.7(7.5)$ \\
\hline 68 & 24 & $1.26(4.15)$ & 1.31 & $49.3 \quad(88.8)$ & & $4.29(1.36)$ \\
\hline 69 & $2<$ & $0.75 \quad(2.45)$ & 0.82 & $50.6(91.0)$ & & $4.29(1.36)$ \\
\hline$? 0$ & 24 & $2.29(7.50)^{\circ}$ & 2.29 & $45.3(81.5)$ & & $5.77(1.83)$ \\
\hline 71 & 5 & $2.76(9.05)$ & 2.67 & $45.4(81.8)$ & & $20.5(6.50)$ \\
\hline 72 & 5 & $1.37(4.50)$ & 1.38 & $46.6(83.8)$ & & $=4.8(4.69)$ \\
\hline 73 & 5 & $5.03(16.5)$ & 4.81 & $44.4(80.0)$ & & $27.0(8.56)$ \\
\hline 74 & 5 & $7.62(25.0)$ & 7.39 & $45.5(81.9)$ & & $31.6(22.7)$ \\
\hline
\end{tabular}

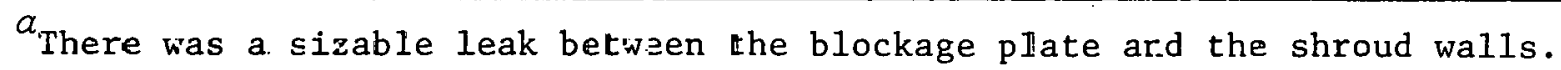




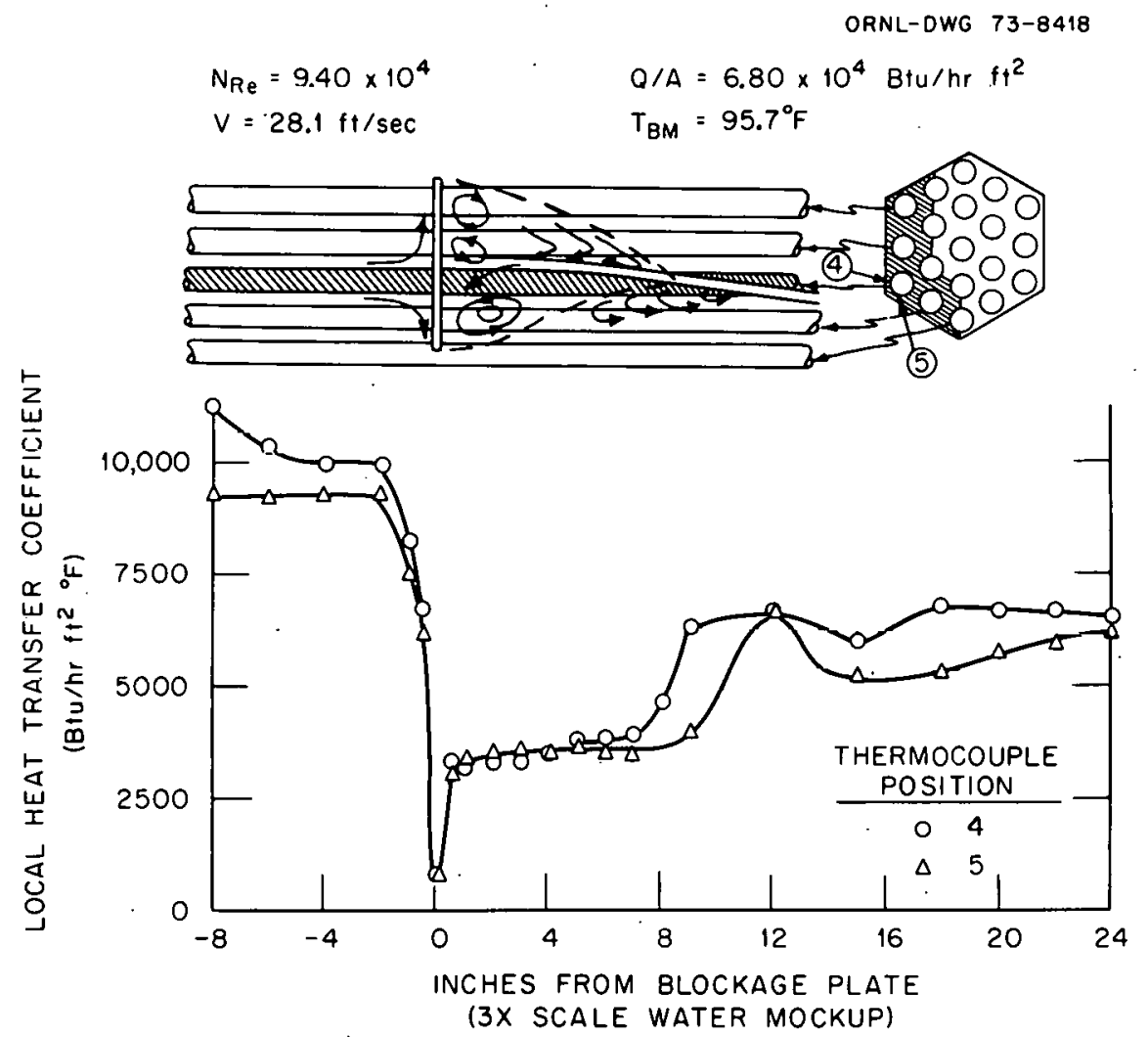

Fig. 37. Local heat transfer coefficient and flow pattern with a 14-channel edge blockage in THORS water mockup at Reynolds number of $9.40 \times 10^{4}$ (Fontana et $a .^{2}$ ).

region is clearly identifiable by the substantial increase in the heat transfer coefficient. The most pronounced feature of the local heat transfer measurements is the substantial decrease in the coefficient downstream of the plate $\left[h_{1}\right.$ and $h_{24}$ are heat transfer coefficients measured $25.4 \mathrm{~mm}$ (1 in.) and $610 \mathrm{~mm}$ (24 in.) downstream of the blockage plate, respectively] to the heat transfer coefficient $203 \mathrm{~mm}$ ( 8 in.) upstream of the plate $\left(h_{-8}\right)$ :

\begin{tabular}{|c|c|c|c|}
\hline $\begin{array}{l}\text { Reynolds } \\
\text { number }\end{array}$ & $\begin{array}{l}\text { Velocity } \\
{[\mathrm{m} / \mathrm{s} \text { (fps)] }}\end{array}$ & $h_{1} / h_{-8}$ & $h_{24} / h-8$ \\
\hline $1.14 \times 10^{4}$ & $1.4(4.6)$ & 0.50 & 0.64 \\
\hline $3.04 \times 10^{4}$ & $3.0(10.0)$ & 0.42 & 0.72 \\
\hline $3.95 \times 10^{4}$ & $6.1(20.0)$ & 0.34 & 0.68 \\
\hline $9.40 \times 10^{4}$ & $8.6(28.1)$ & 0.30 & 0.65 \\
\hline
\end{tabular}


As velocity increases, the effect of the blockage plate on the heat transfer coefficient within $25.4 \mathrm{~mm}$ ( 1 in.) of the plate is markedly increased; however, at $610 \mathrm{~mm}$ downstream from the blockage, the heat transfer coefficient had recovered up to 64 to $72 \%$ of the original value, showing no clear-cut trend with velocity.

Average heat transfer coefficients for the tests with a 14-channel edge blockage are summarized in Fig. 38 for Reynolds numbers from $1.14 \times$ $10^{4}$ to $9.40 \times 10^{4}$. This figure again illustrates the marked decrease in the heat transfer coefficient in the vicinity of the blockage plate (the wake region) and the slow recovery of the heat transfer coefficient in the far-wake region.

At tlie eud of test 60 , a slight leak developed between the blockage plate and the channel wall approximately 1.5 pin diameters from the centerline of the heater corner pin. For test 62 , this leak was deliberately

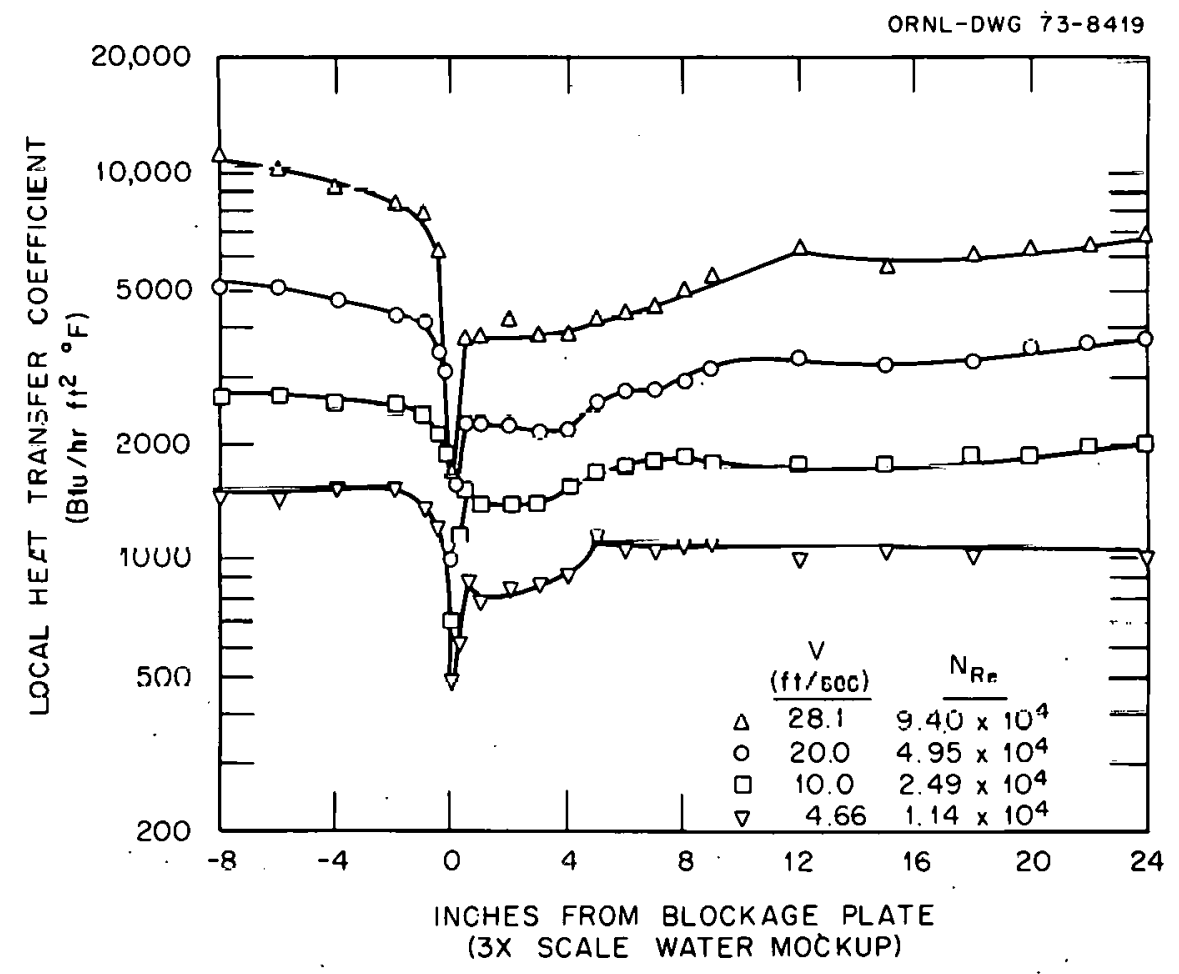

Fig. 38. Average heat transfer coefficients with a 14-channel edge blockage in THORS water mockup (Fontana et al. ${ }^{2}$ ). 
enlarged by forcing the plate away from the channel wall with a machine screw. Although the sealer compound had pulled loose from the blockage plate for this test, it remained fixed to the plate on the side toward the heater tube so that the leakage jet was diverted from the heated tube. Flow visualization studies (Fig. 39) clearly showed the jet, but apparently it was not strong enough to completely destroy the recirculating regions observed in previous tests with no leaks. Furthermore, there appeared to be multiple recirculation zones behind the blockage plate, and there was a marked increase in the heat transfer coefficient in the vicinity of the reattachment point (i.è., where the free stream flow contacts the surface).

At the conclusion of test 62 , the edge blockage plate was removed and the pin bundle returned to the reference condition. The circumferential variation of the heat transfer coefficient for the unblocked reference bundle for various locations along the heated pin is shown in Fig. 40 . For

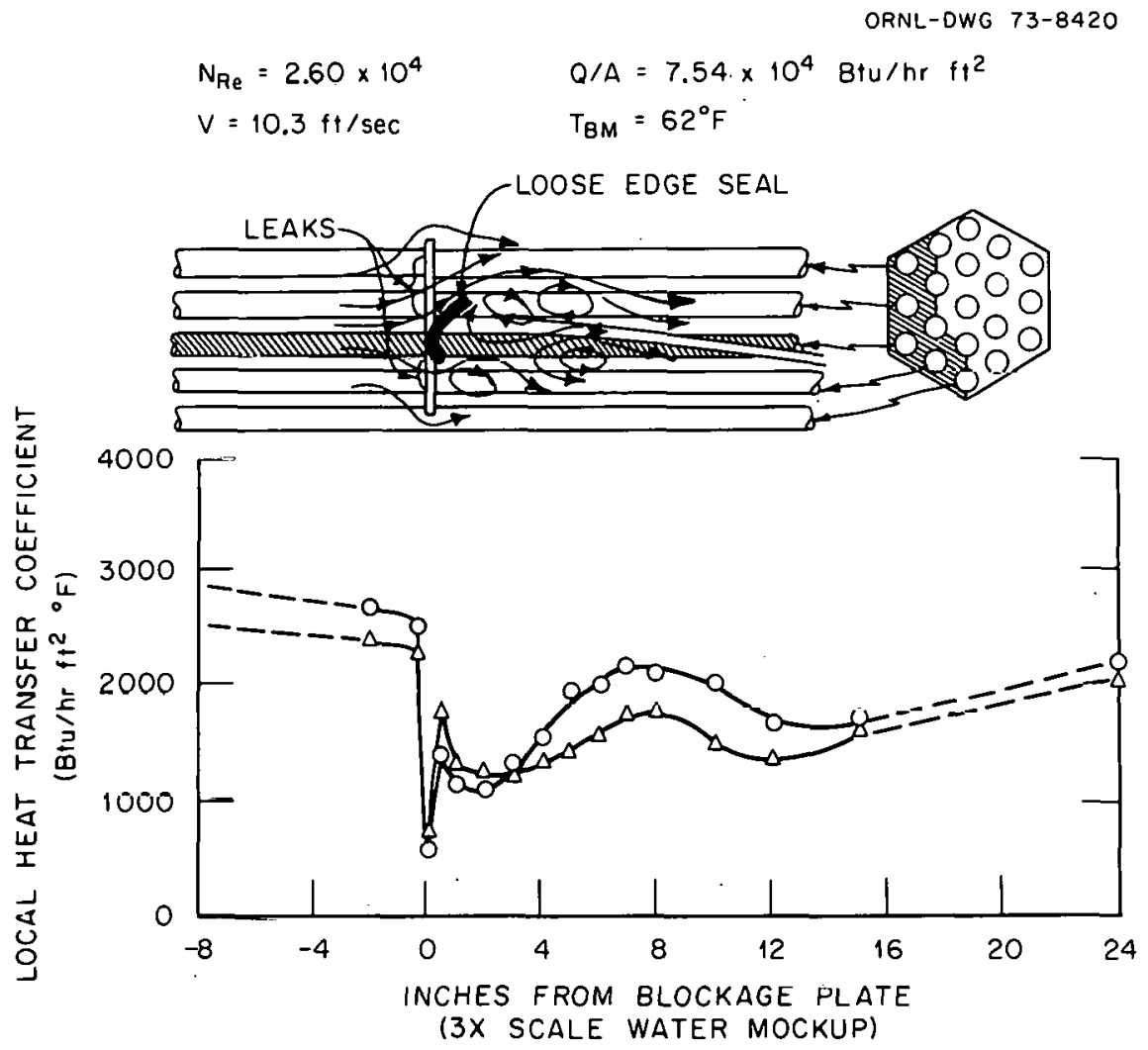

Fig. 39. Effect of edge seal leakage on flow pattern and heat transfer coefficient (Fontana et $a .^{2}$ ). 


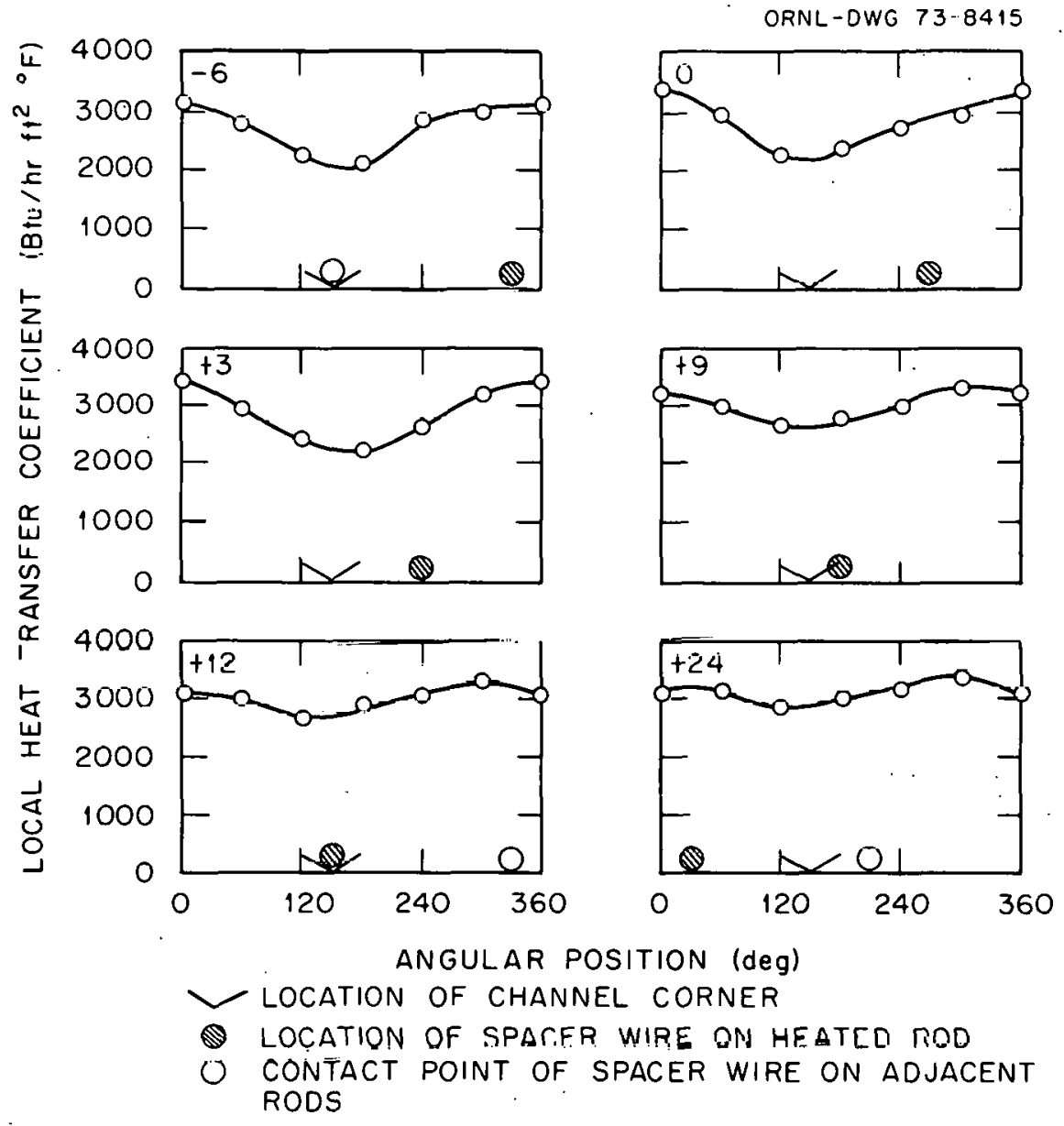

Eig. 40. Variatiun of luch. heat transfer coefficient in unblocked reference bundle with Reynolds number of $2.6 \times 10^{4}$ and water velocity of $3.14 \mathrm{~m} / \mathrm{s}$ (10.3 fps) (Fontana et $\mathrm{al} .^{2}$ ).

convenience, the locations $(-6,0,+3,+9,+12$, and $+2 / f$ in. $)$ are given in Fig. 40 with respect to the location of the edge blockage plate when 1 was in place. The figure also shows the locations of the channel corner and the spacer wires. Near the bundle inlet, the channel corner exerts a major influence on the rircumferential variation of the heat transfer coefficient; near the bundle exit, the variation becomes much smaller.

The circumferential variation in the heat transfex coefficient in the presence of a 14-channel edge blockage plate is illustrated in Fig. 41, which shows results of two different tests run under substantially the same conditions. In one test, temperatures were measured every $15^{\circ}$ of the circumference. Except for the traverse $152 \mathrm{mn}$ (6 in.) upstream of the blockage 


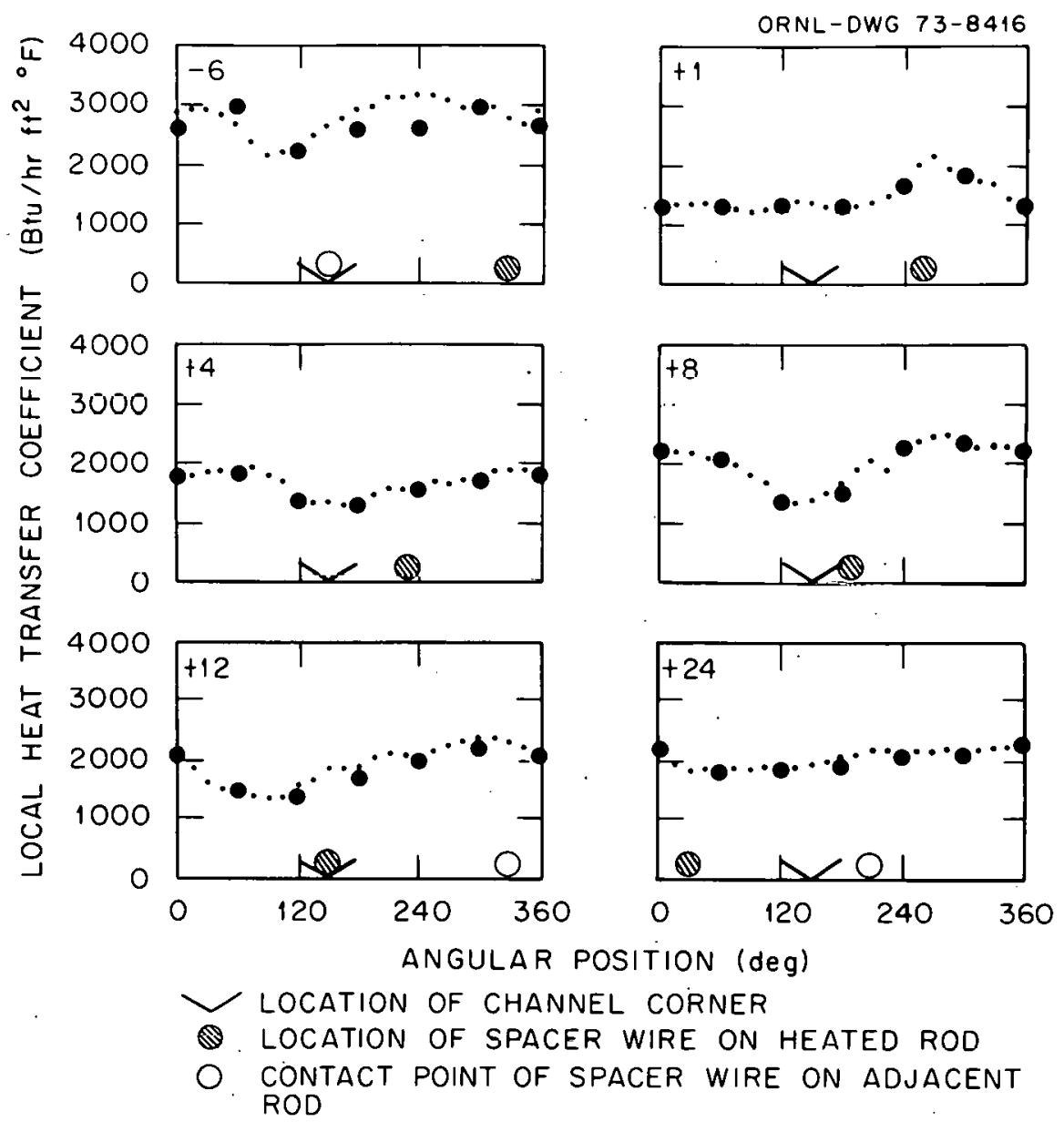

Fig. 41. Variation of local heat transfer coefficient in THORS water mockup with a 14-channel edge blockage at Reynolds number of $2.6 \times 10^{4}$ and water velocity of $3.05 \mathrm{~m} / \mathrm{s}(10 \mathrm{ft} / \mathrm{s})$ (Fontana et $\mathrm{al}^{2}{ }^{2}$ ).

plate, the agreement is quite satisfactory. As was the case in the unblocked reference bundle measurements (Fig. 40), the channel corner seemed to have some influence on the local heat transfer coefficient, and, except for the traverse made $25 \mathrm{~mm}$ ( 1 in.) downstream of the blockage, the circumferential variations for the blocked and unblocked cases were somewhat similar.

Three tests were made with a 24-channel edge blockage plate; the local heat transfer coefficients and flow patterns are shown in Figs. 42 to 44 . In contrast to the tests with the 14-channel blockage, there was 


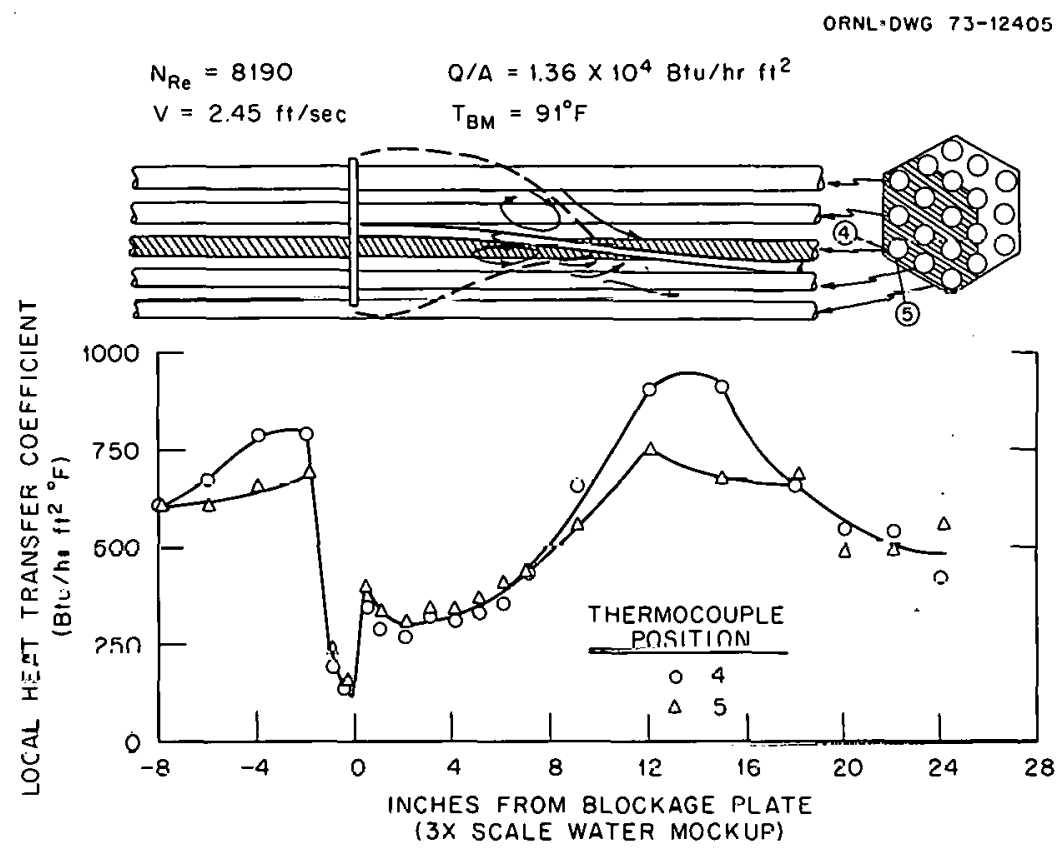

Fig. 42. Local heat transfer coefficient and flow pattern with a 24-channel edge blockage in THORS water mockup at Reynolds number of 8190 (Fontana et $\mathrm{al} .^{2}$ ).

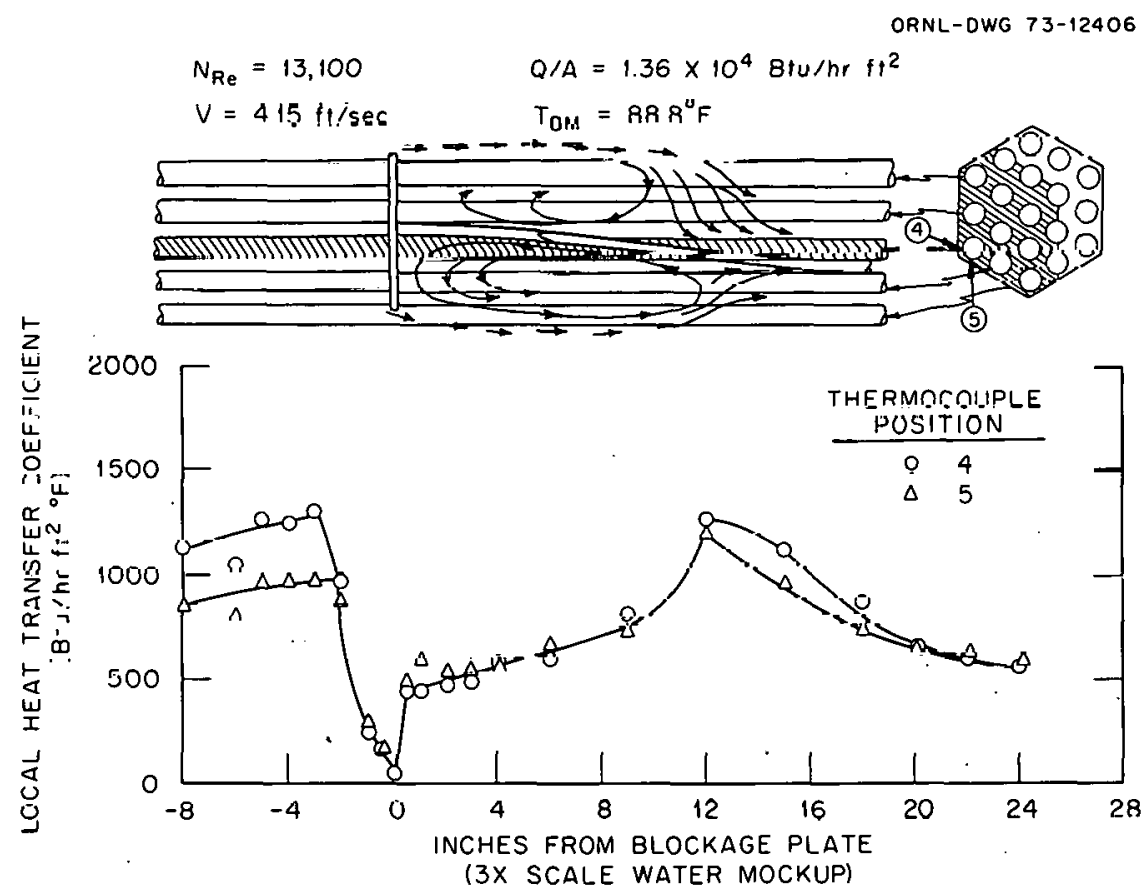

Fig. 43. Local heat transfer coefficient and flow pattern with a 24-channel edge blockage in THORS water mockup at Reynolds number of 13,100 (Fontana et $a 1 .{ }^{2}$ ). 


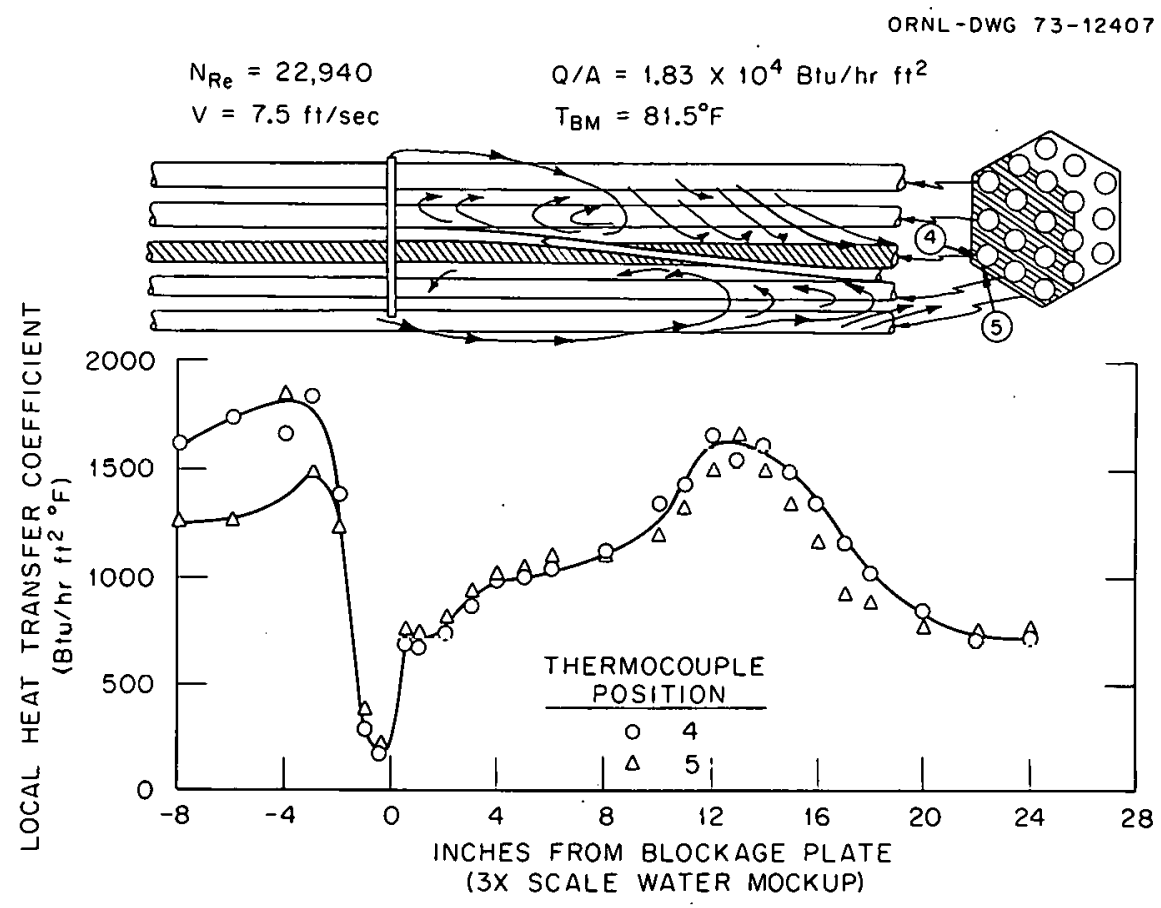

Fig. 44. Local heat transfer coefficient and flow pattern with a 24-channel edge blockage in THORS water mockup at Reynolds number of 22,940 (Fontana et $\mathrm{al} .^{2}$ ).

a pronounced peak in the heat transfer coefficient at approximately $305 \mathrm{~mm}$ (12 in.) downstream of the blockage plate. According to the results of the flow visualization studies, this region corresponded to locations along the heated pin where reattachnent was taking place.

Four tests were made with a b-channel edge blockage plate. Flgures 45 to 48 show axial variations of heat transfer coefficients and flow patterns in the vicinity of the blockage for these tests. Tests using a 5channel edge blockage plate (blocking approximately $13 \%$ of the flow area) demonstrated that the local heat coefficient was somewhat uniform along the heated pin except for the region within 25 or $50 \mathrm{~mm}$ (1 or $2 \mathrm{in.}$ ) upstream and downstream of the blockage. The maxima in the values of the local heat transfer coefficient were closely correlated with regions where flow visualization indicated a strong swirling motion around the heated pin. The greatest effect of this swirling motion. was observed at the lowest velocity, $1.4 \mathrm{~m} / \mathrm{s}$ ( $4.5 \mathrm{fps}$ ), where flow visualization (Fig. 45) indicated the 


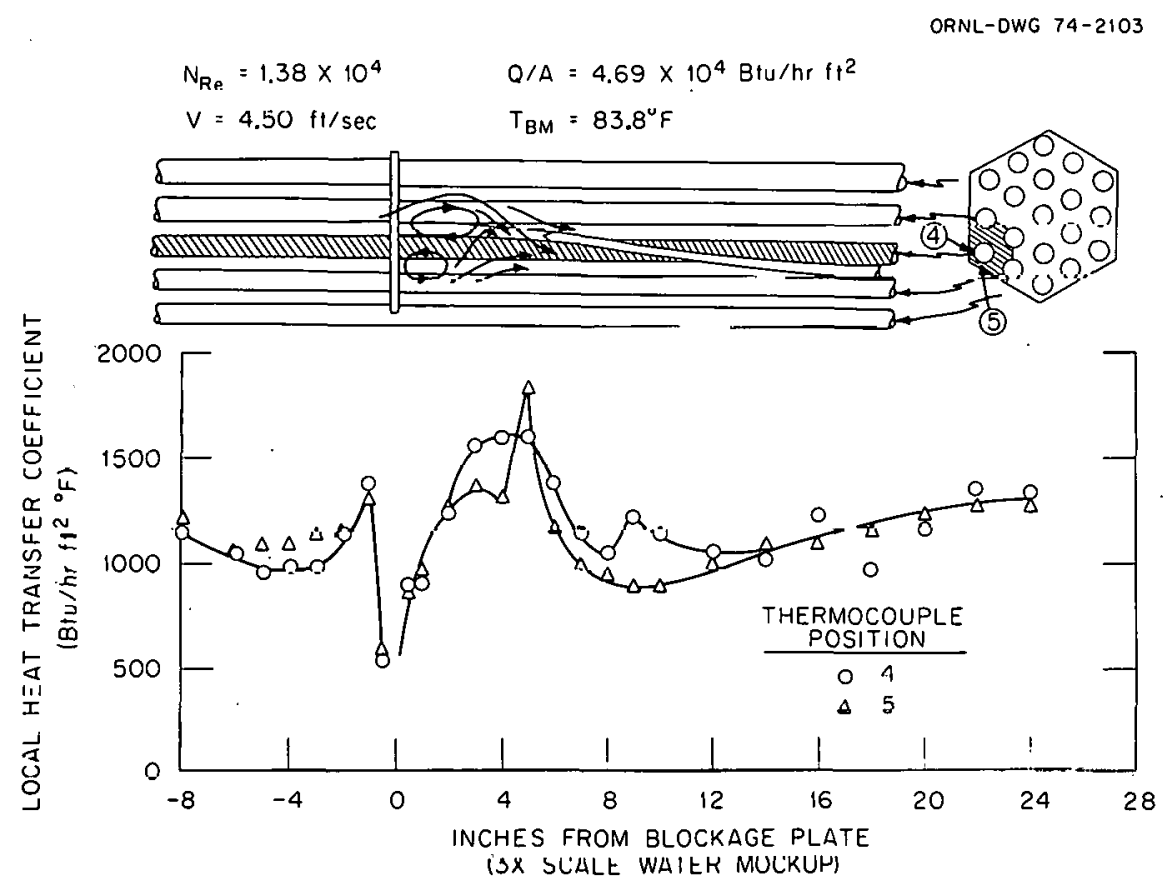

Fig. 45. Local heat transfer coefficient and flow pattern with a 5-channel edge blockage in THORS water mockup at Reynolds number of $1.38 \times 10^{4}$ (Fontana et al. ${ }^{2}$ ).

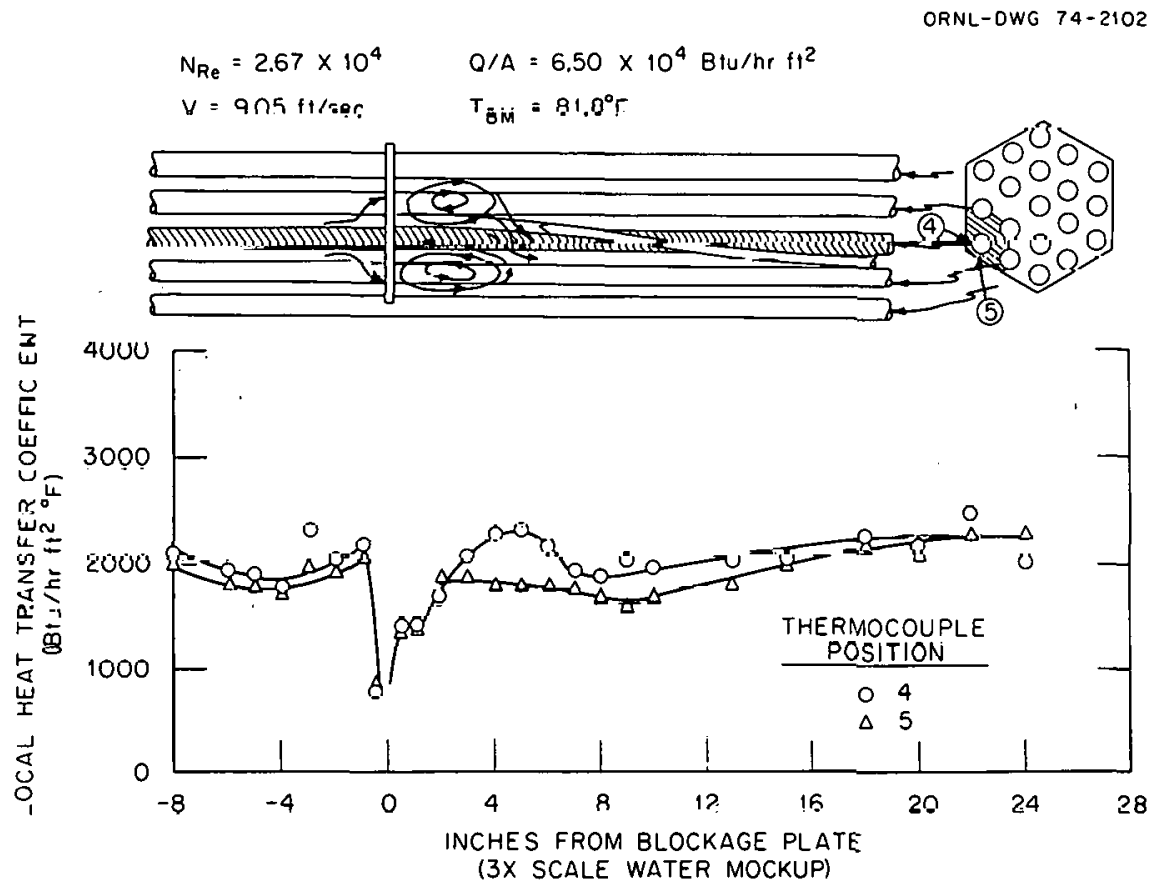

Fig. 46. Local heat transfer coefficient and flow pattern with a 5-channel edge blockage in THORS water mockup at Reynolds number of $2.67 \times 10^{4}$ (Fontana et $a 1 .^{2}$ ). 


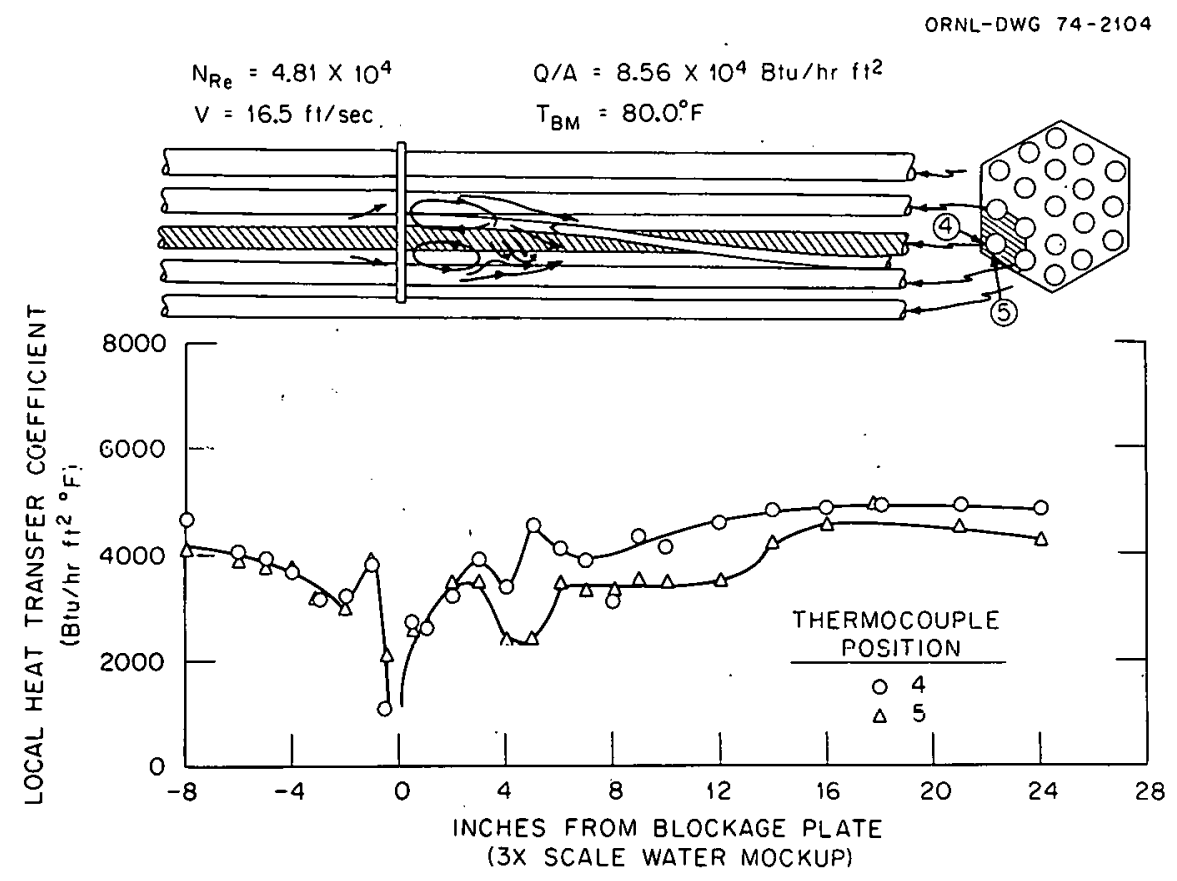

Fig. 47. Local heat transfer coefficient and flow pattern with a 5-channel edge blockage in THORS water mockup at Reynolds number of $4.81 \times 10^{4}$ (Fontana et $a 1 .{ }^{2}$ ).

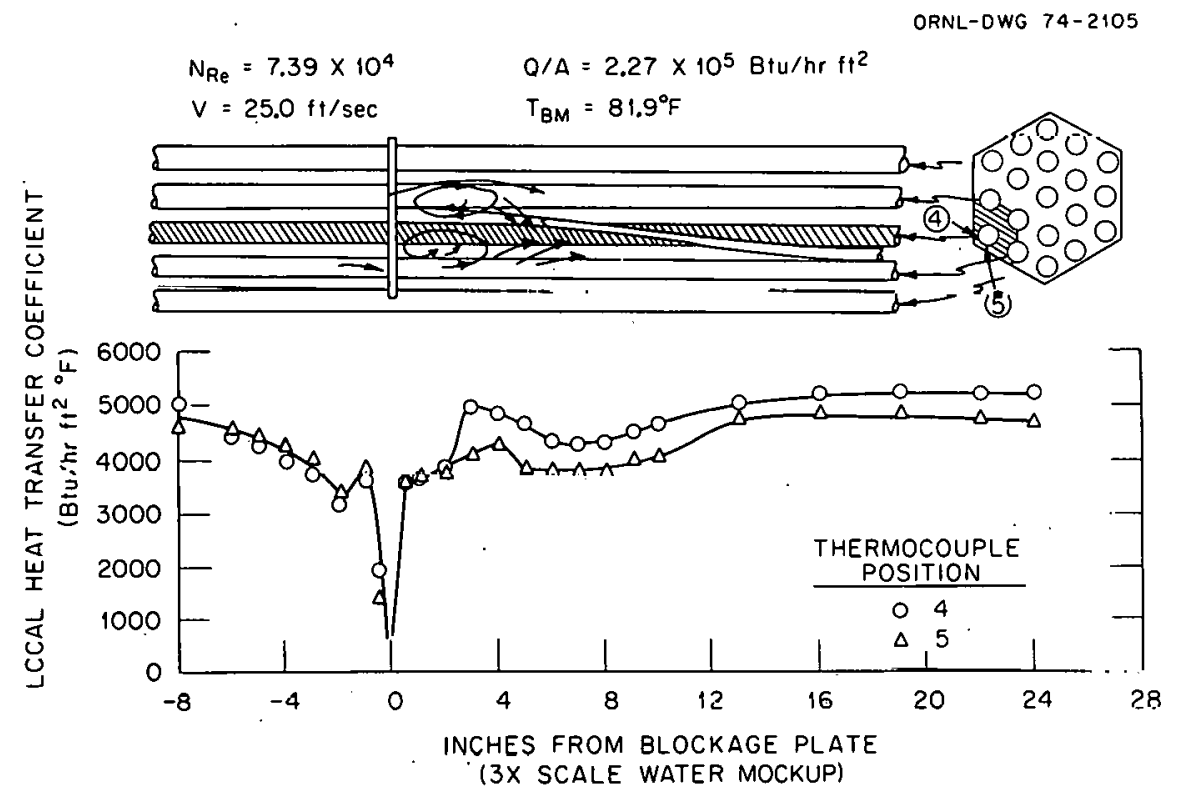

Fig. 48. Local heat transfer coefficient and flow pattern with a 5-channel edge blockage in THORS water mockup at Reynolds number of $7.39 \times 10^{4}$ (Fontana et a1. ${ }^{2}$ ). 
greatest disparity in the recirculating flow region in the channels adjacent to the duct wall.

Pressure drop was measured for the bundle with no blockage and with different central and edge blockage plates. As can be seen from Figs. 49 and 50, pressure drop results from use of edge and central blockages, although greater than those without, were parallel to those for the bundle with no blockage. The edge blockage plate, which blocked one-third of the flow area, caused an approximately $60 \%$ increase in pressure drop, while the plate that blocked $60 \%$ of the area caused an approximately $230 \%$ increase. Figure 51 shows the ratio of the total pressure drop in blocked buindies to that in the unblocked bundle in the THORS water mockup.

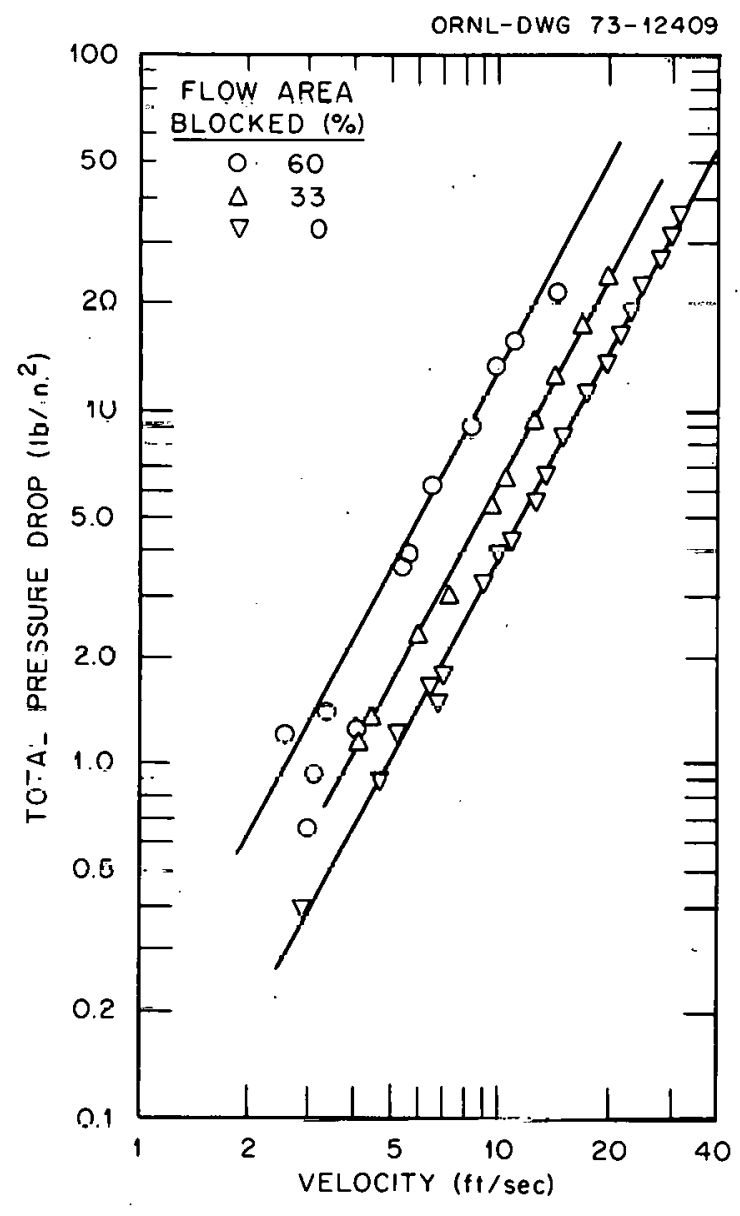

Fig. 49. Pressure drop with edge blockages compared to that for the unblocked reference bundle in THORS water mockup (Fontana et al. ${ }^{2}$ ). 


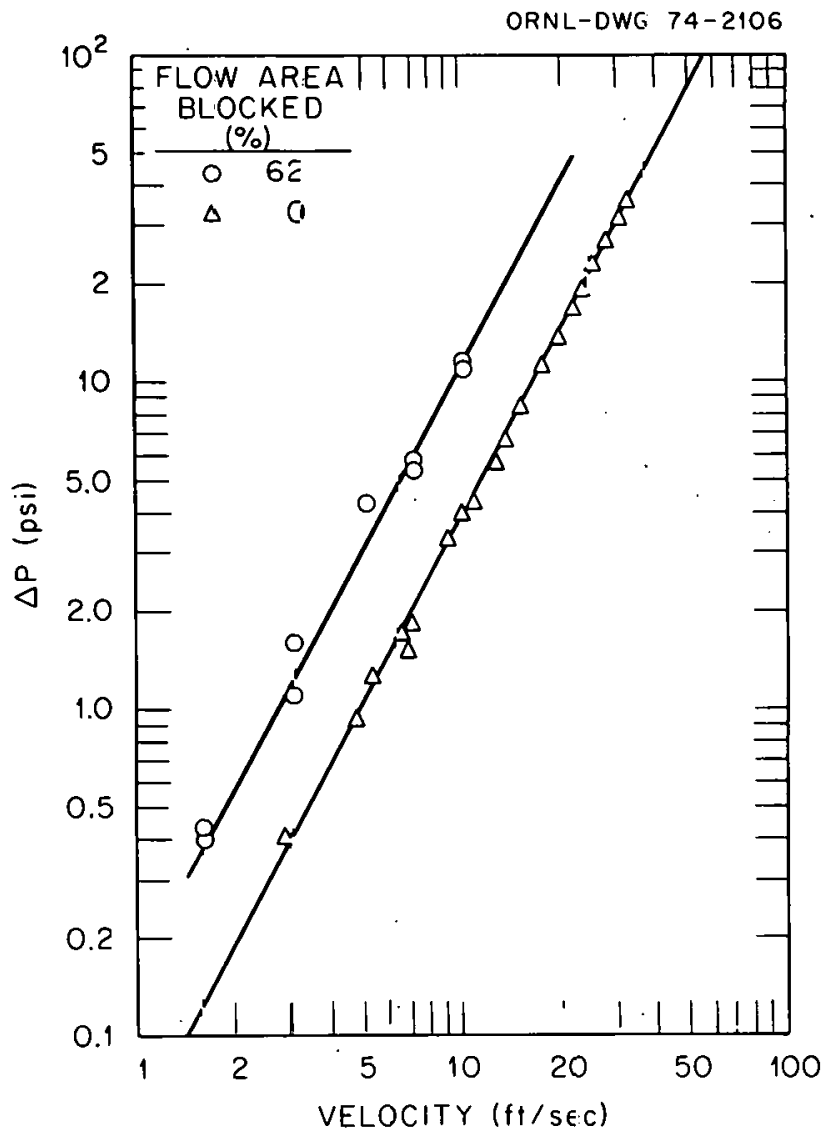

Fig. 50. Pressure drop as a function of velocity for $a$ 24-channel central blockage compared to that for the unblocked bundle in THORS water mockup (Fon tana et $\mathrm{a} 1 \mathrm{.}^{2}$ ).

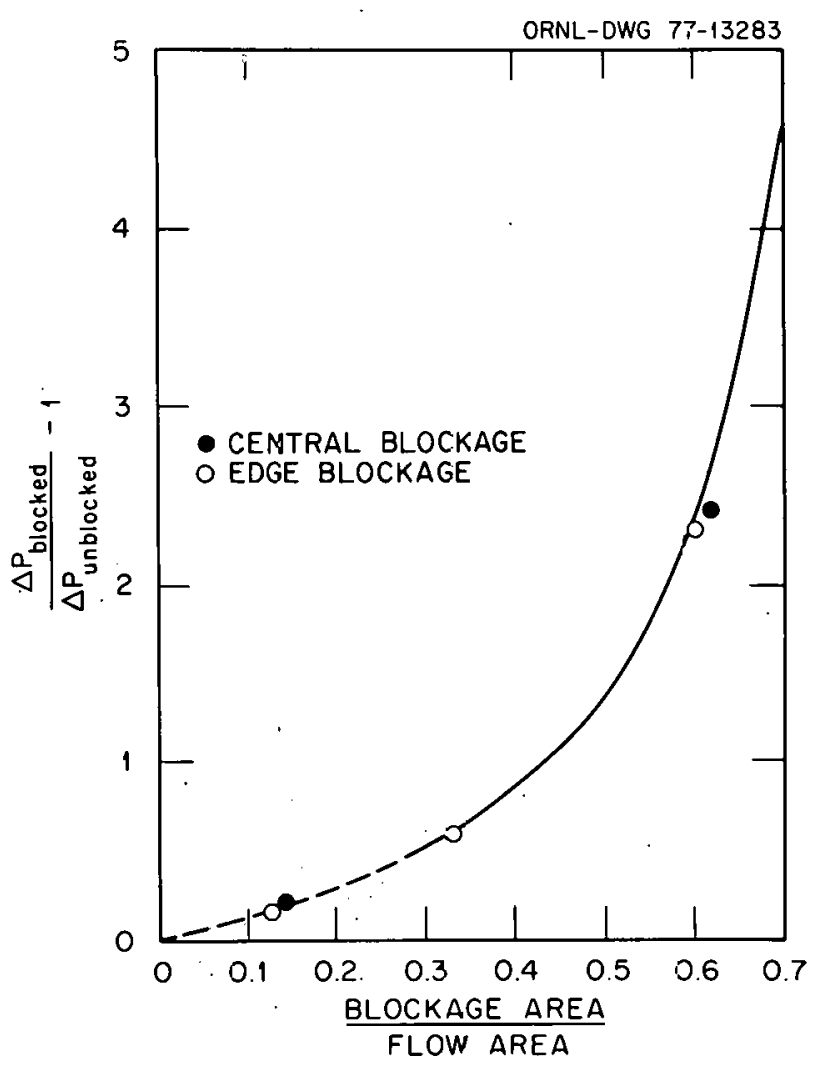

Fig. 51. Blockage effect on pressure drop from THORS water mockup (Fontana et $a 1 .{ }^{2}$ ). 
In order to determine the rate of mass exchange between the wake and the mass flow, tests were conducted in which salt solution was injected into the system. Conductivity probes were located at positions along the channel walls for edge blockages (Fig. 52) and at distances of 25, 127, 203, and $305 \mathrm{~mm}(1,5,8$, and $12 \mathrm{ill}$ ) from the plate along the central pin for central blockage. When edge blockage plates were used, the probes were two $0.762-\mathrm{mm}$-diam (0.030-in.) nickel wires spaced $3.18 \mathrm{~mm}(0.125 \mathrm{in.})$ apart and projecting $\sim 1.59 \mathrm{~mm}(0.0625 \mathrm{in}$.) into the recirculating stream from the walls. When central blockage plates were used the probes were two 0.508-mni-diam (0.020-in.) Chromel wC wires spaced $33.18 \mathrm{~lm}$ (0.125 in.), apart,

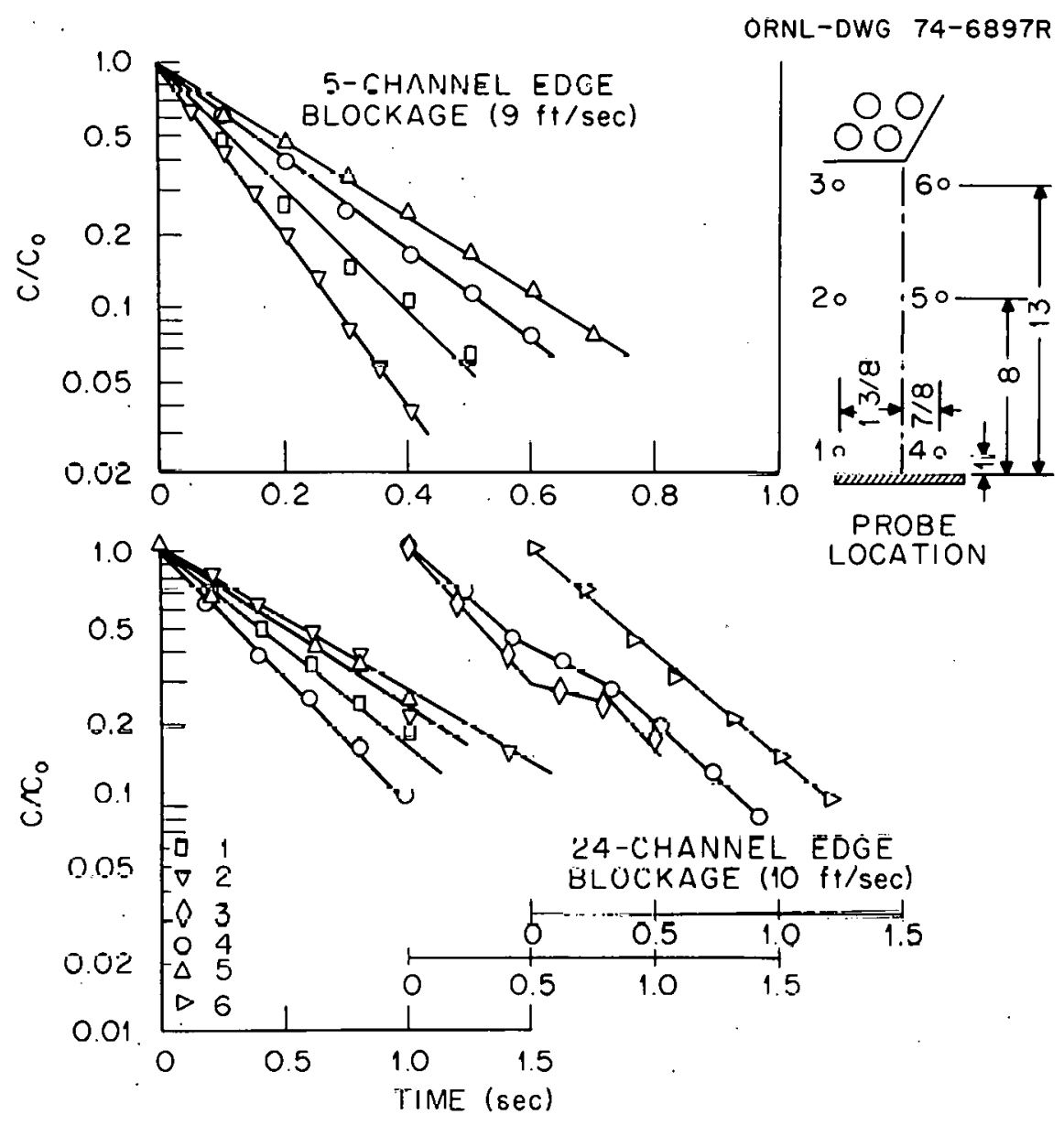

Fig. 52. Salt solution conductivity decay behind edge blockages as a function of time for different probe locations in THORS water mockup (Fontana et al. ${ }^{2}$ ). 
embedded in the central pin, and projecting $\sim 3.18 \mathrm{~mm}$ into the circulating stream. Output from the probes was recorded simultaneously.

The procedure followed in these tests was to adjust the salt concentration so that at least one probe in the set was producing a reading of "full scale." At this time, salt injection was stopped and the salt concentration in the recirculation zone allowed to decay. Over 100 tests were made at different velocities and with different blockage plates. Duplicate tests agreed to within $\pm 30 \%$, and, of over 100 tests, more than $92 \%$ yielded a good exponential decay. The most common departure from an exponential decay was a break in the decay curve for probes 3 and 4 as illustrated in the lower portion of Fig. 52. However, the decay curve before and after the break has substantially the same slope.

Figure 52 shows salt concentration decay as a function of time for different probe locations in the wake and for 5- and 24-channel edge blockages. The observed half-lives ranged $\pm 66 \%$ around the mean for the 5 -channel blockage and $\pm 40 \%$ for the 24 -channel blockage.

Conductivity (in arbitrary units) as a function of time is shown in Fig. 53 for 24-channel edge and central blockages with velocity as a parameter. The conductivity decayed exponentially with time for both blockages, and, as expected, the decay was much more rapid at high velocity than at low: Decay appeared to be more rapid with the central blockage than with the edge hlockage.

Decay of half-life is shown as a function of velocity for three different edge blockages and for the 24-channel central blockage in Figs. 54 and 55, respectively.

Blockages used in this study were arbitrarily defined by the lengths $\ell_{\alpha}$ and $\ell_{\omega}$ illustrated in Fig. 56; these two dimensions represent the largest blockage dimensions at right angles to each other. A characteristic length for each blockage was then calculated by taking the geometric mean of the two dimensions $\sqrt{\ell_{\alpha}{ }^{\prime}}$. Values for each blockage are given in Table 5. Values of the half-life for salt decay behind different blockages are given in Tables 6 to 9 , where $V$ is the mean coolant velocity.

Figure 57 shows the dimensionless mean residence time, $\tau V / \sqrt{\ell} \alpha^{l} \omega$, for fluid behind blockages in pin bundles as a function of Reynolds number 
CRNL-D'NJ 74-2108

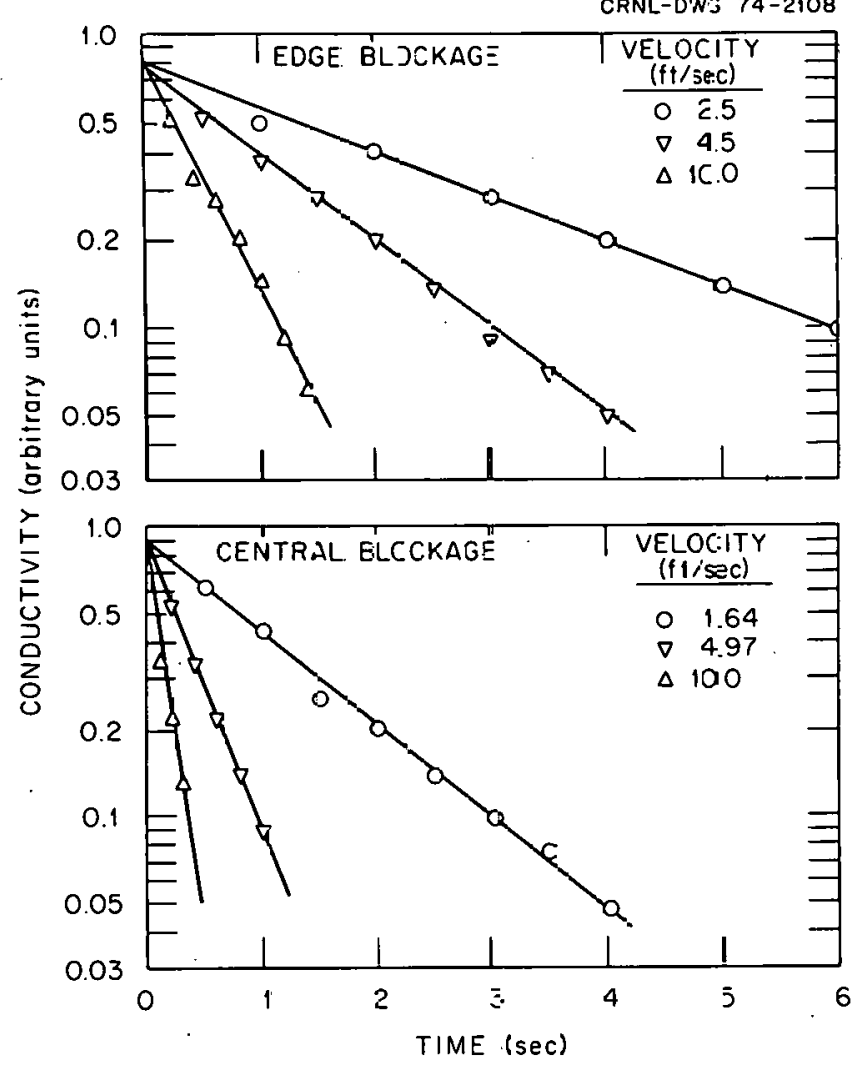

Fig. 53. Salt solution conductivity decay in the wake behind 24-chanrel blcckages in TFORS water mockup (Fontina et a1. ${ }^{2}$.

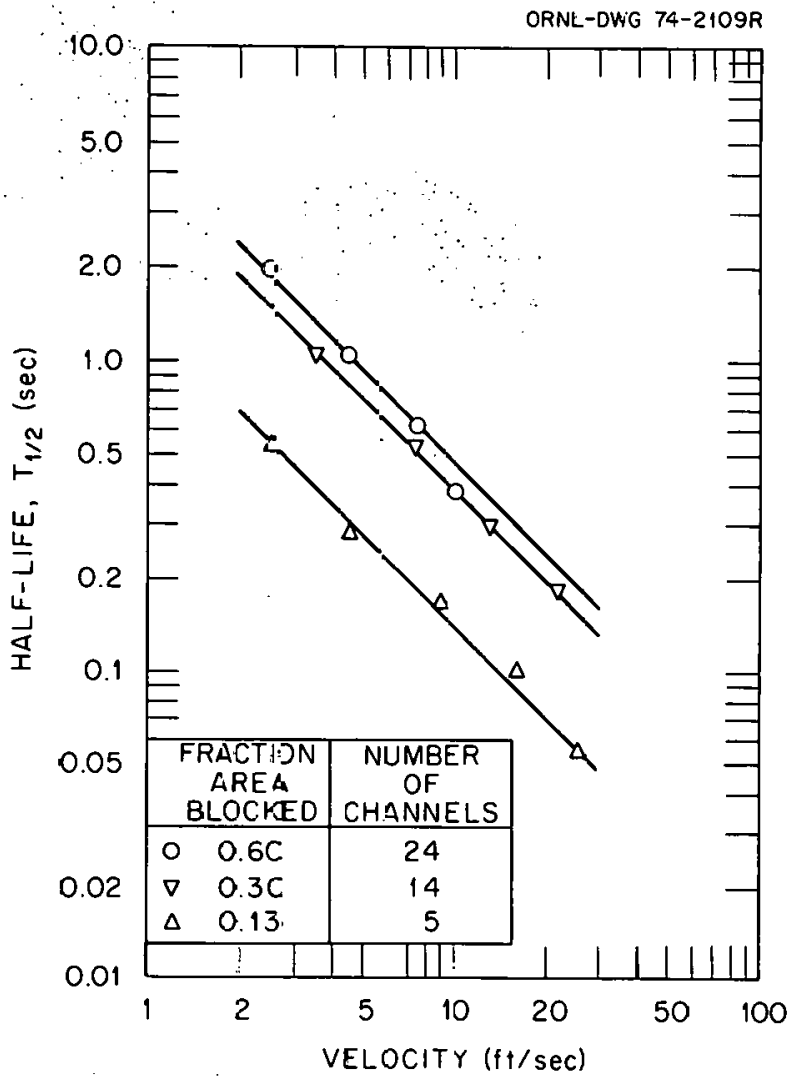

Fig. 54. Effect of velocity on salt concentration decay in the wake behind edge blockages in THORS water mockep (Fontana et $a 1 .{ }^{2}$ ). 


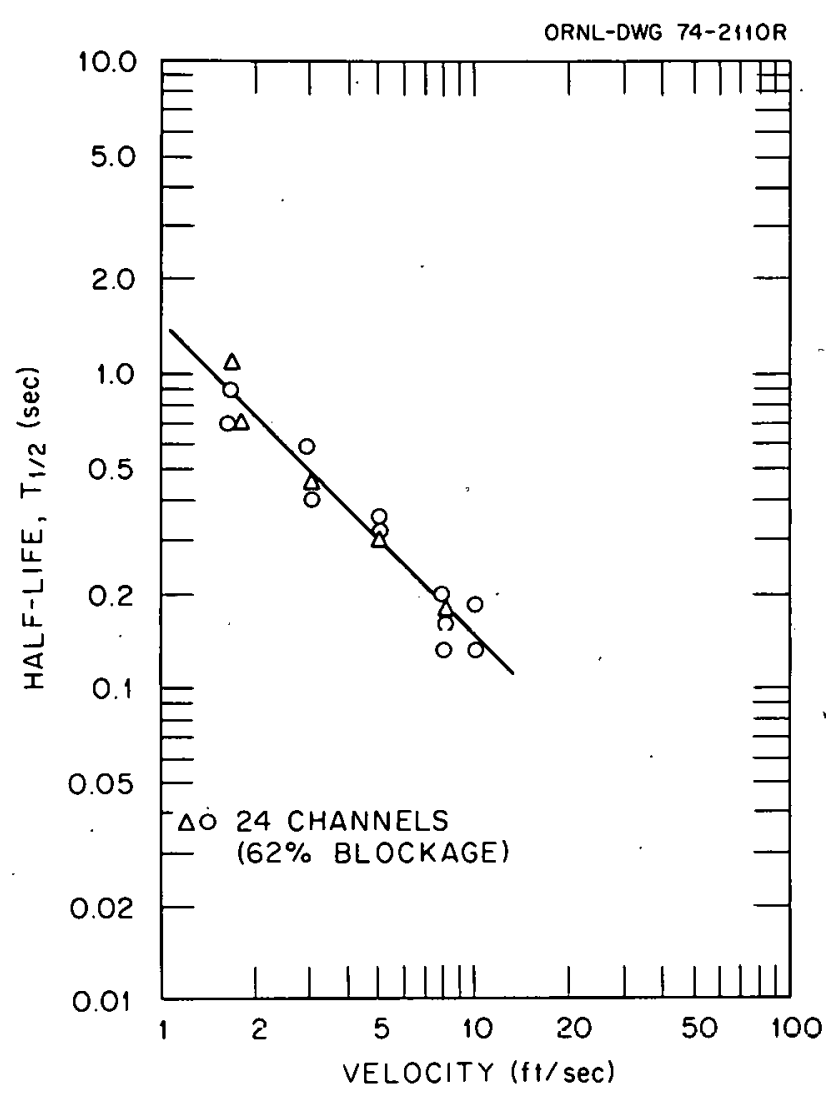

Fig. 55. Effect of velocity on salt concentration decay in the wake of a 24-channel central blockage in THORS water mockup (Fontana et $a 1 .{ }^{2}$ ).

Table 5. Characteristic lengths for flow blockages ${ }^{2}$

\begin{tabular}{lcccccc}
\hline \multirow{2}{*}{$\begin{array}{c}\text { Blockage } \\
\text { type }\end{array}$} & $\begin{array}{c}\text { Number of } \\
\text { channels } \\
\text { blocked }\end{array}$ & $\begin{array}{c}\text { Fraction } \\
\text { of area } \\
\text { blocked }\end{array}$ & $\ell_{\alpha}$ & $\ell_{\omega}$ & $\sqrt{\ell^{\ell} \omega}$ \\
\hline Edge & 5 & 0.13 & $38.1(1.50)$ & $25.4(1.00)$ & $31.0(1.22)$ \\
Edge & 14 & 0.37 & $95.3(3.75)$ & $42.9(1.69)$ & $64.0(2.52)$ \\
Edge & 24 & 0.60 & $95.3(3.75)$ & $69.9(2.75)$ & $81.5(3.21)$ \\
Central & 6 & 0.13 & $36.6(1.44)$ & $39.4(1.55)$ & $37.8(1.49)$ \\
Central & 24 & 0.62 & $79.5(3.13)$ & $79.5(3.13)$ & $79.5(3.13)$ \\
\hline
\end{tabular}


EDGE BLOCKAGE PLATES

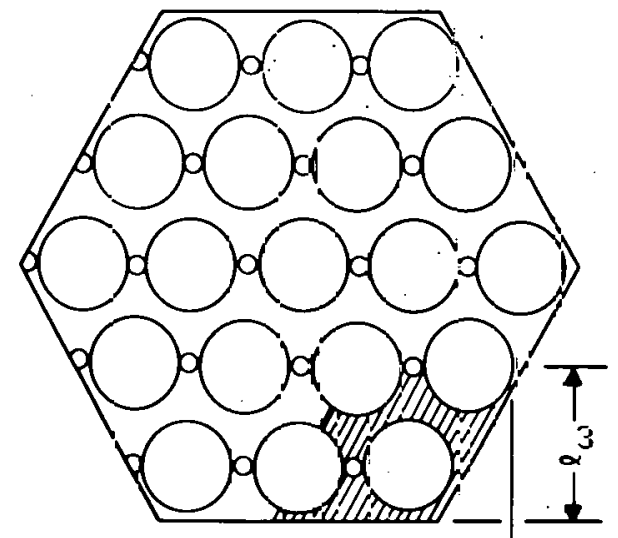

(a) 5 CHANNELS

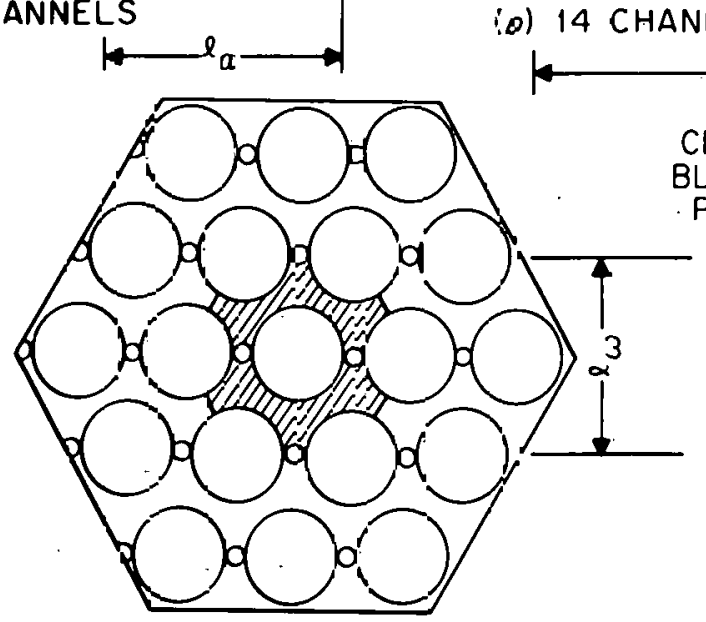

(d) 6 CHANNELS

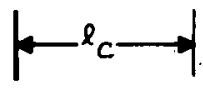

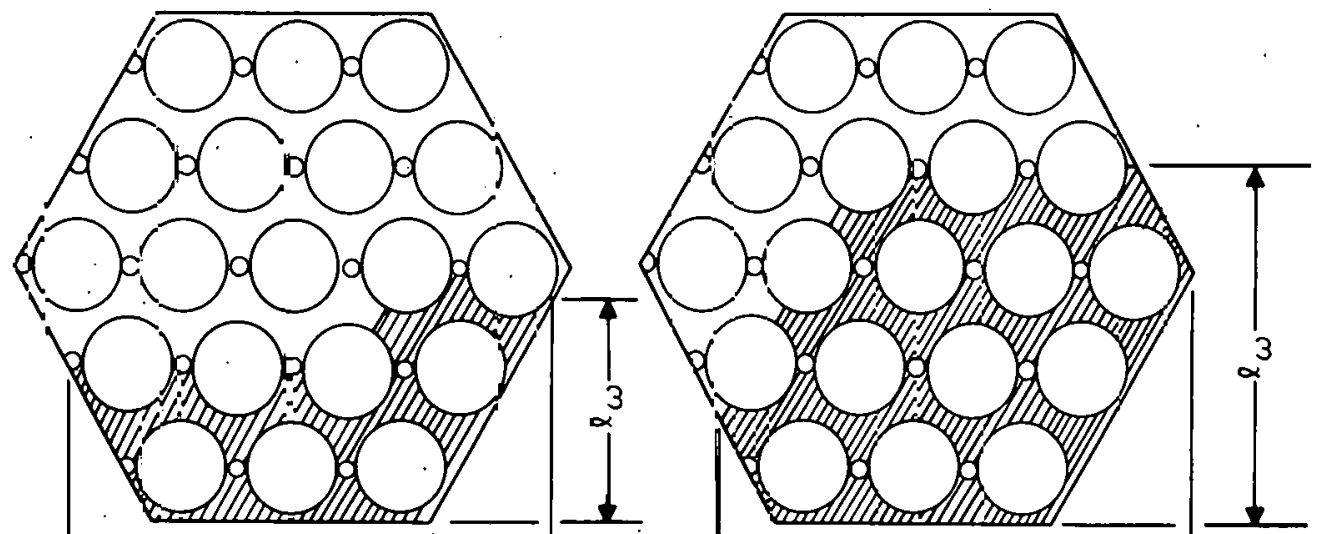

(c) 24 CHANNELS

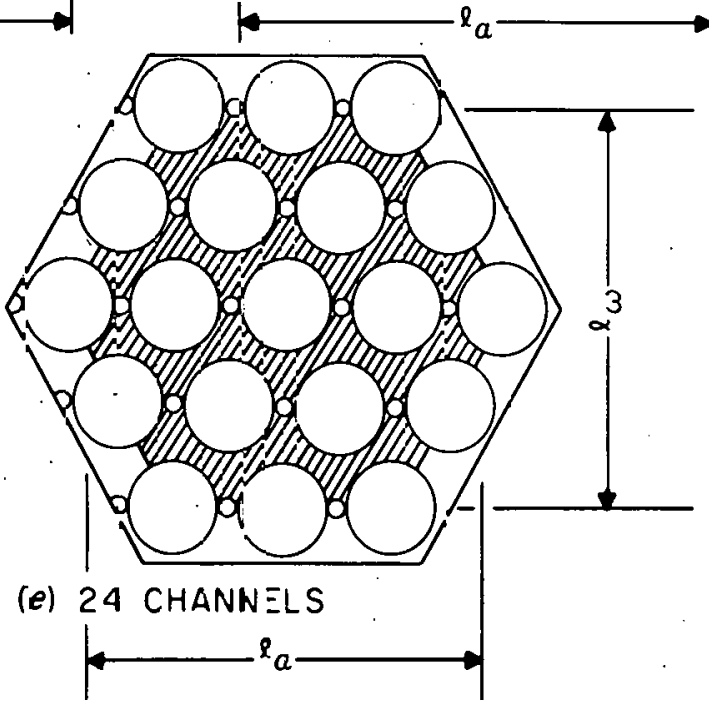

Fig. 55. Blockage plates showing definition of characteristic lengths used ir: THORS water mockup studies (Fontana et al. ${ }^{2}$ ). 
Table 6. Half-life for decay of salt solution behind a 24-channel edge blockage ${ }^{2}$

\begin{tabular}{|c|c|c|c|c|c|c|c|}
\hline \multirow{2}{*}{$\begin{array}{l}\text { Velocity } \\
{[\mathrm{m} / \mathrm{s} \text { (fps)] }}\end{array}$} & \multicolumn{6}{|c|}{$\mathrm{T}_{1 / 2}$ (sec) at probe location ${ }^{a}$} & \multirow{2}{*}{$\frac{\sqrt{\ell \alpha_{\omega}} v}{v}$} \\
\hline & 1 & 2 & 3 & 4 & 5 & 6 & \\
\hline $0.76(2.5)$ & 1.66 & 2.23 & 1.53 & 2.05 & 2.23 & 1.33 & $7.24 \times 10^{4}$ \\
\hline $1.37(4.5)$ & 0.93 & 1.60 & 1.10 & 1.06 & 1.05 & 0.92 & $1.30 \times 10^{5}$ \\
\hline $2.29(7.5)$ & 0.53 & 0.62 & $\mathrm{NA}^{b}$ & 0.62 & 0.75 & $\mathrm{NA}^{b}$ & $2.17 \times 10^{5}$ \\
\hline $3.05(10.0)$ & 0.40 & 0.49 & 0.27 & 0.30 & 0.46 & 0.38 & $2.90^{\circ} \times 10^{5}$ \\
\hline
\end{tabular}

Table 7. Half-life for decay of salt solution behind a 14-channel edge blockage ${ }^{2}$

\begin{tabular}{|c|c|c|c|c|c|}
\hline \multirow{2}{*}{$\begin{array}{l}\text { Velocity } \\
{[\mathrm{m} / \mathrm{s} \text { (fps)] }}\end{array}$} & \multicolumn{4}{|c|}{$\mathrm{T}_{1 / 2}(\mathrm{sec})$ at probe location $^{a}$} & \multirow{2}{*}{$\frac{\sqrt{\alpha_{\alpha}^{\ell} \omega} v}{v}$} \\
\hline & 1 & 2 & 4 & 5 & \\
\hline $1.07(3.5)$ & 1.34 & 1.02 & 1.05 & $\mathrm{NA}^{b}$ & $6.66 \times 10^{4}$ \\
\hline $1.46(4.8)$ & 1.00 & 0.77 & $\mathrm{NA}^{h}$ & $\mathrm{NA}^{b}$ & $9.13 \times 10^{4}$ \\
\hline $2.29(7.5)$ & 0.77 & 0.50 & 0.55 & $\mathrm{NA}^{b}$ & $1.43 \times 10^{5}$ \\
\hline $3.05(10.0)$ & 0.33 & 0.38 & $\mathrm{NA}^{b}$ & $\mathrm{NA}^{b}$ & $1.90 \times 10^{5}$ \\
\hline $3.96(13.0)$ & 0.40 & 0.30 & 0.30 & $\mathrm{NA}^{b}$ & $2.47 \times 10^{5}$ \\
\hline $6.64(21.8)$ & 0.22 & 0.16 & 0.19 & 0.22 & $4.15 \times 10^{5}$ \\
\hline
\end{tabular}

asee Fig. 52 for probe location.

$b_{\mathrm{NA}}=$ not available.

Table 8. Half-life for decay of salt solution behind a 5-channel edge blockage ${ }^{2}$

\begin{tabular}{|c|c|c|c|c|c|c|}
\hline \multirow{2}{*}{$\begin{array}{l}\text { Velocity } \\
{[\mathrm{m} / \mathrm{s} \text { (fps)] }}\end{array}$} & \multicolumn{4}{|c|}{$\mathrm{T}_{1 / 2}$ (sec) at probe location ${ }^{a}$} & \multirow{2}{*}{\multicolumn{2}{|c|}{$\frac{\sqrt{\ell \alpha^{\ell} \omega} v}{v}$}} \\
\hline & 1 & 2 & 4 & 5 & & \\
\hline $0.76(2.5)$ & 0.37 & 0.35 & 0.53 & 0.43 & $2.74 \times$ & $10^{4}$ \\
\hline $1.37(4.5)$ & 0.25 & $0: 2.2$ & 0.28 & 0.30 & $4.95 \times$ & $10^{4}$ \\
\hline $2.74(9.0)$ & 0.12 & 0.090 & 0.17 & 0.21 & $9.88 \times$ & $10^{4}$ \\
\hline $4.88(16.0)$ & 0.085 & 0.080 & 0.10 & 0.10 & $1: 76 \times$ & $10^{5}$ \\
\hline $7.62(25.0)$ & 0.043 & 0.052 & 0.055 & 0.08 & $2.75 \times$ & $10^{5}$ \\
\hline
\end{tabular}


Table 9. Half-life for decay of salt solution behind a 24-channel central blockage ${ }^{2}$

\begin{tabular}{|c|c|c|c|c|c|}
\hline \multirow{2}{*}{$\begin{array}{l}\text { Velocity } \\
{[\mathrm{m} / \mathrm{s} \text { (f.ps)] }}\end{array}$} & \multicolumn{4}{|c|}{$\mathrm{T}_{1 / 2}$ (sec) at probe location ${ }^{a}$} & \multirow{2}{*}{$\frac{\sqrt{\ell \alpha^{\ell}} v}{v}$} \\
\hline & 1 & 2 & 3 & 4 & \\
\hline $0.50(1.64)$ & 0.80 & 0.90 & 0.73 & 1.17 & $4.62 \times 10^{4}$ \\
\hline $0.90 \quad(2.96)$ & 0.50 & 0.45 & 0.43 & $\mathrm{NA}^{b}$ & $8.36 \times 10^{4}$ \\
\hline $1.51(4.97)$ & 0.34 & 0.31 & $\mathrm{NA}^{b}$ & 0.18 & $1.40 \times 10^{5}$ \\
\hline $2.10(6.90)$ & 0.18 & 0.18 & $\mathrm{NA}^{b}$ & $\mathrm{NA}^{b}$ & $1.95 \times 10^{5}$ \\
\hline 3.05 (IU.U) & 0.16 & $\mathrm{NA}$ & $\mathrm{NA}^{b}$ & $\mathrm{NA}^{b}$ & $2.83 \times 10^{5}$ \\
\hline
\end{tabular}

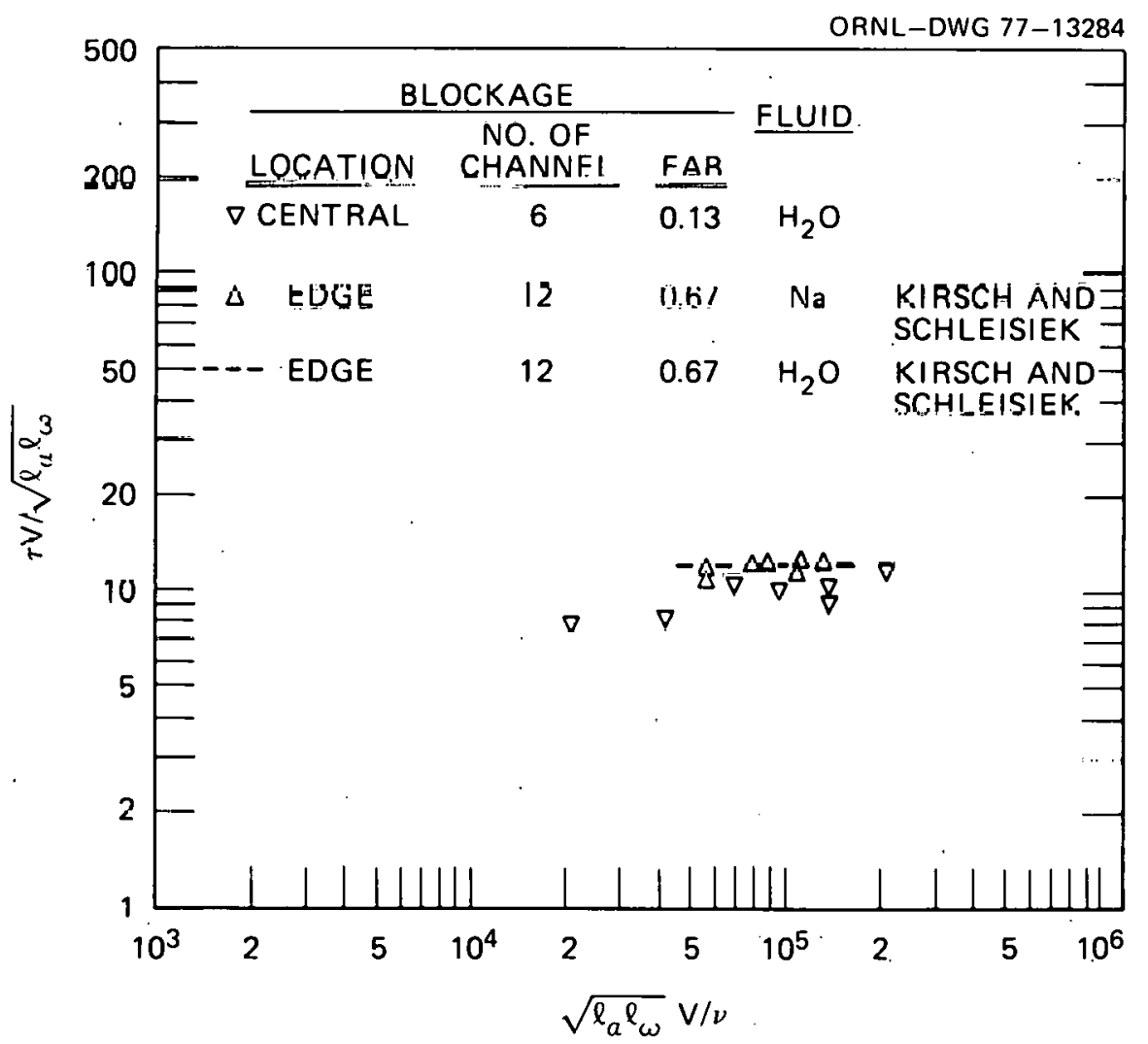

Fig. 57. Dimensionless fluid residence time behind blockages in pin bundles $\left(\mathrm{FAB}=\right.$ fraction of the flow area blocked) (Fontana et $\mathrm{al} .^{2}$ ). 
for the results of the present study as well as for those of Kirsch and Schleisiek. ${ }^{5}$ In Fig. 57, $\mathrm{V}$ represents mean coolant velocity and $\tau$ is the mean coolant residence time in the wake, which is defined in Eq. (8) of Section 2.3. Several items are notable about these results: (1) The characteristic length $\sqrt{l_{\alpha} l_{\omega}}$ seems to be a reasonable definition for use in correlating present results, and (2) Kirsch and Schleisiek's results for sodium and water are substantially indistinguishable. ${ }^{5}$

The axial length of the wake $L$ determined by introducing air bubbles into the system with and without pins is shown in Fig. 58. Within the scatter of the results, the pins appeared to have little effect on the wake

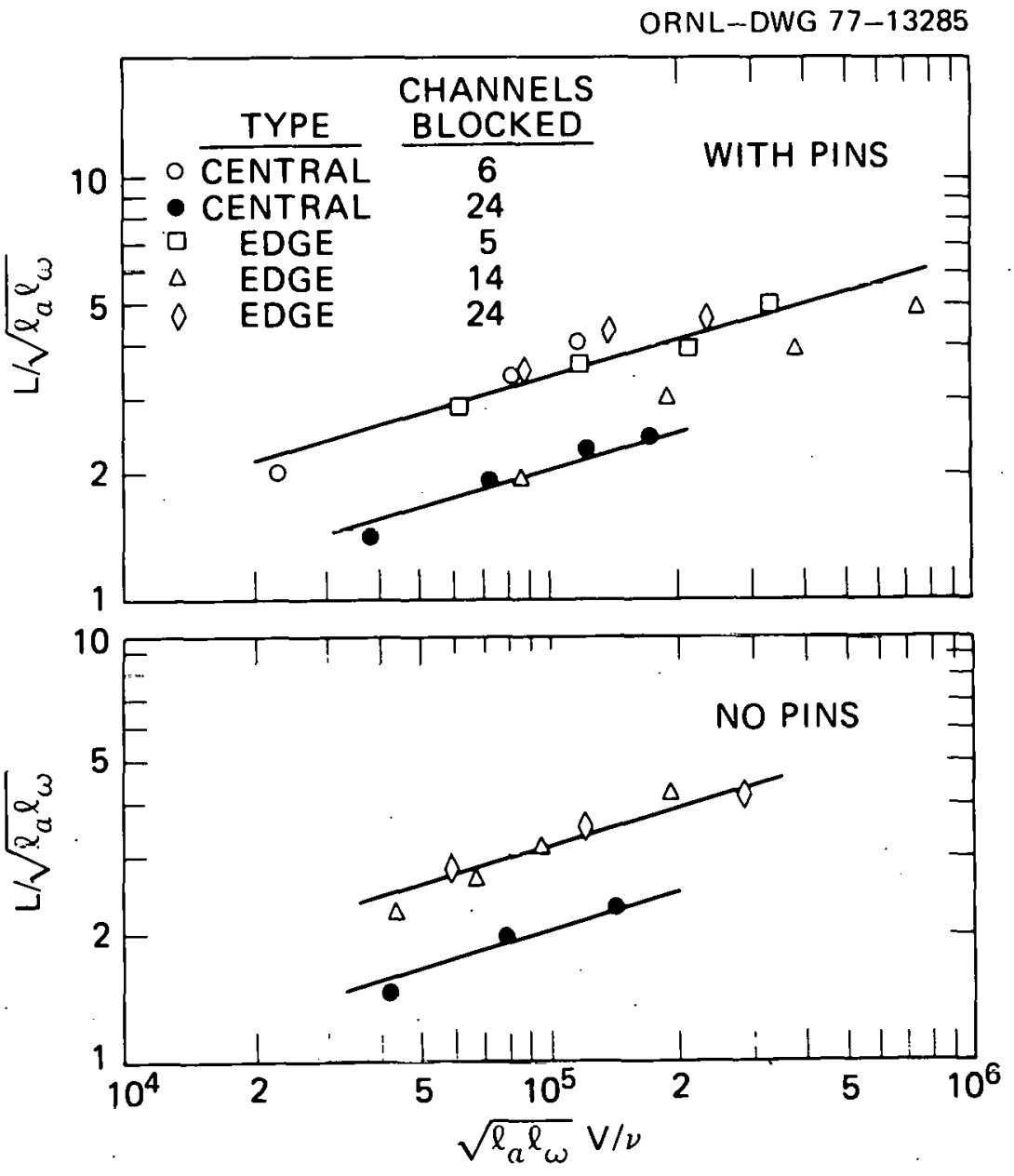

Fig. 58. Dimensionless wake length obtained in THORS water mockup (Fontana et $a l .^{2}$ ). 
length when it was made dimensionless with the characteristic length $\sqrt{\ell_{\alpha} \omega}$. For both edge and central blockages, there was a slight increase in wake length with Reynolds number.

Sheppard $^{4}$ measured the axial pressure distribution and residence time for water flow in a hexagonal duct (no pins) with a permeable blockage. He concluded that when jet velocity is increased through the drilled hole in the blockage plate, the residence time in the wake is reduced.

\subsection{Blockages in Annul1}

\subsubsection{Therma1-hydraul1c studies}

Kirsch and Schleisiek ${ }^{5}$ measured the temperature distribution in a sodium-cooled annulus with a blockage. Temperature measurements were also obtained in the same test section using water as the coolant.

Test section. Figure 59 shows their test section of an annulus with a blockage. An induction-heated tube having an inner diameter of $12 \mathrm{~mm}(0.47$ in.) contained a displacement plug having an outer diamter of $8.2 \mathrm{~mm}(0.32$ in.) with a special profile forming 6 channels whose dimensions were similar to those of a fuel assembly. Four of the channels were completely blocked by a plate. This blockage roughly corresponds to the blockage of 12 channels in a fuel assembly if the sizes are compared on the basis of the distance between the center of the blockage and its outer edge.

The temperatures were measured at various axial positions and channels. Thermocouples of $0.5 \mathrm{~mm}$ (0.02 in.) diameter were inserted through the outer tube into the centers of the channels and fixed with high-temperature solder. Additional 1-mm-diam thermocouples were used to measure the inlet and outlet temperatures of the test section. The sodium velocity was measured by means of a permanent magnetic flowmeter.

The heated length of the test section was $500 \mathrm{~mm}$ (19.7 in.) and the blockage was located in approximately the center of the heated section, making inlet effects minimal. The high-frequency generator operated at approximately $600 \mathrm{kHz}$. At this frequency, the depth of penetration of the current into stainless steel was about $0.5 \mathrm{~mm}(0.02 \mathrm{in.})$; and, consequently, the power generated directly in the sodium was 1 ess than $1 \%$ and could be ignored. 
Results and discussion. Figure 60 shows a typical example of the axial and azimuthal temperature distributions measured in sodium in the region of the blockage. The test conditions were as follows: sodium velocity in the undisturbed region $U$ was $3.05 \mathrm{~m} / \mathrm{s}$ (10 fps) and heat flux $\phi$ was $173 \mathrm{~W} / \mathrm{cm}^{2}$. $\left(5.48 \times 10^{5} \mathrm{Btu} / \mathrm{hr}-\mathrm{ft}^{2}\right)$. In the center of the wake the temperature increases axially in the opposite direction to that of the main flow. The maximum temperature is encountered immediately behind the blockage, where the azimuthal temperature distribution shows a rather flat shape. For comparison, second- and third-order parabolas used as temperature distributions for theoretical studies on local boiling in bundle geometries are included in the drawing. Further downstream of the blockage, there was a slight decrease of temperature in the center of the wake relative to the boundary areas.

This temperature curve indicates that there was a backward flow in the wake, which was confirmed by observing the flow pattern of water in a glass model to which a small amount of air had been mixed. Downstream of the blockage, two vortices, rotating in opposite directions, were formed. The paths of the air bubbles show a relatively slow backward flow in the center of the wake, while there is an intensive exchange of mass on the side facing
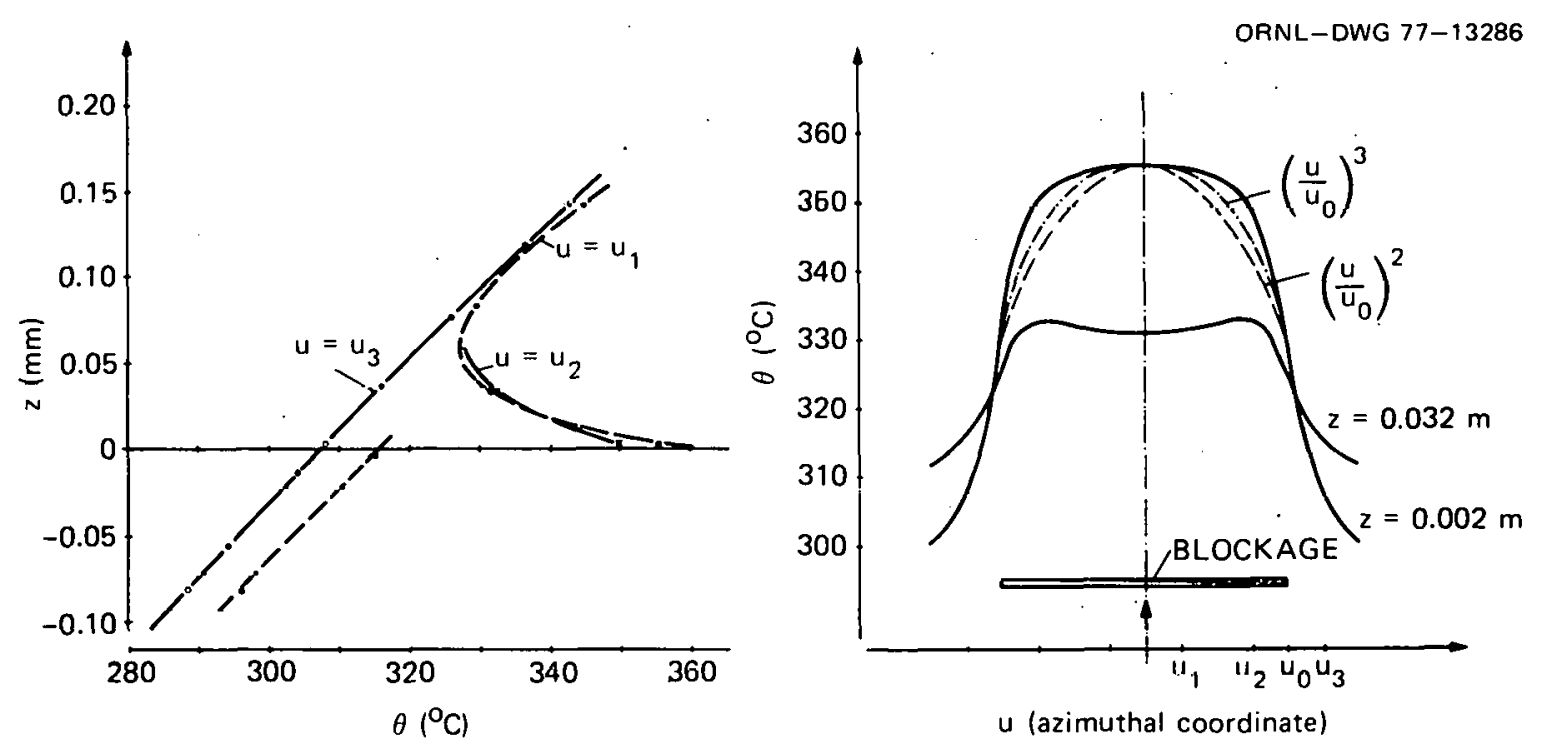

Fig. 60. Axial and azimuthal temperature distribution behind the blockage in the annulus (Kirsch and Schleisiek ${ }^{5}$ ). 
the main coolant. As a result, the energy transport was so good that an increase in wake temperature of only $48^{\circ} \mathrm{C}$ relative to the mean conlant temperature was measured.

The wake length $\mathrm{L}$ can be determined from the axial temperature distribution. The downstream end of the zone is defined as that point of the axial temperature curve where $d \theta / d z=0$ ( $\theta$ represents temperature and $z$ is the axial coordinate). In the example shown, the length is $68 \mathrm{~mm}$ (2.7 in.). Figure 61 shows the wavelength vs sodium velocity $U$. Although the measured values scatter by $\pm 10 \%$, a slight increase in length for a given increase in sodium velocity is apparent.

As shown by the experimental results, the geometry of the test section does not 1mpede the formation of a recirrulation zone. Hence, it may be assumed that a local blockage in an actual pin bundle will also cause recirculating flow behind the blockage.

The mass exchange per unit time between the wake behind the blockage and the surrounding free stream can be evaluated by means of temperature (or salt concentration) measurements. To correlate their data, Kirsch and Schleisiek ${ }^{5}$ performed the following derivations. Let the total surface of

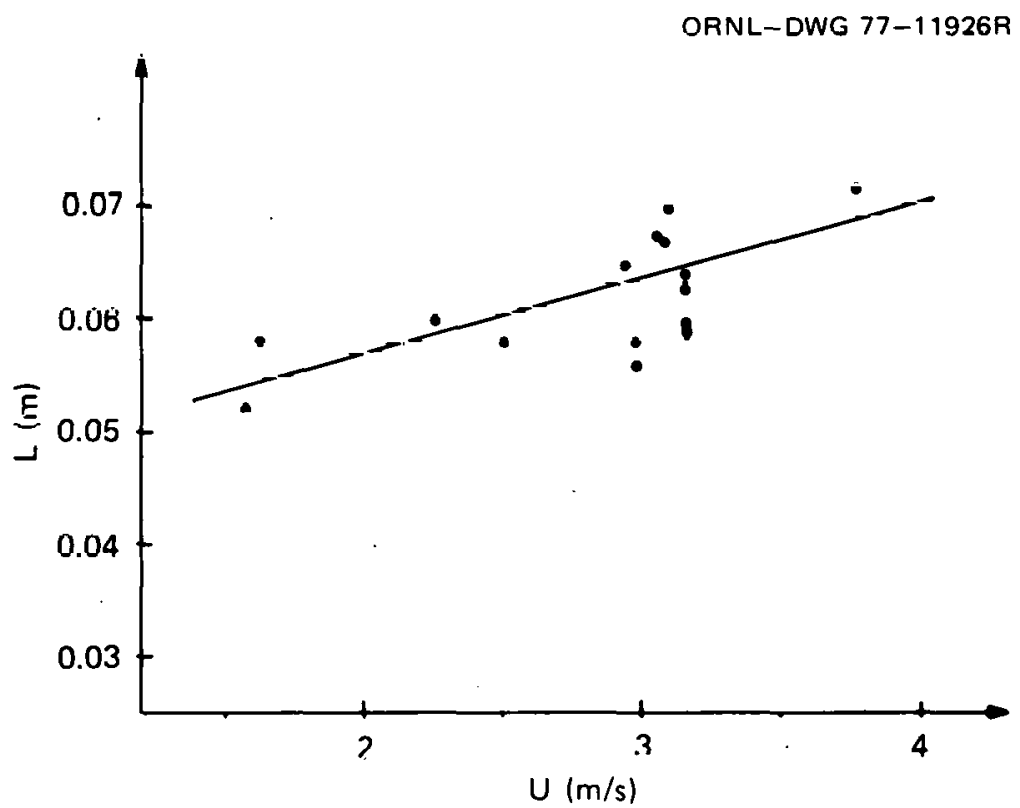

Fig. 61. Wake length $L$ as a function of mean sodium velocity in the annulus (Kirsch and Schleisiek ${ }^{5}$ ). 
the wake in contact with the outer heated tube of the test assembly be $F$ and the corresponding mean wake thickness be $b_{m}$. Let the bulk of the wake with mass $\mathrm{M}=\mathrm{Fb}_{\mathrm{m}} \rho$ be completely mixed. The mass exchange rate between the wake and the free stream is $\dot{m}$. The heat added through the area $F$ increases the temperature in the wake, while the exchange of mass $\dot{m}$ decreases $i t$. For a short time interval dt, the following relation holds for the increase in temperature in the wake:

$$
F \phi d t=M c_{p}(d \theta)
$$

where $\phi$ is heat flux, $c_{p}$ is specific heat of fluid, and $\theta$ is instantaneous fluid temperature in wake,

$$
\frac{d \theta}{d t}=\frac{F \phi}{M c}
$$

The amount $\dot{\mathrm{m}}$ of coolant, with the temperature of the main coolant flow $\theta_{0}$, flows into the wake as a result of the mass exchange. The wake mean temperature is reduced:

$$
\begin{aligned}
& \dot{m c_{p}} \mathrm{dt}\left(\theta-\theta_{0}\right)=-\mathrm{Mc}_{\mathrm{p}}(\mathrm{d} \theta) \\
& \frac{\mathrm{d} \theta}{\mathrm{dt}}=-\frac{\dot{\mathrm{m}}\left(\theta-\theta_{0}\right)}{M}
\end{aligned}
$$

Combining Eqs. (2) and (4) yields

$$
\frac{\mathrm{d} \theta}{\mathrm{dt}}=\frac{\mathrm{F} \phi}{\mathrm{Mc}}-\frac{\dot{\mathrm{m}}}{\mathrm{M}}\left(\theta-\theta_{0}\right)
$$

It is not necessary to solve this equation. What is of interest is the steady-state temperature difference at a constant heat flux density $\phi$. This condition implies that

$$
\frac{d \theta}{d t}=0
$$


and it thus follows from Eq. (5) that

$$
\frac{\mathrm{F} \phi}{\mathrm{Mc} \mathrm{p}_{\mathrm{p}}}=\frac{\dot{\mathrm{m}}}{\mathrm{M}}\left(\theta-\theta_{0}\right) \text {. }
$$

$M$ and $F$ are related by

$$
\mathrm{M}=\mathrm{Fb}_{\mathrm{m}} \rho
$$

Equations (6) and (7) provide the relation for the residence time $\tau$ in the wake:

$$
\underset{\dot{m}}{M}=\tau=\frac{b_{m} \rho c_{p}\left(\theta-\theta_{n}\right)}{\phi} .
$$

In principle, it is also possible to calculate the residence time from the decrease in the temperature after the power shutoff. In that case, $\phi$ is set to 0 in Eq. (5). The solution of the differential equation:

$$
\frac{\mathrm{d} \theta}{\mathrm{d} \mathrm{L}}=-\frac{\dot{\mathrm{m}}}{\mathrm{M}}\left(\theta-\theta_{0}\right)
$$

with the initial condition $\theta=\theta_{\max }$ at $t=0$ is

$$
\frac{\theta-\theta_{0}}{0_{\max }-\theta_{0}}=\mathrm{e}^{-(\dot{\mathrm{m}} / \mathrm{M}) t}=\mathrm{e}^{-\mathrm{t} / \tau} \text {. }
$$

This relation can be used to calculate the residence time, with limitations, because $\theta_{0}$ is not constant during the decrease of $\theta$ and the heat storage capacity of the tube has not been taken into account.

In the derivation of the relation for the residence time, $\theta$ denotes the mean coolant temperature in the wake, which must be determined from the measured temperature distribution by integration in the axial and azimuthal directions. However, the experiments have shown that the shape of the dimensionless temperature field is independent of velocity and heat flux. Hence, it is possible, in principle, to determine correction factors for each thermocouple from one experiment in such a way that, for all other experiments, the mean coolant temperature can be determined by multiplying a 
single temperature difference by the respective correction factor. Since the experiments served to provide the dependence of the residence time on the parameters mentioned above, no general integration of the temperatures was performed. The temperature reading of certain thermocouples was inserted in Eq. (8) as $\theta-\theta_{0}$.

Figure 62 shows the residence time determined with thermocouples 2 and 4 in the first axial plane of measurement immediately downstream of the blockage as a function of coolant velocity $U$. With increasing velocity, there is an increase in turbulence and thus a decrease in the residence time. The curve roughly follows the shape of a hyperbola.

The temperature distribution was also determined with the same test section using water as coolant. The, residence time obtained from this experiment is plotted in Fig. 62 (dashed line). The residence times for water and sodium are in good agreement. Kirsch and Schleisiek concluded that molecular heat conduction does not play a measurable part in energy

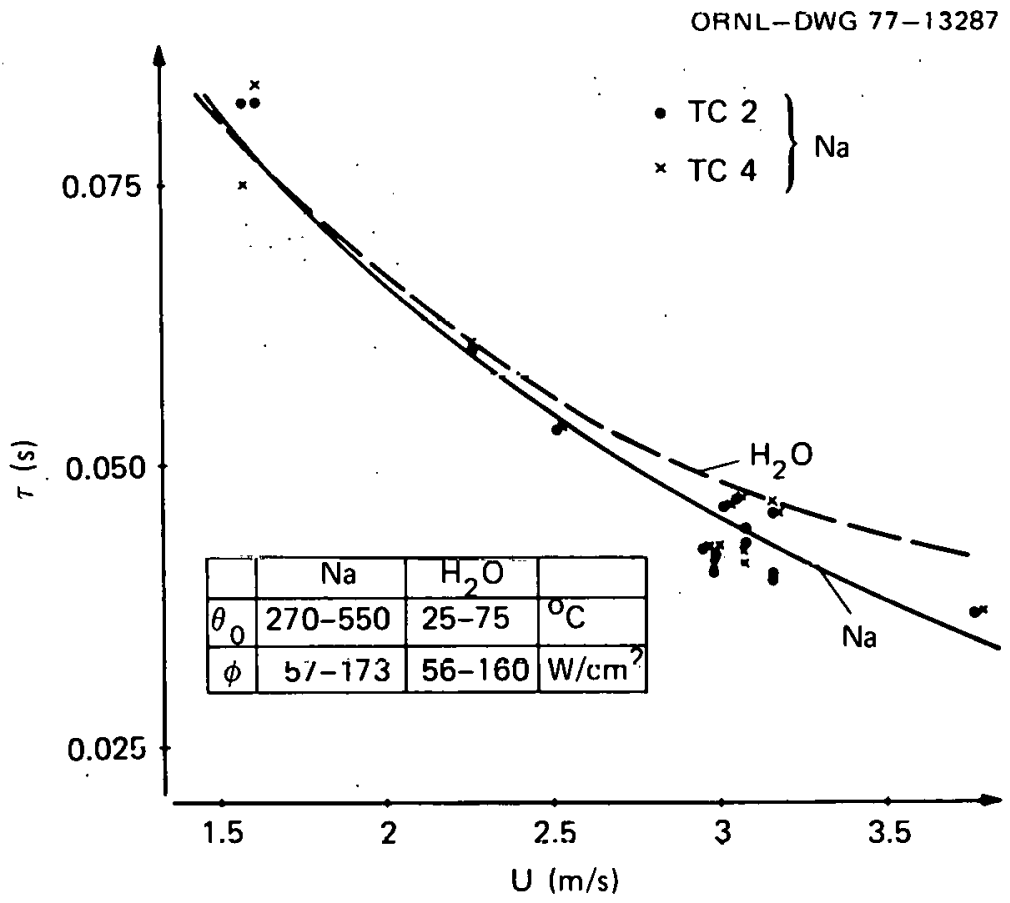

Fig. 62. Comparison of residence times for sodium and water in the wake in a blocked annul.us (Kirsch and Schleisiek ${ }^{5}$ ). 
transport in the wake. The only factor determining the temperature distribution is the turbulent recirculating flow. This means that the results of experiments in water can be extrapolated to sodium by means of Eq. (8).

\subsubsection{Heat transfer in the wake}

Test section. Schleisiek ${ }^{6}$ measured the sodium and the wall temperatures in a similar annulus with a blockage as shown in Fig. 63. The outer

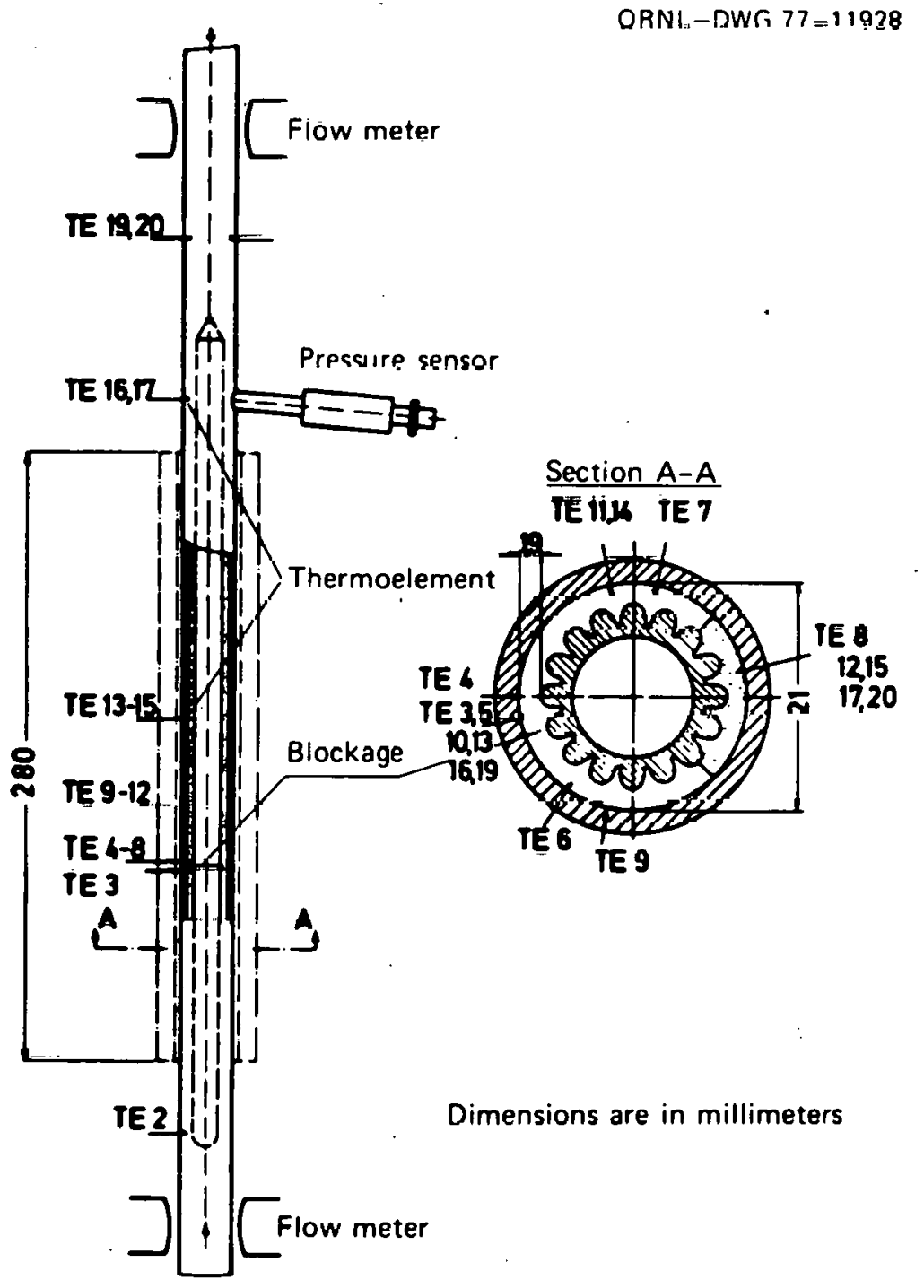

Fig. 63. Test section of an annulus with a blockage of $75 \%$ of flow area $\left(\right.$ Schleisiek $\left.{ }^{6}\right)$. 
tube of the annulus had an inside diameter of $21 \mathrm{~mm}(0.83 \mathrm{in.})$ and a heated length of $260 \mathrm{~mm}$ (10.2 in.). A plug was located in the center of the tube, thus forming an annulus consisting of 16 channels with either sodium or water flowing through. A 1 -mm-thick plate was mounted in the lower third of the heated zone to block a total of 12 channels (75\% of the flow area). The outer tube was made of ultrapure nickel, while the inner plug and the blockage plate were made of stainless steel.

Twenty thermocouples (TE 1 to 20 ) were at various axial and radial locations in the test section (Fig. 63). TE 1 was used to measure the test section inlet temperature, while TE 16 to 20 (all $1 \mathrm{~mm}$ in diameter, noninsulated) gave the temperature at different points at the test section outlet. The 0.5-mm-diam (0.02-in.) thermocouples in the heated zone, TE 3 to 15, had sensing heads soldered to the sheath. TE 4 and TE 9 were used for measuring the wall temperature - TE 4 at the center of the test section immediately downstream of the blockage and TE 9 in roughly the middle of the recirculating flow. The thermocouples for measuring the sodium temperatures passed through the plug and extended from the inside right into the center of the channels. They were located on three different planes at distances of 3,28 , and $68 \mathrm{~mm}(0.12,1.1$, and 2.7 in.) from the blockage, respectively. Thermocouple 3 was used to measure the coolant temperature directly upstream of the blockage.

Two pairs of thermocouples (TE 4/TE 5 and TE 9/TE 11) were arranged in the test section in such a way that the heat transfer coefficient could be measured. The wall thermocouples (TE 4 and TE 9) were embedded in the outer tube and soldered in position at a depth of $0.65 \mathrm{~mm}$. Since the highfrequency current only penetrated a few tenths of a millimeter into the test tube, the inner wall temperature could be determined from the measured wall temperature by the simple equation for the thermal conduction in the cylinder.

Results and discussion. The Nusselt number in the wake behind the blockage is defined as

$$
\mathrm{Nu}=\frac{\phi \mathrm{D}_{\mathrm{h}}}{\mathrm{K} \Delta \mathrm{T}},
$$


where $\phi$ is the pin heat flux, $K$ is the fluid thermal conductivity, $\Delta \mathrm{T}$ is the temperature difference between the tube wall and the fluid, and $D_{h}$ is the hydraulic diameter.

Figure 64 shows the Nusselt numbers calculated from various tests as a function of the Peclet number. A widely used relation for the heat transfer of liquid metal flow in tubes,

$$
\mathrm{Nu}=5+0.025 \mathrm{Pe}^{0.8} \text {, }
$$

is also included for comparison.

The measured values are in the range $40<\mathrm{Pe}<130$. According in the above equation, the curve here is very flat; a further reduction in the Peclet number does not produce any major changes in the Nusselt number. The experiments indicate that Nusselt numbers of at least 4 to 5 can be expected for liquid-metal heat transfer in the wake.

The water tests Schleisiek employed for calculating the heat transfer were those in which the inner wall temperature was kept below $100^{\circ} \mathrm{C}$ to prevent boiling. The results are plotted in Fig. 65 as a function of Reynolds number in the form $\mathrm{Nu} / \mathrm{Pr}^{0.33}$; the Reynolds number is calculated with the

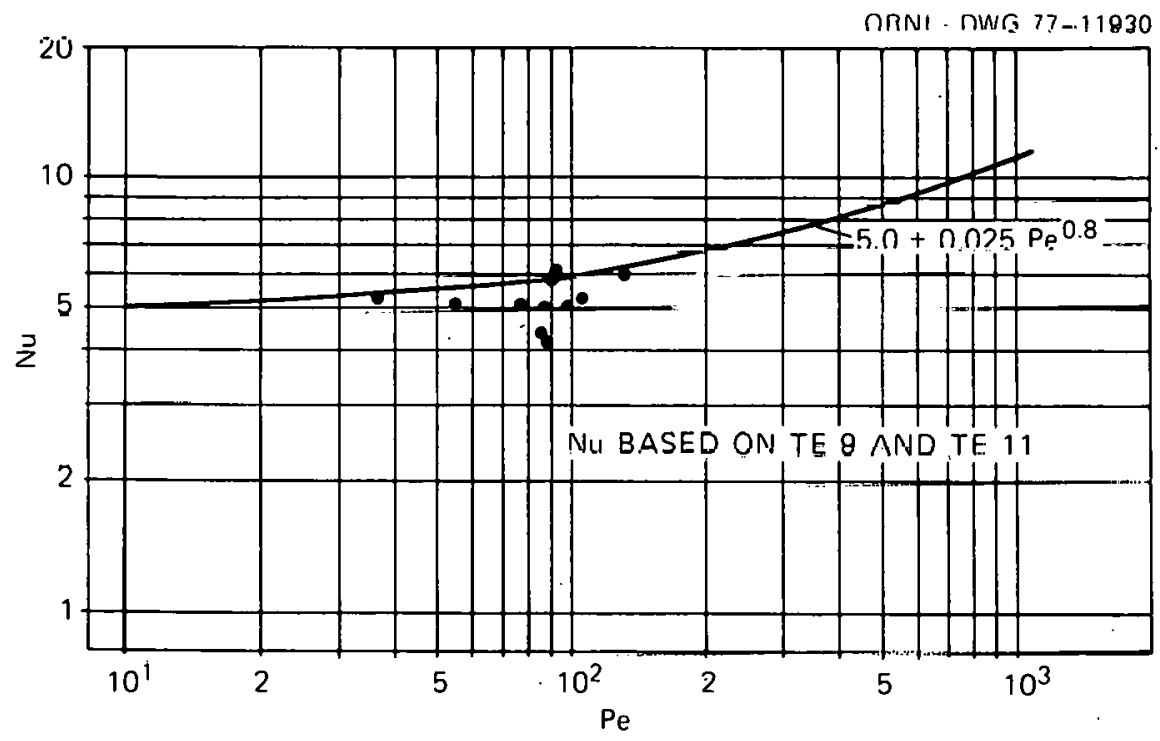

Fig. 64. Nusselt number in the wake behind the blockage in a sodiumcooled annulus (Schleisiek ${ }^{6}$ ). 


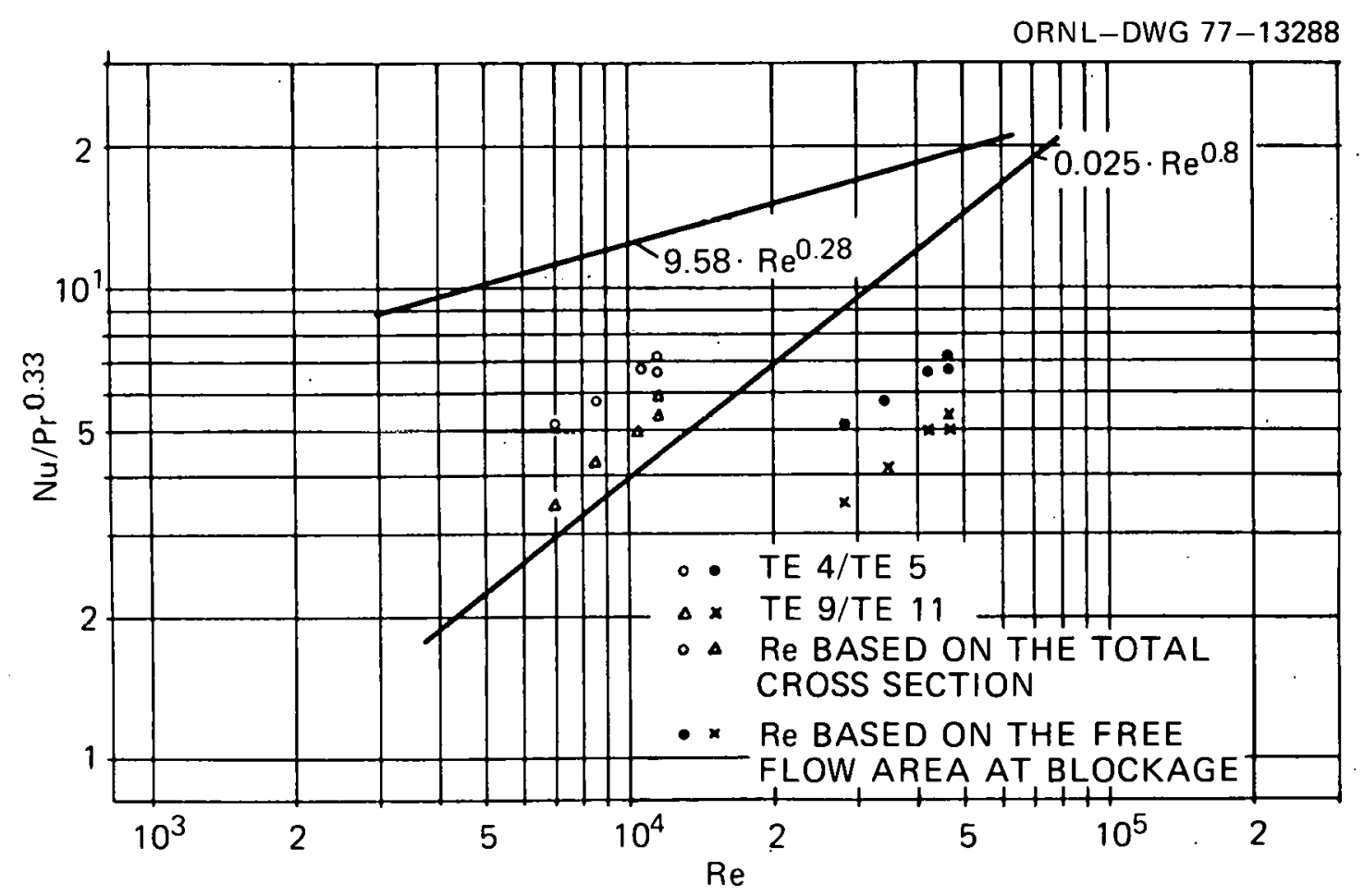

Fig. 65. Nusselt number in the wake behind the blockage with water as the coolant (Schleisick ${ }^{6}$ ).

velocity relative to both the total and the narrowest cross section. Comparison with the Colburn relation, which is also plotted,

$$
\mathrm{Nu}=0.025 \operatorname{Re}^{0.8} \operatorname{Pr}^{0.33},
$$

shows that the measured values are above or below the standard values, depending on the Reynolds number selected. Correlation of the heat transfer coefficients thus poses considerable difficulties, because the local Reynolds numbers are not known and selection of the total or narrowest cross section as a reference parameter is arbitrary. This might also explain the contradictory results obtained by other authors, some of whom report improvements and some a deterioration of the heat transfer in the wake. The dependence of the heat transfer coefficients measured here on the Reynolds number can be given as approximately $\mathrm{Re}^{0.8}$, which corresponds to the Colburn correlation. Figure 65 also shows an empirical correlation given by Van Erp and Chawla ${ }^{10}$ for heat transfer downstream of blockages in a 
water-cooled 19-pin bundle. Their correlation gives much higher values than Schleisiek's and is characterized by a weaker dependence on the Reynolds number $\left(\operatorname{Re}^{0.28}\right)$.

\subsection{Blockages in Simulated SNR Fuel Assemblies}

The German sodium-cooled fast breeder reactor (SNR) has 169 pins in each of its fuel assemblies. The pins have outside diameters of $6.0 \mathrm{~mm}$ (0.236 in.) and are held in position by grid spacers. The distance between adjacent pin centers is $7.9 \mathrm{~mm}(0.311 \mathrm{in.})$. One major difference between. the CRBR and the SNR fuel assemblies is that wire-wrap spacers are used in the former and grid epacere in the latter.

\subsubsection{Phenomenological flow distributions in the wake}

Test section. Basmer, Kirsch, and Schultheiss ${ }^{7}$ performed wake-pattern studies in one-half of the 169-pin bundle using air bubbles for flow visualization in water. One side of the bundle was closed by a Plexiglas plate for observation as shown in Figs. 66 and 67. The transparent plate was either smooth or had a half-pin profile on the side facing the bundle. Both solid and perforated blockages of $41 \%$ of total flow area, located either in the center or attached to the wall of the bundle, were used. The test section was about $600 \mathrm{~mm}$ (23.6 in.) long, which is 116 times the hydraulic diameter of the SNR pin bundle. The blockage plate was axlally located at approximately one-third of this length downstream from the test section entrance; thus, the flow was fully developed before reaching the blockage. Films taken at about $100 \mathrm{frames} / \mathrm{sec}$ and photographs with $1 / 1000$ to $1 / 125$ exposure time were obtained.

Results and discussion. Results obtained for the Reynolds number $\left(\mathrm{UD}_{\mathrm{h}} / \nu\right.$ ) in the range of $2 \times 10^{4}$ to $3.2 \times 10^{4}$ indicated:

1. The Reynolds number dependence on the wake dimensions behind the blockage is small. For the central blockage (as shown in Fig. 66), the ratio of the wake length to diameter over the maximum blockage dimension is $\mathrm{L} / \mathrm{D}=1.5 \sim 2.0$. For the edge blockage attached to the duct wall of the pin bundle (shown in Fig. 67), L/D $=2.4 \sim 3.0$. 

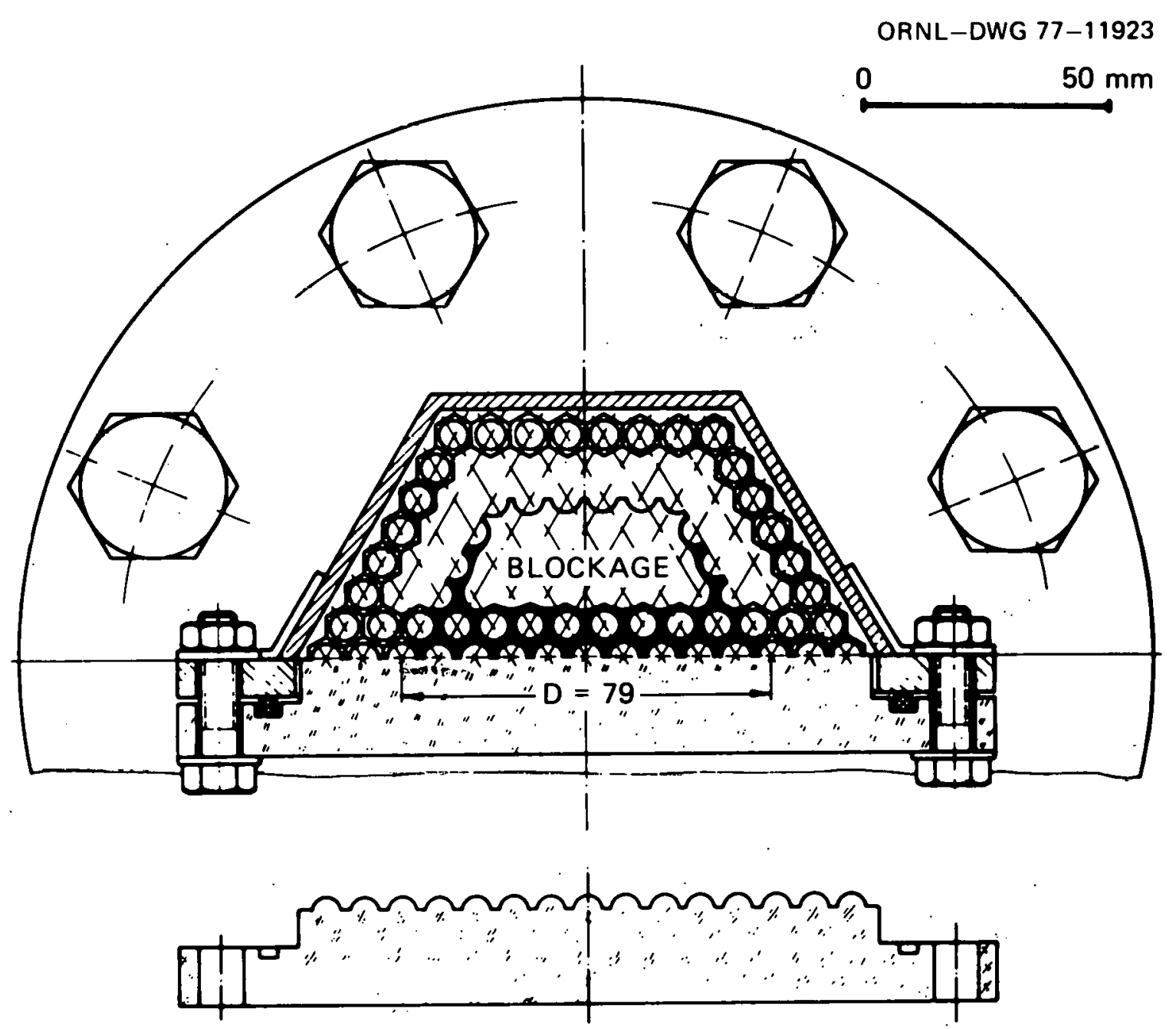

PROFILED WALL (TO CLOSE THE BUNDLE)

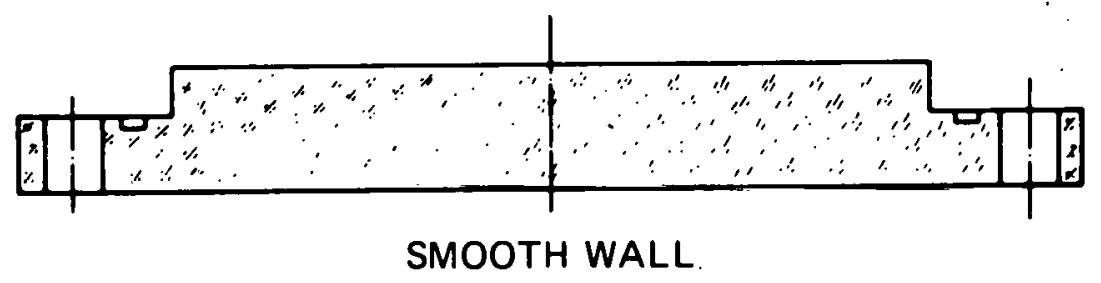

Fig. 66. Cross section in one-half of a 169-pin SNR bundle with central blockage (Basmer, Kirsch, and Schullheiss? ${ }^{7}$. 


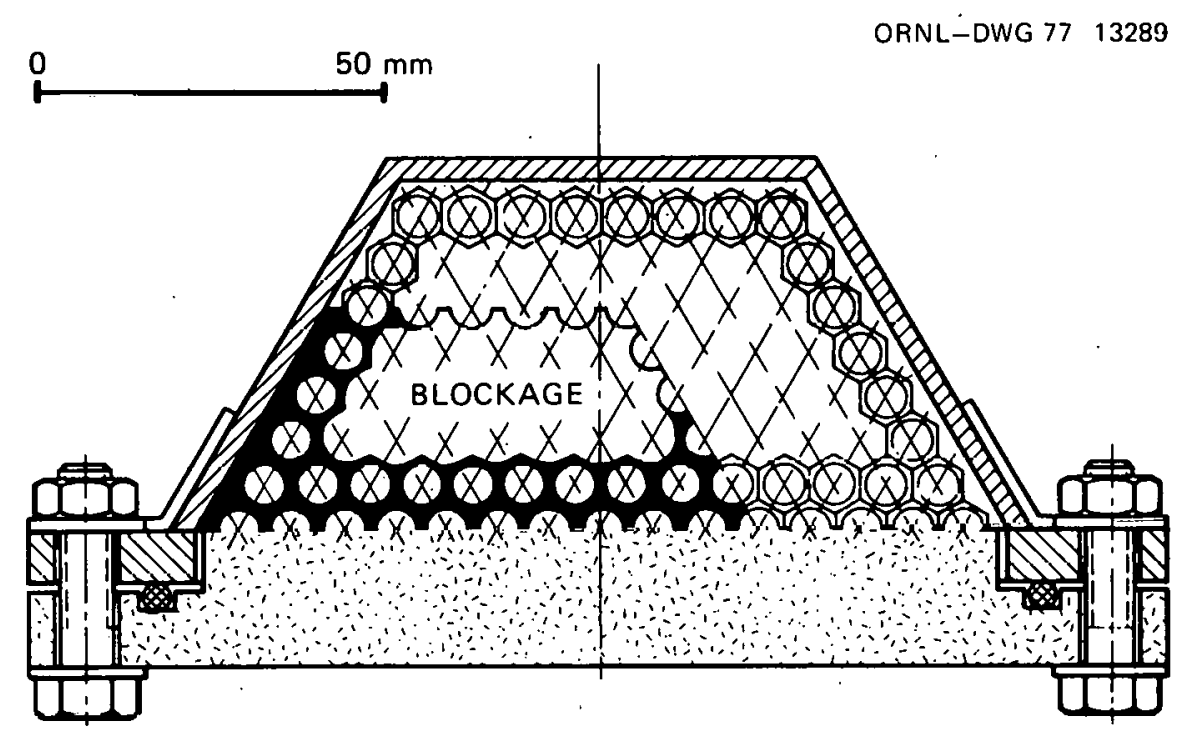

Fig. 67. Cross section in one-half of a 169-pin SNR bundle with an edge blockage (Basmer, Kirsch, and Schultheiss ${ }^{7}$ ).

2. At the same water fluid velocity $U$ and blockage size, the ratio of L/D appears to be unchanged whether or not there are fuel pins.

3. Two profiles of lle Plexlylas plate (F1g. 66) show no significant difference in the wake dimensions or flow behavior.

4. For the blockage with a hole in the center of each channel (Fig. 68), the wake is shifted further downstream. However, as the perforated area Increases to about $15 \%$ of the total blockage plate, the quasi-steady recirculation flow disappears and is replaced by a limited pulsation zone. in which return flows temporarily occur. Sketches of the wake under various blockage conditions are shown in Fig. 69.

\subsubsection{Thermal-hydraulic studies}

Kirsch ${ }^{8}$ obtained pressure, salt concentration, and temperature measurements in a 169-pin water-cooled bundle with various sizes of blockages. The dimensions of the wake and the mass exchange rate between the wake and the main flow were determined.

Test section. Figure 70 shows various shapes and radial locations of the blockages used for pressure measurements. All blockage plates were impermeable except blockage 3 , which had a 1 -mm-diam $(0.04-\mathrm{in}$.) hole at the 


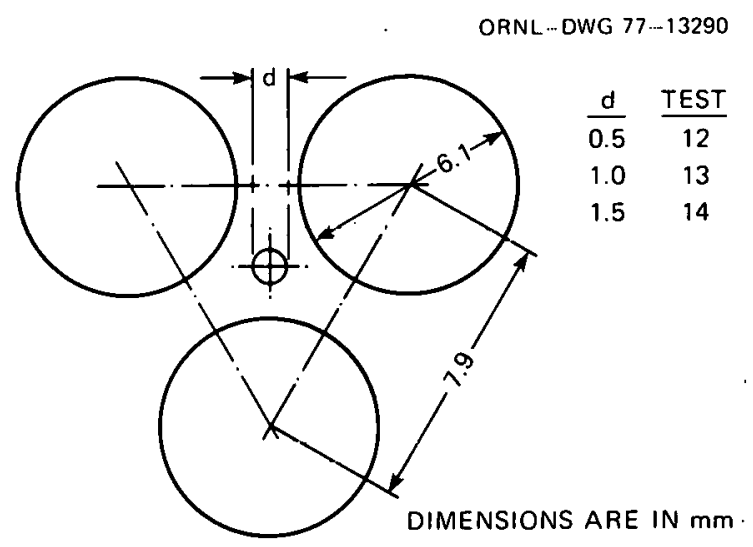

Fig. 68. Geometrical configuration of the holes placed in the blockage to induce a residual flow (Basmer, Kirsch, and Schultheiss ${ }^{7}$ ).

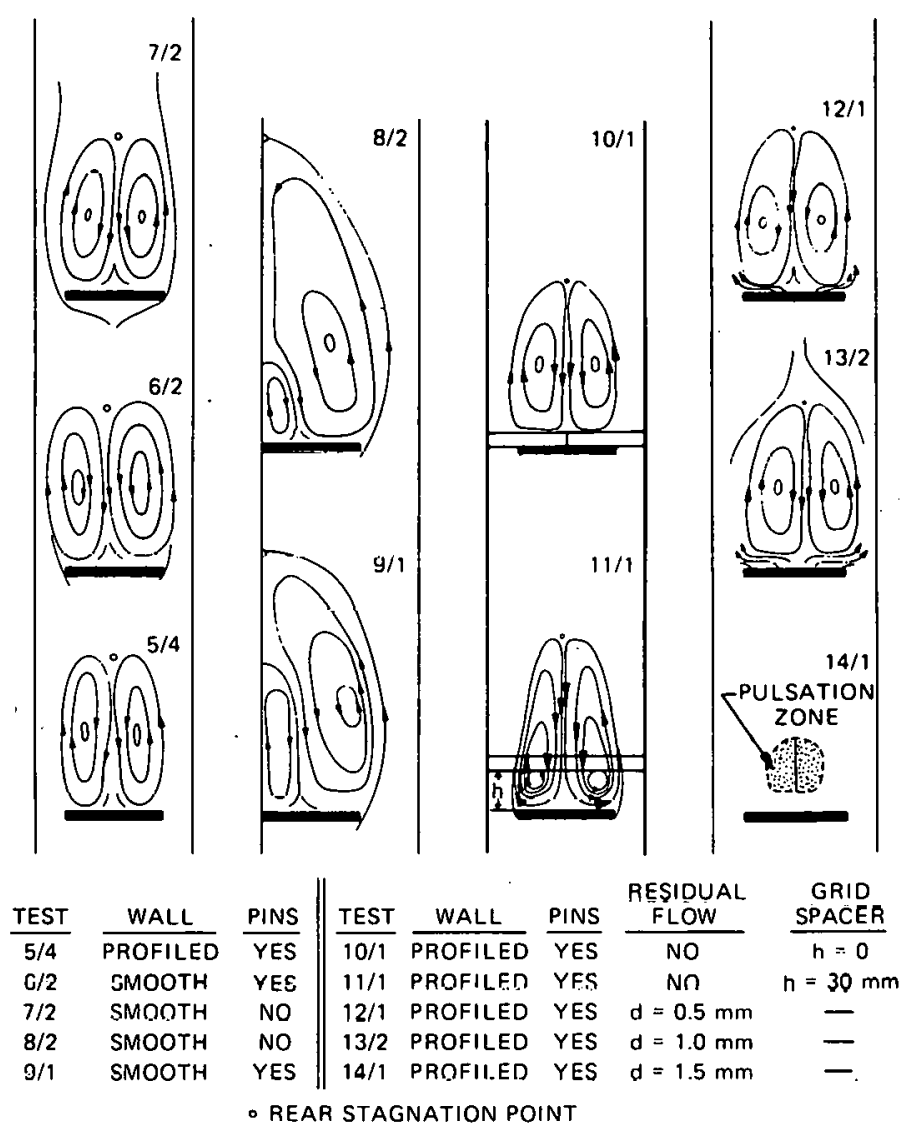

Fig. 69. Flow patterns in the wake behind the blockage in onehalf of a 169-pin SNR bundle (Basmer, Kirsch, and Schulthelss ${ }^{7}$ ). 


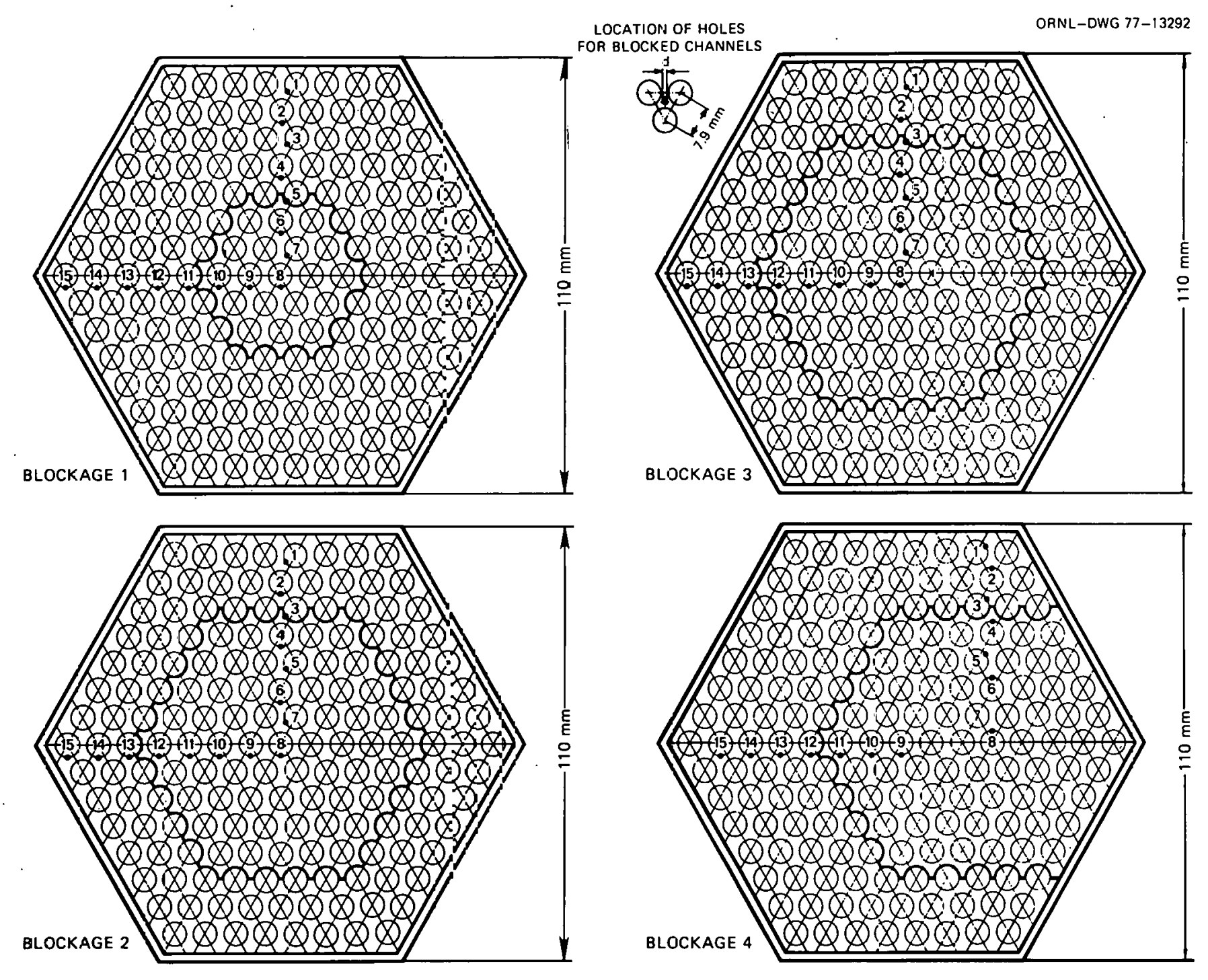

Fig. 70. Locations o jlockage plates and pressure-measuring holes in a 169-pin SNR bundle (Kirseh ${ }^{8}$ ). 
center of each blocked channel. (Fig. 70) to provide a residual flow. The 1.5-mm-diam (0.059-in.) pressure-measuring holes are fixed at the same axial plane and are shown on pins 1 to 15 in Fig. 70. The blockage plates could be moved axially to enable pressure profiles to be taken anywhere upstream and downstream of the blockage.

For the concentration measurements, the $\mathrm{KCl}$ solution was steadily injected 1nto the wake until time $t=0$. The decay of $\mathrm{KCl}$ concentrations in the wake was then determined by measuring the electrical conductivity in water. Figure 71 shows the design of the injector and the test probe. Figure 72 shows the test section of a 169-pin bundle used for temperature measurements. This bundle, which has the same dimensions as an SNR fuel assembly, contains a central blockage with $\beta=0.147$ (Fig. 70). Since the region downstream of this blockage has to be free of spacers because of the presence of thermocouples, the axial layout is not exactly the same as in the SNR.

ORNL-DWG $77-13283$

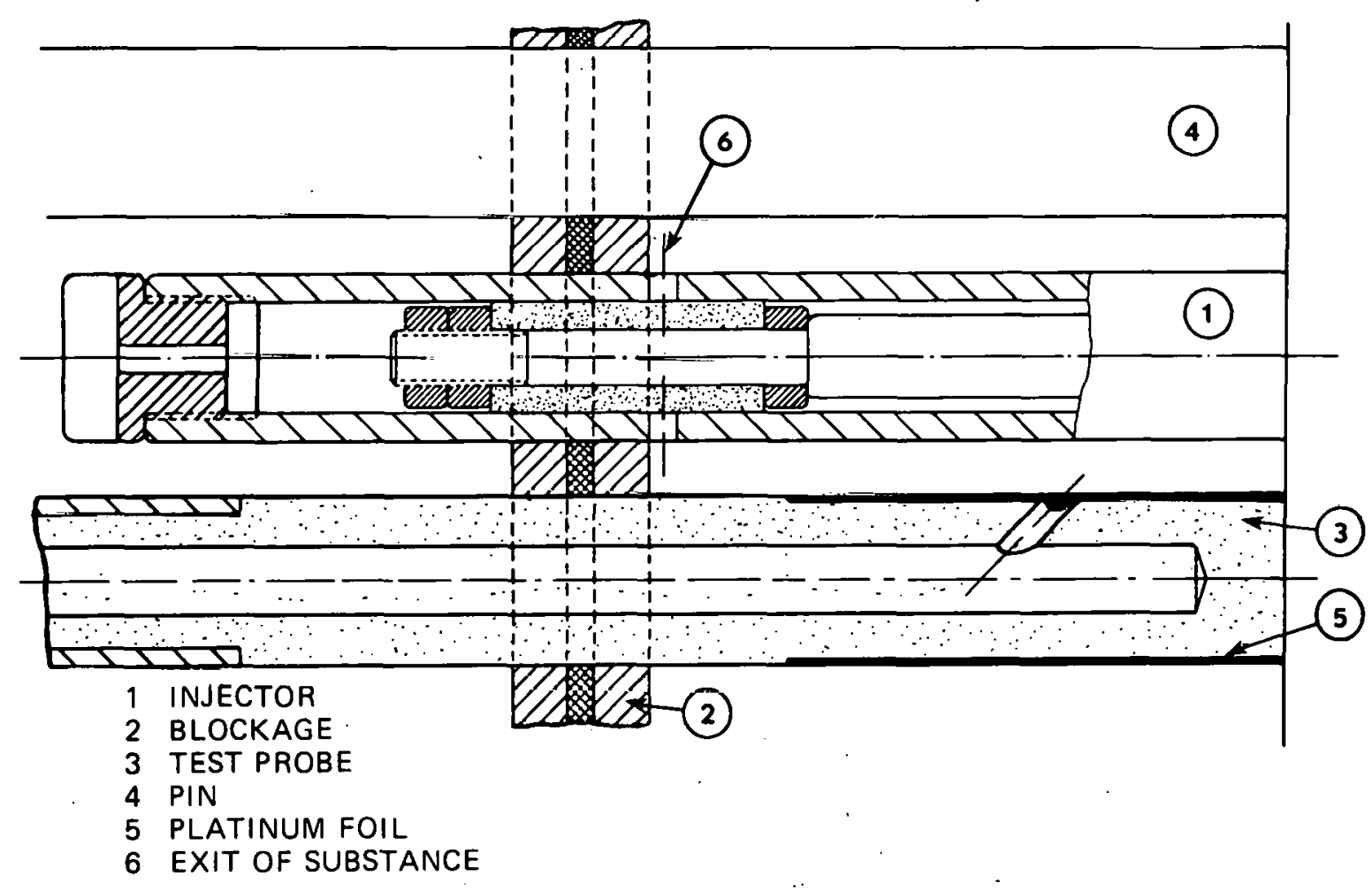

Fig. 71. Salt solution injector and test probe $\left(\operatorname{Kirsch}^{8}\right)$. 


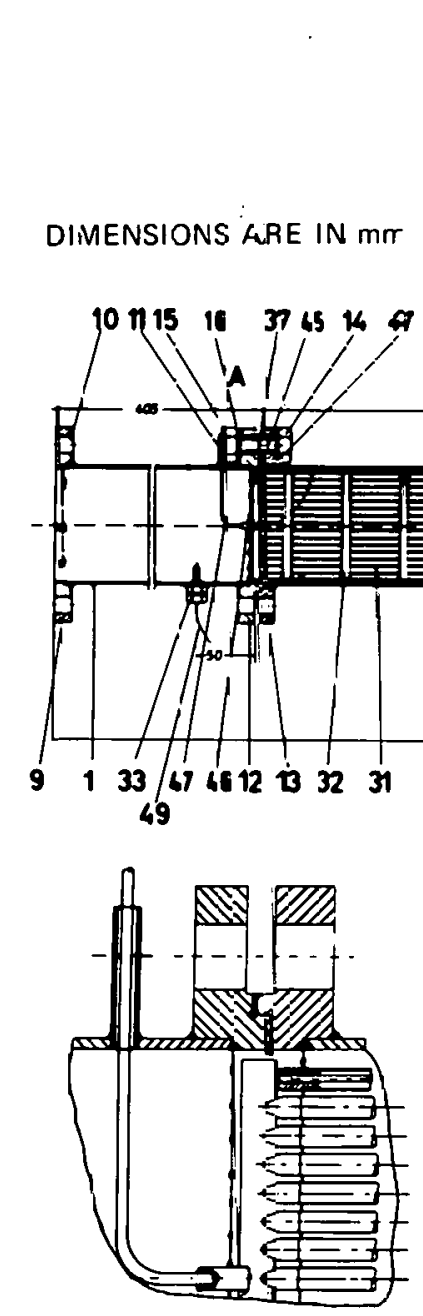

A
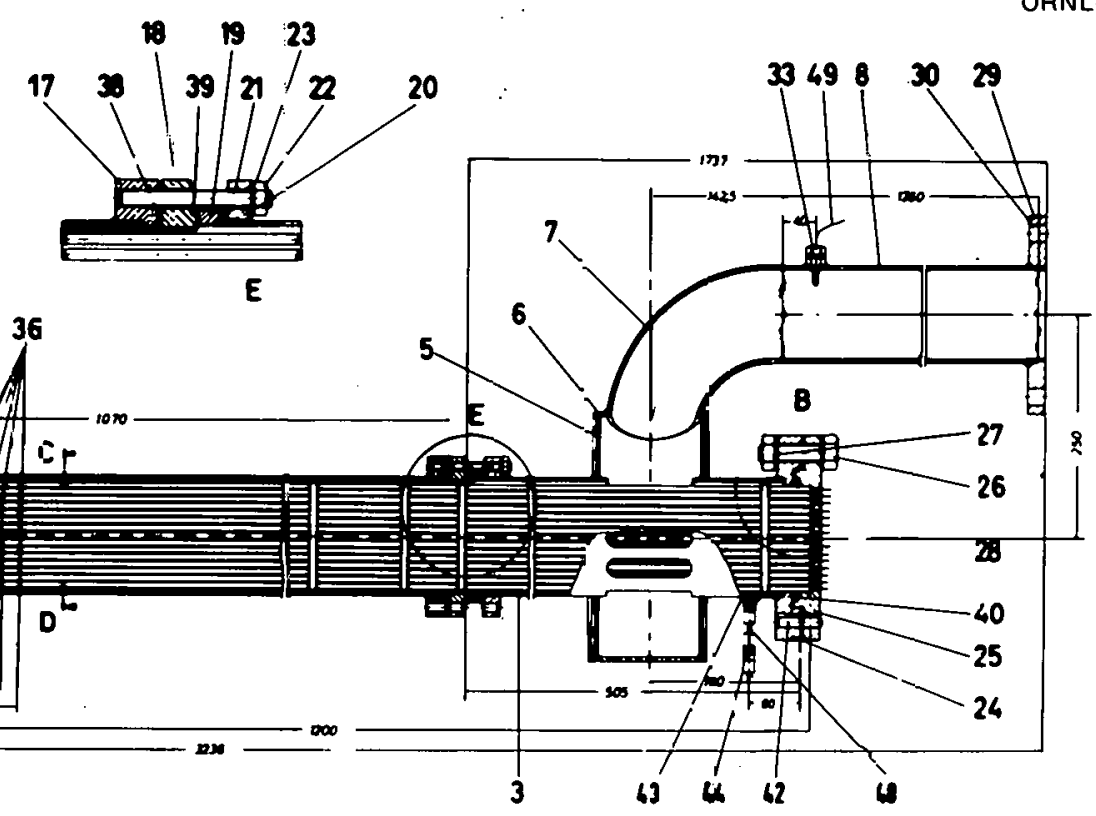

Fig. 72. Test section for temperature measurements behind the blockage in a 169-Fin SNR bundle (Kirsch ${ }^{8}$ ). 
The 169 pins were heated by ac electrical resistance wires over a length of $0.7 \mathrm{~m}(0.1 \mathrm{~m}$ upstream and $0.6 \mathrm{~m}$ downstream of the blockage). Twelve heated pins contained three thermocouples each, as shown in Fig. 73. These thermocouples, located in the wake region, were soldered into grooves in the cladding of the pins in order to disturb the flow as little as possible. Because the cladding has a wall thickness of only $0.45 \mathrm{~mm}$ (0.018 in.), thermocouples with an outer diameter of $0.25 \mathrm{~mm}$ were used. The ends of the thermocouples were bent out of the pin cladding so that they protruded into the center of the channels.

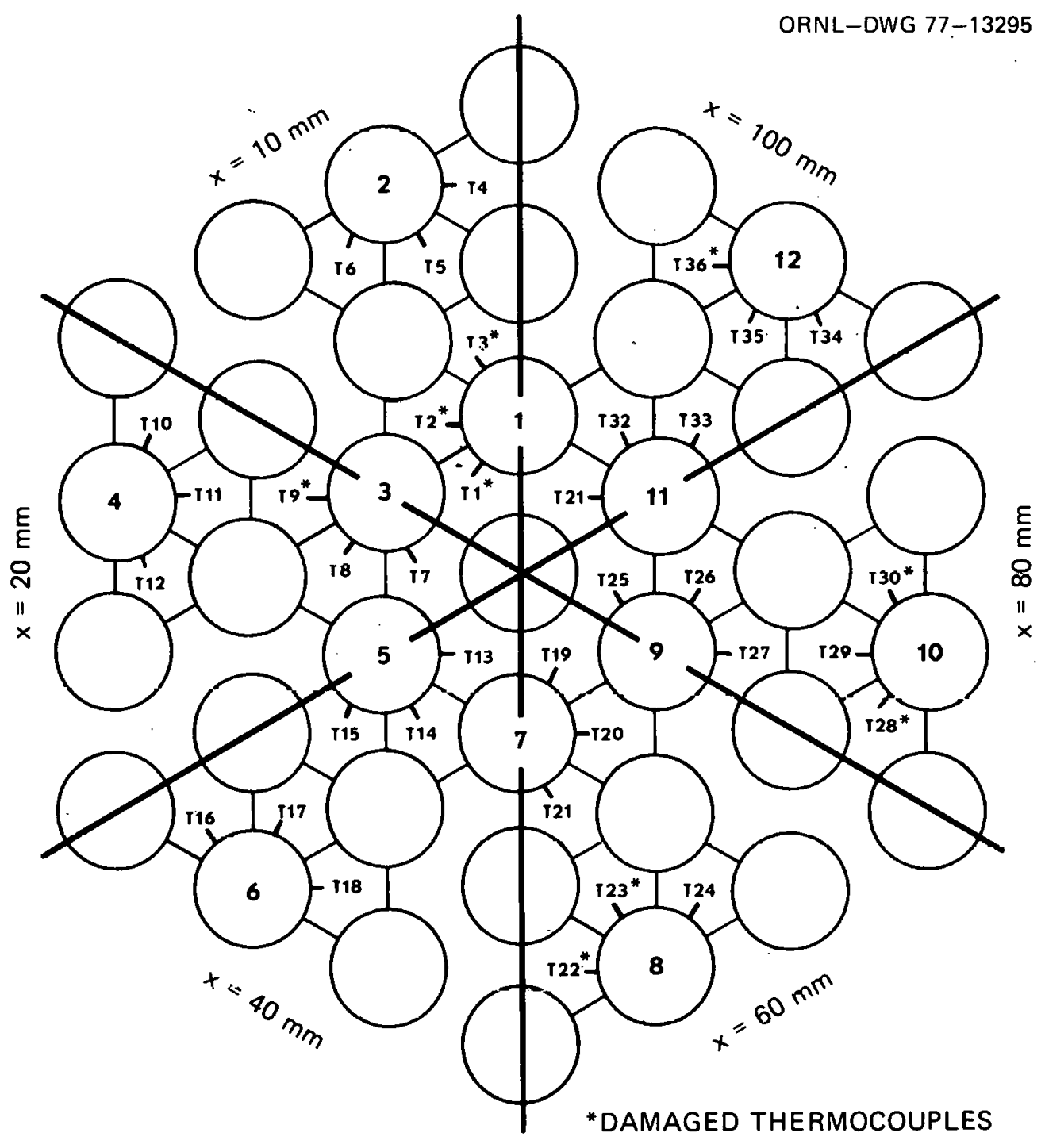

Fig. 73. Thermocouple locations in the test section (Kirsch ${ }^{8}$ ). 
The temperatures were measured at six axial locations $(10,20,40,60$, 80 , and $100 \mathrm{~mm}$ downstream of. the blockage). Despite great care during assembly, only 27 of the 36 thermocouples in the wake region were still intact when the measurements were performed (the damaged thermocouples are marked with asterisks in Fig. 73). However, the remaining 27 gave a good picture of the temperature distribution in the wake.

Results and discussion. Pressure measurements were obtained at $1.3 \times 10^{4} \leq \operatorname{Re}=\mathrm{UD}_{\mathrm{h}} / \nu \leq 10^{5}$ (with the lower limit for a water temperature of $20^{\circ} \mathrm{C}$ and fllow of $11.1 \mathrm{~m} / \mathrm{s}$ and the higher one for a temperature of $90^{\circ} \mathrm{C}$ and a flow of $27.8 \mathrm{~m} / \mathrm{s})$. The dimensionless pressure rise, $\left(P-P_{\text {ccrecr }}\right) /$ $\left[(\rho / 2) U^{2}\right]$, downstream of blockage 1 (see Fig. 70) is plotted in Fig. 74. Its dependence on the Reynolds number is small and practically negligible

ORNL-DWG 77-13296

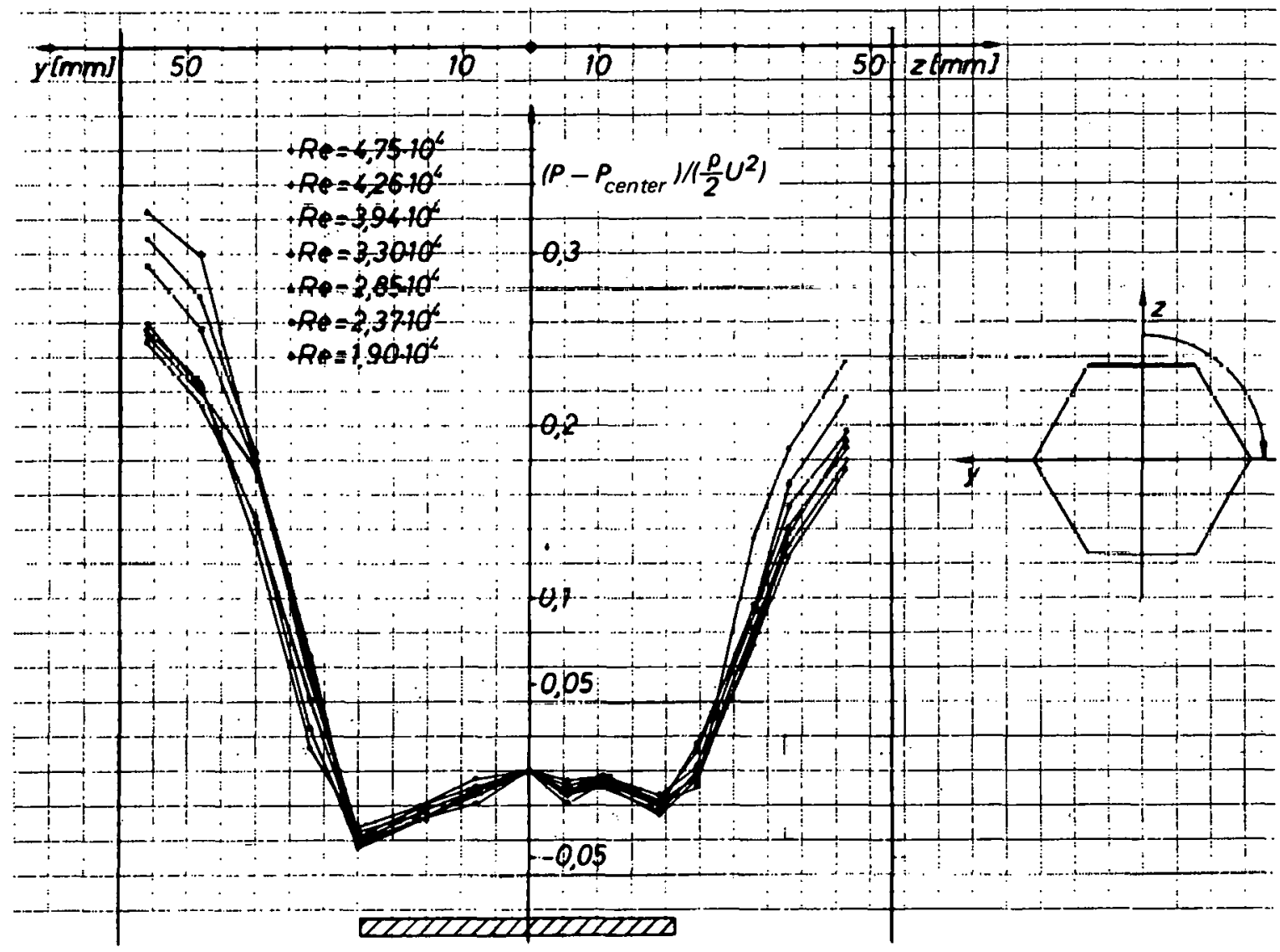

Fig. 74. Dimensionless pressure profiles behind a blockage for various Reynolds numbers in a 169-pin bundle (Kirsch ${ }^{8}$ ). 
within the range of the Reynolds numbers investigated. The same trend was observed for other blockages examined: Figure 75 shows the axial and radial pressure distributions for the central blockage at $\operatorname{Re}=1.86 \times$ $10^{4}$. The point of the maximum pressure gradient is at the radial boundary of the wake. The axial length of the wake, which is assumed to be where the pressure profile no longer changes, is approximately $90 \mathrm{~mm}$ (Fig. 75).

Figures 76 to 78 show the estimated wake boundary for blockages 1 to 4 (defined in Fig. 70). Table 10 gives the wake length $\mathrm{L}$, the maximum radial dimension of the wake $B$, and the wake volume $V_{w k}$ (see Fig. 79). From these results, Kirsch ${ }^{8}$ arrived at the following conclusions:

1. For a fixed geometry, the dimensions of the wake in the range investigated are independent of Reynolds number.

2 . When the fraction of the area blocked $(B)$ is increased, the ratio between the length of the wake and the diameter of the blockage (L/D) decreases.

3. The ratio between the maximum radial dimension of the wake and the diameter of the blockage $(B / D)$ also decreases as $B$ increases, so that the wake becomes "slimmer."

4. The formation of a wake in a bundle geometry is qualitatively the same as in a geometry without pins.

Table 10. Dimensions and volume of the wake determined from the measurements of pressure distribution in a 169-pin SNR bundle

\begin{tabular}{llllll}
\hline Blockage & \multicolumn{1}{c}{1} & \multicolumn{2}{c}{3} & \multicolumn{1}{c}{4} \\
\hline B & 0.147 & 0.411 & 2 & 0.411 & 0.411 \\
$\mathrm{~L}, \mathrm{~mm}$ & $77+5$ & $112 \pm 8$ & $107 \pm 5$ & $174 \pm 5$ \\
$\mathrm{~B}, \mathrm{~mm}$ & $80 \pm 2$ & $96 \pm 2$ & $90 \pm 2$ & $95 \pm 2$ \\
$\mathrm{~L} / \mathrm{D}$ & $1.84 \pm 0.12$ & $1.65 \pm 0.12$ & $1.57 \pm 0.10$ & $2.56 \pm 0.08$ \\
$\mathrm{~B} / \mathrm{D}$ & $1.90 \pm 0.05$ & $1.40 \pm 0.03$ & $1.32 \pm 0.03$ & $1.39 \pm 0.03$ \\
$\mathrm{~V}_{\mathrm{wk}}, \mathrm{cm}^{3}$ & $137 \pm 12$ & $298 \pm 25$ & $238 \pm 20$ & $470 \pm 40$ \\
\hline
\end{tabular}



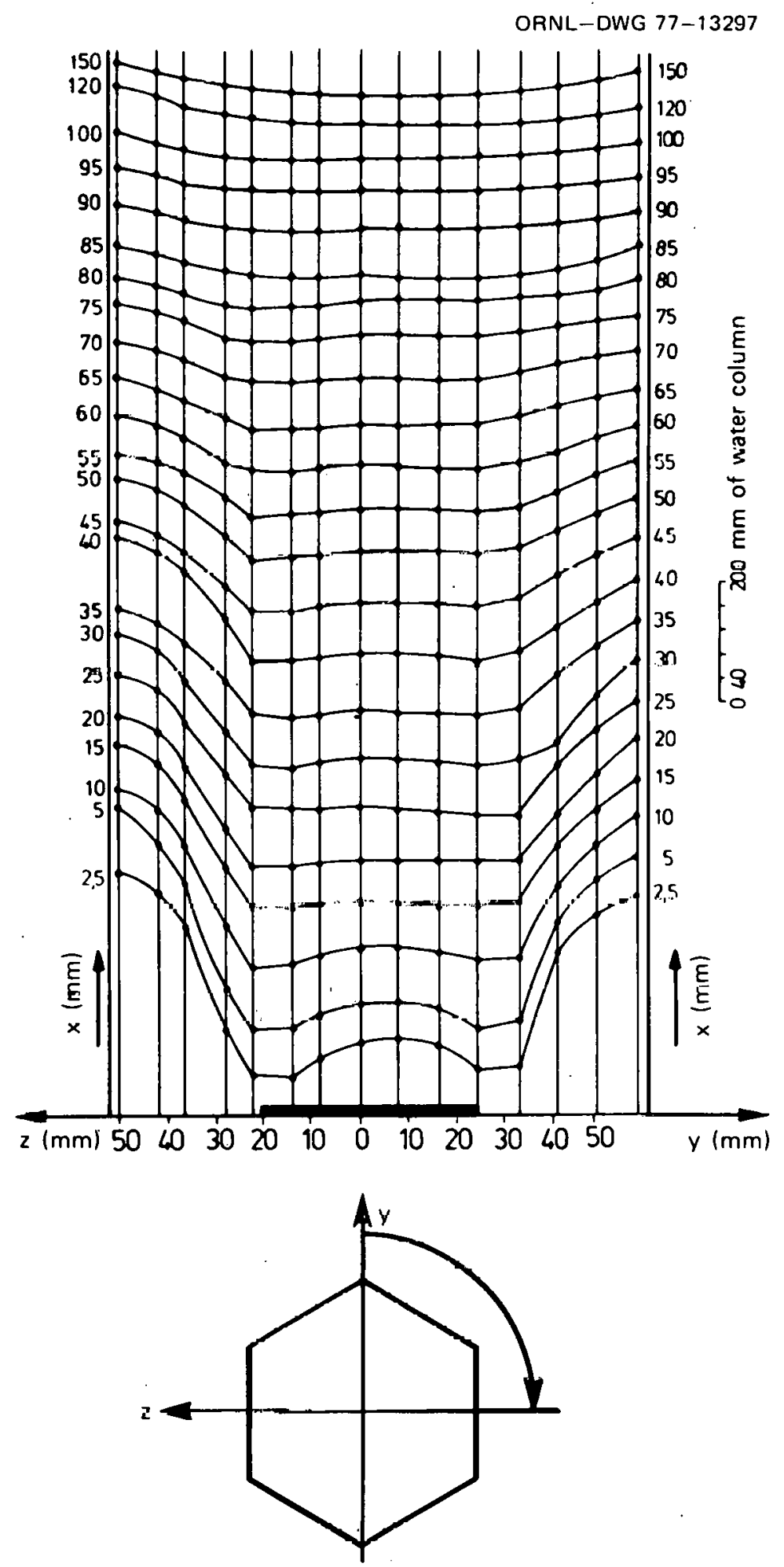

Fig. 75. Pressure profiles at various distances behind a blockage $\left(\operatorname{Kirsch}^{8}\right)$. 

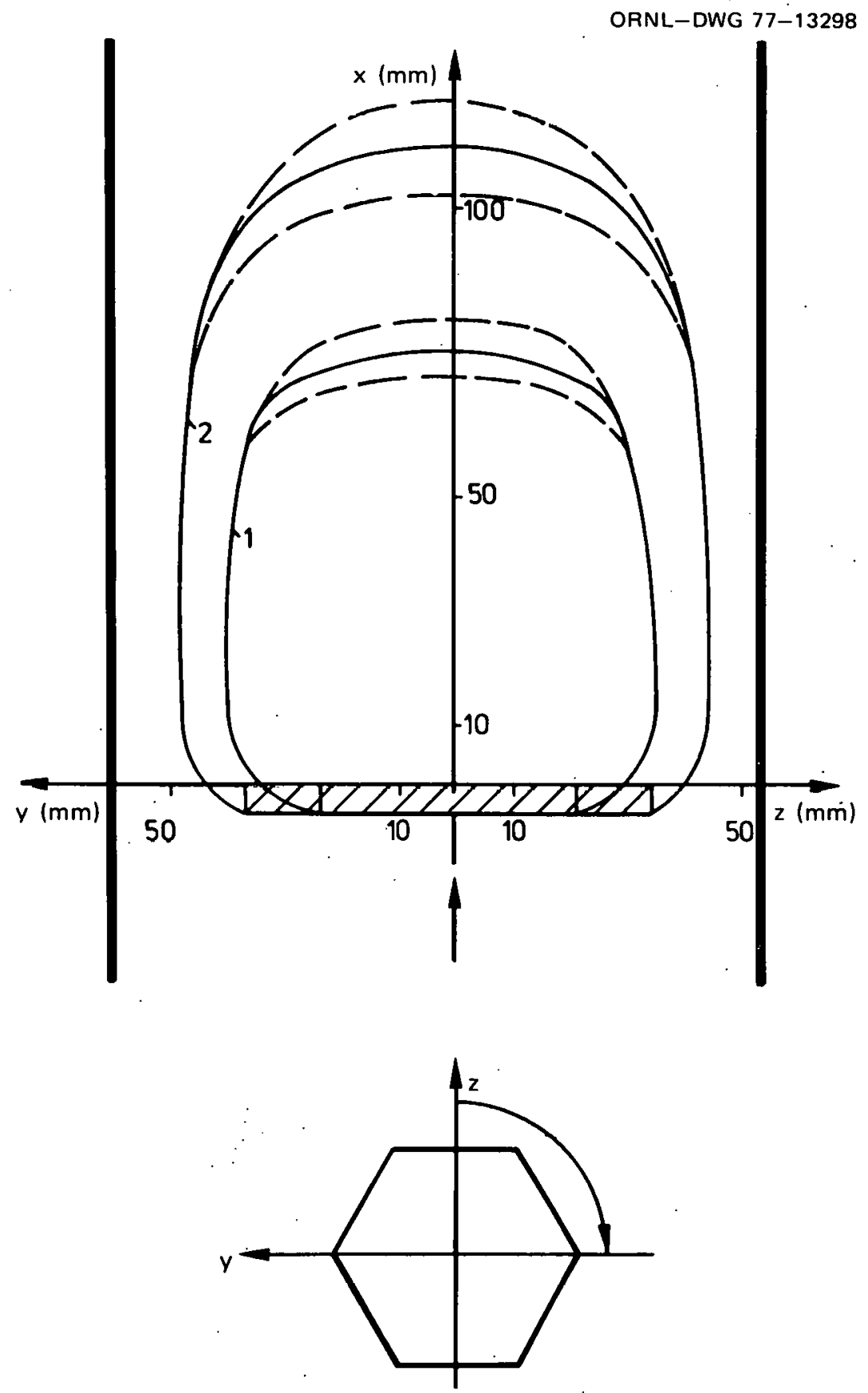

Fig. 76. Wake boundaries for blockages 1 and 2 (see Fig. 70) $\left(\operatorname{Kirsch}^{8}\right)$. 

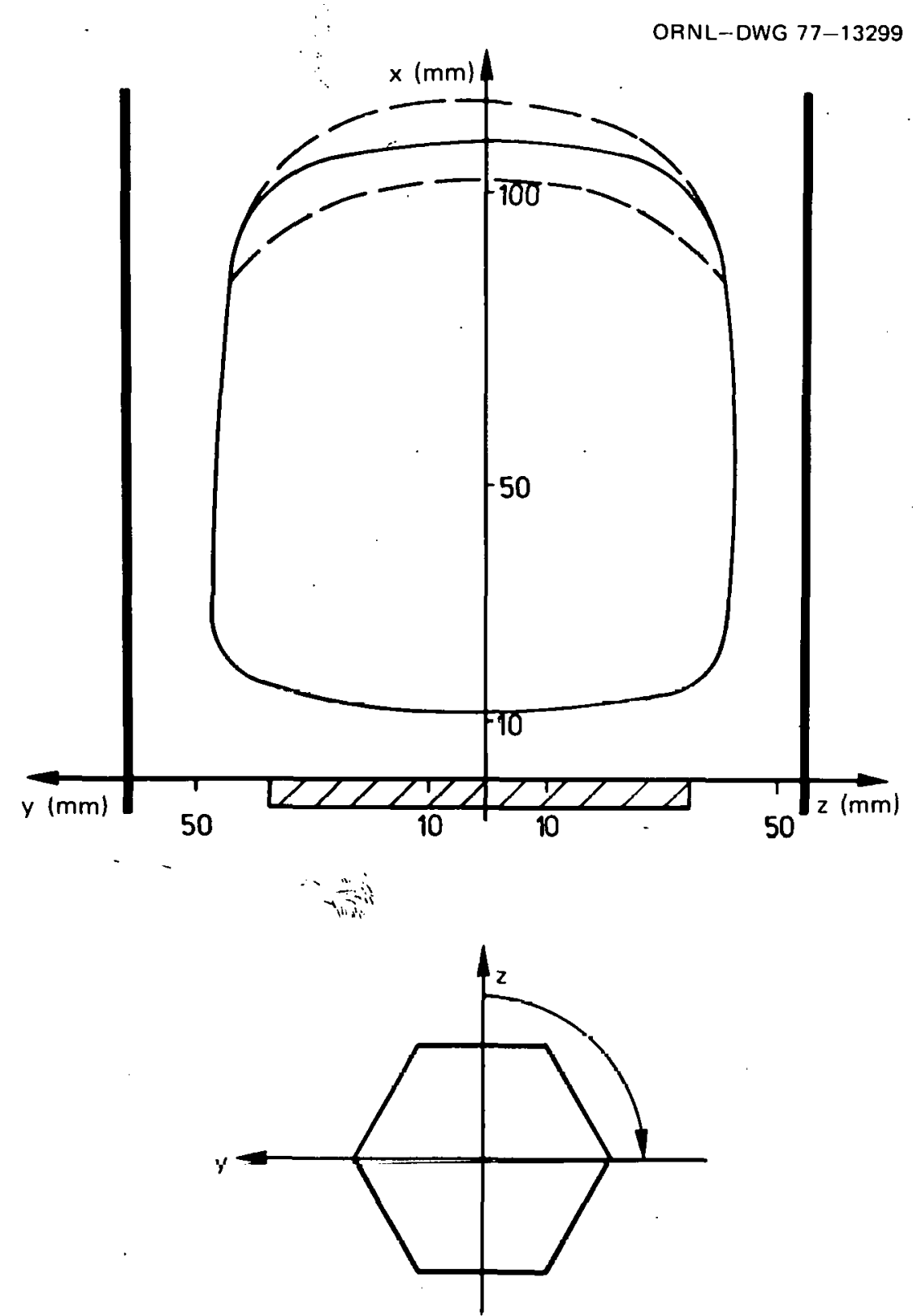

Fig. 77. Wake boundary for blockage 3 (see Fig. 70) (Kirsch ${ }^{8}$ ).

Kirsch introduced $\mathrm{C}$ as the concentration (mass fraction) of $\mathrm{KCl}$ in the water and divided the wake region into inner and outer regions (i.e., adjacent to the surrounding free stream): $\quad C=C_{\infty}$ in the main flow; $C=$ $C_{1}(t)$ in the outer region of the wake adjacent to the surrounding free stream with mass $M_{1}$; and $C=C_{2}(t)$ in the inner core of the wake with mass $M_{2}$. 


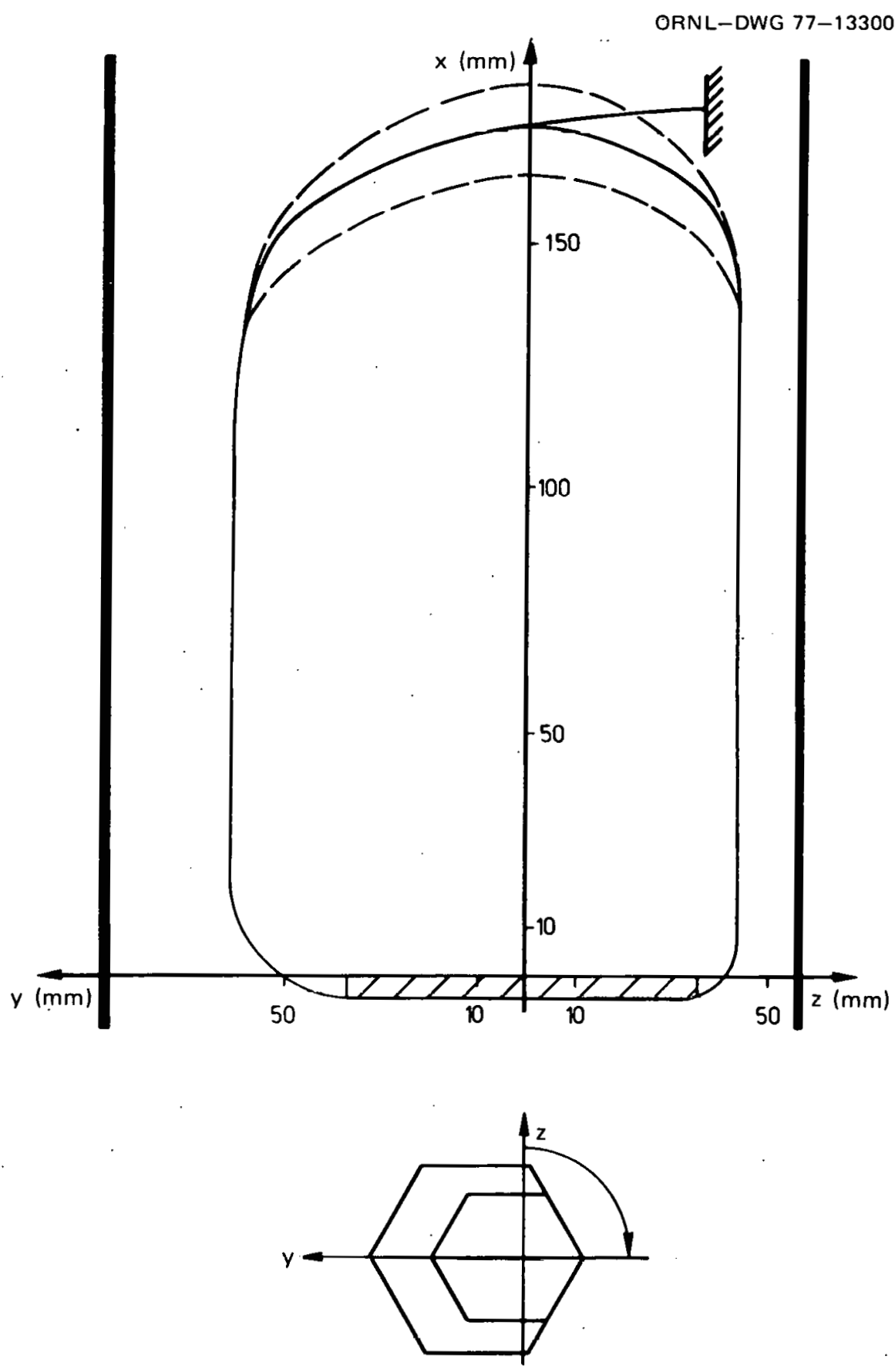

Fig. 78. Wake boundary for blockage 4 (see Fig. 70) $\left(\right.$ Kirsch $^{8}$ ). 


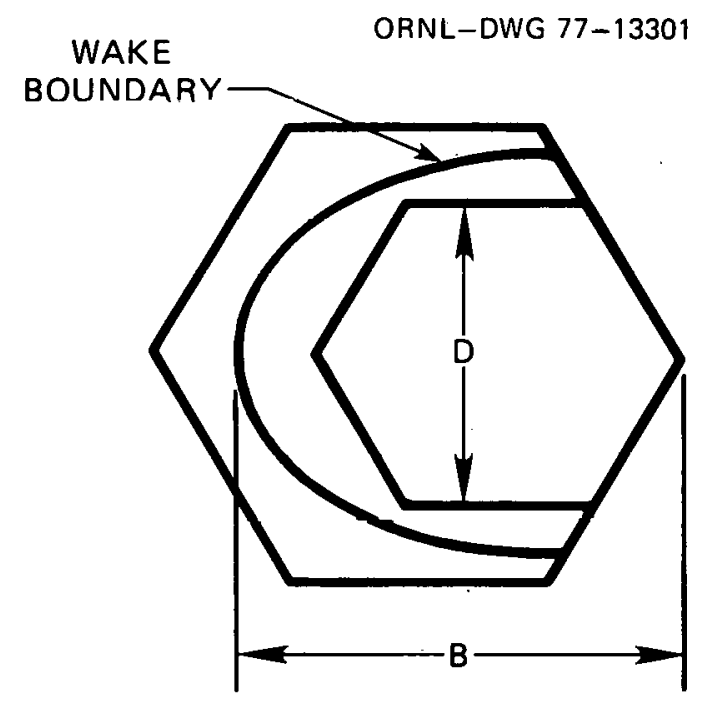

Fig. 79. Wake and blockage dimensions $\left(\mathrm{Kirsch}^{8}\right)$.

The concentration distribution was assumed to remain similar throughout the decay process,

$$
r_{\underline{2}}-r_{B s}=a\left(r_{1}-r_{\dot{\omega}}\right)
$$

where "a" is a proportionality constant that is independent of time and greater chan unity.

Making a maoo balance of $\mathrm{KCl}$ in the wake yields

$$
\dot{\mathrm{m}}\left(\mathrm{C}_{\infty}-\mathrm{C}_{1}\right)=\mathrm{d}\left(\mathrm{M}_{1} \mathrm{C}_{1}+\mathrm{M}_{2} \mathrm{C}_{2}\right) / \mathrm{dt}
$$

Substituting Eq. (14) into Eq. (15) and integrating with respest. to time $t$ yields

$$
\begin{aligned}
C_{1}-r_{\infty} & =\left(C_{1}-C_{\infty}\right)_{\max } \exp \left(-\frac{\dot{m}}{M_{1}+a M_{2}} t\right) \\
& =\left(C_{1}-C_{\infty}\right)_{\max } \exp \left(-t / \tau^{*}\right) .
\end{aligned}
$$

It should be noted that since "a" is greater than $1, \tau^{*}\left[=\left(M_{1}+a M_{2}\right) /\right.$ $\dot{\mathrm{m}}]$ is larger than actual $\tau\left[=\mathrm{M} / \dot{\mathrm{m}}\left(\mathrm{M}_{1}+\mathrm{M}_{2}\right) \dot{\mathrm{m}}\right]$. From concentration measurements, the value of $\tau^{*}$ is determined from Eq. (16). A fictitious mass 
exchange rate $\dot{\mathrm{m}}^{*}=\mathrm{M} / \tau^{*}$ which is somewhat smaller than the actual mass exchange rate of $\dot{\mathrm{m}}=\mathrm{M} / \tau$ can then be obtained. The dimensionless values of $\dot{\mathrm{m}}^{*} / \dot{\mathrm{M}}$ are presented in Table 11 for various blockages (described in Fig. 70), where $\dot{M}$ is the total mass flow in the test section.

The coolant temperature in the wake can now be calculated with the following assumptions:

1. The heat conduction in the blockage area can be neglected.

2. The temperature in the main flow can be averaged over the wake length to give a constant. value $T_{\infty}$.

3. The temperature in the outer wake region of mass $M_{1}$ adjacent to the main flow has a value $T_{1}$.

4. The temperature inside the inner wake region of mass $M_{2}$ has a value $T_{2}$.

5. The average temperature in the wake is $T_{w k}=\left(M_{1} T_{1}+M_{2} T_{2}\right) /$ $\left(M_{1}+M_{2}\right)$.

Using the above assumptions, Kirsch made an energy balance $\dot{Q}$ for the heat transfer from the fuel pins to the fluid in the wake and for the heat transferred through the outer wake region to the surrounding free stream through the mass exchange $\dot{\mathrm{m}}$ :

$$
\dot{\mathrm{Q}}=\dot{\mathrm{mC}}{ }_{\mathrm{p}}\left(\mathrm{T}_{1}-\mathrm{T}_{\infty}\right)
$$

Kirsch introduced a temperature proportionality constant $A_{T}$ such that

$$
T_{2}-T_{\infty}=A_{T}\left(T_{1} \cdots T_{\infty}\right)
$$

where $A_{T}$ is greater than unity.

Table 11. Results of salt concentration measurements in a 169-pin SNR bundle

\begin{tabular}{lllll}
\hline Blockage & 1 & 2 & 3 & 4 \\
\hline$\beta$ & 0.147 & 0.411 & 0.411 & 0.411 \\
$\mu=\dot{\mathrm{m}}^{*} / \dot{\mathrm{M}}$ & $0.032 \pm 0.002$ & $0.059 \pm 0.004$ & $0.055 \pm 0.020$ & $0.070 \pm 0.025$ \\
\hline
\end{tabular}


Substituting Eq. (18) and the definition of $\mathrm{T}_{\mathrm{wk}}$ into Eq. (17) yields

$$
\dot{Q}=\ddot{m}_{T}^{*} C_{p}\left(T_{w k}-T_{\infty}\right)
$$

where $\dot{\mathrm{m}}_{\mathrm{T}}^{*}=\dot{\mathrm{m}}\left[\left(\mathrm{M}_{1}+\mathrm{M}_{2}\right) /\left(\mathrm{M}_{1}+\mathrm{A}_{\mathrm{T}} \mathrm{M}_{2}\right)\right]$. Rearranging the terms in Eq. (19) yields

$$
\mathrm{T}_{w \mathrm{k}}=\mathrm{T}_{\infty}+\frac{\dot{\mathrm{Q}}}{\dot{\mathrm{m}}_{\mathrm{T}}^{*} \mathrm{C}_{\mathrm{p}}} \text {. }
$$

'I'he average oodium temperatures in the wake behtnd the four hioskages (see Fig. 70) were calculated from Eq. (20) and are presented in Table 12. The blockages are assumed to be located axially in the core center (at maximum axial pin power) of an SNR fuel assembly, the volume of the wake $V_{\text {wk }}$ is taken from Table 10, and $\dot{m}_{\mathrm{T}}^{*}$ is approximated by the value of $\dot{\mathrm{m}}^{*}$ given in Table 11. The temperatures thus calculated for all four blockages are lower. than the sodium boiling temperature of approximately $1000^{\circ} \mathrm{C}$.

Table 12: Average sodium temperature in the wake behind the blockage in the SNR fuel, assembly at the highoot power

\begin{tabular}{lllll}
\hline Blockage & \multicolumn{1}{c}{1} & \multicolumn{1}{c}{2} & \multicolumn{1}{c}{3} & \multicolumn{1}{c}{4} \\
\hline$B$ & 0.147 & 0.411 & 0.411 & 0.411 \\
$\mathrm{~T}_{\infty},{ }^{\circ} \mathrm{C}$ & 478 & 489 & 489 & 489 \\
$\mathrm{~T}_{\mathrm{wk}} \cdot{ }^{\circ} \mathrm{C}$ & $710 \pm .30$ & $800+50$ & $760 \pm 170$ & $900 \pm 280$ \\
\hline
\end{tabular}

The temperature distributions in the wake were measured in 10 tests, each at a different flow (11 to $28 \mathrm{l} / \mathrm{s}$ ) and at a different water temperature $\left(20,60\right.$, and $\left.90^{\circ} \mathrm{C}\right)$. The Reynolus number $\left(R e_{\infty}\right)$ in the bundle was in the range of $1.35 \times 10^{4}$ to $9.61 \times 10^{4}$, thus approaching the Reynolds number in the SNR fuel assembly $\left(\operatorname{Re} \approx 10^{5}\right)$. The power absorbed by the bundle was limited by the energy supply available; in all the experiments it was 
$4.61 \pm 0.04 \mathrm{~kW} / \mathrm{m}$ per pin $(15.1 \pm 0.013 \mathrm{~kW} / \mathrm{ft})$ with the margin of error causing the fluctuations between the individual experiments.

Figures 80 and 81 show the measured temperature increases (above the inlet temperature) at various distances downstream of the blockage for the lowest and highest Reynolds number $\left(\operatorname{Re}_{\infty}=1.35 \times 10^{4}\right.$ and $\left.9.61 \times 10^{4}\right)$.

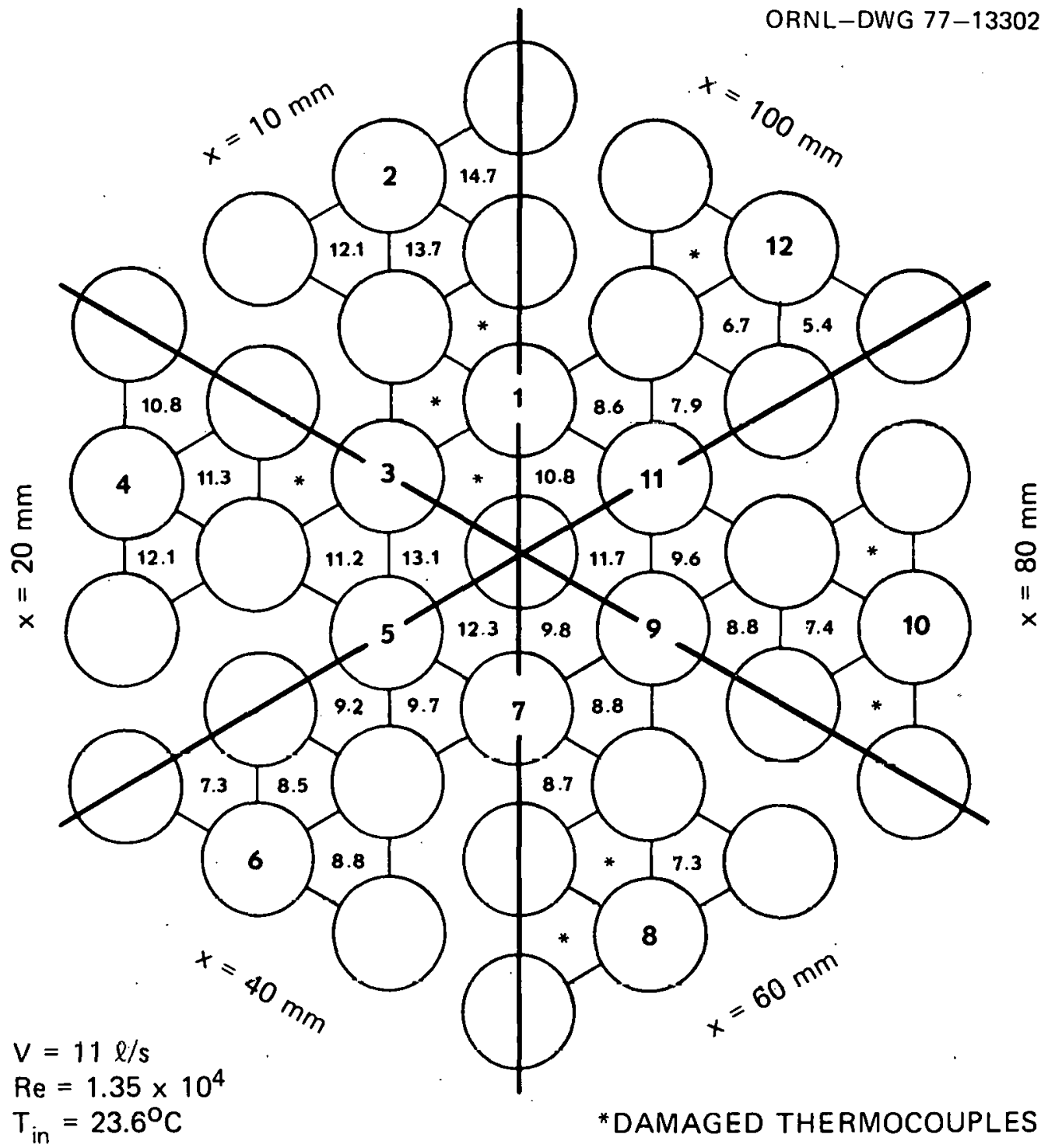

Fig. 80. Temperature rises above inlet temperature behind a central blockage in a 169-pin SNR bundle at Reyuulds number of $1.35 \times 10^{4}$ (Kirsch $^{8}$ ). 


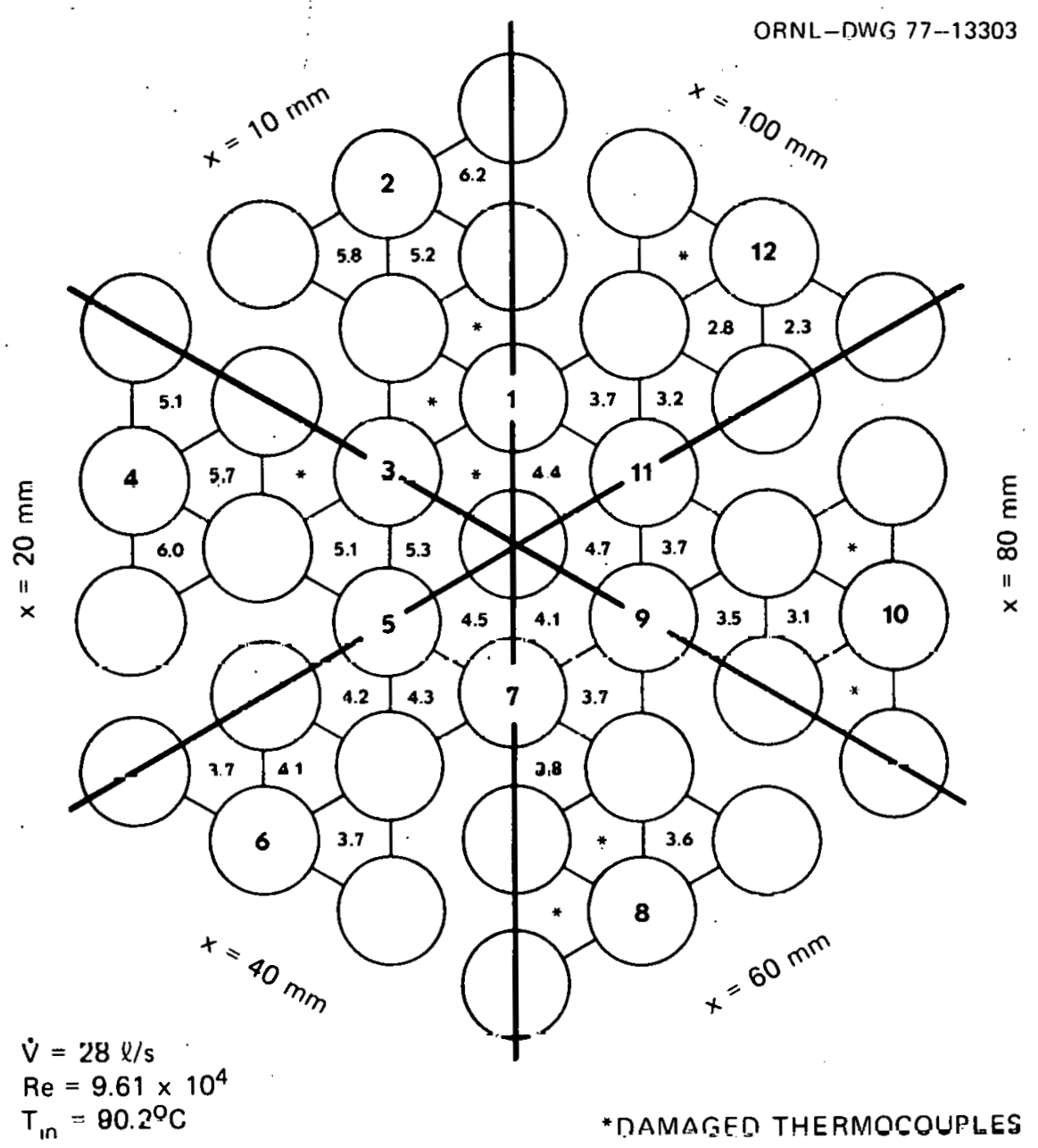

Fig. 81. Tempcrature rizes above lillet cemperature behind a centrai blockage in a.169-pin SNR bundle at Reynolds number of $9.61 \times 10^{4}$ (Kirsch $^{8}$ ).

Throughout the range investigated $\left(10^{4} \lesssim \operatorname{Re} \delta 10^{5}\right.$, the nondimensional temperatures $\bar{\theta}_{i}$ are independent of the Reynolds number; that is; $\bar{\theta}_{1}=\left(\mathrm{T}_{i}\right.$, 'I' ${ }_{B} / I^{\prime}$ out $-T_{i n}$ ', where $T_{B}=$ bulk mean temperature at the hinckage:

Figure 82 . shows the dimensionless temperatures $\bar{\theta}_{4}$ and $\bar{\theta}_{19}$ for thermocouples T4 and T19 (see Fig. 73) as a function of Reynolds number Re. A similar trend was found for all other thermocouples.

The temperature distribution in the wake is shown in Fig. 83, where the values of $\bar{\theta}$ calculated from measured data are plotted for $\operatorname{Re}_{\infty}=9.61 \times$ $10^{4}$. It can be seen that the temperature at the center of the wake rises 


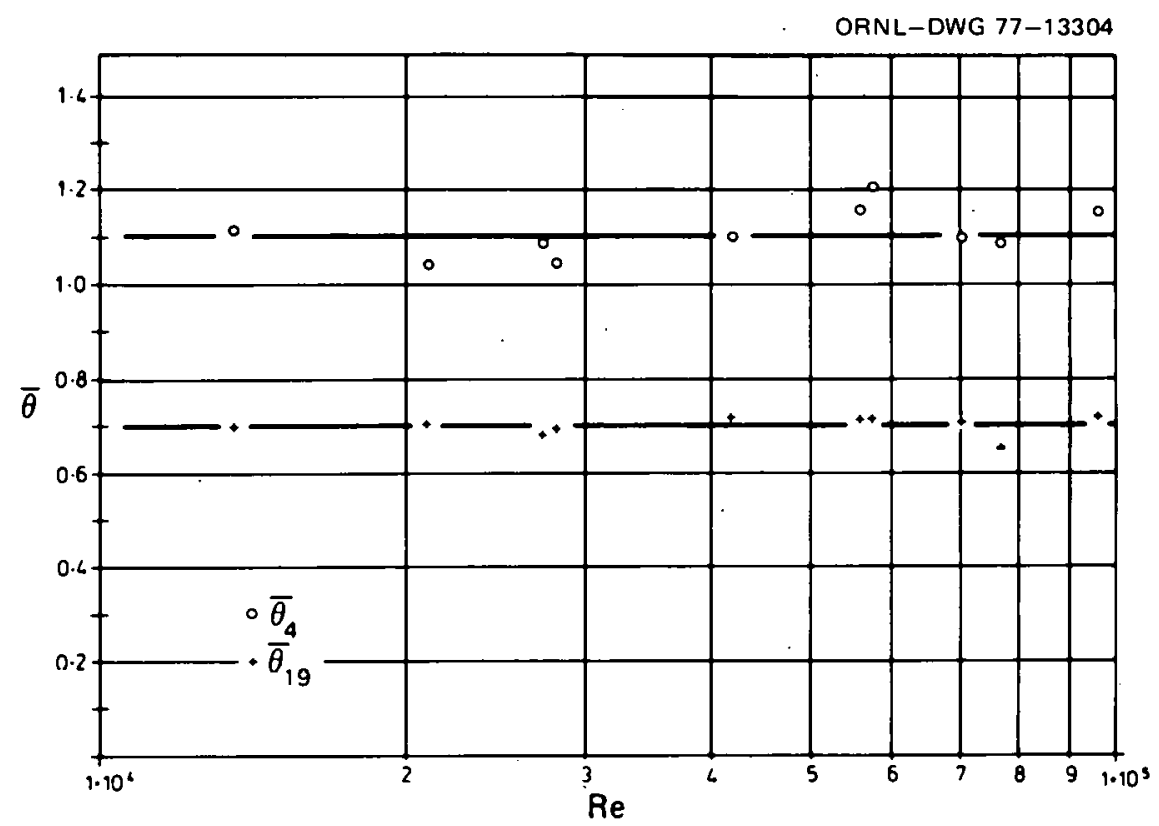

Fig. 82. Dimensionless temperatures as a function of Reynolds number from two thermocouples in the wake behind a central blockage (Kirsch ${ }^{8}$ ).

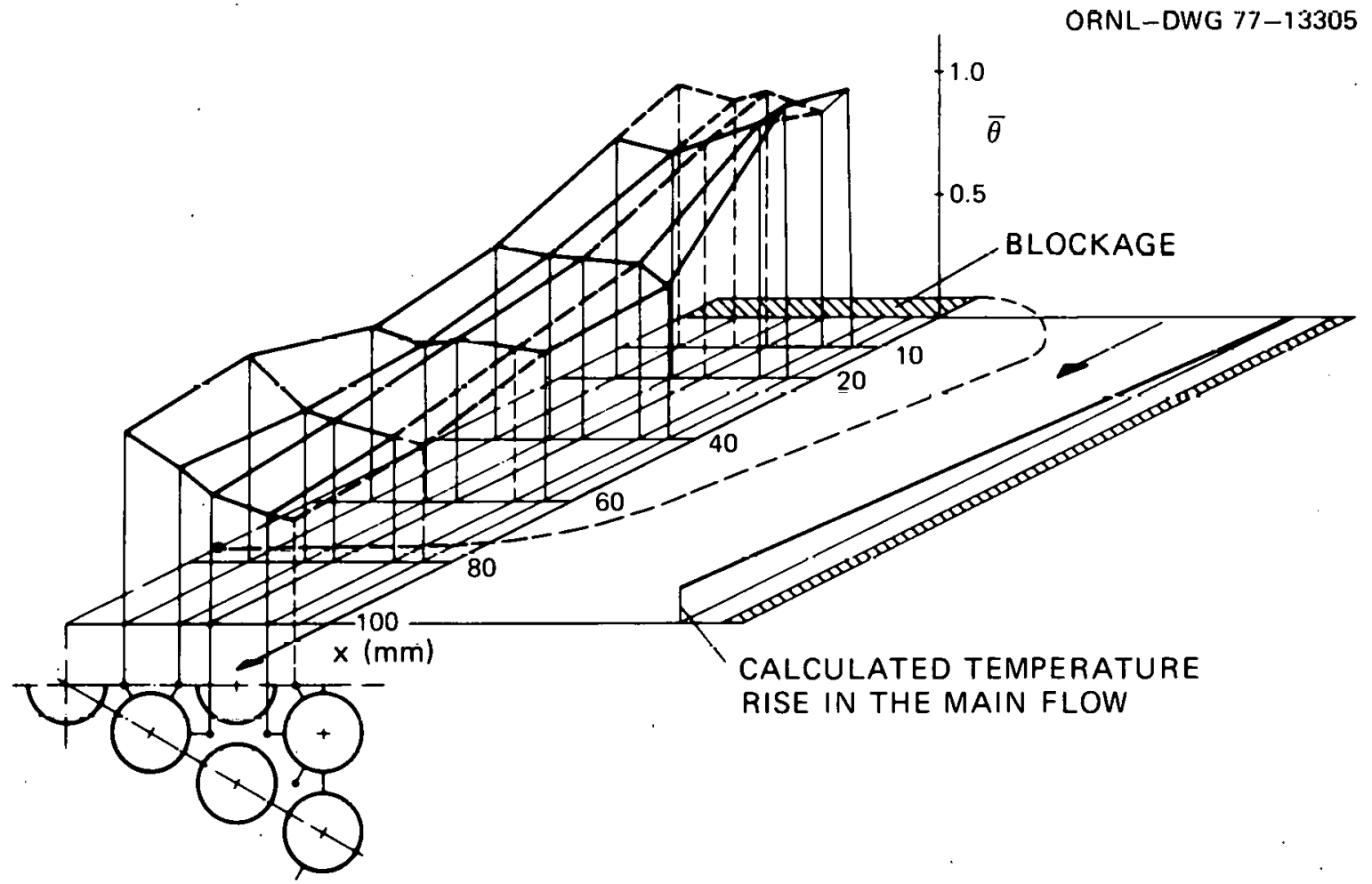

Fig. 83. Dimensionless temperature distribution behind a central blockage with Reynolds number of $9.61 \times 10^{4}\left(\mathrm{Kirsch}^{8}\right)$. 
axially toward the blockage. The temperature peak is located immediately downstream and near the outer edge of the blockage rather than at the center; this can be accounted for by the flow pattern, since downstream of the blockage the fluid flows radially outward from the center and is further heated up in the process.

\subsection{Miscellaneous Results}

\subsubsection{Six-channel blockage in a 7-pin sodium-cooled bundle}

Daigo et al. 9 measured surface temperatures of fuel pins in a 7-pin sodium-cooled electrically heated bundle with the central six channels blocked by a plate. Results were obtained at sodium velocity in the range of 0.37 to $5.00 \mathrm{~m} / \mathrm{s}$ ( 1.2 to $16.4 \mathrm{fps}$ ) with a power level in the range of 0.85 to $12.7 \mathrm{~kW} / \mathrm{m}(0.26$ to $3.87 \mathrm{~kW} / \mathrm{ft})$ per pin.

Test section. Figure 84 shows the test section with a local blockage at the spacer grid. The seven electrically heated pins are enclosed in a hexagonal duct with an inner flat-to-flat distance of $24 \mathrm{~mm}$ (0.94 in.). The dimensions and configuration of the pins are similar to those of the fuel assembly of MONJU, the Japanese prototype LMFBR, except that the heated length is $450 \mathrm{~mm}(17.7 \mathrm{in.})$ rather than $900 \mathrm{~mm}$ (35.4 in.): Each pin has an outer diameter of $6.5 \mathrm{~mm}(0.26 \mathrm{in.})$ and the distance between pin centers is $7.9 \mathrm{~mm}$ ( $0.31 \mathrm{in,)}$. The pitch-to-diameter ratio is 1.22 . The central six channels are blocked by a non-heat-generating 0.5 -mm-thick (0.02 in.) stainless steel plate which is welded on the upstream side of the grid $350 \mathrm{~mm}$ ( $13.8 \mathrm{in.}$ ) from the start of the heated zone. A detailed description of the blockage and the grid spacers is shown in Fig. 85 . The grid spacer consists of stainless steel tubes with an outer radius of $3.95 \mathrm{~mm}(0.16 \mathrm{in.})$ and a height of $5 \mathrm{~mm}(0.2 \mathrm{in.})$. The blockage and the grid spacer cover $42 \%$ of the total flow area. Sodium enters through a nozzle and flows upward in the bundle. To maintain a minimum heat loss, the outer wall of the test tube is insulated and a guard heater is used.

The pin surface temperatures are measured by $0.3-\mathrm{mm}$-diam (0.01-in.) Chromel-Alumel thermocouples embedded in the surface of each pin. The hot 


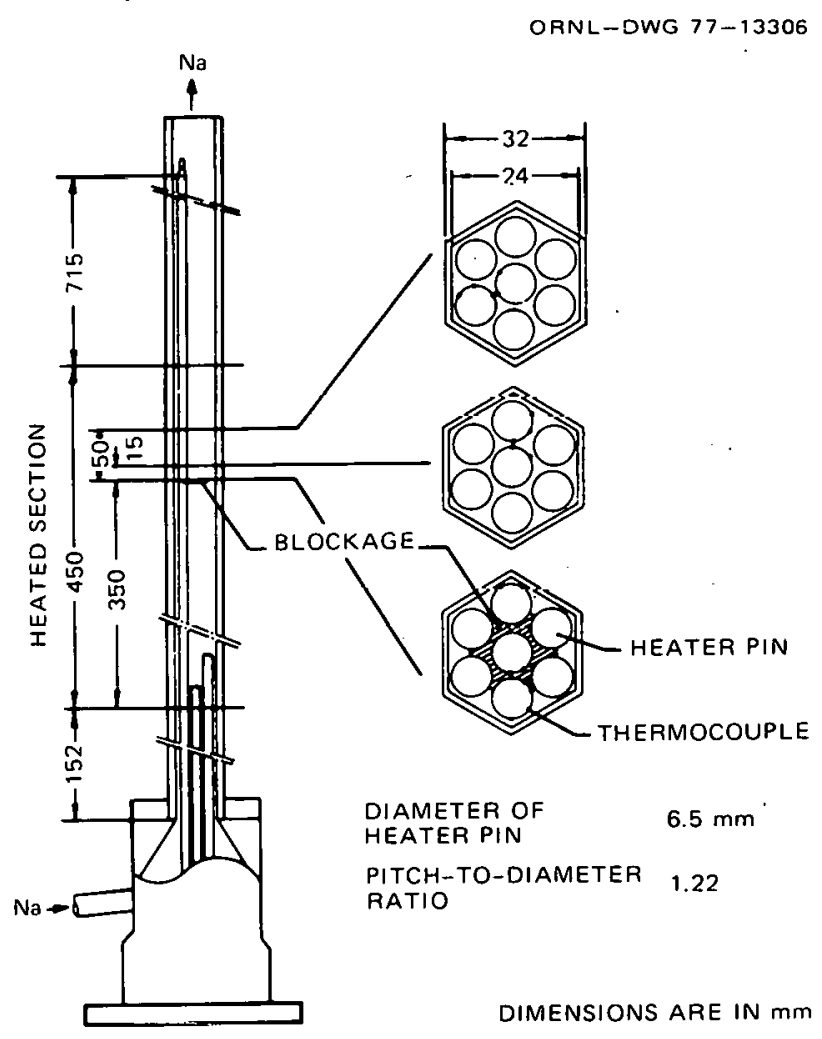

Fig. 84. Test section of a 7-pin bundle with a 6-channel central blockage (Daigo et a1. ${ }^{9}$ ).

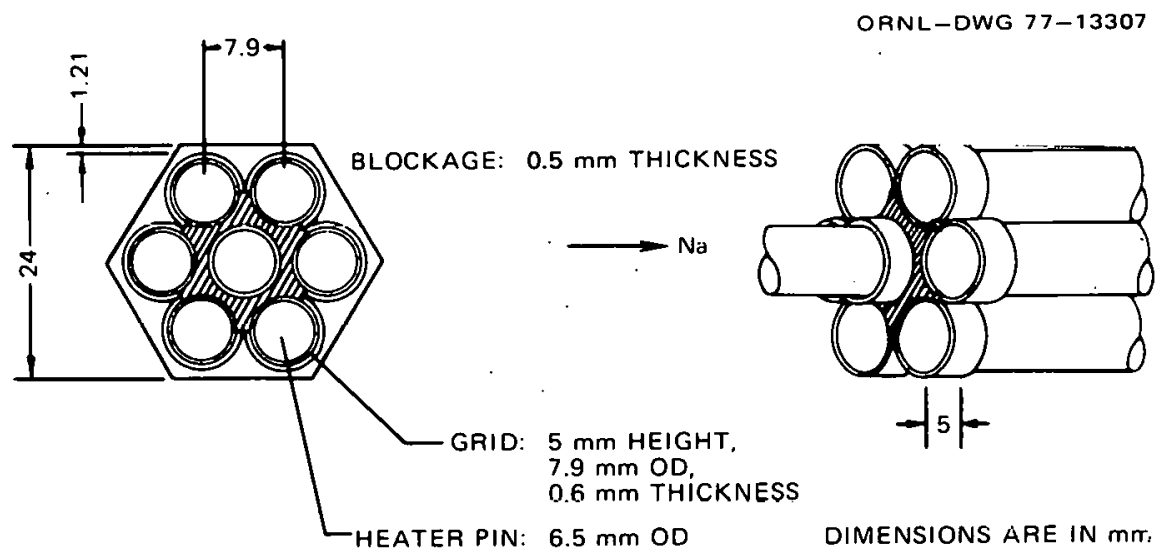

Fig. 85. Blockage plate and grid spacer (Daigo et al. ${ }^{9}$ ). 
junctions of the thermocouples are grounded and are located at the blockagc and 15 and $50 \mathrm{~mm}$ (0.59 and $2.0 \mathrm{in.})$ downstream from the blockage.

Results and discussion. Figure 86 shows the longitudinal wall temperature distribution behind the blockage. The ordinate is the temperature difference between the wall and the bulk coolant at the blockage location; the abscissa is distance downstream from the blockage. The highest wall temperature (as shown in Fig. 86) was measured on the surface of the central pin at the blockage. The temperature decreases with the distance downstream from the blockage. Daigo et al. assumed that the temperature rise downstream from the blockage was due to the stagnation of ronlant flow

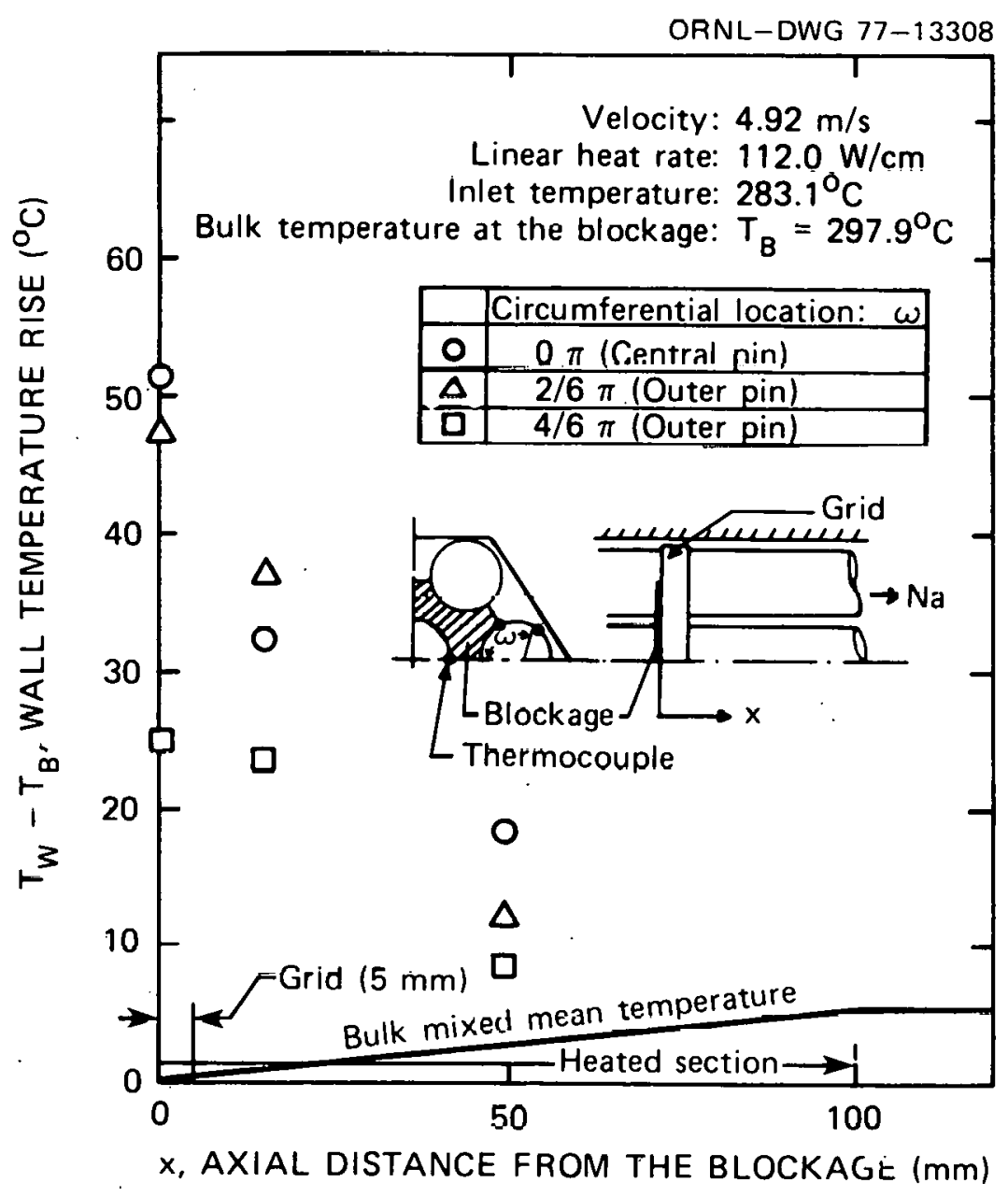

Fig. 86. Axial wall temperature distribution behind a 6-channel central blockage (Daigo et al. ${ }^{9}$ ). 
caused by the grid spacer, which prevented the mass exchange between the blocked channel and the outer normal channels.

Figure 87 shows the measured circumferential wall temperature distribution at the blockage and 15 and $50 \mathrm{~mm}$ downstream from the blockage. The temperature peak occurred on the surface of the outer pin facing the edge of the blocked channel and $15 \mathrm{~mm}$ downstream of the blockage. The coolant is further heated when it is flowing radially from the center of the blockage to its edge. At $50 \mathrm{~mm}$ downstream of the blockage, however, no temperature rise was observed at the edge of the blocked channel. The axial length

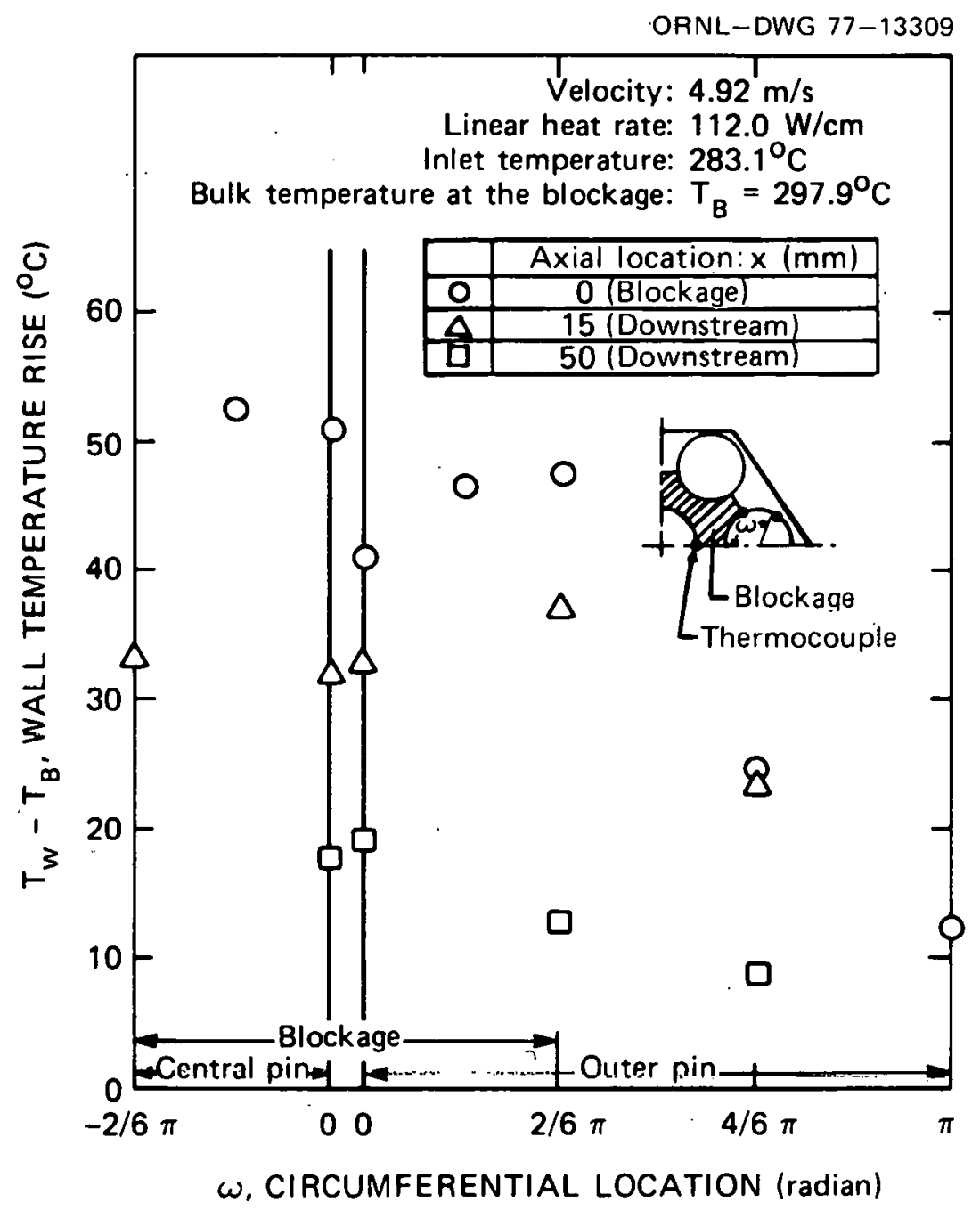

Fig. 87. Circumferential wall temperature distribution around the blockage (Daigo et al. ${ }^{9}$ ). 
of the wake was estimated to be in the range of 20 to $25 \mathrm{~mm}(0.079$ to 0.098 in.).

Figures 88 and 89 show the effect of linear heat rate on wall-temperature rise behind the blockage under constant flow velocity. As shown, the wall temperature increases linearly with the increase of linear heat rate. The heat transfer coefficient is therefore constant both at the blockage position and $15 \mathrm{~mm}$ downstream.

Figure 90 shows the Nusselt number at the blockage position and 15 and $50 \mathrm{~mm}$ downstream of the blockage. The wall temperatures were measured on the surfacc of the central pin facing the outer pin. The bulk conlant temperatures across the cross section at the same axial positions where the wall temperatures were measured were calculated from the measured inlet and outlet temperatures and the distance between the start of the

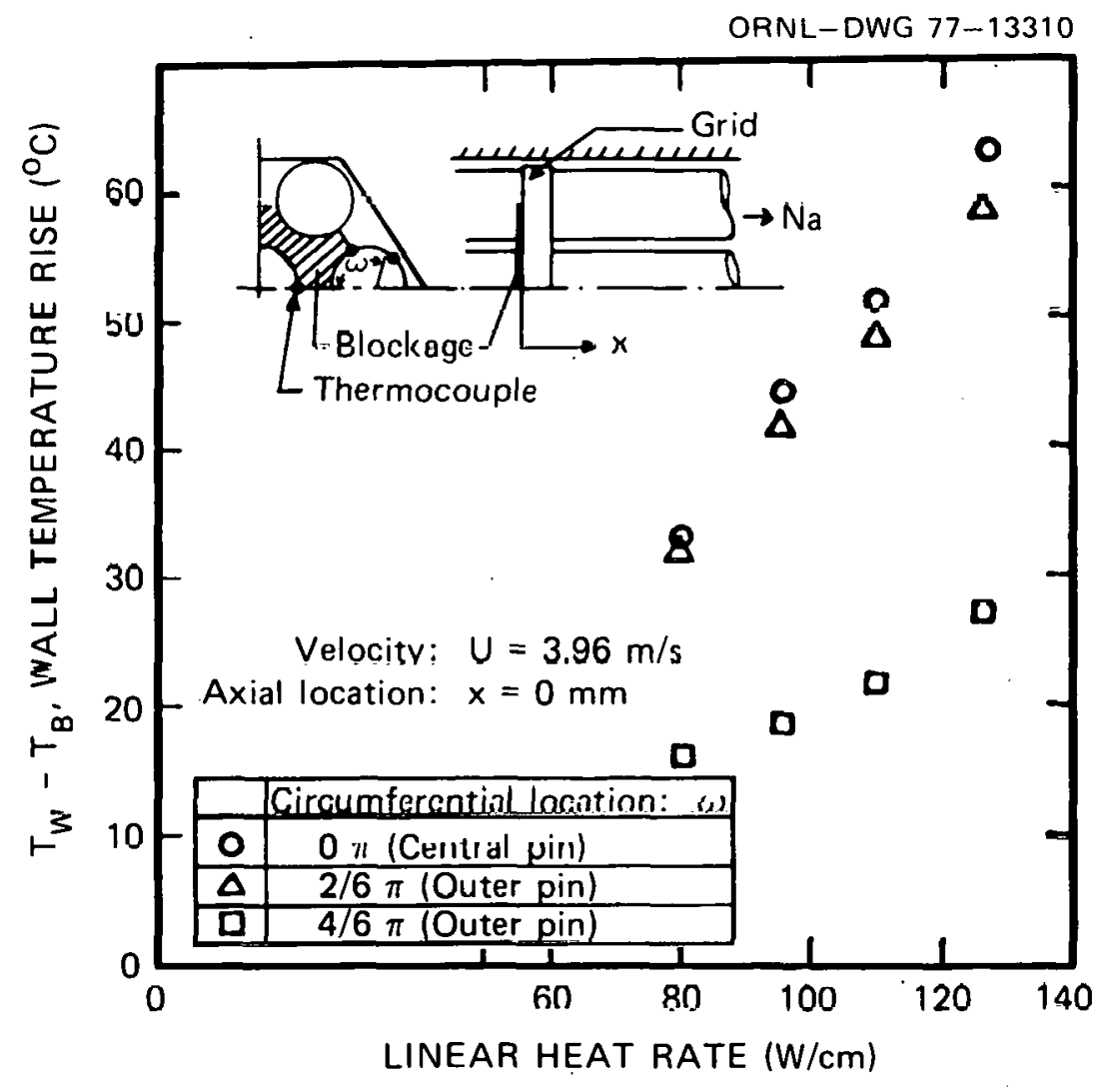

Fig. 88. Effect of linear heat rate on wall temperature rise at the blockage (Daigo et al. ${ }^{9}$ ). 


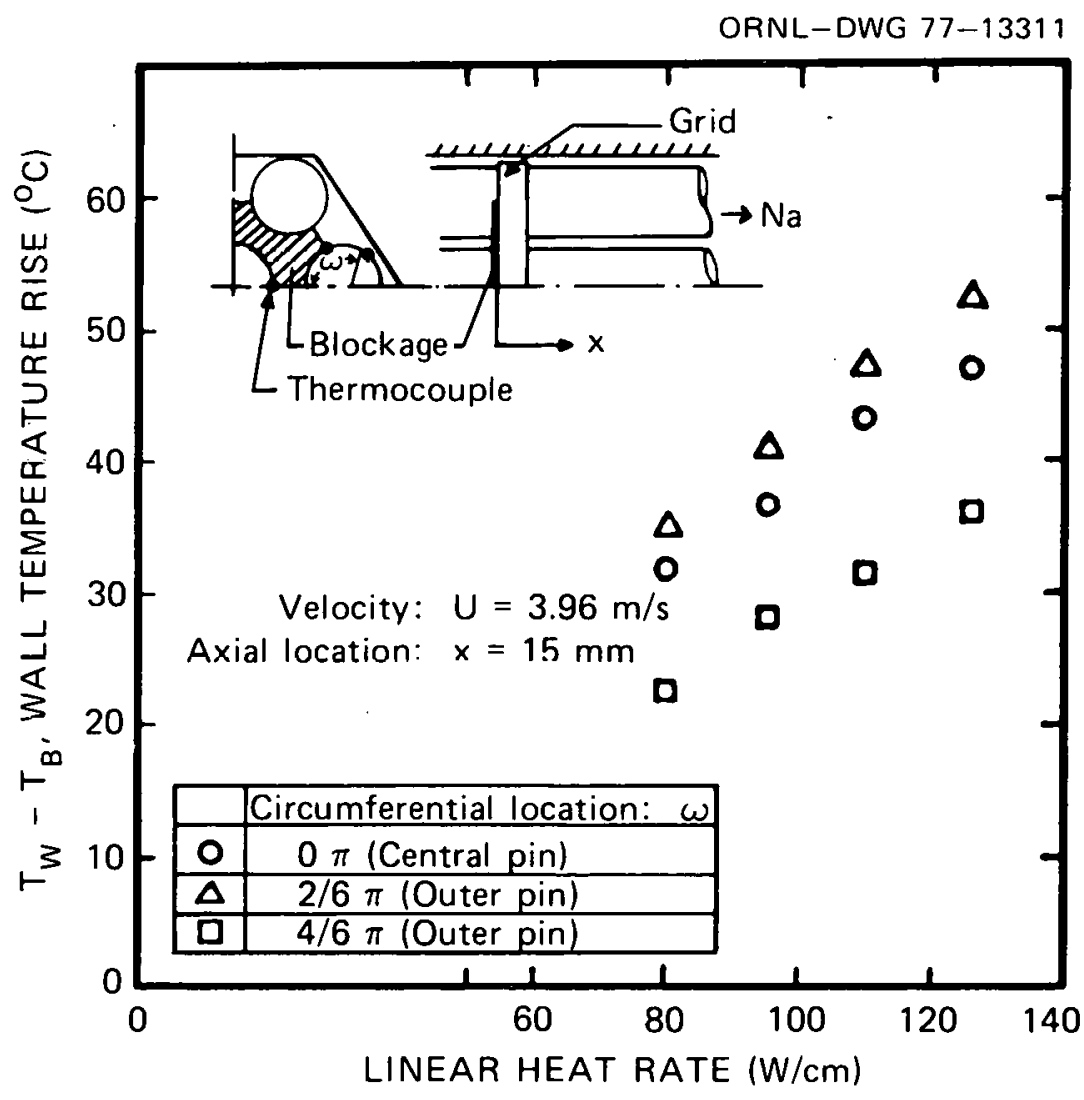

Fig. 89. Effect of linear heat rate on wall temperature at $15 \mathrm{~mm}$ ( 0.59 in.) downstream from the blockage (Daigo et al. ${ }^{9}$ ).

heated section and the measuring point. The experimental results for a normal 7=pin bundle with wire-wrap spacers are also shown in Fig. 90. As shown, the Nusselt number is higher with higher flow velocity. In the figure, $U$ is the coolant flow velocity through the normal section, and $\mathrm{U}_{\mathrm{B}}$ is the velocity through the narrowest flow section. The Nusselt number obtained at the blockage position is lower than that obtained in the normal pin bundle. The Nusselt number at $50 \mathrm{~mm}$ downstream from the blockage agrees well with that obtained in the normal pin bundle with wire-wrap spacers. Daigo et al. 9 concluded that if the experimental results are extrapolated to the fuel assembly conditions of the MONJU (Japanese LMFBR) (with a linear heat rate of $40 \mathrm{~kW} / \mathrm{m}$ and a sodium velocity of $5 \mathrm{~m} / \mathrm{s}$ ), the wall temperature rise due to a 6-channel blockage would be less than $130^{\circ} \mathrm{C}$. 


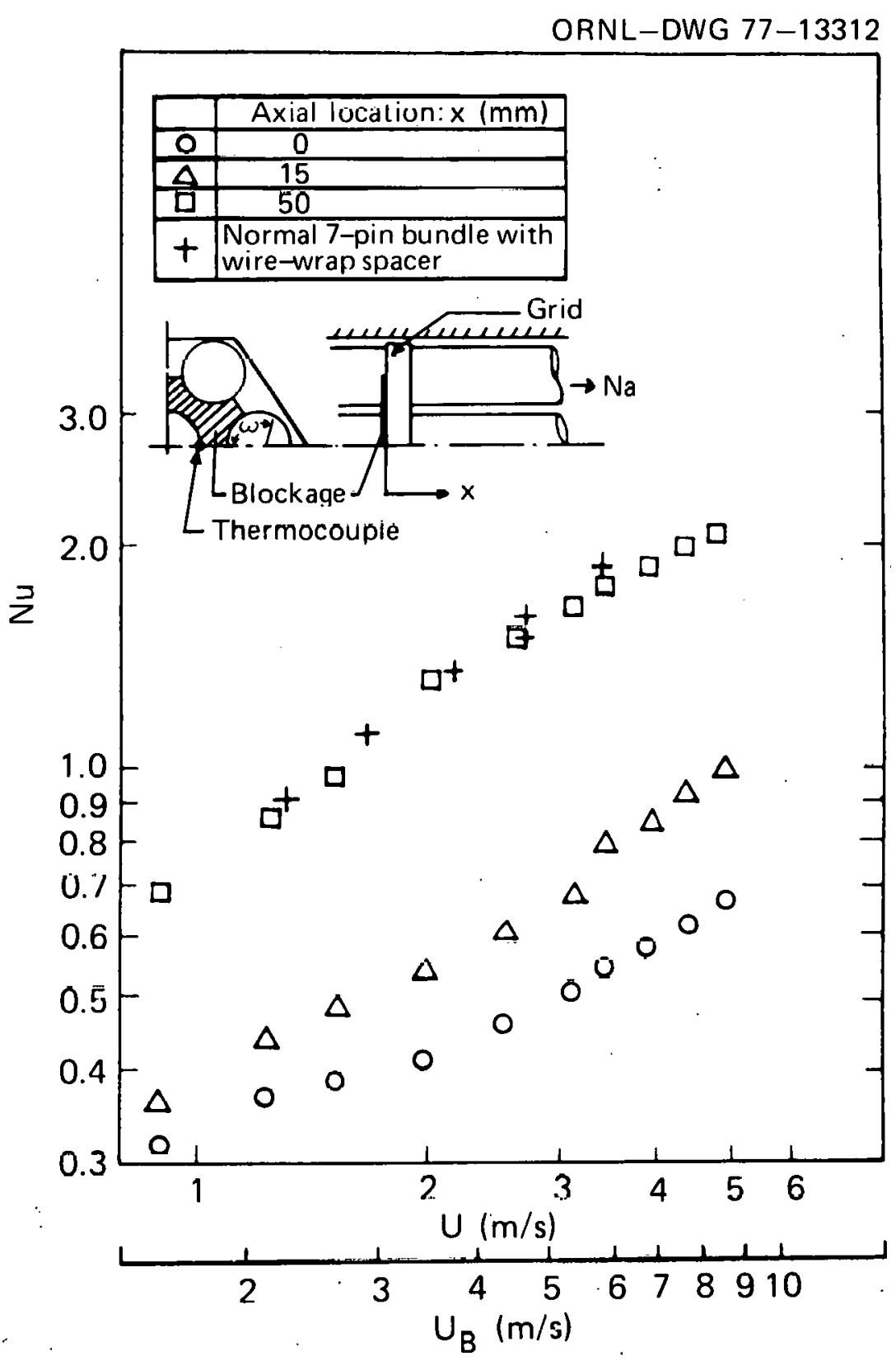

Fig. 90. Nusselt number behind the 6-channel central blockage in a 7 -pin sodium-cooled bundle (Daigo et a1. ${ }^{9}$ ). 


\subsubsection{Four-channel blockage in a 19-pin water-cooled bundle}

Van Erp and Chawla ${ }^{10}$ obtained temperature measurements in a watercooled 19-pin bundle with a 4-channel blockage ( 1 channel plus its adjacent 3 channels).

Test section. The experiments were performed at Argonne National Laboratory (ANL) as part of the fission-gas release program and utilized a test section comprising a hexagonal array of 19 electrically heated, water-cooled, thin-walled pins in an equilateral triangular arrangement which simulated part of an LMFBR assembly. The outer diameter and length of the pins were $6.35 \mathrm{~mm}$ (0.250 in.) and $1830 \mathrm{~mm}$ (72 in.), respectively. The pins were spaced by $1.27-\mathrm{mm}(0.05-\mathrm{in}$.$) wires at a pitch of 7.68 \mathrm{~mm}$ (0.3025 in.) and an axial pitch of $305 \mathrm{~mm}$ (12 in.). Thermocouples were installed inside the pins in representative channels at various axial locations, both in the coolant (protruding through the pin wall and insulated from it, with a time constant of approximately $2 \mathrm{msec}$ ) and spot welded onto the pin wall.

Results and discussion. The 4-channel flow blockage was studied by heating the test section uniformly (maximum heat flux approximately 20 $\mathrm{W} / \mathrm{cm}^{2}$ ) and recording the steady-state values of the coolant and pin-wall temperatures at various axial locations, both in channels behind the blockage and in unblocked channels. It was found that the heat transfer coefficient in the central channel of the blocked region at an axial location $6.35 \mathrm{~mm}$ ( $0.25 \mathrm{in.})$ downstream from the blockage, as determined from coolant and pin-wall temperatures, can be represented by

$$
\mathrm{Nu}=(9.58) \operatorname{Re}^{0.28} \operatorname{Pr}^{0.33} .
$$

The heat transfer coefficient in unblocked channels was experimentally funid to follow the expression

$$
\mathrm{Nu}=(0.041) \operatorname{Re}^{0.8} \operatorname{Pr}^{0.39} .
$$

For coolant velocities less than approximately $9.1 \mathrm{~m} / \mathrm{s}$ (30 fps), the local heat transfer coefficient for the blocked case was higher than that of the unb1nrked case, whereas the opposite occurred for coolant velocities 
greater than approximately $9.1 \mathrm{~m} / \mathrm{s}$. Equation (21) is shown in Fig. 65 along with Schleisiek's results.

\subsubsection{Velocity profiles in a 39-pin air bundle with 1 - and 4-channel blockages}

Vegter et al. ${ }^{11}$ measured velocity distributions in a 39-pin air-cooled bundle with 1 - and 4-channel blockages. The bundle is a one-sixth portion of an 11:1 scale 217-pin LMFBR fuel assembly using grid spacers, as shown in Figs. 91 and 92. Velocity profiles upstream and downstream of the blockage, excluding the wake region, were obtained at a Reynolds number of 71,000 .

Test section. The test section ronsisted of a" 5720-mm-1ong (225-in.) air flow duct scaled 11:1 over present design parameters for an LMFBR assembly without wire-wrap spacers. The simulated fuel pins had an outside diameter of $63.5 \mathrm{~mm}$ (2.5 in.) and a pin pitch of $79.8 \mathrm{~mm}$ (3.14 in.). Three grid spacers were axially located to hold the pins as shown in Fig. 93.

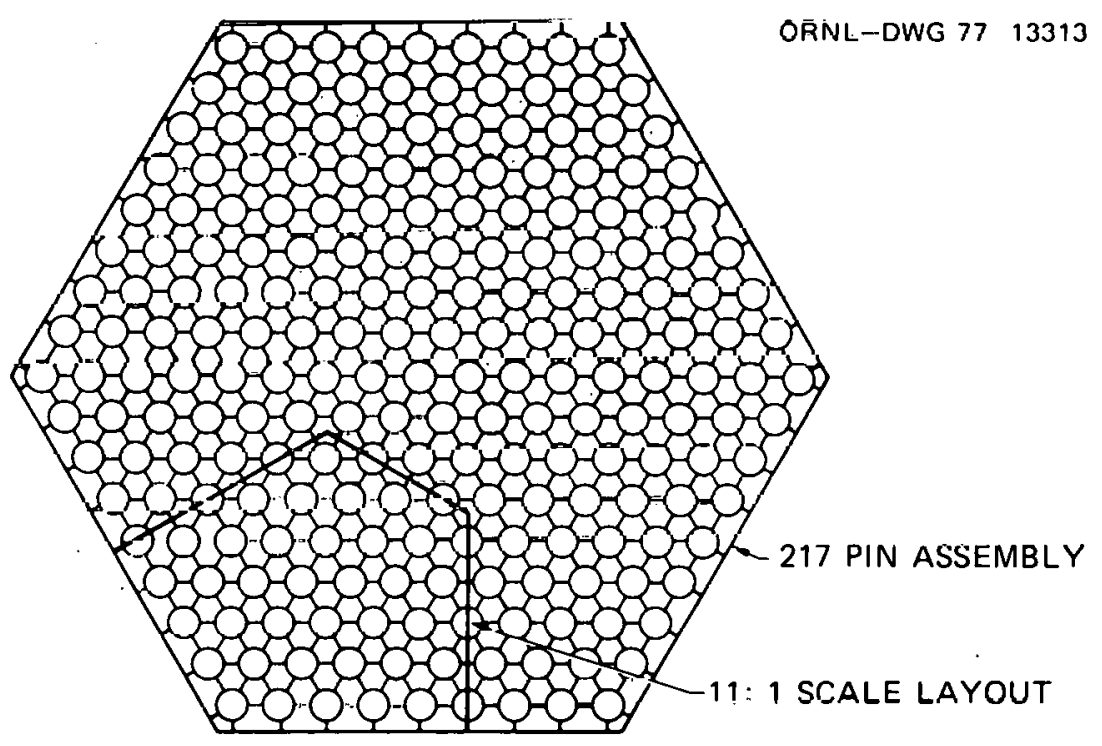

Fig. 91. A 217-pin bundle with one-sixth of its cross section superimposed (Vegter et al.11). 


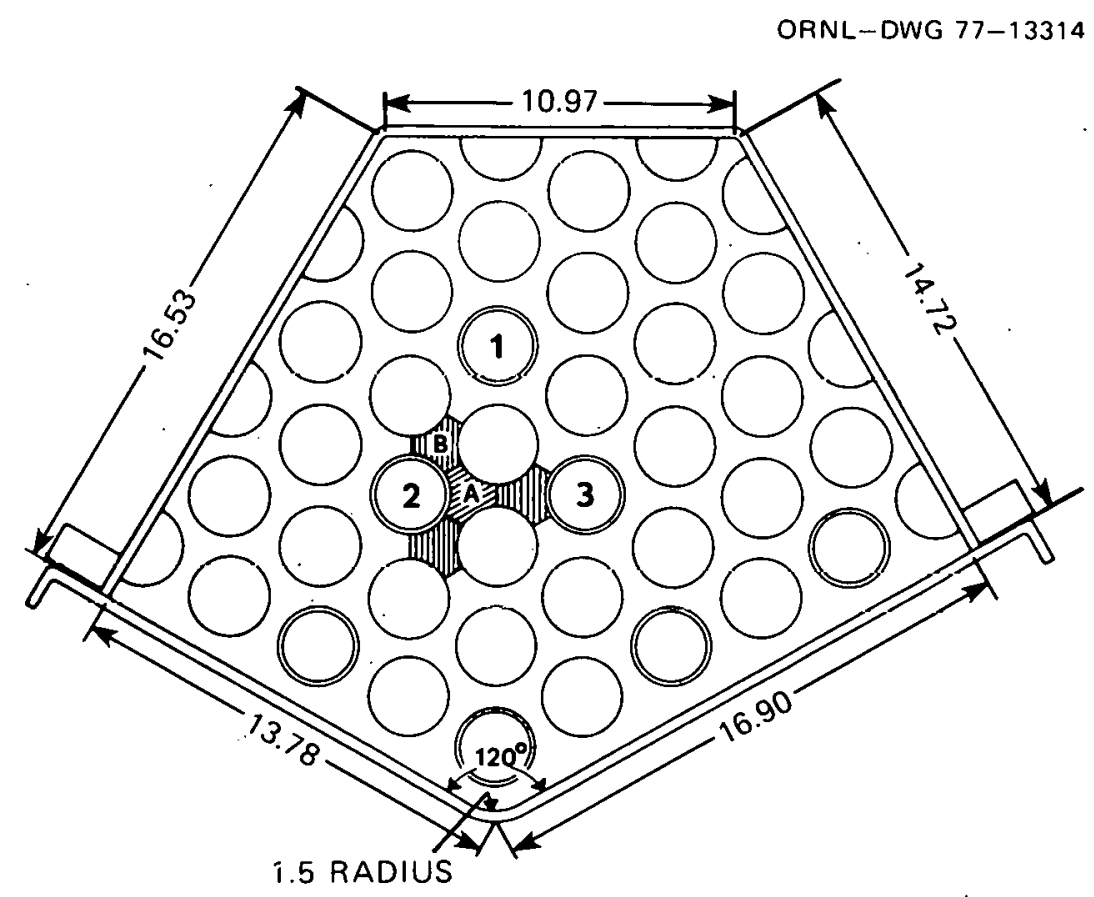

Fig. 92. Test section with blockage locations (dimensions in inches) (Vegter et al. ${ }^{\text {l }}$ ).

ORNL-DWG 77-13315

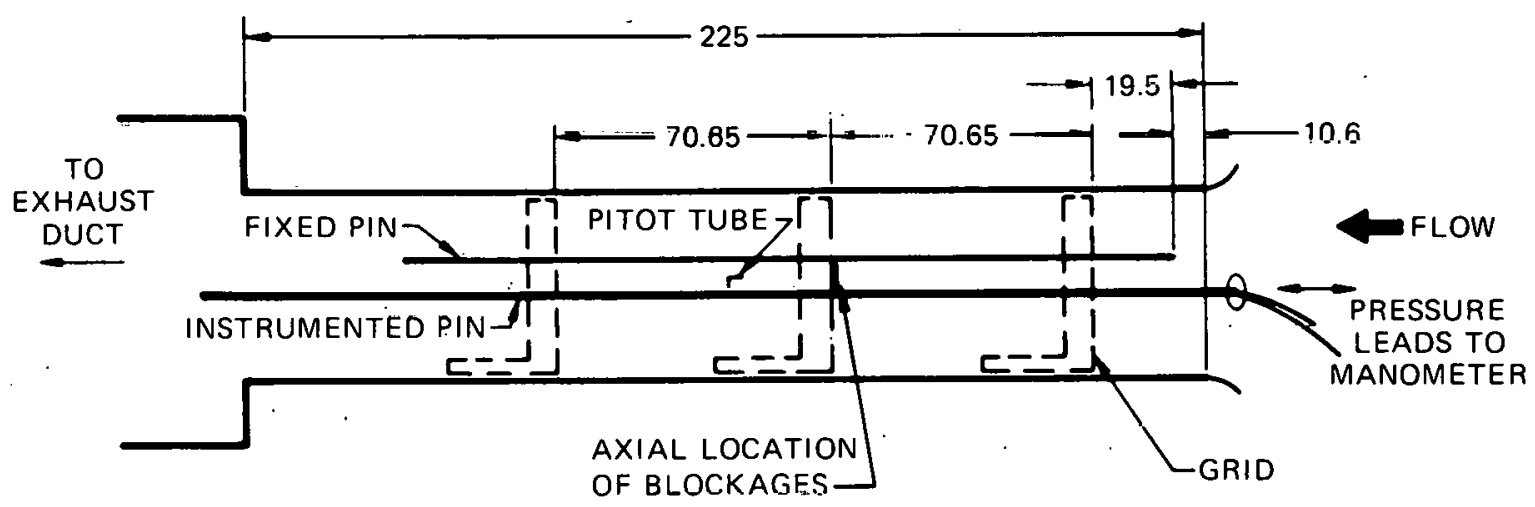

Fig. 93. Schematic diagram of 11:1 scale pin bundle using grid spacers (dimensions in inches) (Vegter et al. ${ }^{11}$ ). 
The three numbered pins in Fig. 92 housed 1.59-mm-diam (0.0625-in.) pitot-static probes that could be raised and lowered from outside the upstream entrance to the duct. These instrumented pins could also be rotated and moved axially in and out of the duct to provide considerable measurement flexibility.

Two different blockages were inserted into the test section as shown in Fig. 92 at the radial positions indicated by the cross-hatching. Configuration A blocks one channel and configuration B blocks the same and three adjacent channels. Figure 94 shows the dimensions of the blockage plates, which were made of $6.35-\mathrm{mm}$-thick (0.25-in.) plastic.

Results and discussion. The experimentally determined velocities were normalized with respect to the mean velocity through the pin bundle with a

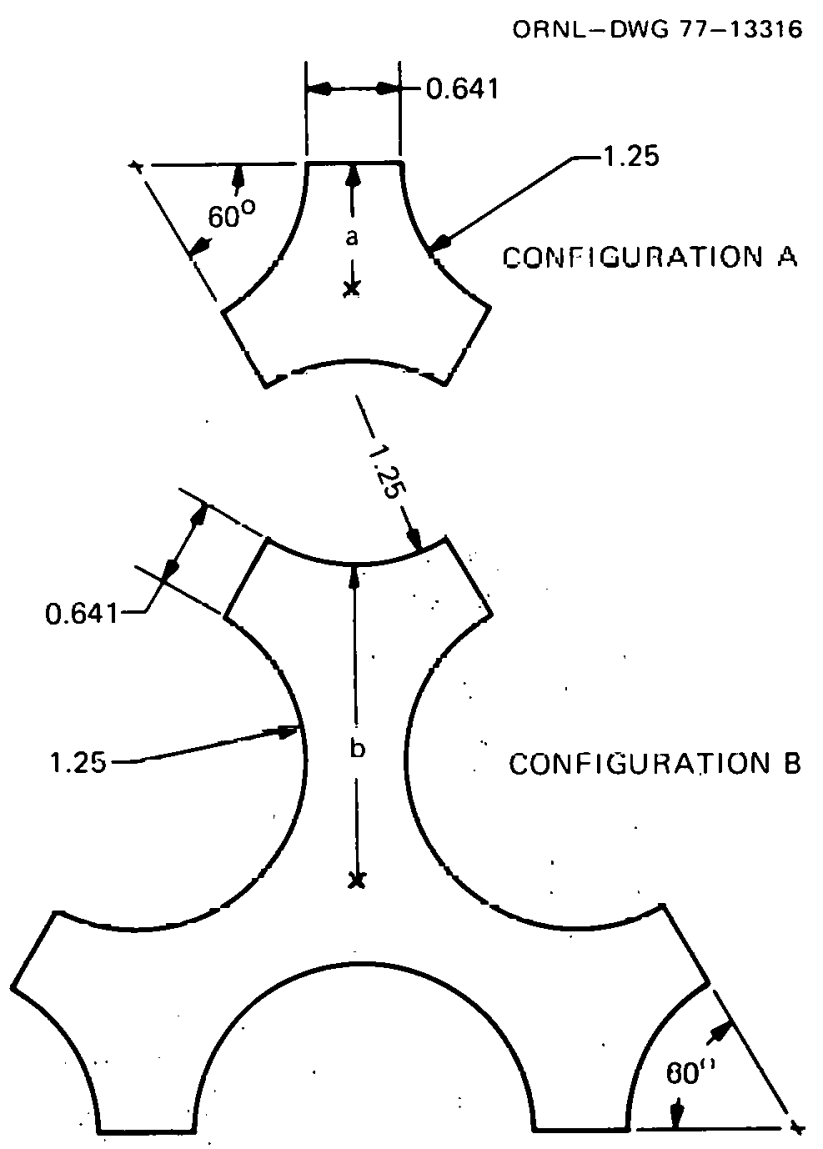

DIMENSIONS ARE IN INCHES

Fig. 94. Blockage dimensions (Vegter et a1. ${ }^{11}$ ). 
Reynolds number of 71,000 , which is comparable to that of an LMFBR fuel assembly design. Figure 95 shows the transverse velocity profile downstream of the 1-channel blockage, and Fig. 96 shows the transverse velocity profile downstream of the 4-channel blockage (positive angle in clockwise direction). The axial velocity distributions downstream of these two blockages are shown in Fig. 97.

For blockages approximated as disks with radii of $a=23 \mathrm{~mm}(0.91 \mathrm{in.})$ for configuration $\mathrm{A}$, and $\mathrm{b}=58 \mathrm{~mm}$ (2.28 in.) for configuration $\mathrm{B}$ (Fig. 94), Vegter et al. ${ }^{1}$ obtained the following wake lengths: $\mathrm{L} / \mathrm{a}=5.8 \pm 0.5$ for 1 -channel blockage and $\mathrm{L} / \mathrm{b}=5.1 \pm 0.25$ for 4-channel blockage, where $\mathrm{L}$ is measured from the upstream face of the blockage. These results are in good agreement with Carmody's ${ }^{12}$ disk value of 5.2 and indicate that the presence of pins or grid spacers does not appear to affect the wake length behind the blockage.

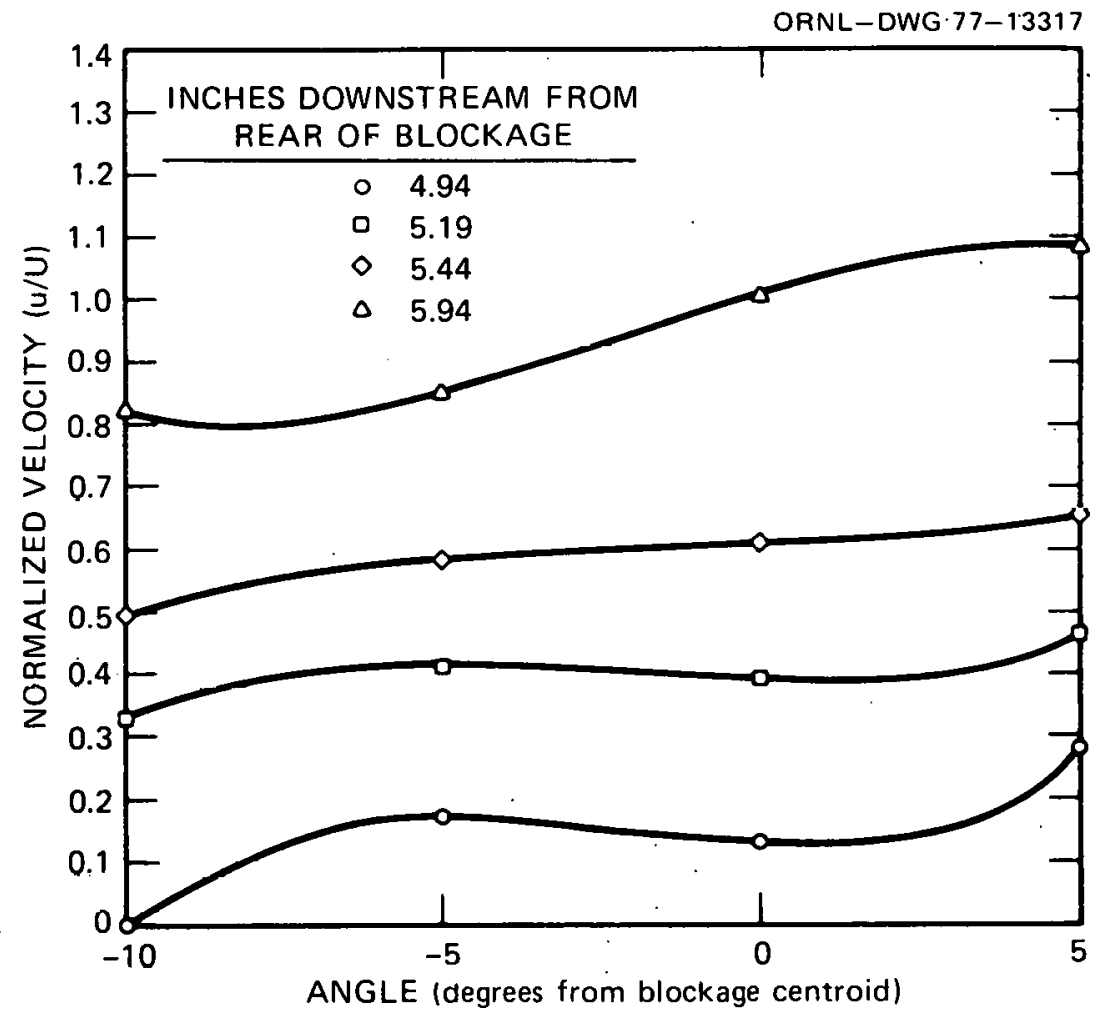

Fig. 95. Transverse velocity profile downstream of a 1-channel blockage (configuration A in Fig, 92) (Vegter et al. ${ }^{11}$ ). 


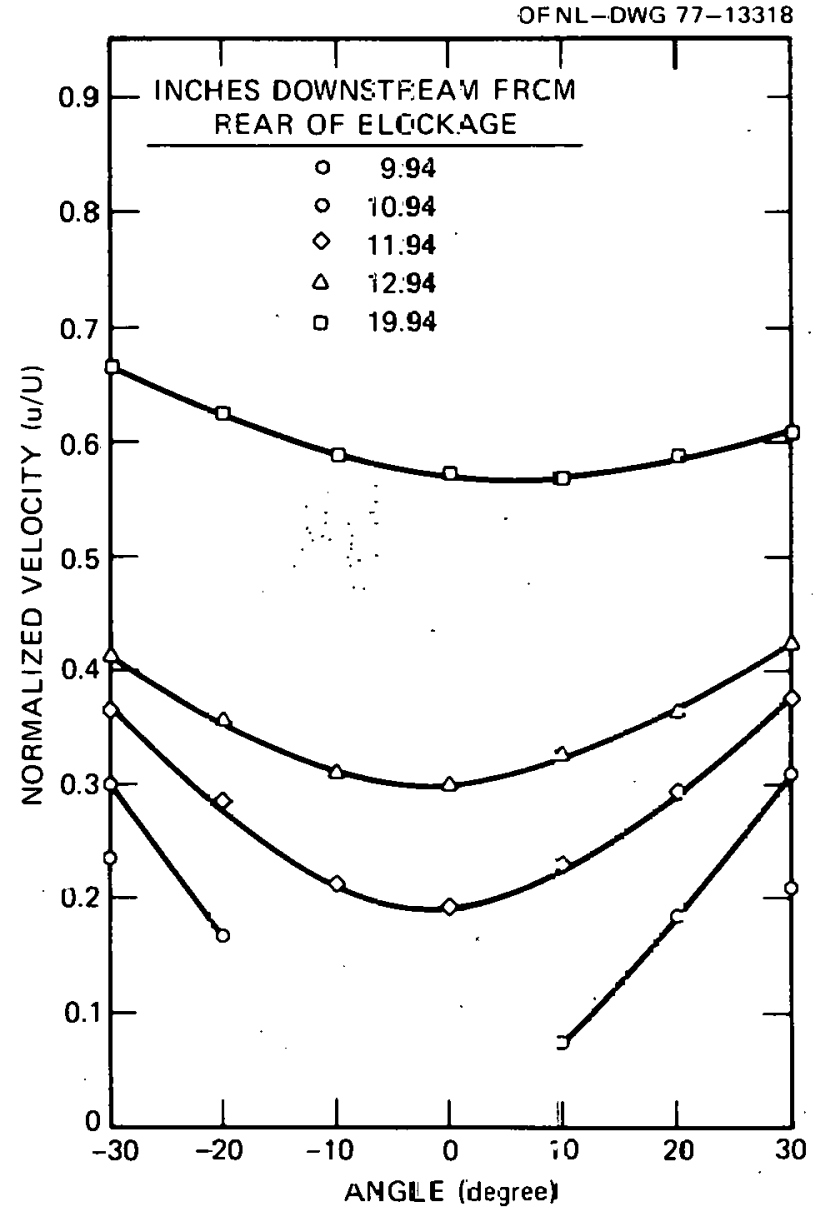

Fig. 96. Transverse velocity profile downstream of a 4-channel blockage (configuration $B$ in Fig. 92i (Vegter et al. ${ }^{11}$ ).

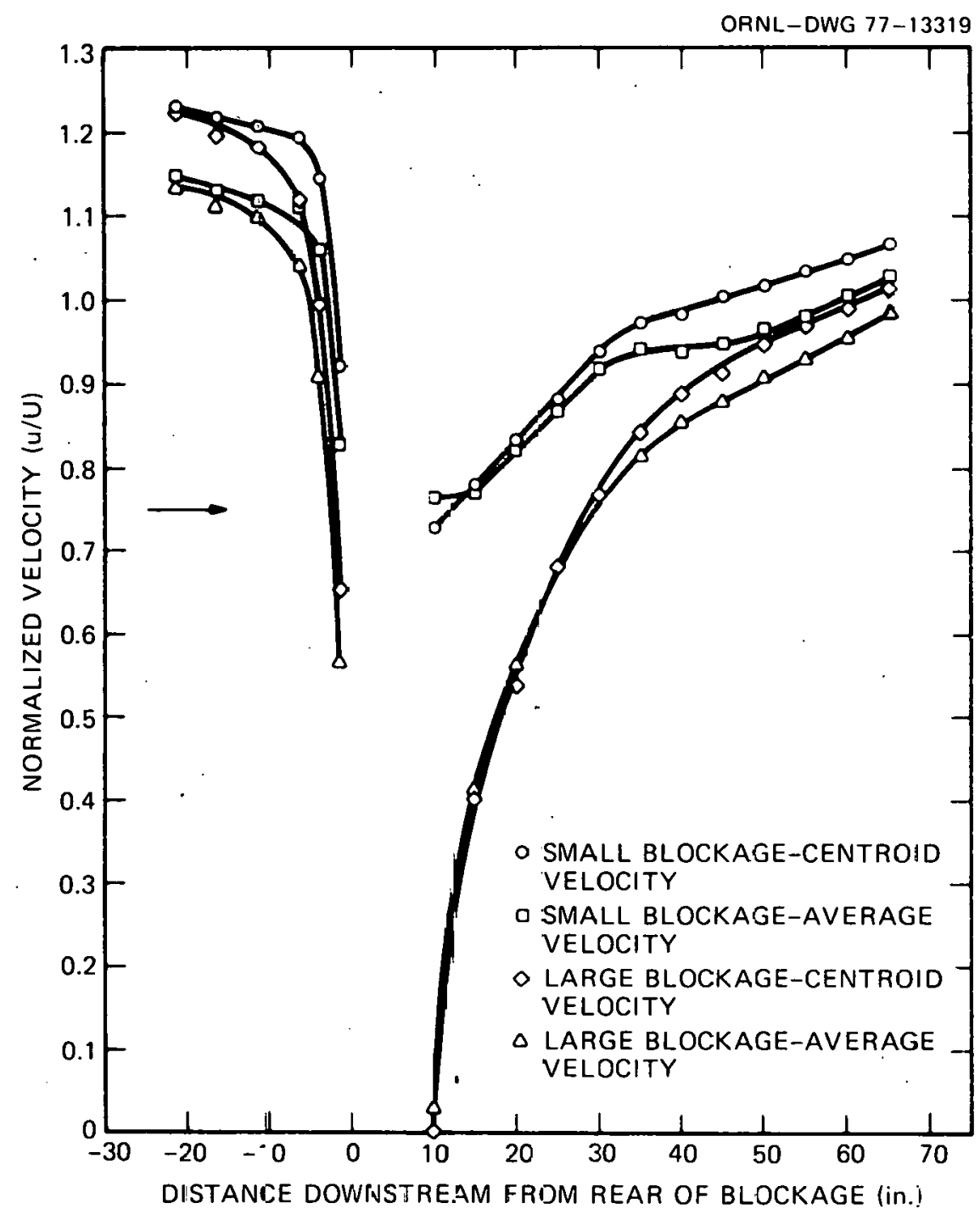

Fig. 97. Axiai velocity distribution cownstream of the small i-channel) and the large (4-channe1) blockages (Vegter et al. ${ }^{11}$ ). 


\subsubsection{Studies of wakes behind blockages without pins}

Some investigations ${ }^{7,8,11}$ have shown that the wakes behind a blockage without pins are qualitatively similar to those with pins in the fuel assemblies. Carmody ${ }^{12}$ investigated the wake characteristics behind a disk normal to an air stream at $R e=2 U R / V=7 \times 10^{4}$, with $U$ being the velocity upstream of the disk and $R$ being the disk radius. Two 6.35-mm-thick (0.25-in.) brass disks were used as test specimens wi.th the sharp-edge upstream face in a recirculating air tunnel. The air velocity was $7.6 \mathrm{~m} / \mathrm{s}$ (25 fps) for a 152-mm-diam (6-in.) disk and $23 \mathrm{~m} / \mathrm{s}$ (75 fps) for a 51-mmdiam (2-in.) disk. Hot-wire anemometer and pressure probes were used to measure the velocity, turbulence intensity, and pressure. Figure 98 shows the orientation of the disk used in Carmody's experiment ( $x$ is the axial distance starting at the upstream surface of the disk). Figure 99 illustrates the dimensionless axial velocity $u / U$ distributions. The recirculation zone is located at an $x / 2 R$ ratio of less than 3 . Figure 100 shows the distribution of the stream function $\psi\left(=\int_{0}^{r} u r d r\right)$. The wake length $L$ is approximately equal to 5.2R. This result compares favorably with the result of Vegter et $a 1^{11}$ for blockage in the pin bundle, as described in Sect. 2.5.3. It also supports the results of Basmer, Kirsch, and Schultheiss, ${ }^{7}$ which indicate that the wake length appears to be unchanged whether

ORNL-DWG $77-13320$

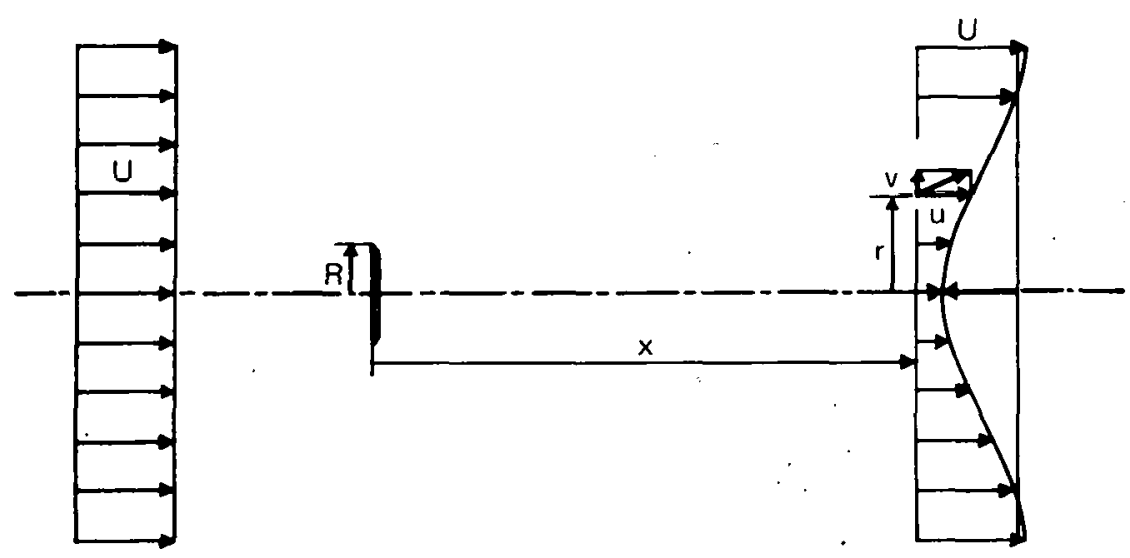

Fig. 98. A disk in an air stream (Carmody ${ }^{12}$ ). 


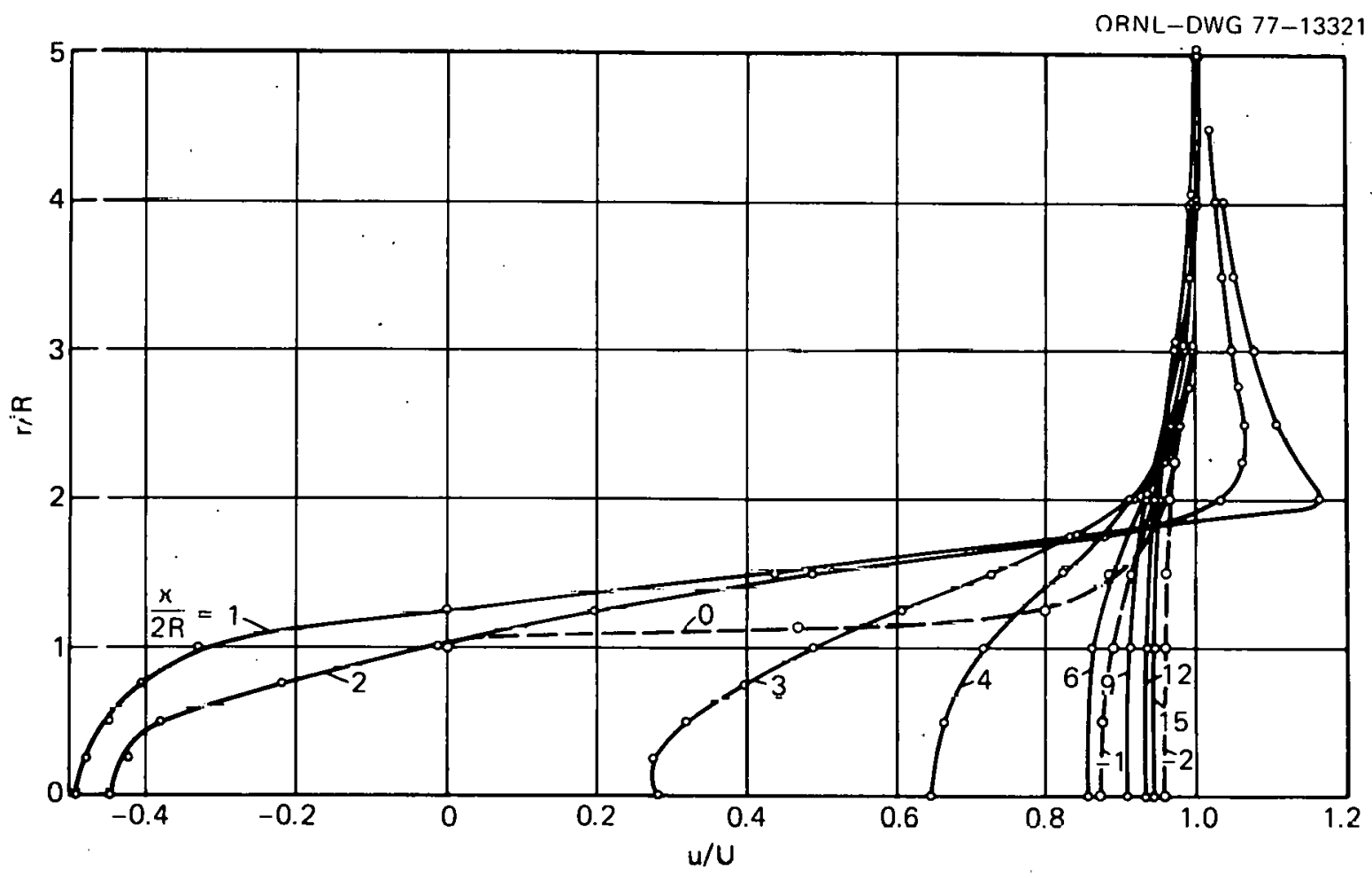

Fig. 99. Distribution of mean axial air velocity around a disk (Carmody ${ }^{2}$ ).

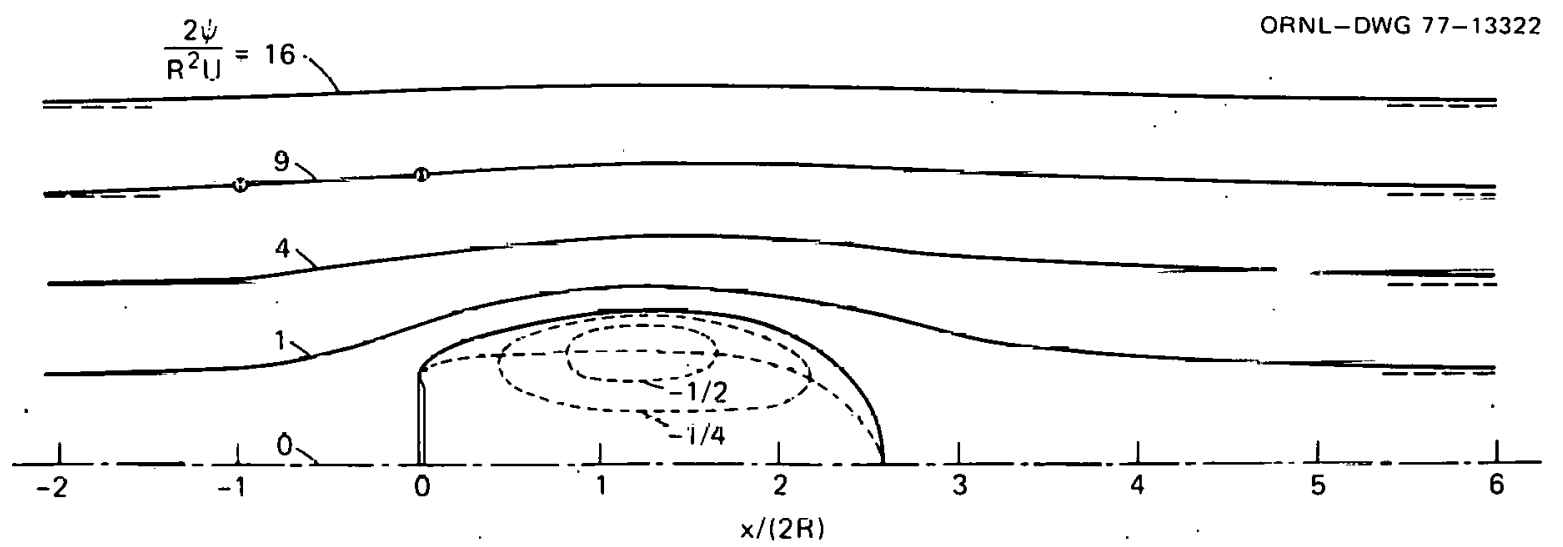

Fig. 100. Mean streamline pattern around a disk in a free stream $\left(\right.$ Carmody $\left.{ }^{12}\right)$. 
the pins are present or not, at least for the pin bundles using grid spacers.

Castro ${ }^{13}$ examined the wake formed behind a two-dimensional perforated plate normal to an air stream at $2.5 \times 10^{4} \leq \operatorname{Re}=U \ell_{1} / V \leq 9.0 \times 10^{4}$, where $U$ is the free stream velocity ahead of the plate and $\ell_{1}$ is the plate chord length [41 mm (1.63 in.)]. Figure 101 shows details of the plate. By varying the hole diameter of the plate, a range of porosity ( $\alpha=$ open area/ total plate area) of 0 to 0.645 was achieved. A hot-wire anemometer was used to measure the velocities and turbulence intensities. It was found that for a porous plate $(\alpha>0)$, the bleed air will move the recirculation. zone downstream from the blockage plate as shown in Fig. 102; the larger the porosity, the further downstream the recirculation zone will be moved. In the experiment performed by Basmer, Kirsch, and Schultheiss ${ }^{7}$ (see

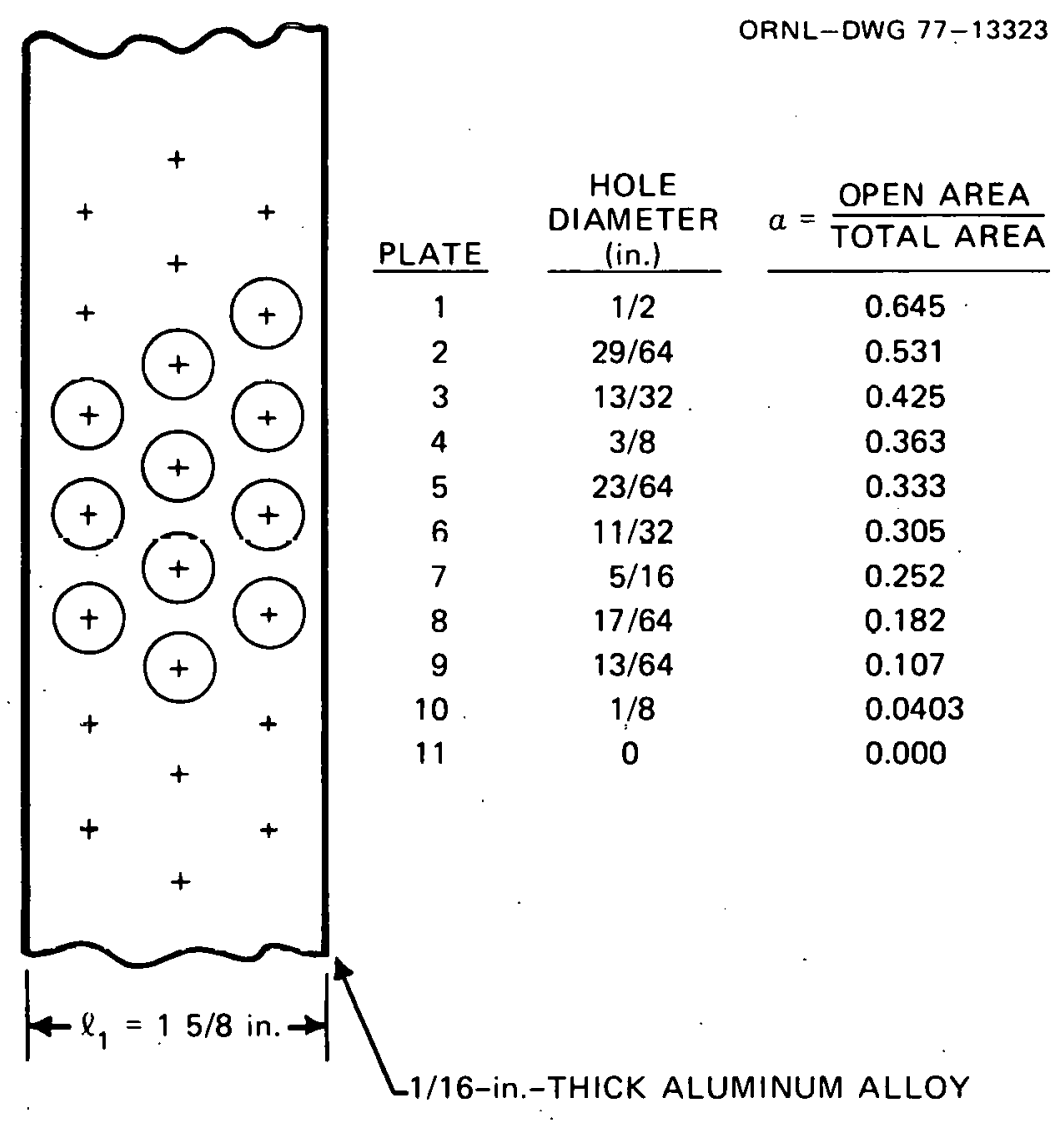

Fig. 101. Details of perforated plates (Castro ${ }^{13}$ ). 
(a)

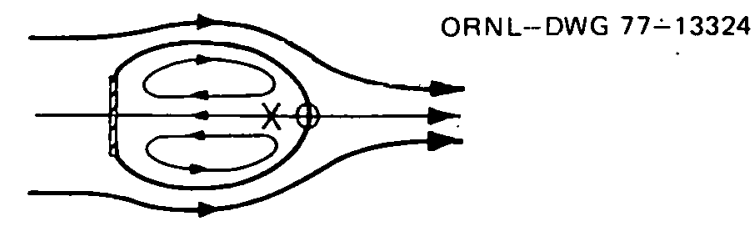

(b)

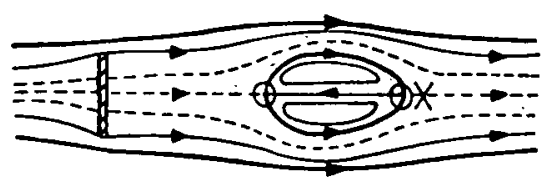

(c)
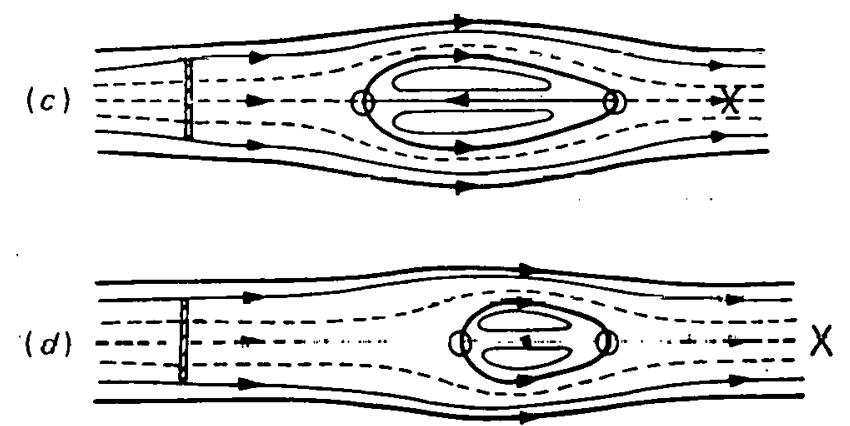

Fig. 102. The effect of $\alpha$ on the near wake. $X$, points of maximum turbulence intensity; ----, bleed air, 0 ; stagnation points. ( $\alpha) \alpha=0$. (b) $\alpha=0.182$. (c) $\alpha=0.252$. (d) $\alpha=0.305$. $\alpha$ is the ratio of the open area to the total plate area (Castro ${ }^{13}$ ).

Sect. 2.4.1) for the wake formed behind the blockage in the presence of pins, the same phenomenon was qualitatively observed. However, Fig. 102 shows the presence of the recirculation zone even at porosity $\alpha=0.305$. For a blockage with fuel pins, ${ }^{7,8}$ the recirculation zone ceased to exist at $\alpha \gtrsim 0.15$. The presence of fuel pins appears to have some effect on the existence of the recirculation zone behind a pornus blockage. 


\section{THEORETICAL BLOCKAGE STUDIES}

There are a few theoretical studies on blockage effects. The results are presented, along with some general computer codes that have been partially successful in solving blockage problems.

\subsection{Results and Discussions}

Fauske ${ }^{14,15}$ predicted that a planar blockage extending radially over $50 \%$ of the cross section of an FFTF fuel assembly at the midcore would cause a 5 to $10 \%$ flow reduction that would be detectable by sensors at the assembly outlet. Assuming that the local sodium boiling takes place in the wake downstream of the blockage, Fauske calculated the transient boiling process considering the lifetime of a single bubble. Typical onedimensional cylindrical vapor-bubble growth and collapse histories for the central channel of the wake are shown in Fig. 103 for various initial superheats. The values of the bubble lifetimes in Fig. 103 can be considered as upper limits because the substantial effects of radial subcooling in the wake and the frictional and gravitational forces were neglected in the calculations. Fauske concluded that local dryout is unlikely during the lifetime of the bubble because a thin ( $0.15-m m-t h i c k)$ liquid layer remains on

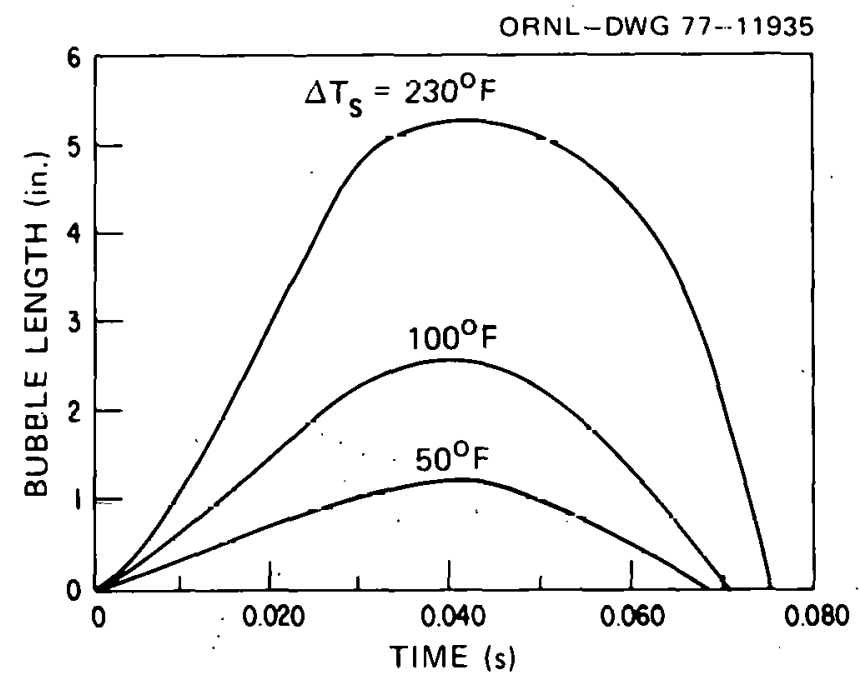

F1g. 103. Bubblc growth and collapse for local boiling behind a 50\% flow-area blockage in an FFTF assembly (Fauske ${ }^{34}, 15$ ). 
the fuel-pin surface and will maintain cooling for 0.2 to $0.3 \mathrm{sec}$. Even if the breakup of the liquid film occurs, the cladding temperature will only be increased by 17 to $22^{\circ} \mathrm{C}\left(30\right.$ to $40^{\circ} \mathrm{F}$ ), and cladding rewetting will take place as the bubble collapses. Furthermore, in the case of little or no superheating, which may occur after the generation of the first few bubbles, the large amount of subcooling in the wake prevents the steady-state vapor velocity from exceeding the flooding velocity. Fauske concluded that dryout, overheating of the cladding, and release of molten fuel are very unlikely; even for a blockage large enough to be detected.

Gast and Schmidt ${ }^{16}$ stated that a blockage of $30 \%$ of the flow area in an SNR fue.1 assembly would result in a $5 \%$ flow reduction.

Sha ${ }^{17}$ studied the Inlet-flow redistribution due to a blockage located around the center pin and at various axial locations in a 19-pin bundle. Computer code THI3D (Thermal-Hydraulic-Interaction Multichannel Computer Program) was used to solve these boundary-value problems with a pressuredrop boundary condition. Figure 104 shows the blocked central channe1 (3) and other unblocked adjacent channels. The channel height of $914 \mathrm{~mm}$ (36 in.) is divided into 18 equal increments, which are numbered in ascending

ORNL ... DWG 77-13325

$\otimes$ CHANNEL NUMBER PARTIALLY BLOCKED CHANNEL

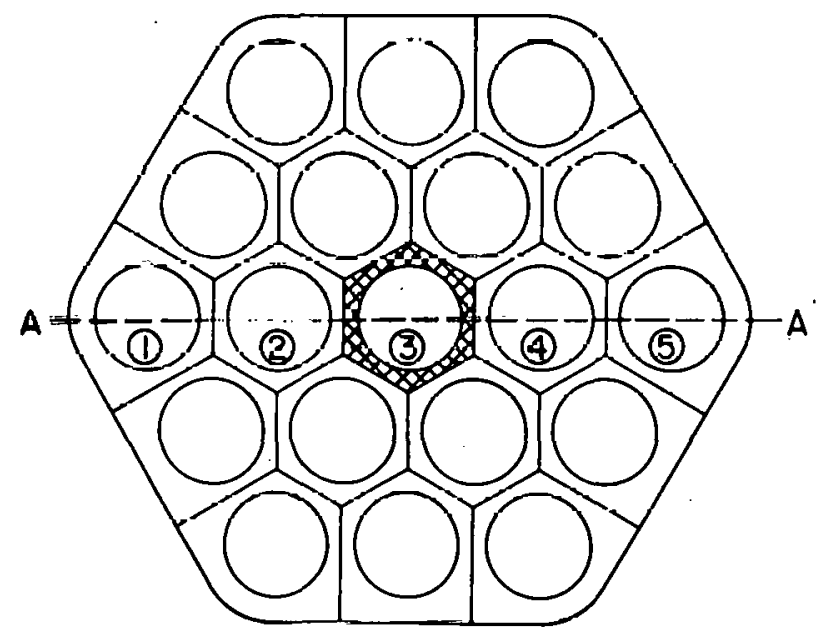

Fig. 104. A 19-pin bundle with flow channels (Sha ${ }^{17}$ ). 
order from bottom to top. Flow blockage is simulated by varying the flow area of the central pin from 0 to $90 \%$. The blockage locations corresponding to steps $1,6,9,13$, and 18 are designated as inlet, one-third lower core, midcore, two-thirds upper core, and outlet blockage, respectively. All channel geometry and fluid parameters are typical of LMFBR fuel assemblies. Axial cosine and radial uniform heat generation are assumed. Figure 105 presents normalized-core-averaged inlet-mass-velocity $\left(M_{R 2}\right)$ distributions along A-A (see Fig. 104) of the inlet, midcore, and outlet blockage locations, along with normalized inlet-mass-velocity distributions at

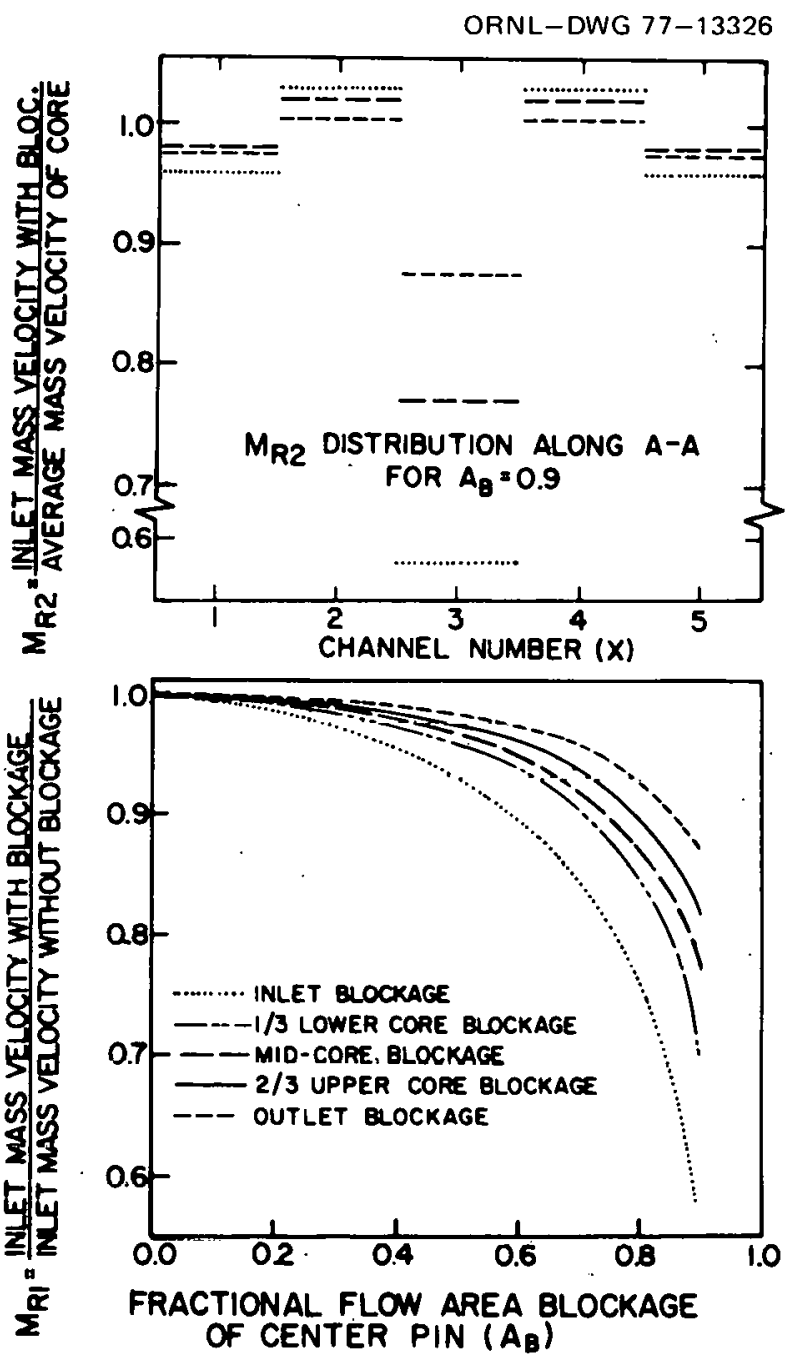

Fig. 105. Inlet flow redistributions at the central channel (Sha ${ }^{17}$ ). 
various locations along the central pin vs the degree of partial flow blockage. It should be noted that THI3D does not investigate the recirculating flow in the wake.

Crawford, Marr, and Padilla ${ }^{18}$ investigated a planar-type blockage located near the core midplane. The wake length was assumed to be two to three blockage diameters and to be independent of the coolant velocity. Enhanced coolant mixing due to wire-wrap spacers was neglected. Typical results calculated for the maximum coolant temperature increase in the wake region downstream of the blockage are shown in Fig. 106 for an FFTF fuel assembly as a function of the number of flow channels blocked (percent blockage $=$ number of blocked flow channels/434).

Marr and Crawford ${ }^{19}$ mndeled the blockage formed by fuel debrio from failed pins with a porous heat-generating bed. One-dimensional heat flow and constant thermophysical properties were assumed, and computer code PORPLUG was developed to solve the problem. Parametric studies were performed. The minimum thickness of the porous bed that will result in sodium boiling is shown as a function of particle diameter $D_{p}$ and bed porosity $\varepsilon$ in Fig. 107. Since the fuel debris may consist of particle diameters between 100 to $1000 \mathrm{\mu m}$ (with an average effertive particle diameter between 500 to $600 \mu \mathrm{m}$ ) and a bed porosity between 0.35 to 0.45 , Marr and Crawford concluded that at least 2 to $5 \mathrm{~g}$ of fuel per channel would be

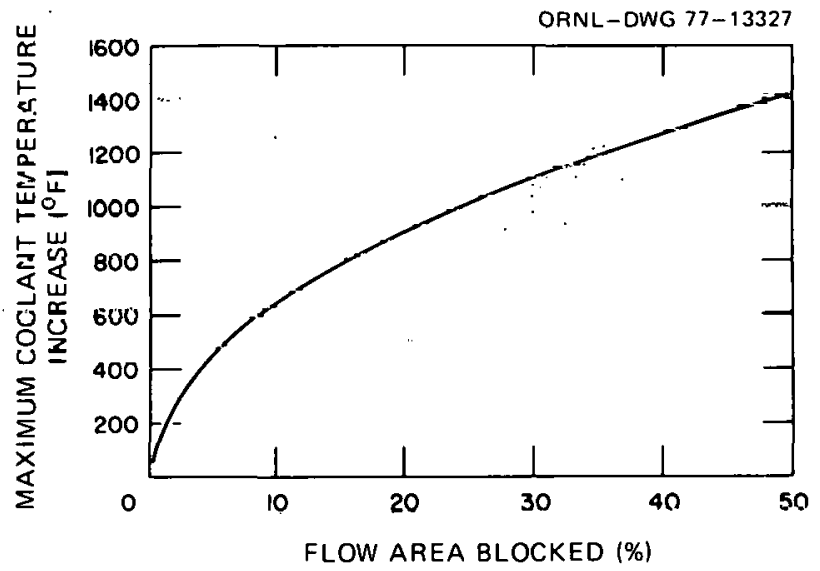

Fig. 106. Coolant temperature increase downstream of a blockage (Crawford, Marr, and Padilla ${ }^{18}$ ). 


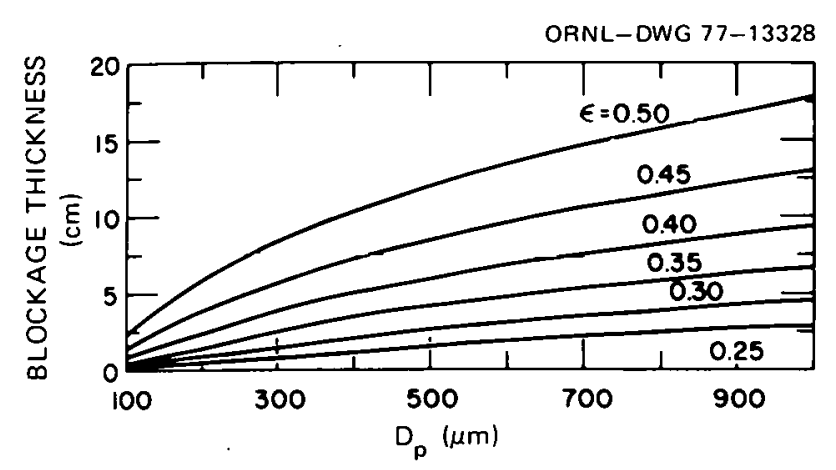

Fig. 107. Maximum allowable blockage thickness for various bed porosities and particle sizes (Marr and Crawford ${ }^{19}$ ).

required to produce coolant boiling, and steady-state temperatures within the porous medium would be attained a few seconds after blockage initiation.

Scott and Williams ${ }^{20}$ investigated flow blockage in an LMFBR using a version of the TART computer code. They found that in the absence of protective action, sodium bniling would not occur behind blockages that allow $30 \%$ or more of the normal coolant flow to pass through a fuel assembly.

Bishop, Graham, and Zoubek ${ }^{21}$ studied the hydrodynamic characteristics of a wake and concluded that the wake behind an internal blockage in a fuel assembly has a significantly shorter length, smaller volume, higher average turbulence intensity, and higher entrained flow than the wake formed behind an edge blockage having the same cross-sectional area.

Baker, MacFarlane, and Marchaterre ${ }^{2}$ calculated the accident sequences for the FFTF and a representative 1000-MW(e) LMFBR using the ANL SAS1A code. The results indicate that in the very unlikely event of a full fuel-assembly blockage, there is a minimum of $0.7 \mathrm{sec}$ before sodium boiling could begin. After boiling initiation, it is expected that there would be a general expulsion of coolant from the assembly; however, a residual film of sodium will remain and provide cooling for an additional period of time. After film dryout, it is assumed that there is complete vapor blanketing of the fuel assembly. After blanketing, about $3.7 \mathrm{sec}$ is required to melt $50 \%$ of the fuel pin cross-sectional area at the hottest point and about $5 \mathrm{sec}$ to melt $50 \%$ of the fuel in a single assembly. Their calculations show that 
considerable time is available for protective action even in the very unlikely event of a full fuel-assembly blockage.

Van Erp and $J_{u d d}{ }^{3}$ pointed out that sudden complete insulation of an LMFBR fuel pin operating at maximum normal power would lead to $20 \%$ fuel melting in $4.5 \mathrm{sec}$ at the core midplane. For blockages in a fuel assembly, a flow reduction of $50 \%$ at full power would probably not cause cladding failure, while a flow reduction of about $65 \%$ or more would cause sodium boiling, cladding failure, and fuel melting.

Teague $^{24}$ stated that the flow would be reduced to one-half its normal value provided $90 \%$ of the inlet flow area is blocked in a PFR (British prototype LMFBR) assembly. Teague also pointed out that the wake temperature was extremely sensitive to the coolant seepage rate through a porous blockage, and no boiling would occur in an inert porous blockage provided a flow about $1 \%$ of normal flow was available for every $1-\mathrm{cm}$ thickness of the blockage. For heat-generating fissile blockages, the required seepage flow to prevent coolant boiling would be about two to three times greater.

$J_{u d d} 25$ indicated that an area of approximately $1 \mathrm{~cm}^{2}$ of the fuel pin surface had to be completely blocked in order to melt fuel in a $40-\mathrm{kW} / \mathrm{m}$ $(12.2-\mathrm{kW} / \mathrm{ft})$ pin. The occurrence of such a blockage is unlikely.

\subsection{Computer Codes}

Some general computer codes have been develnped to obtain temperature and flow distributions in the wake behind a blockage, ${ }^{26-31}$ but, due to the complexity of the problem, successful simulation has heen on.ly partially achieved. Following are brief descriptions of these codes and comparisons between their results and the experimental data.

\subsubsection{SARRE:}

Computer code SABRE (Subchannel Analysis of Blockage in Reactor Elements), developed by Spalding's team, ${ }^{26}$ solves elliptic equations for a solid or a porous blockage located at any point in the pin bundle. The axial and lateral velocities, pressure, and temperature distributions in the bundles are calculated. However, the present SABRE code assumes the pins to be separated by grid spacers; these are not specifically modeled, 
but their effect on pressure drop can be simulated by suitable choice of friction factor.

The control volumes are formed between pins as shown in Figs. 108 and 109. The $z$ coordinate is in the axial direction, while $x$ and $y$ coordinates are in the transverse direction. Pressure and temperature nodes are located along the centerlines of channels as well as the axial velocity $W$ nodes located halfway between the pressure (or temperature) nodes. The nodes for transverse velocities ( $U$ and V in Fig. 108) are placed along the centerlines of the gaps between fuel pins. The conservation of mass, momentum, and energy for each control volume provides a set of simultaneous equations, which are solved iteratively using the boundary conditions specified to yield dependent variables of $P, T, U, V$, and $W(P$ is pressure and $T$ is temperature). Empirical expressions have been used to approximate the flow resistances through the channels and gaps and the blockage that is introduced into the momentum equations as a sink term representing friction.

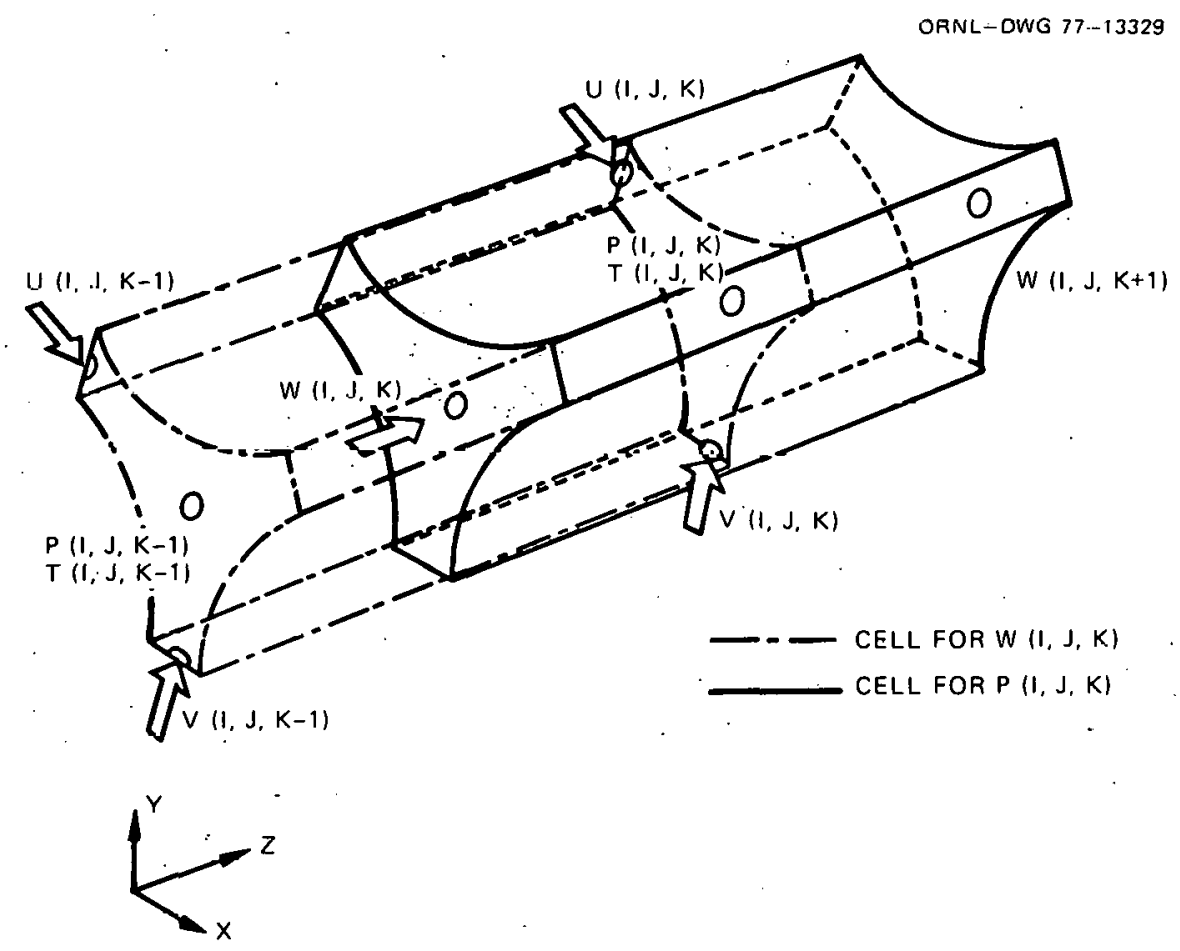

Fig. 108. A sketch of $W$ and $P$ cells and surrounding velocity nodes used in SABRE cudé (Gosman et $a 1 .{ }^{26}$ ). 


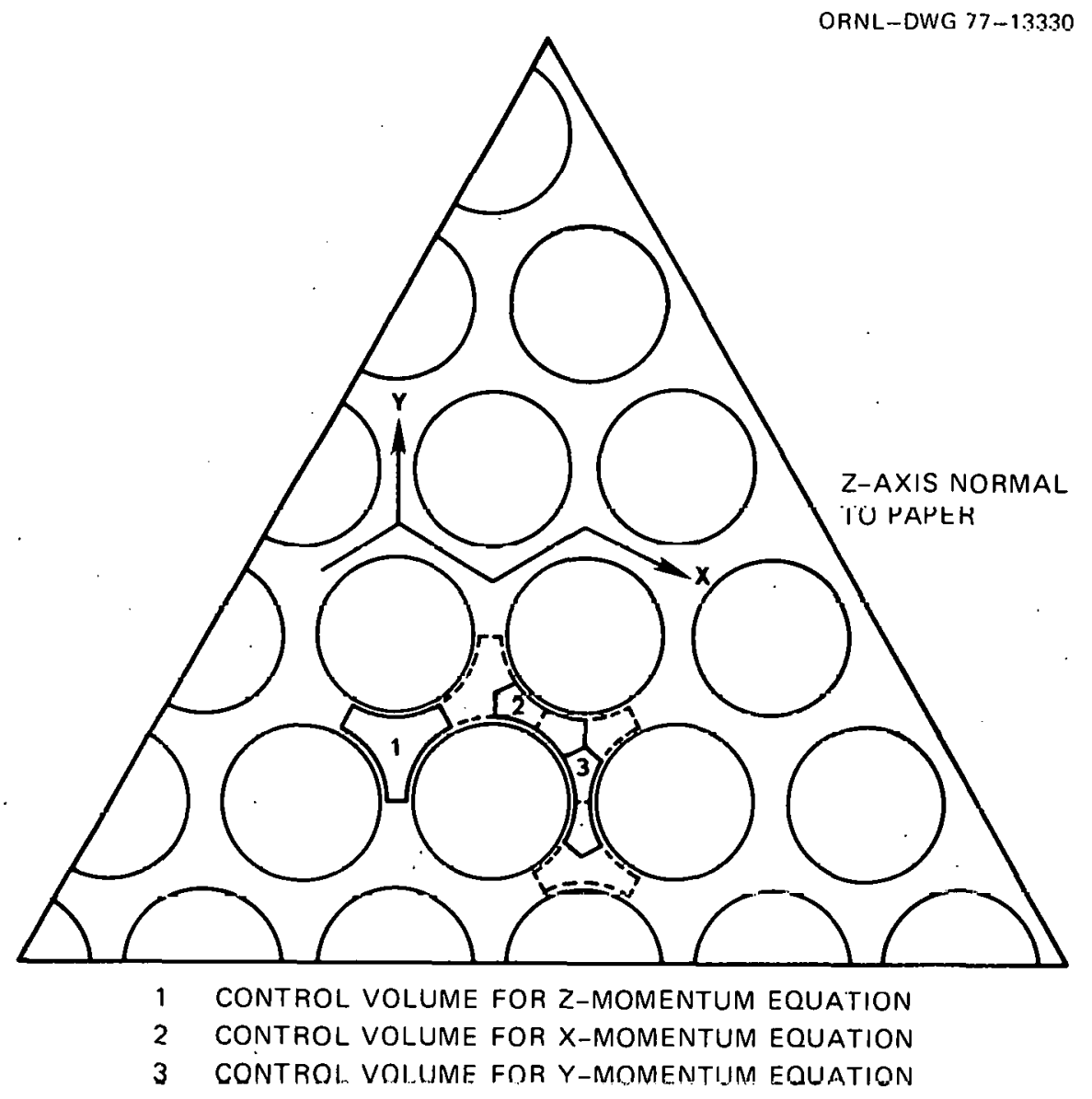

Fig. 109. Axes and channels used in SABRE code (Gosman et al. ${ }^{26}$ ).

Figure 110 shows a comparison of the SABRE axiall velocity calculations with the water experiment in a $60^{\circ}$ sector of a large-scale pin bundle. Good agreement exists between calculations and experiments for the size of the wake behind the blockage as well as the actual flow values.

Herbert and $\mathrm{Kirsch}^{27}$ used the SABRE code to calculate temperature profiles in the wake behind a solid non-heat-generating blockage. Their results are compared with temperature measurements taken in a simulated watercooled 169-pin SNR bundle. Figure 111 shows the temperature profiles at three axial locations behind a $14.7 \%$ central blockage plate (see Fig. 70) about $10 \mathrm{~mm}$ thick, where $\Delta \theta$ is the difference between the local temperature and the bundle inlet temperature. The SABRE result is generally lower than the measured one, but the shape of the temperature profile is represented fairly well by the calculated results. Figure 112 shows the temperature 


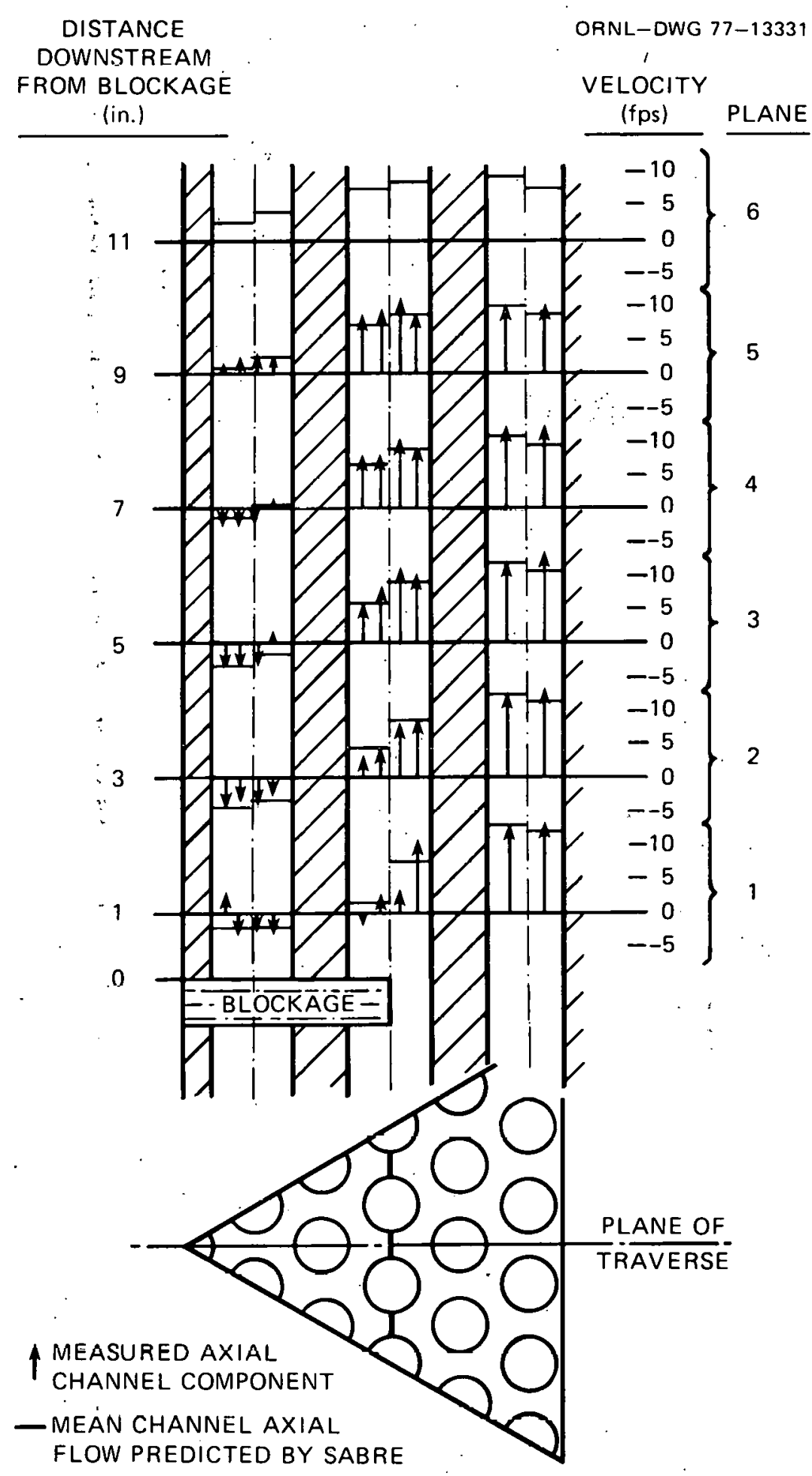

Fig. 110. Flow comparison between experimental and SABRE results (Gosman et a1. ${ }^{26}$ ). 


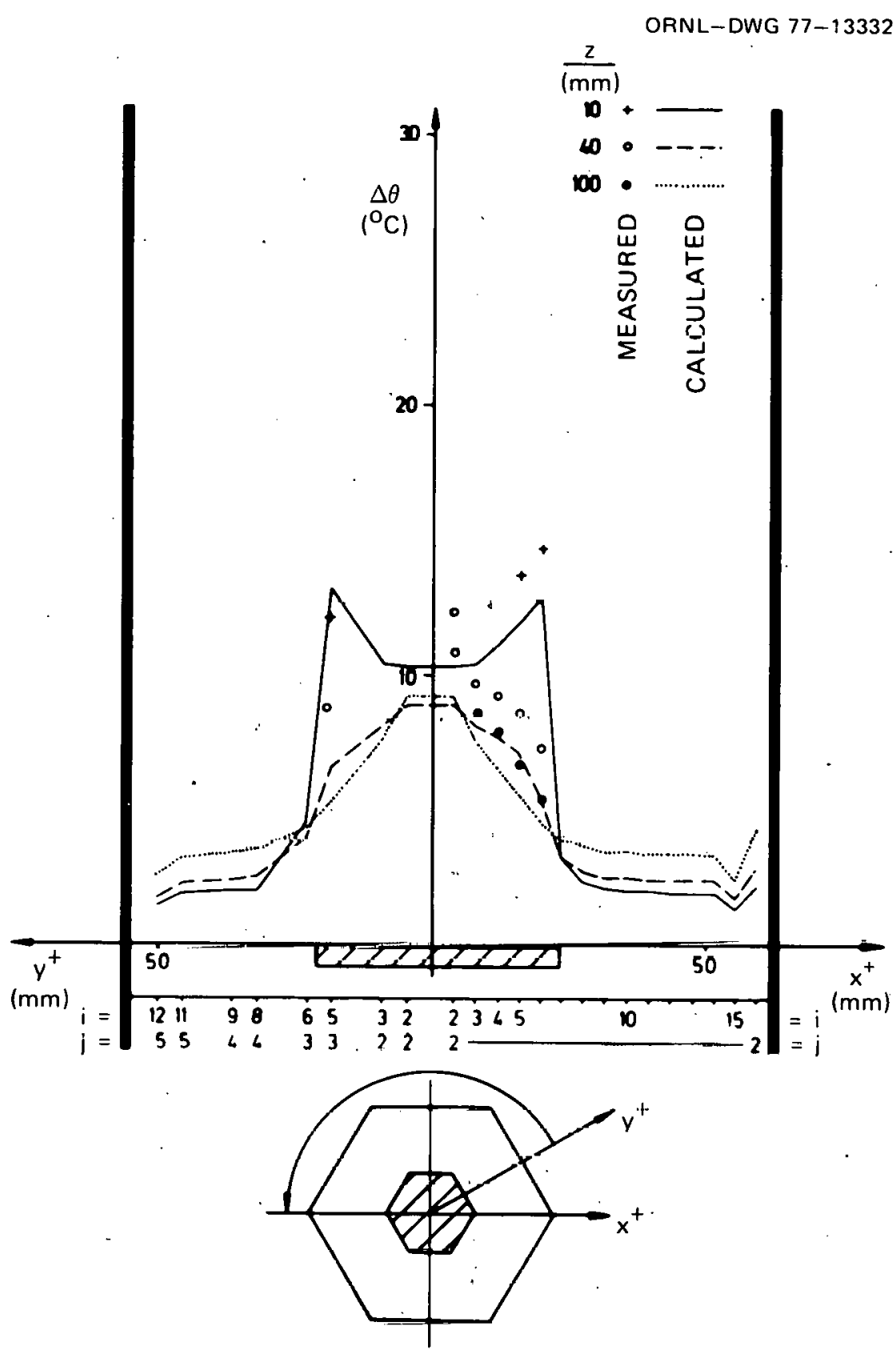

Fig. 111. Comparison of measured and SABRE calculated temperature rises behind a $14.7 \%$ central blockage (Herbert and Kirsch ${ }^{27}$ ). 


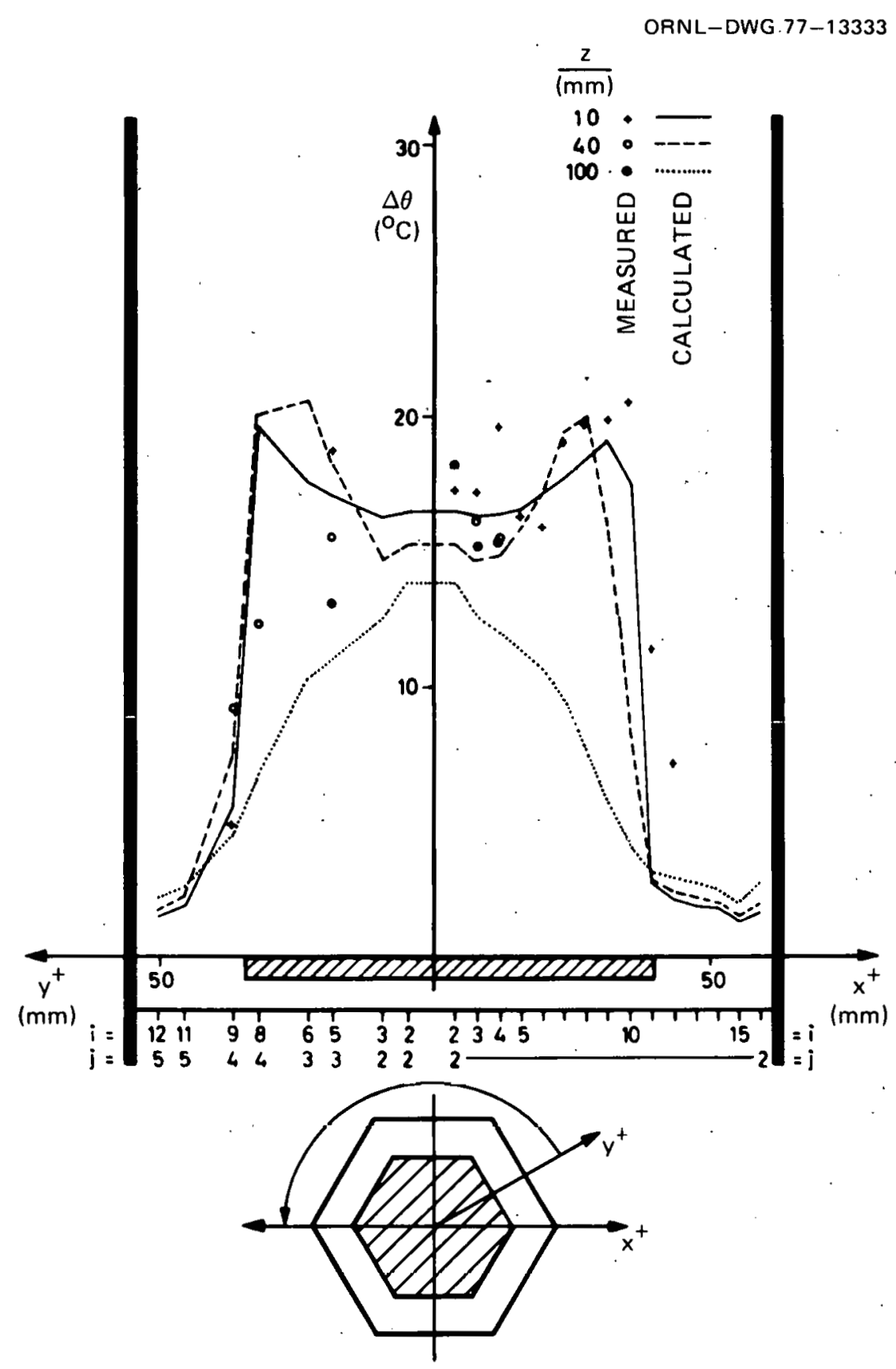

Fig. 112. Comparison of measured and SABRE calculated temperature rises behind a $41 \%$ central blockage (Herbert and Kirsch ${ }^{27}$ ). 
profiles behind a $41 \%$ central blockage plate (Fig. 70). Again, the SABRE results predict somewhat lower temperatures than the measured ones. However, the SABRE code yields a maximum temperature at about $40 \mathrm{~mm}$ downstream from the blockage in the core of the wake and thus disagrees with the experimental data in which the maximum wake temperature is located directly behind the blockage and radially near its edge (as shown in Fig. 112 at approximately $\mathrm{Z}=10 \mathrm{~mm})$. Figure 113 shows the temperature profiles behind an edge blockage plate that blocks $47 \%$ of the flow area (Fig. 70). In this case, the greatest discrepancy between measured and SABRE calculated values is found. First, the maximum temperature in the wake is again obtained by the SABRE code in the core of the wake, which is about $40 \mathrm{~mm}$ downstream of the blockage, while the experimental data indicate that the maximum temperature $1 \mathrm{~s}$ about $10 \mathrm{~mm}$ downstream and near the outer edge of the blockage. Second, the increase in temperature at $Z=10 \mathrm{~mm}$ toward the edge of the blockage is steeper for the measured than for the calculated profile by SABRE:

In spite of the fact that some discrepancies do exist between the SABRE calculations and experimental results and some parameters used in calculations are not well known, it is felt that the SABRE code is a useful tool for safety investigations on blockages in pin bundles using grid spacers.

\section{2 .2 WAKE}

Using the techniques and the code developed by Gosman et al. ${ }^{28}$ the computer code $\operatorname{WAKE}^{29}, 30$ solves the momentum, energy, and mass conservation equations coupled to a two-equation (turbulent kinetic energy and the turbulence dissipation rate) model for the flow behind a blockage. WAKE is a two-dimensional axisymmetric code in which the fuel assembly is represented by a cylinder having the same hydraulic diameter as the assembly including fuel pins and the blockage is represented by a central circular disk of any thickness. Thus, the main approximation in the WAKE code results from neglect of physical representation of the fuel pins, and the power produced by fuel pins is approximated by a uniformly distributed heat source in the fluid to produce the same power. Furthermore, the flow resistance in the radial direction due to fuel pins is approximated by using an anisotropic 


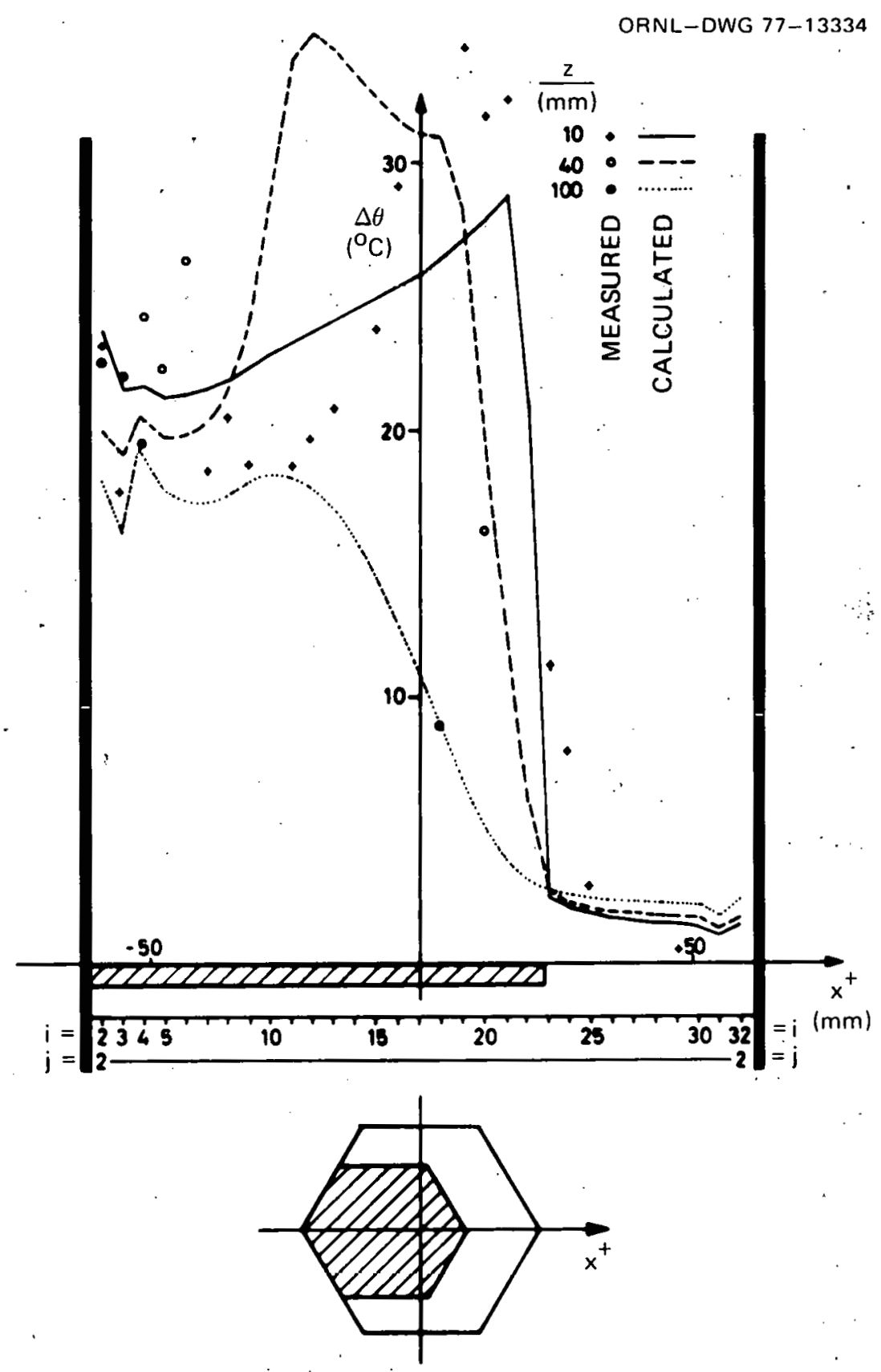

Fig. 113. Comparison of measured and SABRE calculated temperature rises behind a $47 \%$ edge blockage (Herbert and $\mathrm{Kirsch}^{27}$ ). 
viscosity. Figure 114 illustrates a geometric model used in WAKE. ${ }^{29}$ It should be noted that the wake behind an edge blockage or any non-axisymmetric blockage cannot be studied by using the WAKE code.

A comparison between the results calculated by WAKE and SABRE (given by Gregory and Lord ${ }^{29}$ ) is presented in Table 13 for the PFR (British prototype LMFBR) fuel assembly. The WAKE code tends to obtain a higher temperature than the SABRE code, but its difference is within 20\%. Table 14 presents Gregory and Lord's results for the maximum and mean wake temperature rises above the free stream temperature for various sizes of impermeable blockages. The ratio of these two temperature rises is in the range of 1.5 to 2.0 .

Gregory and Lord ${ }^{30}$ also performed calculations for blockages of uniform and nonuniform porosities. Figure 115 shows the maximum wake temperature rises normalized to the corresponding maximum for an impermeable blockage, both for a blockage with a.hole in the center and for a uniformporosity blockage. As shown, the maximum temperature rise behind a uniform-porosity blockage can be approximately 50\% higher than that behind an impermeable blockage of the same size. Gregory and Lord concluded that a 60 to 70 channel central blockage with homogeneous porosity could initiate

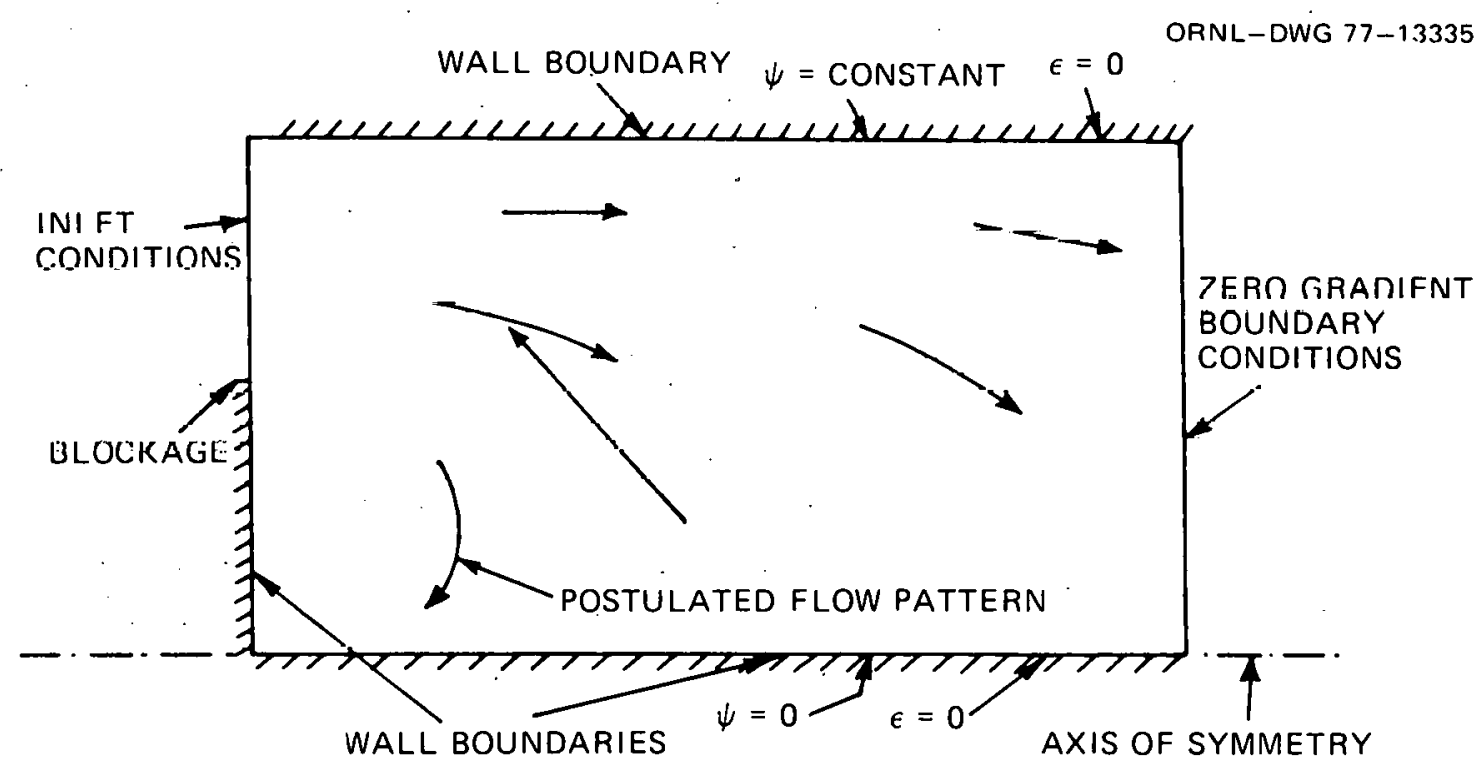

Fig. 114. Geometric model used in WAKE code (Gregory and Lord ${ }^{29}$ ). 
sodium boiling in the PFR, while approximately 100 channels might have to be blocked in an impermeable blockage before local boiling behind the blockage could occur.

Table 13. Comparison between WAKE and SABRE calculations for PFR fuel assembly

\begin{tabular}{cccc}
\hline \multirow{2}{*}{$\begin{array}{c}\text { Number } \\
\text { of blocked } \\
\text { channels }\end{array}$} & \multicolumn{3}{c}{ Maximum wake temperature rise } \\
& SABRE & WAKE & WAKE/SABRE \\
\cline { 2 - 4 } 24 & 94 & 111 & 1.18 \\
54 & 135 & 161 & 1.19 \\
96 & 190 & 208 & 1.09 \\
150 & 222 & 237 & 1.07 \\
\hline
\end{tabular}

Table 14. Calculated mean and maximum wake temperatures using WAKE code.

\begin{tabular}{|c|c|c|c|c|}
\hline $\begin{array}{l}\text { Blockage size } \\
\text { (\% of flow area) }\end{array}$ & $\begin{array}{c}\text { Reynolds No. } \\
\left(\times 10^{4}\right)\end{array}$ & $\underset{\left({ }^{\circ} \mathrm{C}\right)}{\Delta \mathrm{T}_{\text {mean }}}$ & $\begin{array}{l}\Delta \mathrm{T}_{\max } \\
\left({ }^{\circ} \mathrm{C}\right)\end{array}$ & $\Delta \mathrm{T}_{\text {max }} / \Delta \mathrm{T}_{\text {mean }}$ \\
\hline 10.16 & 4.81 & 7.5 & 12 & 1.59 \\
\hline 10.16 & 10.0 & 3.3 & 5.5 & 1.52 \\
\hline 25.5 & 5.17 & 10.2 & 17 & 1.67 \\
\hline 25.5 & 10.0 & 5.2 & 10 & 1.90 \\
\hline 42.5 & 3.98 & 16.5 & 26 & 1.58 \\
\hline 42.5 & 10.0 & 6.3 & 10 & 1.59 \\
\hline
\end{tabular}




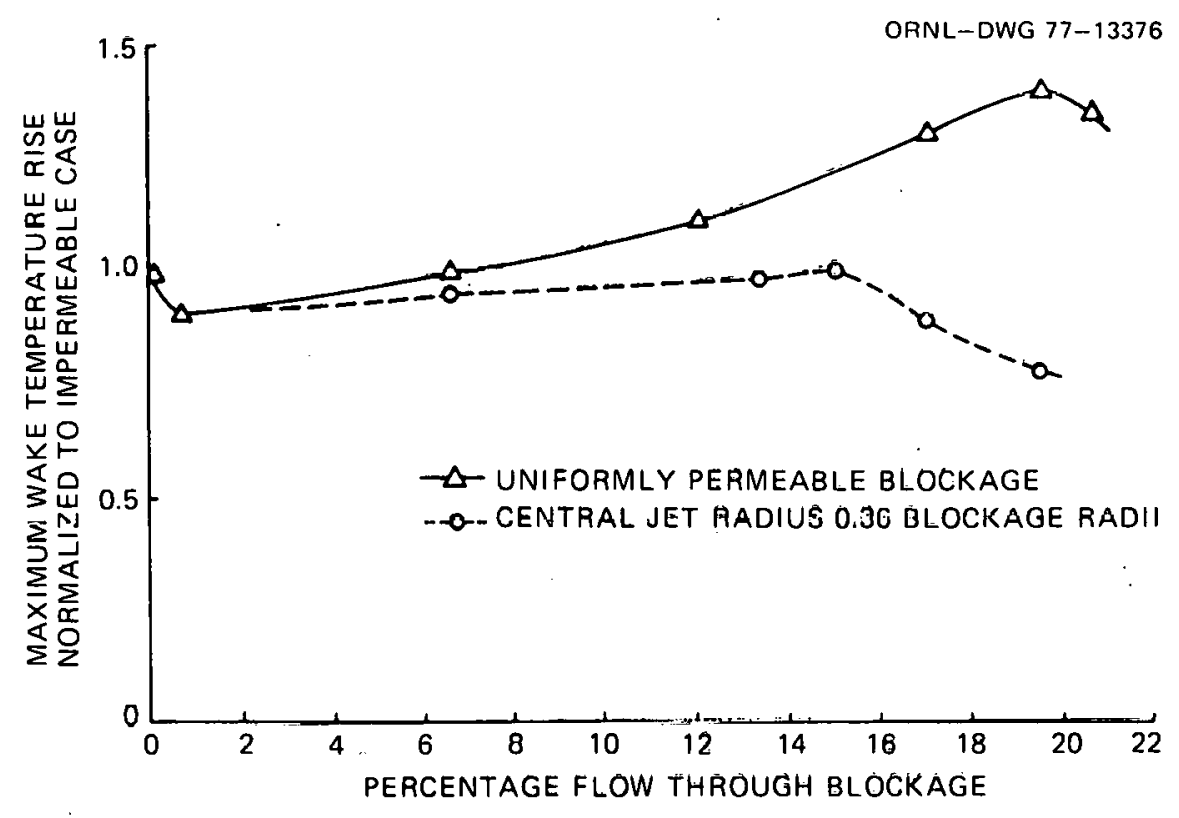

Fig. 115. Effect of blockage porosity on wake temperature rise (Gregory and Lord $^{30}$ ). 


\section{BLOCKAGE DETECTION}

As described in the preceding chapters, a blockage in a fuel assembly has the following effects: (1) the coolant outlet temperature is somewhat higher than the normal temperature; (2) the coolant flow rate is reduced; (3) the growth and collapse of the coolant vapor bubbles behind the blockage create a pressure wave; and (4) the fission gas and the oxide fuel are released into the coolant if fuel pins fail. However, the magnitude of outlet temperature rise and flow reduction are generally small unless the blockage is very large. Furthermore, temperature fluctuation downstream of the blockage is higher than the normal temperature condition without blockage; this phenomenon provides a means for blockage detection.

Based upon these effects, several blockage detection methods have been proposed: (1) outlet temperature measurements,,$^{32-34}$ (2) temperature noise (or fluctuation) measurements at each assembly outlet, ${ }^{35-42}$ (3) flow mea".. surements, ${ }^{35}$ (4) acoustic noise detection, ${ }^{42-50}$ (5) delayed-neutron detection,,$^{32}$ and (6) neutron-flux noise measurements. ${ }^{4-53}$

It is interesting to point out that the French PHENIX ${ }^{32}$ reactor has a monftoring system for each individual assembly as well as the global core. There are two thermocouples at the outlet and a delayed-neutron detection system (DND) for each assembly, and reactivity monitoring, bulk-sodium delayed-neutron detection, gaseous fission product monitoring in the argon cover gas, and acoustic boiling detection for the whole reactor core. The SUPER-PHENIX reactor, ${ }^{3} 3$ to be built, will have all detection systems now in the PHENIX reactor plus a fast-response thermocouple at each assembly outlet to detect small disturbances and a special computer correlation of a11 signals that can trip the reactor. It should be noted that flowmeters are not and will not be used in the PHENIX and the SUPER-PHENIX reactors due to complications.

The CRBR ${ }^{34}$ will have one thermocouple placed at the outlet of each fuel and radial blanket assembly to monitor the coolant temperature. The thermocouples will probably have an operating range of 200 to $760^{\circ} \mathrm{C}$ (400 to $1400^{\circ} \mathrm{F}$ ), an accuracy of $1 \%$, and repeatability of $1 / 2 \%$.

The SNR 300 reactor $^{35}$ (German prototype LMFBR) will have an electromagnetic flowmeter and three thermocouples at the outlet of each assembly 
to measure outlet temperatures and sodium flow. The increase in average outlet temperature above a preset value will be used as a warning or, upon further increase, as a reactor shutdown signal. 


\section{CONCLUSIONS}

The thermal-hydraulic effects of a blockage in the LMFBR fuel assemblies are determined by the size and thermal-physical properties of the blockage, the location of the blockage, the coolant flow, and the fuel-pin power. The smaller the blockage size, the lower the power; the higher the coolant flow, the less the temperature rise in the wake. The following conclusions were reached:

1. Recirculating flow indeed exists in the wake downstream of a blockage. The coolant residence times in the wake measured in water experiments agree well with those obtained in sodium for turbulent flow. This indicates that molecular heat conduction is not important in transferring energy from the wake into the free stream, which is caused mainly by the mass exchange between them. Water experiments can therefore be used to obtain the residence time and the corresponding average wake temperature behind the blockage for sodium can be estimated.

2. For the CRBR and the FFTF at the design conditions, a 6-channe1 internal blockage made of non-heat-generating material will not cause sodium boiling. Therefore, the reactor can still be operated safely. The same statement can be applied to both a 14-channel edge blockage attached to the assembly duct wall and a 24-channel inlet blockage.

3. A blockage that blocks $50 \%$ of the flow area in an FFTF fuel assembly will result in 5 to $10 \%$ reduction in coolant flow and is therefore detectable. Analysis has shown that it will be very unlikely to cause flow instability and gross cladding melting in the assembly.

4. Computer codes such as SABRE and WAKE have partially succeeded in predicting the temperature distributions in the wake behind blockages in the pin bundles. However, further improvements and modifications will be required in order to achieve satisfactory agreement between computer predictions and experimental results. 


\section{ACKNOWLEDGMENTS}

The author wishes to thank M. H. Fontana for his helpful discussions during this study and $\mathrm{J}$. L. Wantland for reviewing the manuscript.

The author expresses appreclation to the following organizations for permission to use figures from their publications: the American Nuclear Society, the American Society of Mechanical Engineers, Pergamon Press Incorporated, Cambridge University Press, Karlsruhe Nuclear Research Center, United Kingdom Atomic Energy Authority, ERDA Technical Information Center, and the Institution of Civil Engineers, United Kingdom. 


\section{REFERENCES}

1. M. H. Fontana et al., Effect of Partial Blockages in Simulated LMFBR Fuel Assemblies, ORNL/TM-4324 (December 1973).

2. M. H. Fontana et al., Thermal-Hydraulic Effects of Partial Blockages in Simulated LMFBR Fuel Assemblies with Applications to the CRBR, ORNL/TM-4779 (July 1975).

3. J. L. Wantland, ORRIBLE - A Computer Progrom for Flow and Temperature Distribution in LMFBR Fuel Rod Bundles, ORNL/TM-3516 (October 1971).

4. J. D. Sheppard, FFM Water Mockup Studies of the Near-Wake Region of Permeable Flow Blockages, ORNL/TM-5514 (October 1976).

5. D. Kirsch and K. Schleisiek, "Flow and Temperature Distributions Around Local Coolant Blockages in Sodium-Cooled Fuel Subassemblies," Progress in Heat and Mass Transfer, vol. 7, ed. by 0. E. Dwyer, Pergamon, 1973.

6. K. Schleisiek, Sodium Experiments for the Investigations of Local Cooling Disturbances in Test Assemblies Similar to Fuel Elements, KFK-1914 (EURFNR-1156) (February 1974).

7. P. Basmer, D. Kirsch, and G. F. Schultheiss, Phenomenological Investigations into Flow Distribution Behind Local Coolant Channel Blockages in Rod Bundles, KFK-1548 (EURFNR-1007) (January 1972).

8. D. Kirsch, Studies on Flow and Temperature Distribution in the Region of Lucal Channel Blockages in Bundle Fuel Elements, KFK-1794 (EURFNR1106) (May 1973).

9. Y. Daigo et al., Local Temperature Rise due to a 6-Channel Blockage in a 7-Pin Bundle, JAPFNR-202 (September 1975).

10. J. B. Van Erp and T. C. Chawla, "Experimental Study of Coolant Crossflow and Subchannel Flow Blockage in a Simulated LMFBR Subassembly," Trans. Amer. Nucl. Soc. 14, 746-47 (1971).

11. B. J. Vegter et al.; "Measurements of Velocity Downstream of Blocked Subchannels in a Model Reactor Rod Bundle," ASME 75-HT-2 (August 1975).

12. T. Carmody, "Establishment of the Wake Behind a Disk," Trans. ASME, J. Basic Eng. 86, 869.82 (1964):

13. I. P. Castro, "Wake Characteristics of Two-Dimensional Perforated Plates Normal to an Air-Stream, J. Fluid Mech. 46, Part 3, pp. $599-609$ (1971).

14. H. K. Fauske, "Evaluation of Dryout and Flow Instability in the Wake Downstream of a Blockage in an LMFBR Subassembly," Trans. Amer. Nucl. Soc: $15,352-53(1972)$.

15. H. K. Fauske, "Some Aspects of Fuel-Pin-Failure Propagation in SodiumCooled Fast Reactors," Nucl. Sci. Eng. 54, 10-17 (1974).

16. K. Gast and D. Schmidt, "Cooling Disturbances in the Core of SodiumCooled Fast Reactors as Causes of Fast Failure Propagation," Nucl. Eng. Des. 14, 12-22 (1970). 
17. W. T. Sha, "Effect of Partial Flow Blockage on Inlet-Flow Redistribution," Trans. Amer. Nucl. Soc. 15, 353-54 (1972).

18. R. M. Crawford, W. W. Marr, and A. Padilla, "Coolant Temperature Downstream of a Subassembly Blockage," Trans. Amer. Nucl. Soc. 15, 352-53 (1972).

19. W. W. Marr and R. M. Crawford, "Porous, Heat-Generating Blockage in a Fuel Subassemb1y," Trans. Amer. Nucl. Soc. 15, 350-51 (1972).

20. J. H. Scott and R. L. Williams, "A Comprehensive Analysis of FlowInduced Accident Initiating Conditions in an LMFBR," Trans. Amer. Nucl. Soc. 13, 649-50 (1970).

21. A. A. Bishop, J. Graham, and J. A. Zoubek, "Hydrodynamic Characteristics of a Wake Behind a Fuel Assembly Local Flow Blockage," Trons. Amer. Nucl. Soc. 14, 748-49 (1971).

22. L. Baker, Jr., D. R. MacFarlane, and J. F. Marchaterre, "Delineation of LMFBR Single Subassembly Accidents," Trans. Amer. Nucl. Soc. 13, 647-48 (1970).

23. J. B. Van Erp and A. M. Judd, "Local Core Accidents: A Comparison Between LMFBR's and LWR's," Trans. Amer. Nucl. Soc. 13,670 (1970).

24. H. J. Teague, Cooling Faizure in a Subassembly. An Appreciation of Fast Reactor Safety, UKAEA Report AHSB(s)R-188 (1970).

25. A. M. Judd, "Fuel Pin Failure Propagation in a Sodium-Cooled Fast Reactor," J. Br. Nucl. Energy Soc. 12(1), 35-42 (1973).

26. A. D. Gosman et a1., The SABRE Code for Prediction of Coolant Flows and l'emperatures in Fin Bundies Containing Blockages, URAEA Repori AEEW-R-905 (1973).

27. R. Herbert and D. Kirseh, A. Compurison of Temperature Distributions Calculated by the SABRE Progronme with Experimental Results, UKAEA Report AEEW-R-987 (1975).

28. A. D. Gosman et al., Heat and Masc Transfer in Recirculating Flows, Academic Press, 1969.

29. C. V. Gregory and D. J. Lord, "The Study of Local Blockage in Fast Reactor Subassemblies," J. Br. Nucl. Energy Suc. 13(3), 251-60 (1974).

30. C. V. Gregory and V. J. Lord, "Effect of Permeabll1ty on the Cunsequences of Local Blockages in Fast Reactor Subassemblies," J. Br. Nucl. Energy Soe. 15(1), 53-60 (1976).

31. J. Р. H. Blake et al., "lheoretieal studies Rclaccd to Lucul Bluckajes in Fast Reactor Subassemblies," Haper 33, pp. 713-29, Proc. Int. Curlf. Eng. Fast Reactors for Safe and Reliable Operation, Karlsruhe, Germany, Oct. 9-13, 1972 .

32. J. F. Petit, "Safety Design Basis for Power T.MFRR in France," pp. 1683-93, Proc. Fast Reactor Safety Meeting, Apr. 2-4, 1974, Beverly Hills, Calif. 
33. J. Megy et a1., "SUPER-PHENIX Preliminary Safety Analysis," pp. 29-50, Proc. Fast Reactor Safety Meeting, Apr. 2-4, 1974, Beverly Hills, Calif.

34. Project Management Corporation, Preliminary Safety Analysis Report for the CRBR, pp. 4.4-36, 4.4-37, vol. 5 (March 1974).

35. L. Krebs and G. Weinkotz, Detection of Blockages of Cooling Channels in Sodium-Cooled Breeder Reactors by Measurement of Temperature Fluctuations at Fuel-Element Outlet, trans. from German by R. G. Mansfield, ORNL-tr-2908 (1973).

36. F. G. Bentley, The Problem of Detection of Blockages in the Coolant Passages of a Fast Reactor by Measurement of Coolant Temperature, TRG Report 1197 (1963).

37. P. G. Bentley, Temperature Noise Produced by Turbulent Mixing of Coolurlt from Fast Reactor Subassemblies, TRG Report 2484 (1974).

38. D. N. Fry, "Temperature Noise Measurements in Blocked and Unblocked 19-Pin Electrically Heated LMFBR Fuel Subassembly Mockups," Ann. Nucl. Energy. 2, 233-34 (1975).

39. Mika et al., Investigation on Temperature Noise in Liquid Sodium Flowing through an Electrically Heated 4-Pin Bundle, RCN-195, IKH-14/1973.

40. R. W. Keaten, "Evaluation of Thermocouples for Blockage Detection in LMFBR Fuel Assemblies," Trans. Amer. Nucl. Soc. 13, 362-63 (1970).

41. Y. Oka, S. Kondo, and S. An, "Experiments on Temperature and Flow Velocity Fluctuation of Coolant and the Possibility of Determination of Noise Source," J. Nucl. Sci. Technol. 9(6), 330-38 (1972).

42. L. Krebs and G. Weinkotz, "Measurements of Temperature Noise Signals at the Outlet of Fuel Elements for Detection of Blocked Cooling Channels," Paper 71, presented at International Meeting on Reactor Heat Transfer, Karlsruhe, Oct. 9-11, 1973.

43. M. H. Fontana and J. L. Wantland, LMFBR Safety and Core Systems Programs Progress Report for Apriz-June 1975, ORNL/TM-5076 (January 1976).

44. A. J. Walton, Sonic Methods for P.F.R. Channel Blockage Détection, TRG Report 665(R) (1963).

45. Y. Kikuchi, Y. Daigo, and K. Haga, Acoustic Noise with Sodium Boiling in a Seven-Pin Bundle, JAPFNR-201 (1975).

46. F. H. Berg, L. R. Boyd, K. A. Smith, and J. Wallach, State-of-the-Art Report on Acoustical Monitoring of Nuclear Reactors, GEAP-13979 (July 1973).

47. H. Nishihara, "Resonant Acoustic Noise Spectra of Nucleate Coolant Boiling," J. Nucl. Sci. Technol. 11(01), 1-7 (1974).

48. H. Nishihara, "Triangulation of Local Coolant Boiling by Cross-Correlating Acoustic Noise Signals," Nucl. Technol. 23, 222-32 (1974).

49. R. F. Saxe, "The Detection of Boiling in Nuclear Reactors," IEEE Trans. Nucl. Sci. 18, 337-39 (1971). 
50. A. P. Gavin and T. T. Anderson, "H1gh-Temperature Acoust1c Sensors for Bo1ling Detection," IEEE Trans. Nucl. Sci. 18, 340-44 (1971).

51. D. N. Fry et al., Neutron-Fluctuation Measurements at Oak Ridge National Laboratory, CONF-660206.

52. D. N. Fry and J, C. Robinson, Neutron Density Fluctuations as a Reactor Diagnostic Tool, CONF-671011.

53. T. J. Marciniak, L. J. Habegger, and H. Greenspan, Summary Review of Neutronic Noise Techniques for Incipient Boiling Detection in Liquid Metal Fast Breeder Reactors, ANL-7652 (January 1970). 
ORNL / TM-5839

D1st. Category UC-79, $-79 e,-79 p$

\section{Internal Distribution}

1. A. H. Anderson

2. S. Baron

3. N. E. Clapp

4. C. W. Collins

5. W. E. Cooper

6. W. B. Cottrell

7. F. L. Culler, Jr.

8. J. F. Dearing

y. G. G. Fee

10-20. M. H. Fontana

21. D. N. Fry

22. P. W. Garrison

23. P. A. Gnadt

24. M. J. Goglia

25. A. G. Grindell

26-39. J. T. Han

40. N. Hanus

41. W. 0. Harms

42. J. F. Harvey

43. R. A. Hedrick

44. H. W. Hoffman

45. T. L. Hudson

46. T. S. Kress

47. W. H. Leavell

48. M. Levenson

49. R. E. MacPherson
50. C. D. Martin

51. M. V. Mathes

52. R. W. McCulloch

53. R. L. Moure

54. B. H. Montgomery

55. R. H. Morris

56. L. C. Oakes

57. L. F. Parsly

58. R. J. Ribando

59. J. L. Redford

60. M. R. Sheldon

61. W. H. Sides

62. M. J. Skinner

63. C. M. Smith

64. I. Spiewak

65. D. G. Thomas

66. R. H. Thornton

67. D. B. Trauger

68. J. L. Wantland

69. G. D. Whitman

70. W. J. Wilcox

71. R. Saxe (Consultant)

72-73. Central Research Library

74. Y-12 Document Reference Section

75-77. Laboratory Records Department

78. Laboratory Records (RC)

\section{External Distribution}

79. Assistant Administrator, Nuclear Energy, ERDA, Washington, D.C. 20545

80-81. Director, Division of Reactor Development and Demonstration, U.S. Energy Research and Development Administration, Washington, D.C. 20545

82. Director, Reactor Division, ERDA, Oak Ridge Operations Office

83. Research and Technical Support Division, ERDA, Oak Ridge Operations office

84-322. For distribution as shown in TID-4500 under categories UC-79, $-79 e$, and $-79 p$ 